\title{
Economic Development, Nutrition Transition and Gender Discrimination in China
}

\author{
Dissertation \\ to obtain the $\mathrm{Ph}$. D. degree \\ in the International Ph. D. Program for Agricultural Sciences in Goettingen (IPAG) \\ at the Faculty of Agricultural Sciences, \\ Georg-August-University Göttingen, Germany
}

presented by

$\mathrm{Xu}$ Tian

born in Hubei, China

Göttingen, March 2013 
1. Name of supervisor:

2. Name of co-supervisor:
Prof. Xiaohua $\mathrm{Yu}, \mathrm{PhD}$

Prof. Stephan Klasen, $\mathrm{PhD}$

Date of dissertation: $16^{\text {th }}$ May 2013 (please fill in the date of dissertation - it's the day before the doctoral celebration, on this day the faculty council makes your grades public) 


\section{Acknowledgement}

My Ph.D. study is sponsored by the Chinese Scholarship Council (CSC). I would like to thank them for providing enough funding for me to live in Germany, which allows me to focus on my research.

During the time of my Ph.D. study, I have received multifaceted support from numerous people. First and foremost, I would like to express my special gratitude to my supervisor Professor Xiaohua Yu for his excellent guidance and selfless support during my $\mathrm{Ph} . \mathrm{D}$. study. Xiaohua Yu led me to research and gave countless help to me both in academic and personal lives. I also appreciate for his valuable inputs on our several papers. My further thanks go to my co-advisor Professor Stephan Klasen. I wish to thank him for inviting me to study in Goettingen and his great comments on our paper. I also would like to thank Professor Berhnard Bruemmer for his help in my research and career. My colleagues, Rainer Holst, Stefan Meyer, and De Zhou shared a lot of good ideas with me in the weekly group discussion, and helped me a lot in many other ways. My research assistant Frank Butterworth takes a lot of time to polish my thesis, I really appreciate for his great work.

I am also very grateful to my wife Hui Wang. Thank you for staying with me for all these years. Finally, I wish to express my particular gratitude to my parents and elder brother for their support on my education and doing Ph.D. abroad.

In addition, case study two and three use the data from the China Health and Nutrition Survey (CHNS). We thank the National Institute of Nutrition and Food Safety, China Center for Disease Control and Prevention; the Carolina Population Center, University of North Carolina at Chapel Hill; the National Institutes of Health (NIH; R01HD30880, DK056350, and R01-HD38700); and the Fogarty International Center, NIH, for financial support for the CHNS data collection and analysis files since 1989. We thank 
those parties, the China-Japan Friendship Hospital, and the Ministry of Health for support for CHNS 2009 and future surveys.

Xu Tian

Goettingen, Germany.

March 2013 


\section{Table of Contents}

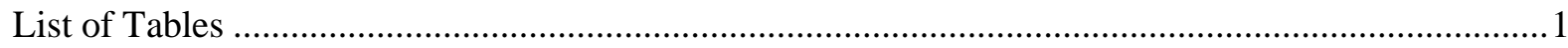

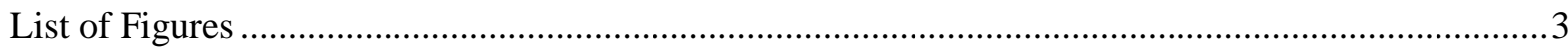

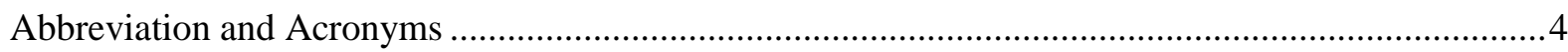

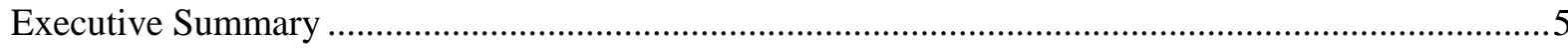

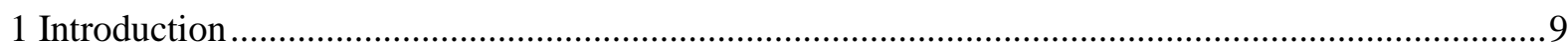

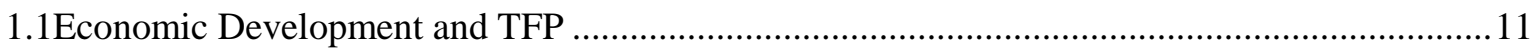

1.1.1 Economic Development and Technological Progress in China ........................................11

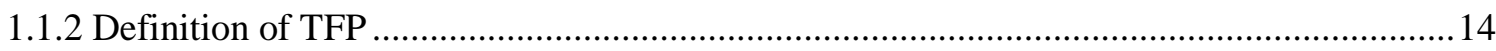

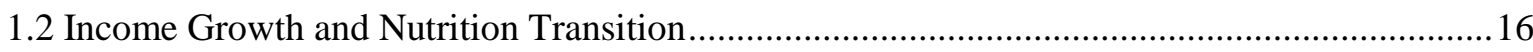

1.3 Engel's Index, Son Preference and Economic Development................................................... 19

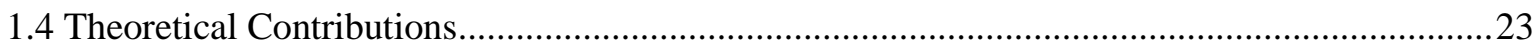

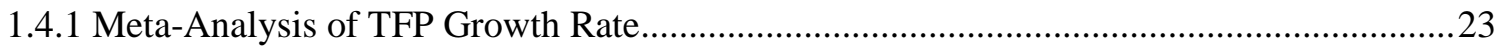

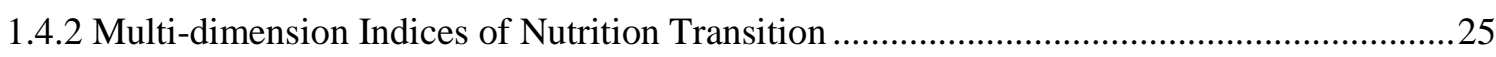

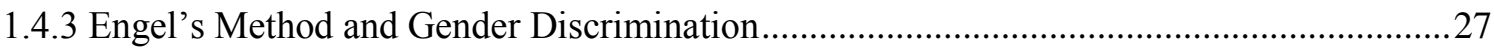

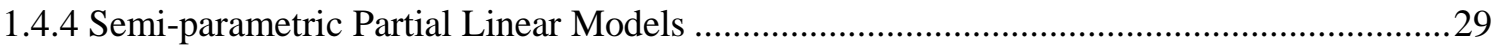

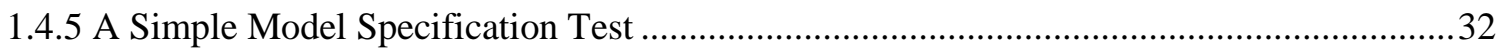

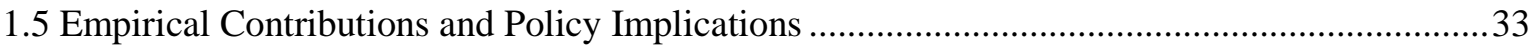

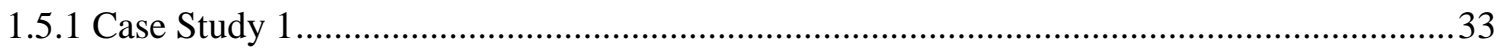

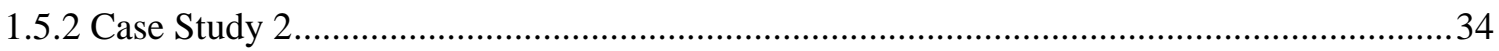

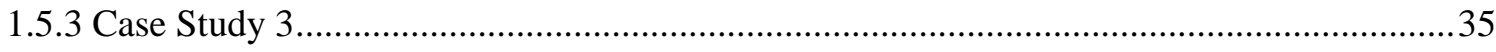

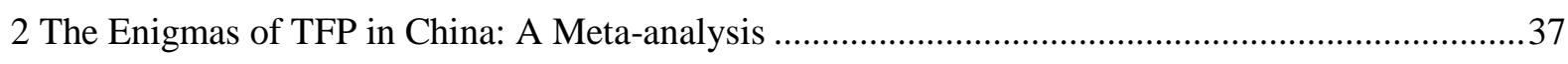

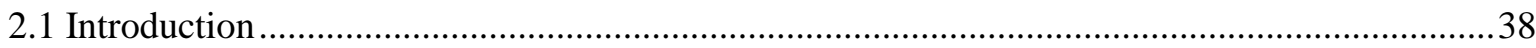




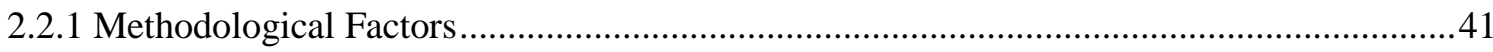

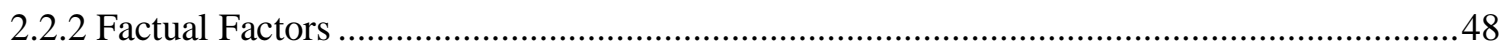

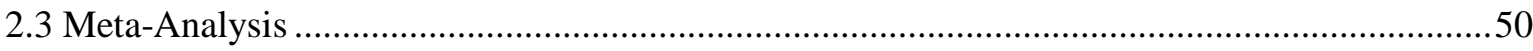

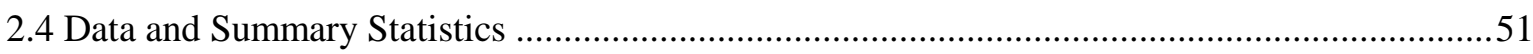

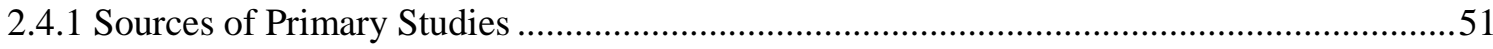

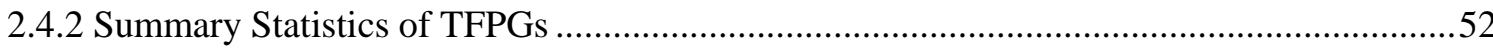

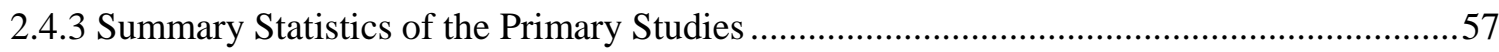

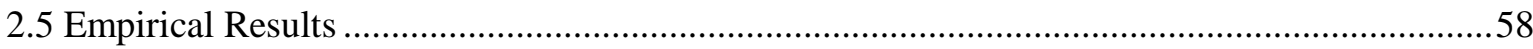

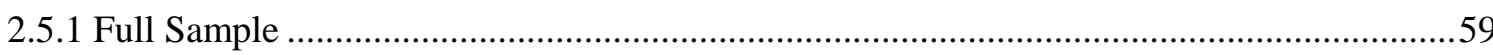

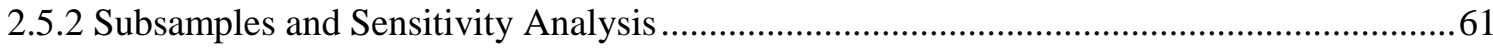

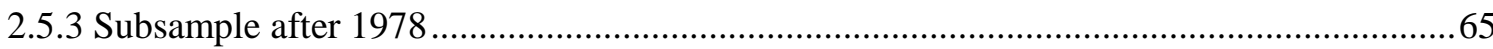

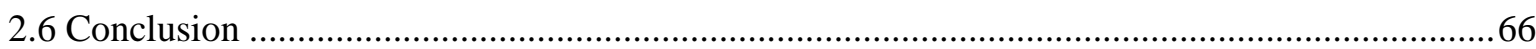

3 Using Semi-parametric Model to Study Nutrition Transition with Different Indices: The

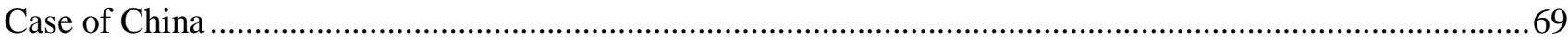

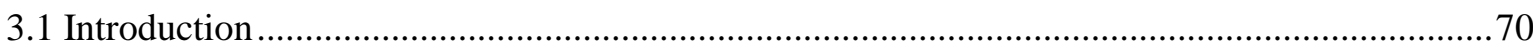

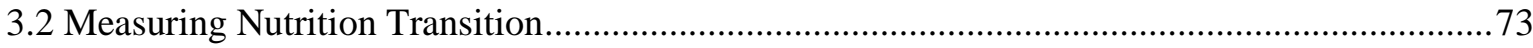

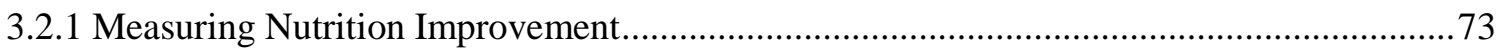

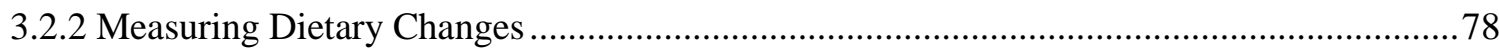

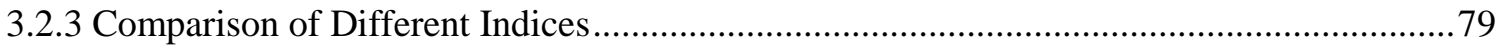

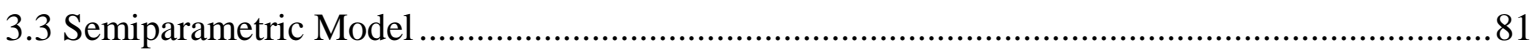

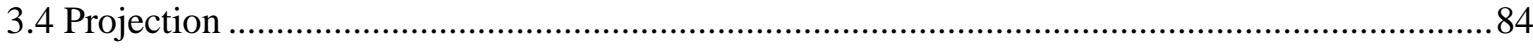

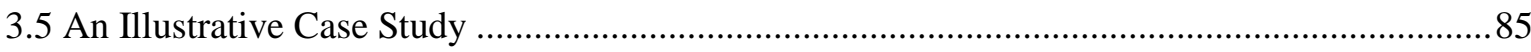




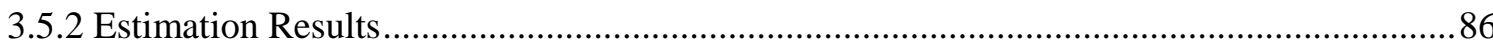

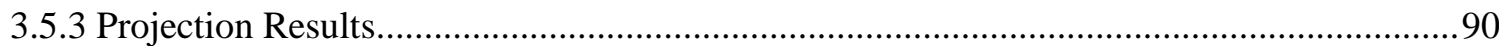

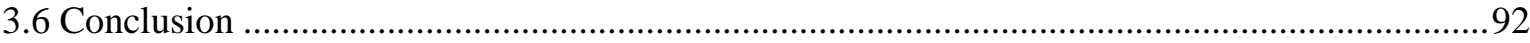

4 A Comparison of Gender Discrimination in Rural and Urban China: The Engel's

Method .95

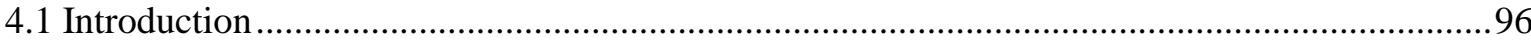

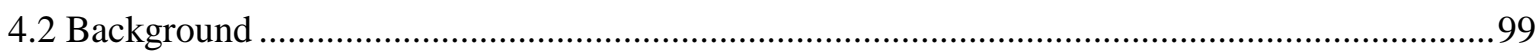

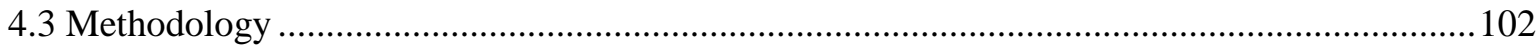

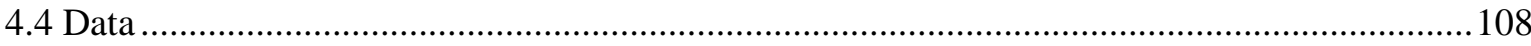

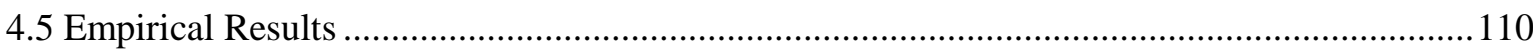

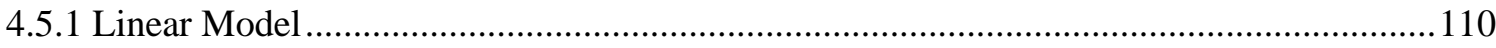

4.5.2 Adjusting for The Difference in Requirement for Food.................................................. 113

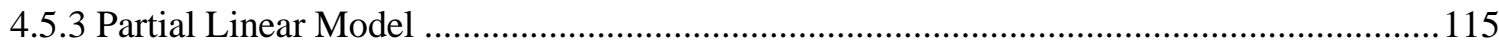

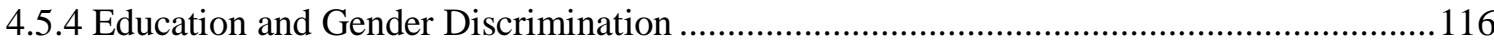

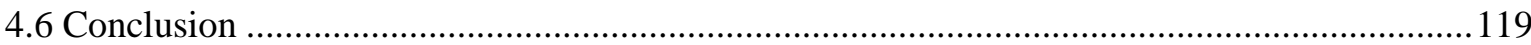

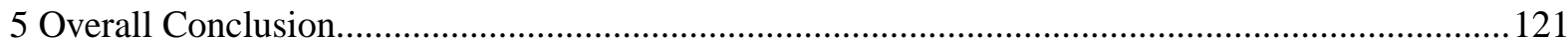

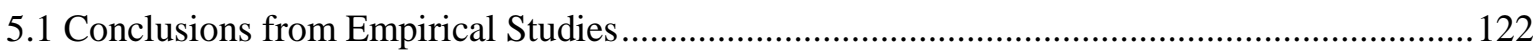

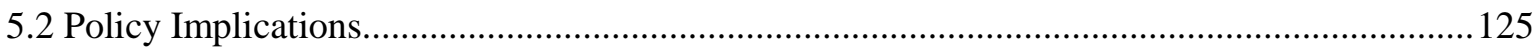

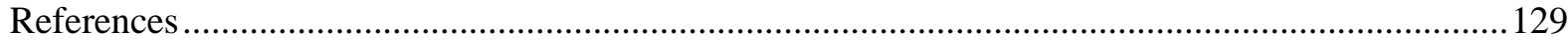

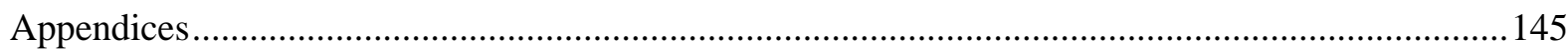

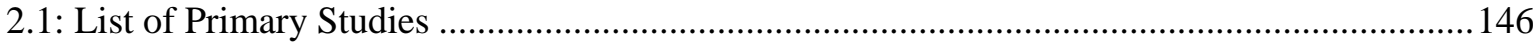

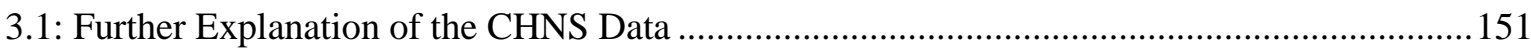


3.2: Descriptive Statistic of Nutrition Improvement and Dietary Changes Indices 153

3.3: Definitions and Descriptive Analysis of Variables .154

3.4: Non-income Effect of Nutrition Improvement 155

3.5: Non-income Effect of Food Structural Change 156

4.1: Descriptive Analysis of Variables. 158

4.2: Results in Original Model 159

4.3: Results in Extended Model 160

Curriculum Vitae. 162 


\section{List of Tables}

Table 1.1: GDP and Population in China and Other Major Regions: 1700-2003

Table 1.2: GDP Growth Rates in China and Other Major Regions: 1700-2003

Table 1.3: Average Daily Nutrient Intakes by Gender and Age

Table 1.4: Comparison of Daily Average Basal Metabolism Ratio per kg by Gender

Table 2.1: TFPGs in Different Periods

Table 2.2: TFPGs in Different Sectors, Regions and Approaches

Table 2.3: Summary of Primary Studies

Table 2.4: Definition of Variables

Table 2.5: Results Based on the Full Sample

Table 2.6: Results Based on Subsamples

Table 2.7: Results after 1978

Table 3.1: Comparison of Different Indices

Table 3.2: Specification Test for Income Function

Table 3.3: Projections of Nutrition Transition in China at Different Income Levels

Table 4.1: Results in Original Model

Table 4.2: Gender Bias, Equivalent Scale and Gender Price in Linear Model-Before Adjustment

Table 4.3: The Ratio of Energy Requirement (RER)

Table 4.4: Gender Bias, Equivalent Scale and Gender Price in Linear Model -After Adjustment 
Table 4.5: Model Specification Test in Original Model

Table 4.6: Gender Bias in Partial Linear Model

Table 4.7: Results in Extended Model

Table 4.8: Education Effects and Gender Bias in Extended Linear Model

Table 4.9: Model Specification Test in Extended Model

Table 4.10: Education Effects and Gender Bias in Extended Partial Linear Model 


\section{List of Figures}

Figure 1.1: Poverty Ratio and Malnutrition: 1980-2011

Figure 1.2: Calorie Intake by Food Items: 1961-2009

Figure 1.3: Sources of Calorie, Protein and Fat: 1961-2009

Figure 2.1: Average TFPGs from 1950 to 2009

Figure 2.2: Nation-level Average TFPGs by Sectors (1950-2009)

Figure 2.3: Nation-level Average TFPGs by Regions (1950-2009)

Figure 3.1: Local Polynomial Smooth for Nutrition Improvement Indices

Figure 3.2: Local Polynomial Smooth for Calorie Share of Specific Food Groups

Figure 3.3: Local Polynomial Smooth for Expenditure Share of Specific Food Groups 


\section{Abbreviation and Acronyms}

BMI: Body Mass Index

BMR: Basal Metabolic Ratio

CHNS: China Health and Nutrition Survey

CNKI: China National Knowledge Infrastructure

DR-NCD: Diet-related, Non-Communicable Diseases

ES: Equivalent Scale

FAO: The Food and Agricultural Organization of the United Nations

GDP: Gross Domestic Products

OLS: Ordinary Least Square Regression

PKcal: Daily Calorie Intake per Capita

PPP: Purchasing Power Parity

RER: The Ratio of Energy Requirement

TFP: Total Factor Productivity

TFPG: Total Factor Productivity Growth Rate

UN: The United Nations

US: The United States

USSR: The Union of Soviet Socialist Republic

WHO: The World Health Organization

WLS: Weighted Least Square Regression 


\section{Executive Summary}

Since the implementation of the "reform and opening up" policy in 1978, China has been experiencing remarkable economic growth. This economic success can be partly attributed to technological progress, even though no consensus has been reached regarding how much economic growth can be explained by it (Hsieh and Klenow, 2009; Tian and $\mathrm{Yu}, 2012)$. Along with this impressive economic development, an increasing number of Chinese families are relieved from hunger and poverty. Accordingly, patterns of food consumption have also been changing dramatically. The traditional Chinese diet, which consists mainly of grain and vegetables with very little meat, is gradually being replaced by a modern western diet that is high in fat and sugar (Drewnowski and Popkin, 1997; Guo et al., 2000; Popkin, 2003; Du et al., 2004; Meng et al., 2009). Moreover, it has become a reflection of poverty rather than culinary tradition. These changes indicate that China is undergoing a nutrition transition (Monteiro et al., 1995; Popkin et al., 2001;

Du et al., 2002; Popkin, 2001b, 2003; Wang et al., 2007; Gao et al., 2010). Rapid economic development not only changes the eating habit, but also leads to some changes in social value such as the attitude toward girls. Traditionally, Chinese people favor boys over girls and devote more resources to boys. However, successful economic reform and accompanied social and institutional changes alter the traditional culture of preference for sons and reduce the incentive to favor boys. Therefore, whether girls are still discriminated in China becomes ambiguous. Given the significance of the Chinese economy and population in the world, it is particularly important to investigate the driving force behind economic development and its impact on nutrition transition and gender inequality.

In this dissertation, I will offer a particular focus on three topics: the contribution 
share of technological progress to China's economic growth, the impact of income growth on nutrition improvement and culinary structural change, and the identification of gender discrimination against girls after the successful economic development. Each topic is investigated in one case study.

The first case study presents a meta-analysis of total factor productivity growth (TFPG) in China, which is the most widely used indicator to measure technological progress. I collect 5308 observations from 150 primary studies to provide insight and explanations of the controversies regarding productivity growth in China in the current literature. The main findings include: (1) The mean TFPG of the aggregate economy at the national level in the current literature is only about $2.42 \%$ after 1978 , which barely contributes to 24\% economic growth; (2) There are three cycles for TFPG after 1978 and each cycle lasts about ten years; (3) TFPG after 1978 is generally greater than that before 1978 and contributes more to economic growth. Moreover, TFPG also varies in different regions and sectors, and is partly determined by the characteristics of the research such as language and peer-review process.

The second case study focuses on the relationship between income growth and nutrition transition. As aforementioned, China is undergoing a nutrition transition due to rapid income growth. Current literature on nutrition transition mainly focus on estimating the calorie elasticity with respect to income by parametric models. However, nutrition transition might be a nonlinear function of income. Its contents are not limited to calorie intake, but also include dietary change and nutrition improvements. In this thesis, I methodologically propose 10 different indices to measure nutrition transition from different perspectives, and then introduce a semiparametric model to capture the complicated relationship between nutrition transition and income growth with these indices, which can be further used to directly project the nutrition improvement and 
dietary change at different income levels from different aspects. I take China as an illustrative example and find that nutrition transition will slow down in the future and the concern about diet-related, non-communicable diseases (DR-NCD) such as obesity might be not as pessimistic as we expected before.

The third case study sheds light on gender inequality in the context of successful economic development. As we know, China has a long history of son preference. However, empirical studies yield controversial results, which might be attributed to the methodological flaws in the current methods used to test gender bias. Therefore, this case study compares two approaches inspired from the Engel's method to directly measure and test gender bias by household expenditure data. Using both parametric and semiparametric estimates, I find that gender inequality still exists in China, particularly in rural China. However, no evidence supports that education could help reduce gender inequality in China.

A brief conclusion can be drawn from these three case studies. After 1978, TFP grows at $2.4 \%$ per year in China. Meanwhile, input factors such as labor and capital grow at an even faster rate. All of these have lead to an impressive rate of economic growth during the past three decades. Accordingly, household income has increased significantly and there has been a very substantial reduction of poverty. As people become richer, their dietary preferences shift from staple food to fruit, meat and dairy, which are usually more expensive and of higher value, and the calorie intake also increases. However, the consumption of high-value and high-calorie food does not increase monotonically with income, since rich people are more concerned about health than energy. Rapid economic growth and accompanied social and institutional changes also influenced the discrimination against girls in China. Our results find that gender inequality still exists in China. Particularly, rural girls are more likely to be discriminated than their urban 
counterparts.

Furthermore, general policy implications can be deduced from these findings. First, both technological progress and input accumulation are crucial to economic growth. In order to maintain sustainable economic success in China, particularly in the poor West and Central regions, policy should focus on eliminating the barriers that prevent technological spillover since the TFPGs in Western and Central regions are rather low compared to those in the East. Second, income growth leads to nutrition improvement and dietary change, but not monotonically. The dietary role of staple food will decrease, while that of fruit and dairy will increase. Third, discrimination against girls still exists in China, particularly for teenage girls who are supposed to get education, which might be attributable to slightly higher return to education for male. Therefore, the increasing economic and social status of women, as well as the population shortage of women reaching marriage age cannot fully offset the traditional son preference in China. 


\section{Introduction}


China has experienced remarkable economic development during the past three decades. Along with economic success, three controversial issues still prevail: how much economic growth can be attributed to technological progress, how do nutrition status and food structure change with income increase, and whether girls are still discriminated against in China.

In order to answer the aforementioned questions, this dissertation investigates the three topics in three case studies respectively. First, a meta-analysis is conducted to evaluate the contribution share of technological progress in economic growth. Thereafter, the impact of income increase on nutrition improvement and dietary change is estimated by several indicators from different perspectives, both in parametric and semi-parametric methods. Finally, a new method is developed to identify gender inequality using household expenditure data. 


\subsection{Economic Development and TFP}

\subsubsection{Economic Development and Technological Progress in China}

China used to be the world's leading economy during the tenth and fifteenth centuries in terms of per capita income. It outperformed Europe not only in terms of income, but also levels of technology and its capacity for administering a huge territorial empire. Even though it was gradually overtaken by Europe in the following three centuries, it was still the world's largest economy at the beginning of $1800 \mathrm{~s}$, and accounted for 32.4\% of the world's GDP in 1820 (Maddison, 2007; Lin, 2007). However, due to technological backwardness and weakness of governance, China suffered from internal conflicts and collusive foreign intrusions on its territory and sovereignty from 1840 to 1950 . Accordingly, its economic performance became disastrously poor and per capita income began to decline (Maddison, 2007; Lin, 2007). On the contrary, the world economy made enormous progress during this period. The per capita income rose threefold in the world as a whole, four-fold in Europe, and nine-fold in the US (see Table 1.1). Accordingly, the share of China's GDP in the world fell down sharply to 5.2\% in 1952. Meanwhile, technological progress no longer rooted itself in the experience of farmers and workers, but rather came from laboratory experiments after the scientific revolution in the fifteenth and sixteenth centuries (Lin, 2007). Because of the Renaissance and the Enlightenment, superstition, magic and submission to religious authority were gradually abandoned by western elites. Furthermore, the modern approach to technical change and innovation emerged in the seventeenth century and started to impregnate the modern educational system, which was the fundamental base of modern science (Maddison, 2007). Hence, China lost the advantage in technological accumulation and fell far behind Europe and America in a very short time. 
Table 1.1: GDP and Population in China and Other Major Regions: 1700-2003

\begin{tabular}{c|ccccccc|c}
\hline Year & China & Japan & Europe & United States & USSR & India & World & China/World \\
\hline \multicolumn{7}{c}{ GDP (billion 1990 “international” dollars) } \\
\hline 1700 & 82.8 & 15.4 & 92.6 & 0.5 & 16.2 & 90.8 & 371.4 & $22.29 \%$ \\
1820 & 228.6 & 20.7 & 184.8 & 12.5 & 37.7 & 111.4 & 694.5 & $32.92 \%$ \\
1952 & 305.9 & 202.0 & 1730.7 & 1625.2 & 545.8 & 234.1 & 5912.8 & $5.17 \%$ \\
1978 & 935.1 & 1446.2 & 5268.2 & 4089.5 & 1715.2 & 625.7 & 18969.0 & $4.93 \%$ \\
2003 & 6188.0 & 2699.3 & 8643.8 & 8430.8 & 1552.2 & 2267.1 & 40913.4 & $15.12 \%$ \\
\hline \multicolumn{7}{c}{ Population (million) } \\
\hline 1700 & 138.0 & 27.0 & 100.3 & 1.0 & 26.6 & 165.0 & 603.2 & $22.88 \%$ \\
1820 & 381.0 & 31.0 & 169.5 & 10.0 & 54.8 & 209.0 & 1041.7 & $36.57 \%$ \\
1952 & 569.0 & 86.5 & 398.6 & 157.6 & 185.9 & 372.0 & 2616.0 & $21.75 \%$ \\
1978 & 956.0 & 114.9 & 480.1 & 222.6 & 261.5 & 648.0 & 4279.7 & $22.34 \%$ \\
2003 & 1288.4 & 127.2 & 516.0 & 290.3 & 287.6 & 1050.0 & 6278.6 & $20.52 \%$ \\
\hline \multicolumn{8}{c}{ GDP per capita (1990 “international” dollars) } \\
\hline 1700 & 600 & 570 & 923 & 527 & 610 & 550 & 615 & $97.56 \%$ \\
1820 & 600 & 669 & 1090 & 1257 & 688 & 533 & 667 & $89.96 \%$ \\
1952 & 538 & 2336 & 4342 & 10316 & 2937 & 629 & 2260 & $23.81 \%$ \\
1978 & 978 & 12585 & 10972 & 18373 & 6559 & 966 & 4432 & $22.07 \%$ \\
2003 & 4803 & 21218 & 16750 & 29037 & 5397 & 2160 & 6516 & $73.71 \%$ \\
\hline
\end{tabular}

Notes: 1. Data comes from Maddison's estimation, see www.ggdc.net/Maddison.

2. Europe includes 29 west and 10 east European countries (Turkey is not included).

3. The figures for India include India, Bangladesh and Pakistan, but Bangladesh and Pakistan are excluded from 1952.

4. The figures for the United States include the indigenous population.

After the foundation of the People's Republic of China, the Chinese government followed the Soviet model and adopted the planned economic system, which is characterized by a high rate of capital accumulation at the expense of consumption and the promotion of industry (especially heavy industry) at the expense of agriculture (Chow, 1993). Per capita income started to recover due to the urbanization and modernization organized by the nation (Lin, 2007). According to the official estimate, output grew at an annual average rate of 5.9 percent during 1953 and 1978. However, the acceleration in economic development is attributed to a massive increase in inputs of physical and human capital, rather than technological progress. According to the estimations of Chow (1993), Wang and Yao (2003), and Maddison (2007), the physical capital stock increased from 2.4 billion in 1953 (measured in 1978 Yuan) to 14.1 billion in 1978 (measured in 1978 
Yuan); human capital stock also grew by 4.87 percent per year due to significant advances in education and health. On the other hand, technological progress was absent and technical efficiency was also rather low, due to the erroneous economic development strategy which gave priority to the capital-intensive heavy industry. This strategy violated the structure of factor endowment in China, which was rich in cheap labor but lacked capital (Borensztein and Ostry, 1996; Chow and Li, 2002; Wang and Yao, 2003; Lin, 2007; Tian and Yu, 2012). Moreover, frequent political upheavals, wars with neighboring countries, isolation from the international market, and long years of almost complete autarchy plagued China's economic performance (Borensztein and Ostry, 1996; Maddison, 2007). In addition, because of Chairman Mao's distorted ideology that more people equals more strength, the population exploded. The total population increased from 588 million in 1953 to 963 million in 1978 and as a result, the per capita GDP only increased at a rate of $2.3 \%$, which was even lower than the world average (see Table 1.2). China's GDP share in the world also declined further to 5\% in 1978 (Lin, 2007).

Table 1.2: GDP Growth Rates in China and Other Major Regions: 1700-2003

\begin{tabular}{c|cccc|cccc}
\hline \multirow{2}{*}{ Regions } & \multicolumn{4}{|c|}{ GDP } & \multicolumn{4}{c}{ per capita GDP } \\
\cline { 2 - 8 } & $1700-1820$ & $1820-1952$ & $1952-1978$ & $1978-2003$ & $1700-1820$ & $1820-1952$ & $1952-1978$ & $1978-2003$ \\
\hline China & 0.85 & 0.22 & 4.39 & 7.85 & 0.00 & -0.10 & 2.33 & 6.57 \\
India & 0.17 & 0.56 & 3.85 & 5.28 & -0.03 & 0.13 & 1.66 & 3.27 \\
Japan & 0.25 & 1.74 & 7.86 & 2.53 & 0.13 & 0.95 & 6.69 & 2.11 \\
Europe & 0.58 & 1.71 & 4.37 & 2.00 & 0.14 & 1.05 & 3.63 & 1.79 \\
United States & 2.72 & 3.76 & 3.61 & 2.94 & 0.72 & 1.61 & 2.24 & 1.85 \\
USSR & 0.69 & 2.05 & 4.5 & -0.40 & 0.10 & 1.11 & 3.55 & -0.78 \\
World & 0.52 & 1.64 & 4.59 & 3.12 & 0.07 & 0.93 & 2.62 & 1.55 \\
\hline
\end{tabular}

Notes: 1. Data comes from Maddison's estimation, see www.ggdc.net/Maddison. All growth rates are annual average compound growth rates.

2. Europe includes 29 west and 10 east European countries (Turkey is not included).

3. The figures for India include India, Bangladesh and Pakistan, but Bangladesh and Pakistan are excluded from 1952.

4. The figures for the United States include the indigenous population.

During the reform period from 1978, substantial changes in social policy successfully generated remarkable economic development for more than three decades. 
The World Bank data shows that China's GDP increased more than 20 times from 1978 to 2011 (measured in 2000 constant US \$) with an average annual growth rate of close to $10 \%$, and became the second biggest economy in the world accouning for $15 \%$ of the world's GDP (Maddison, 2007; Tian and Yu, 2012). GDP per capita also rose 16-fold during this period, which was faster than any other Asian country, west Europe and the US, and was four times as fast as the world average (Maddison, 2007). Along with the impressive economic development, numerous arguments have been raised regarding the driving forces behind the economic miracle, especially the role of productivity growth (Hsieh and Klenow, 2009; Tian and Yu, 2012). For instance, Liang (2000) and Young (2003) find that the economic growth in China after 1978 was mainly caused by soaring increases in inputs such as rising labor participation rate, rural-urban migration, improvements in educational attainment, and capital investment, while total factor productivity (TFP) growth rate was lower than $1.5 \%$ and only accounted for less than $15 \%$ of the economic growth. On the other hand, other studies such as Chow and Li (2002), and Maddison (2007) claim that the TFP growth rate is remarkable (about 3\% per year) and contributes to more than $30 \%$ of China's economic growth. Given the huge size of China's economy and population, the debate is crucial both from a political perspective and an academic perspective. To shed light on this controversy, the first case study (Chapter 2) presents a deep discussion via a meta-analysis of TFPG.

\subsubsection{Definition of TFP}

Total factor productivity (TFP) is the most widely used indicator to measure productivity, which is regarded as the transformation ratio of total inputs into total outputs (Diewert and Nakamura, 2007). In the neoclassical framework, economic growth is believed to stem from two sources: factor accumulation and productivity (TFP) growth (Felipe, 1999). In order to decompose the sources of economic growth, Solow (1957) 
suggested an aggregate production function with a Hicksian neutral shift parameter and constant return to scale, which can be written as follows:

$$
\begin{aligned}
& Q_{t}=A_{t} F\left(K_{t}, L_{t}\right) \\
& A_{t}=\frac{Q_{t}}{F\left(K_{t}, L_{t}\right)}
\end{aligned}
$$

Here $A_{t}$ refers to exogenous, disembodied, and Hicks-neutral technical progress, and measures the shift in the production function at given levels of labor and capital (Felipe, 1999; Hulten, 2000). Solow (1957) provided a simple way to measure $A_{t}$ using a nonparametric index number approach: taking the logarithm and total differential of the production function.

$$
\frac{\dot{Q_{t}}}{Q_{t}}=\frac{\partial Q}{\partial K} \frac{K_{t}}{Q_{t}} \frac{\dot{K}_{t}}{K_{t}}+\frac{\partial Q}{\partial L} \frac{L_{t}}{Q_{t}} \frac{\dot{L_{t}}}{L_{t}}+\frac{\dot{A_{t}}}{A_{t}}
$$

This expression implies that the growth rate of output can be decomposed into the weighted growth rate of capital and labor and the growth rate of the Hicksian efficiency index $A_{t}$ (Felipe, 1999; Hulten, 2000). Under the assumption of cost minimization, each input is paid the value of its marginal product: $\frac{\partial Q}{\partial K}=\frac{r_{t}}{p_{t}}$, and $\frac{\partial Q}{\partial L}=\frac{w_{t}}{p_{t}}$. Therefore, the unobserved output elasticities can be substituted by the observable income shares of capital $\left(s^{K}\right)$ and labor $\left(s^{L}\right)$, and we can rewrite equation (1.2) as follows:

$$
\mathfrak{R}_{t}=\frac{\dot{A_{t}}}{A_{t}}=\frac{\dot{Q}_{t}}{Q_{t}}-s^{K} \frac{\dot{K}_{t}}{K_{t}}-s^{L} \frac{\dot{L}_{t}}{L_{t}}
$$

$\mathfrak{R}_{t}$ is the Solow residual, which measures the productivity growth (TFPG) in growth accounting framework (Felipe, 1999). However, TFPG measured in Solow's method has too many strict assumptions such as the existence of an aggregate production 
function with constant returns to scale, homogeneous of degree one, diminishing returns to each input, and positive elasticity of substitution (Felipe, 1999; Hulten, 2000). In order to overcome these limitations, numerous new methods have been developed after Solow's pioneering work. More discussions are provided in chapter 2.

\subsection{Income Growth and Nutrition Transition}

Successful economic development after 1978 resulted in a significant increase in income in China. According to figures obtained from National Statistic Bureau of China, urban per capita disposable income in 2010 was almost ten-fold that of 1978 and the same level income growth also happened in rural region. Consequently, the poverty ratio declined dramatically from more than $80 \%$ to less than $10 \%$ according to the international poverty line ( $\$ 1.25$ per capita per day) (see Figure 1.1 ).

Figure 1.1: Poverty Ratio and Malnutrition: 1980-2011

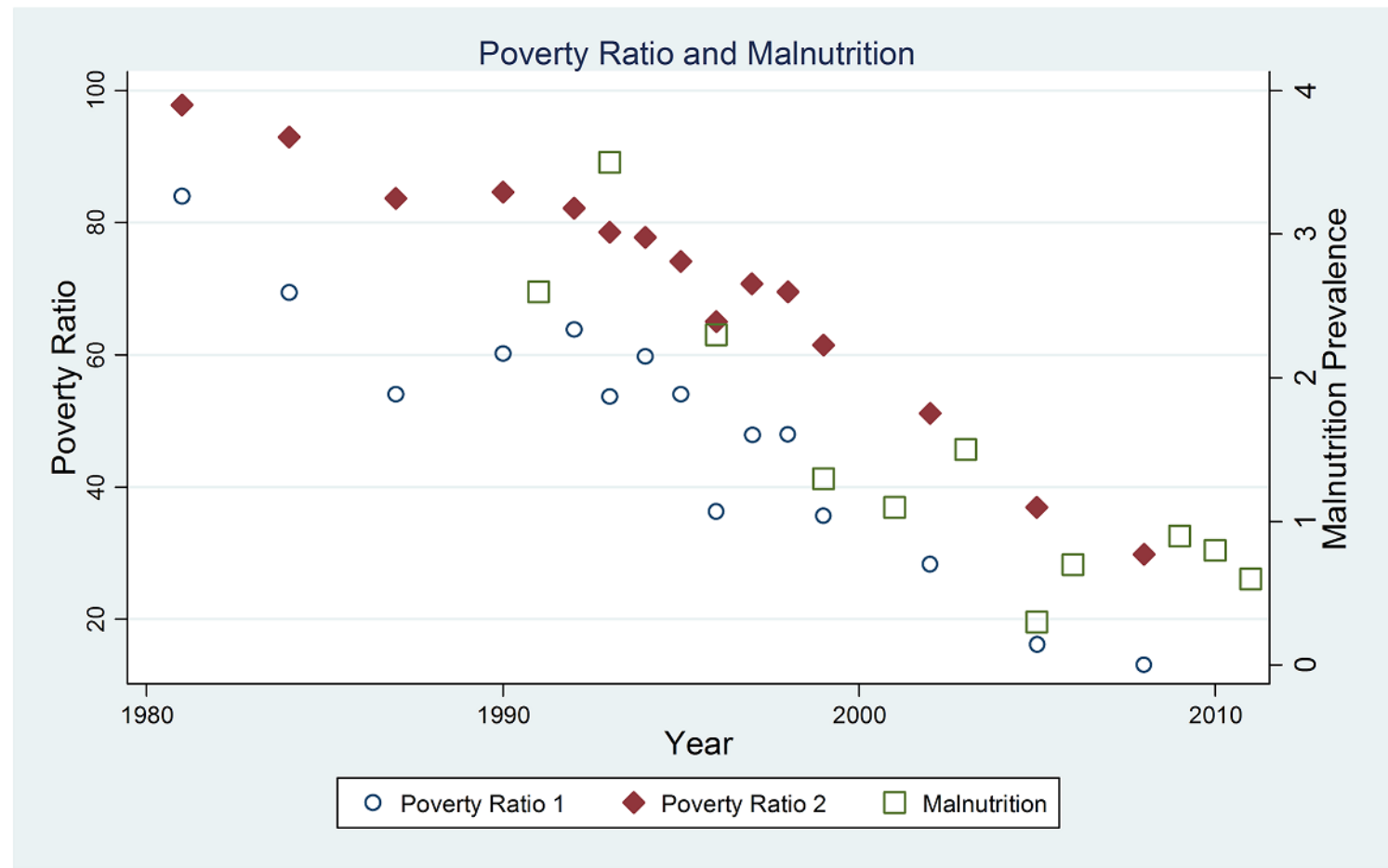

Notes: 1. Calculations are based on data in World Bank.

2. Poverty Ratios 1 and 2 refer to the headcount ratios below $\$ 1.25$ and $\$ 2$ a day respectively (PPP) (\% of population), and Malnutrition refers to the percentage of children under the age of 5 whose weight for age is more than two standard deviations below the median for the international reference population ages 0-59 months. The data are based on the WHO's new child growth standards released in 2006. 
Rising income and liberalization of food production and sales lead to higher food consumption and energy intake, particularly in China where all food products sold in urban areas were operated through a coupon ration system and people could not purchase as much food as they need before the reform (Du et al., 2002; Meng et al., 2009). The FAOSTAT food balance sheet shows that China's calorie intake per capita per day increased from 1426 kilocalories in 1961 to 2079 kilocalories in 1978, then it quickly rose to 2526 kilocalories in 1990 and a further 3036 kilocalories in 2009. Because of the improvement in nutrition, the prevalence of underweighted children dropped sharply from $3 \%$ in the early 1990 s to $0.6 \%$ in 2011 (see Figure 1.1 ).

However, the impact of income growth on diet is not limited to increases in food consumption and calorie intake. Current literature shows that as income increases, the traditional Chinese diets that were high in complex carbohydrates and fibers are shifting to a western diet that is high in fats, saturated fats, sugar and refined foods, which is usually termed as nutrition transition (Drewnowski and Popkin, 1997; Guo et al., 2000; Popkin, 2003; Du et al., 2004; Meng et al., 2009). According to Popkin (1993), there are five broad nutrition patterns, namely collecting food, famine, receding famine, degenerative diseases, and behavioral change. China is believed to be undergoing a nutrition transition and is transforming rapidly from the stage of receding famine to that of degenerative diseases (Monteiro et al., 1995; Popkin et al., 2001; Du et al., 2002; Popkin, 2001b, 2003; Wang et al., 2007; Gao et al., 2010). Accordingly, the consumption of vegetal foods such as cereals and starchy roots decline gradually and are replaced by the increasing consumption of animal products such as meat, eggs, fish and milk products (see Figure 1.2). 
Figure 1.2: Calorie Intake by Food Items: 1961-2009

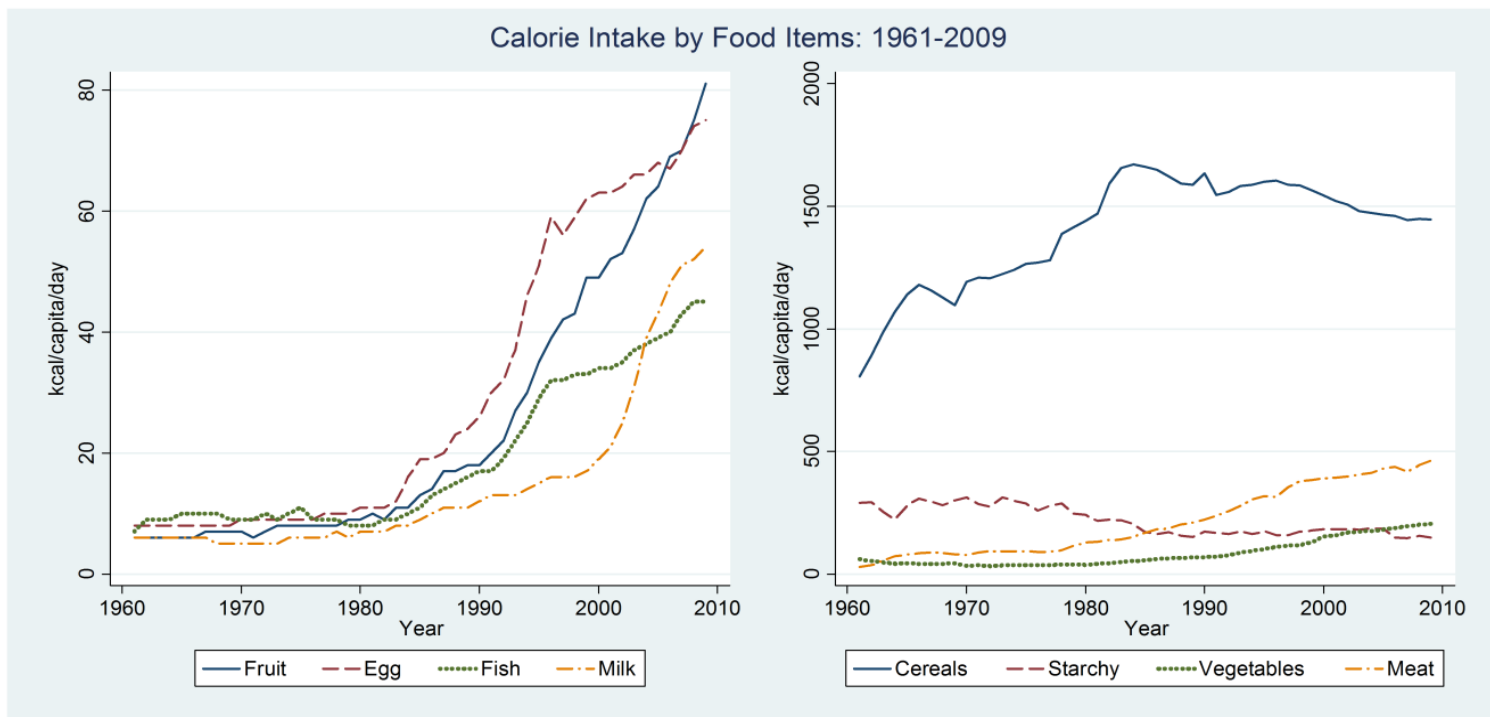

Notes: 1. Calculations are based on data in FAOSTAT.

2. Beer is excluded from Cereals, wine is excluded from fruits, and butter is not included in Milk.

In opposition to the decreasing consumption of vegetal foods, fat plays a rising role in energy sources, particularly the fat from animal products (see Figure 1.3).

Figure 1.3: Sources of Calorie, Protein and Fat: 1961-2009

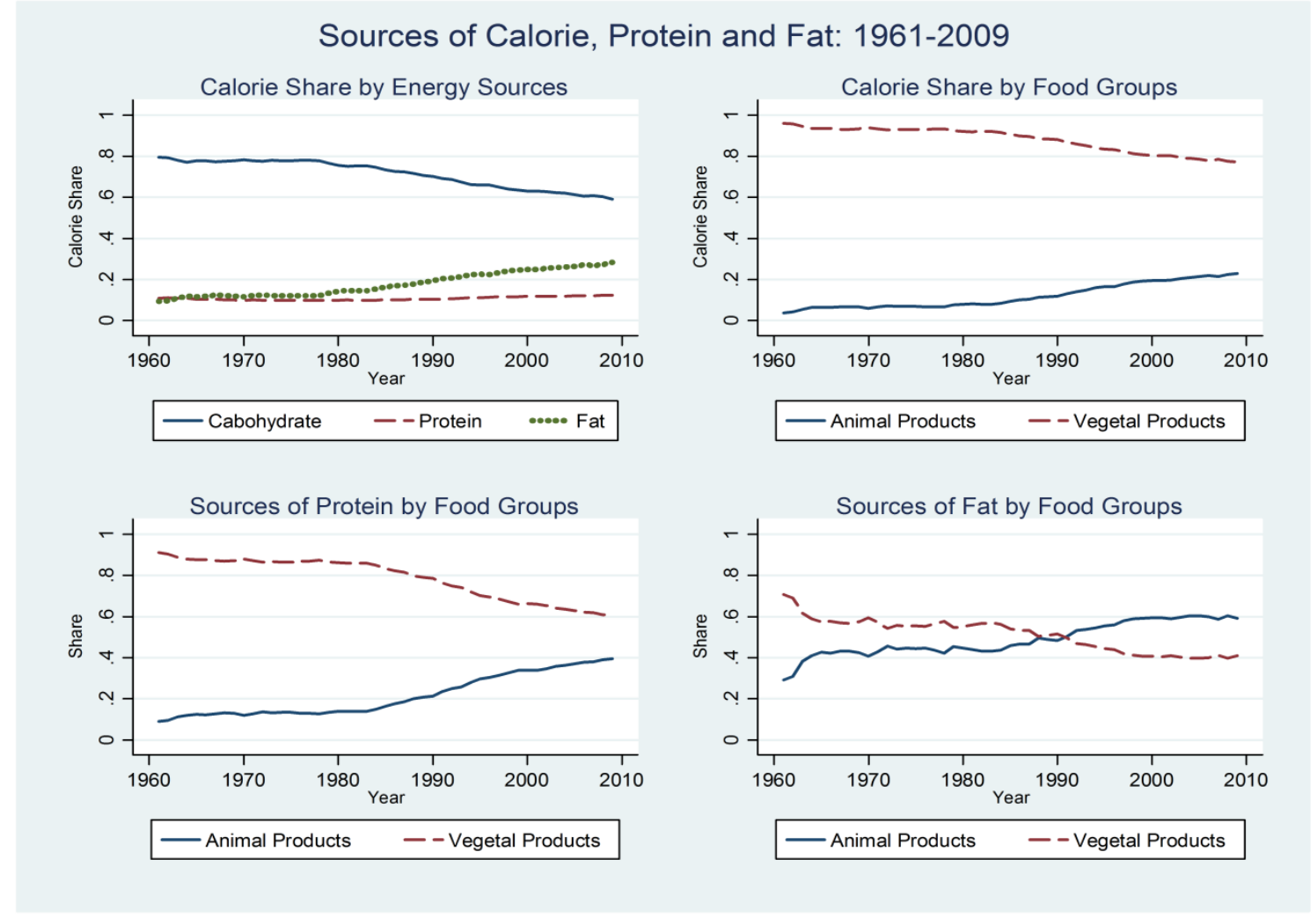

Notes: 1. Calculations are based on data in FAOSTAT.

2. Beer is excluded from Cereals, wine is excluded from fruits, and butter is not included in Milk. 
Along with the nutrition transition, a great shift took place in patterns of disease: Cases of infectious and nutrient deficiency related diseases were gradually replaced by a growing concern over the amount of cases of the diet-related, non-communicable diseases (DR-NCD) such as obesity, diabetes mellitus, cardiovascular disease, and cancer (Omran, 1971; Drewnowski and Popkin, 1997; Popkin, 2003). For instance, Du et al. (2004) show that the combined prevalence of overweight and obesity (BMI>25) for adults aged 20 to 45 years old increased from $10.3 \%$ in 1989 to $15.4 \%$ in 1997 . WHO further claims that the mean BMI increased from less than 22 in 1980 to more than 23 in 2008, and the overall prevalence of overweight and obesity reaches $31.1 \%$ in 2008 .

To conclude, income growth leads to significant changes in diet, which causes further improvement in nutrition and structural change in food consumption, as well as a rapid increase in DR-NCD. Current studies (e.g., Strauss and Thomas, 1995; Gibson and Rozelle, 2002; Jensen and Miller, 2010) show that the relationship between income growth and nutrition transition is nonlinear. In particular, the food consumption pattern of poor people is more sensitive to income change than that of rich people. Therefore, a parametric model might be too restrictive to capture the exact relationship. In order to better understand the impact of income growth on the undergoing nutrition transition in China, case study two provides a semi-parametric method to model the complex relationship with several indicators from different perspectives, which can be further used to directly project the nutrition transition at higher income levels.

\subsection{Engel's Index, Son Preference and Economic Development}

Changing food consumption is not only a reflection of economic development, but can also give some implication to the welfare of family (Haddad and Kanbur, 1990). As the most fundamental human need, food is often given priority in expenditure for the 
extremely poor people. In 1974, the World Food Conference declares that "Every man, woman and child has the inalienable right to be free from hunger and malnutrition in order to develop fully and maintain their physical and mental faculties" (UN, 1975). Having enough money to buy the food that is required for basic subsistence becomes an attractive definition of poverty and living standards (Deaton, 1997). Based on the observation that poor families spend a higher share of expenditure on food than rich ones, and large households have a higher food share than small ones at the same level of total expenditure, Engel (1895) originally uses the share of food as an indirect indication of welfare, suggesting that two families with the same food share should have the same level of welfare, or real income (Deaton and Muellbauer, 1980). Deaton $(1987,1989,1997)$ and Haddad and Kanbur (1990) further claim that welfare, living standard, and poverty are all characteristics of individuals, not households, although households are often the primary income recipients. However, if resources are not equally distributed in the household, for instance, if women systematically get less than men, the estimated social welfare will be overstated when we assume that everyone in the household is equally treated (Abdullah, 1989; Thomas, 1990; Burgess and Wang, 1995; Gong et al., 2005). Therefore, household composition must be taken into account when measuring social welfare.

In light of the pioneering works of Engel and Deaton, an alternative way to test gender discrimination against girls can be provided under the assumptions that parents' welfare can be correctly indicated by food share (Engel's index) and boys and girls have the same pattern of consumption: taking a childless couple as reference, comparing the compensations needed by families with the arrival of a new child with different genders, to restore to their original welfare level. If families with a new boy need higher compensation to maintain their welfare level than that with a new girl, discrimination 
against girls can be claimed (Deaton and Muellbauer, 1980, 1986; Deaton, 1987, 1989, 1997). Furthermore, the equivalent scale of a child can be straightforwardly measured by calculating the compensation that has to be paid to the parents to restore the household food share to its prenatal level (Deaton and Muellbauer, 1986).

Table 1.3: Average Daily Nutrient Intakes by Gender and Age

\begin{tabular}{|c|c|c|c|c|c|c|c|c|c|}
\hline \multicolumn{10}{|c|}{ Rural } \\
\hline Ages & \multicolumn{3}{|c|}{$0-7$} & \multicolumn{3}{|c|}{$8-15$} & \multicolumn{3}{|c|}{$16-60$} \\
\hline Gender & Males & Females & Male/Female & Males & Females & Male/Female & Males & Females & Male/Female \\
\hline Calories (kcal) & 1471 & 1440 & 1.02 & 2161 & 2007 & 1.08 & 2974 & 2571 & 1.16 \\
\hline Proteins (g) & 44.6 & 43.6 & 1.02 & 63.9 & 59.8 & 1.07 & 88.1 & 76.5 & 1.15 \\
\hline Fat $(\mathrm{g})$ & 36.1 & 36.7 & 0.98 & 50.8 & 47.0 & 1.08 & 69.9 & 60.6 & 1.15 \\
\hline \multicolumn{10}{|c|}{ Urban } \\
\hline Ages & \multicolumn{3}{|c|}{$0-7$} & \multicolumn{3}{|c|}{$8-15$} & \multicolumn{3}{|c|}{$16-60$} \\
\hline Gender & Males & Females & Male/Female & Males & Females & Male/Female & Males & Females & Male/Female \\
\hline Calories (kcal) & 1576 & 1545 & 1.02 & 2237 & 2019 & 1.11 & 2736 & 2336 & 1.17 \\
\hline Proteins (g) & 52.0 & 49.5 & 1.05 & 72.3 & 65.4 & 1.11 & 87.6 & 75.4 & 1.16 \\
\hline Fat (g) & 50.7 & 52.6 & 0.96 & 69.7 & 62.3 & 1.12 & 85.5 & 74.0 & 1.16 \\
\hline
\end{tabular}

Notes: 1. Data source: Park and Rukumnuaykit (2004) "Eat drink man woman: Testing for gender bias in China using individual nutrient intake data".

2. Data is from the 1991 and 1993 waves of China Health and Nutrition Survey (CHNS) administered by the Population Center at the University of North Carolina at the Chapel Hill, which covers seven provinces in different parts of China: Guangxi, Henan, Hubei, Hunan, Jiangsu, Liaoning, and Shandong.

Current literatures already show that boys usually have higher nutrient intake than girls at the same age cohort (see Table 1.3). However, the differences in nutrient intake and food consumption might be due to the different requirements needed to maintain the basic metabolic ratio of boys and girls, rather than gender discrimination. It is well known that human beings need energy for the following activities: first, basal metabolism, which further depends on gender, age, physical activity, body composition and body size (Whitney and Rolfes, 2005); second, metabolic response to food; third, physical activity; fourth, growth; fifth, pregnancy; sixth, lactation (FAO, 2001). Other things being equal, males still have a higher requirement for energy than female (see Table 1.4). Therefore, the difference in requirements for energy must be taken into account when using the food 
share to measure welfare. More discussions about this approach are provided in the third case study.

Table 1.4: Comparison of Daily Average Basal Metabolism Ratio per kg by Gender

\begin{tabular}{c|ccc|ccc|ccc}
\hline Ages & \multicolumn{3}{|c|}{$18-29.9$} & \multicolumn{3}{c|}{$30-59.9$} & \multicolumn{3}{c}{$60+$} \\
\hline Weight (kg) & Males & Females & Male/Female & Males & Females & Male/Female & Males & Females & Male/Female \\
\hline 50 & 29 & 25 & 1.16 & 29 & 25 & 1.16 & 23 & 22 & 1.05 \\
55 & 28 & 24 & 1.17 & 27 & 24 & 1.13 & 22 & 21 & 1.05 \\
60 & 27 & 23 & 1.17 & 26 & 22 & 1.18 & 22 & 20 & 1.10 \\
65 & 26 & 22 & 1.18 & 25 & 21 & 1.19 & 21 & 19 & 1.11 \\
70 & 25 & 22 & 1.14 & 24 & 20 & 1.20 & 20 & 18 & 1.11 \\
75 & 24 & 21 & 1.14 & 23 & 19 & 1.21 & 20 & 18 & 1.11 \\
80 & 24 & 21 & 1.14 & 22 & 19 & 1.16 & 19 & 17 & 1.12 \\
85 & 23 & 21 & 1.10 & 22 & 18 & 1.22 & 19 & 17 & 1.12 \\
\hline
\end{tabular}

Notes: 1. Calculations are based on daily energy requirements for children and adults in FAO/WHO/UNU, 2001, pp. 26-27, pp. 48.

2. Figures are measured in kilocalorie per kilogram.

Regarding China, a country with a long history of son preference, no consensus over sexual discrimination has been reached in empirical studies. On the one hand, China has a strong tradition of favoring boys over girls, which can be traced back to the origins of ancestral worship and further reinforced by the patrilocal and patrilineal familial systems (Bray, 1997; Lee and Wang, 1999). Traditionally, only sons could support their parents (Aha, 1994; Graham et al., 1998; Li and $\mathrm{Wu}, 2011$ ) and moreover, boys were believed to have higher expected work value since they usually had higher productivity in heavy farm work and are much easier to find an off-farm job with a higher salary (Rozelle et al., 2002; Knight et al., 2010; Li and Wu, 2011). Some empirical studies also confirm the son preference from different perspectives (e.g., Knight and Song, 1993; Burgess and Wang, 1995; Graham et al., 1998; Gong et al., 2005).

On the other hand, successful economic development and the accompanied social changes weaken the preference for sons from several aspects: first, the increasing income and job opportunities available to females have raised the bargaining power of women 
(Lee, 2008), and further encourages them to participate more in household resource allocation ( $\mathrm{Li}$ and $\mathrm{Wu}, 2011$ ); second, the increasing income and improving endowment insurance lower the incentive to raise boys for old time; third, the female emancipation and egalitarian movements in the last century challenge the traditional preference of sons and have significantly improve women's status in China (Leung, 2003; Shu, 2004). Moreover, the unbalanced sex ratio at birth due to the implementation of the family planning system in the early 1980s resulted in a huge shortage of women at marriage age, which increases the relative value of females in the marriage market (Chu, 2001; Wei and Zhang, 2011a, 2011b). Therefore, the interaction between traditional preference for sons and economic and social developments makes gender inequality in China ambiguous.

\subsection{Theoretical Contributions}

\subsubsection{Meta-Analysis of TFP Growth Rate}

Clarifying the determinants of heterogeneity in TFP growth rate is very important for estimating in a correct way and finding out the real driving force behind economic growth. However, it has not been studied systematically and quantitatively. The second section of this dissertation tries to fill in this gap by conducting a meta-analysis.

Meta-analysis is the statistical analysis of a body of similar related studies for the purpose of integrating and evaluating the reliability of their findings (Glass, 1976; Stanley and Jarrell, 1989; Card and Krueger, 1995). The need for the meta-analysis stems from the variation and fragility of the reported empirical results in the exploding literatures on the same topic. By incorporating the characteristics of the primary studies such as the model specification, contexts, classes of subjects, data, and many other factors into an econometric model, meta-analysis can provide a means to analyze, estimate and discount the influence of these factors on the empirical results, and further find out the 
determinants of the variation in primary results (Glass, 1976; Stanley and Jarrell, 1989). In this way, it gives some implication for how to accurately estimate the empirical magnitudes (Stanley and Jarrell, 1989). This technique has been widely used in economic literature after the pioneering introduction of Stanley and Jarrell in 1989 (Nelson and Kennedy, 2009).

In standard meta-analysis, the object is effect size or the results from primary empirical studies, and the control variables include all factors that might affect the empirical results in the primary studies, such as dummy variables which are used to control unobservable effects in primary studies, specification variables that account for differences in functional forms, type of regression, data definitions, sample size, characteristics of the authors of the primary literature, and measure of data quality (Stanley and Jarrell, 1989; Tian and Yu, 2012).

The choice of a proper meta-analysis model and the validity of the results depend on four characteristics of the data. First, sample heterogeneity caused by factual factors (e.g., TFP growth rates differ across regions and years) and methodological factors (e.g., TFPG heterogeneity arises from the use of different estimation models, type of regression etc.) (Christensen, 2003; Nelson and Kennedy, 2009). This dissertation uses dummy variables to control those effects by dividing the regressor into several categories, such as approaches to measure TPFG, definition of inputs, whether dummy variables are used in primary studies, which price is used, language and peer-review process of primary studies, time, region and sector and type of data. Furthermore, separate regressions for several homogeneous subsamples are also presented. Second, heteroskedasticity of effect-size variance due to different primary sample sizes, different sample observations and different estimation procedures (Nelson and Kennedy, 2009). Nelson and Kennedy (2009) argue that the heteroskadesticity can be accounted for by giving greater weight to the 
more reliable estimates if these variances are known. However, most primary studies do not report variance in TFPG estimation. Therefore, this dissertation uses the sample sizes to proxy the variances and adopts the weighted least squares regression (WLS) to handle the heteroskedasticity. Third, non-independence of primary studies. Nelson and Kennedy (2009) figure out several possible reasons why these results might be dependent upon one another: (1) some primary studies use the same data; (2) some primary studies have more than one estimate; (3) similar adjustment to the primary data is used by different studies; (4) several primary studies may share an unobservable characteristic; (5) several primary studies may share an observable characteristic. This dissertation uses dummies to control the possible non-independence. Fourth, sample selection bias caused by the selection criteria of the primary studies. Meta-analysis asks reviewers to include all studies, published and unpublished, or at least take a random sample of these studies (Stanley and Jarrell, 1989; Walker et al., 2008). This dissertation does its utmost to include all related papers that can be found in Google Scholar and the database of the China National Knowledge Infrastructure (CNKI) to avoid selection bias. Finally, 150 papers are collected. More discussions about the model selection and practice of meta-analysis are presented in section 2 .

\subsubsection{Multi-dimension Indices of Nutrition Transition}

As aforementioned, income growth is accompanied by nutrition transition, a large body of papers have tried to explore the relationship between these two variables (e.g., Behrman and Deolalikar, 1990; Bouis, 1994; Subramanian and Deaton, 1996; Behrman et al., 1997; Dawson, 1997; Dawson and Tiffin, 1998; Gibson and Rozelle, 2002; Skoufias, 2003; Aromolaran, 2004; Kochar, 2005; Shimokawa, 2010). However, current literatures on nutrition transition mainly focus on the estimation of calorie elasticities with respect to income or expenditure. Calorie intake is certainly an important aspect of nutrition 
transition, but it is not the whole story. When hunger is not an issue, people might care more about non-nutritional attributes such as tastes, appearance, odour, status value, degree of processing, and variety, than calorie content (Behrman and Doelalikar, 1987; Jensen and Miller, 2010). Therefore, the composition of food and nutrition will change simultaneously with income growth. Moreover, dietary change is always accompanied by the shift in patterns of disease from infectious and nutrient deficiency related diseases toward diet-related, non-communicable diseases (DR-NCD) (Omran, 1971; Drewnowski and Popkin, 1997; Popkin, 2003).

In order to better understand nutrition transition, this dissertation develops ten aggregated indicators to capture changes in trophic structures, corresponding outcomes of nutrition transition, and dietary changes: (1) per capital calorie intake, (2) share of calorie obtained from protein, (3) share of calorie obtained from fat, (4) unit value of food, (5) unit value of calorie, (6) food diversity, (7) average calorie density (unit calorie) and (8) body mass index (BMI), (9) calorie shares and (10) expenditure shares of specific food groups, The first seven indicators can measure the improvement in nutritional status, the eighth indicator is used to proxy the consequence of nutrition transition, and the last two capture the food structure changes. Using these measures, this dissertation provides a multi-dimensional angle to understand nutrition transition from different perspectives. Further descriptions of these indicators are presented in section 3.

Moreover, the relationship between income and nutrition transition is quite complicated and usually nonlinear (Strauss and Thomas, 1995; Gibson and Rozelle, 2002; Meng et al., 2009). The estimation is biased if the predetermined model is incorrectly specified. Therefore, more flexible model such as nonparametric and semi-parametric estimations is needed to study nutrition transition. Section 1.4 .4 provides a brief discussion about model specification. Furthermore, in order to compare the results in 
different approaches, we also introduce Yatchew's model specification test (1998) which will be presented in section 1.4.5.

\subsubsection{Engel's Method and Gender Discrimination}

A large amount of literature documents discrimination against females, at least in some areas of the world (Deaton, 1997). However, there are some shortcomings in current methods which are used to measure gender inequality. For instance, detecting whether resources are equally distributed within households between males and females is very difficult, since female discriminated in some aspects may be compensated in other aspects (Lee, 2008). Additionally, it cannot be measured comprehensively and accurately taking into account the limited data and the difference in demand (Gibson and Rozelle, 2004); using biologic indicators might be misleading because females and males have different characteristics; in addition, unequal opportunity and bargaining power between men and women might be partly caused by gender difference rather than discrimination. Deaton $(1987,1989,1997)$ develops a new approach to test gender inequality among children using only household expenditure data. According to this methodology, gender discrimination is tested by comparing the reductions in adult-goods expenditure caused by both boys and girls, which reflect the additional needs of the children. If the reduction is larger for the households with boys, then households are diverting more resources to boys than to girls (Deaton, 1989). However, Deaton (1997) also points out that it is often difficult to find commodities that are only consumed by adults; children could also change the consumption pattern of the family rather than the substitution effects.

This dissertation goes back to the original idea of Deaton and tries to compare the reductions in adults' welfare caused by the additional child. Different from Deaton's method, this dissertation uses Engel's index as an indicator of adults' welfare. As 
aforementioned, households of different sizes are equally well-off if, and only if, they spend the same fraction of total expenditure on food (Deaton, 1997). Therefore, taking a childless couple as the reference family, the arrival of a child will increase families' food expenditure and decrease their welfare level according to Engel's law (here we do not take the happiness brought by the child to the couple into account since we only need to compare the "cost" of the child). In order to maintain their original welfare level, parents need a compensation. Therefore, gender inequality can be measured by comparing the compensations needed by the arrival of a new child with different genders. Moreover, the required compensation can also be detected by the change in food share, which suggests a straightforward way to test gender inequality by comparing the marginal effects of an additional boy and girl on food share. Compared with all current approaches, Engel's method is simpler and more straightforward, and only requires data on food expenditure share and household characteristics, which are usually available in most household surveys. In practice, gender discrimination can be identified in two ways: (1) comparing the compensation needed by families with a boy and that with a girl; (2) comparing the marginal effects of an additional boy and girl on the Engel index using a simple one-sided $\mathrm{t}$ test. If families with a new boy need higher compensation than that with a girl, or boys have significantly larger marginal effect on the family's Engel index than girls, discrimination against girls can be claimed.

However, food share might not change monotonically with income. Thus, more flexible approaches are also needed to test the robustness of the results. This dissertation uses both parametric linear model and semi-parametric partial linear model, and compares the results of these two approaches. The partial linear model allows full flexibility of income and simultaneously controls demographic ratios and other control variables in a linear function. The advantages of using this partial linear model will be presented in the 
following section.

\subsubsection{Semi-parametric Partial Linear Models}

In general, two approaches are used to explore the relationship between two variables. The first one analyzes the relationship by assuming a pre-specified functional form and thus is called parametric approach. An alternative approach is estimating the relationship without referencing to any specific functional form, which is named as nonparametric approach (Hardle et al., 2000). Both have their merits and shortcomings. On one hand, parametric model, if it has a reasonable form, can afford precise inference; but it is difficult to model very complicated relationships and the estimation is biased if the model is incorrectly specified. On the contrary, nonparametric model is more flexible and robust since it has no assumptions about functional form; while it is less precise and is restricted to low dimensional relationships (Robinson, 1988; Hardle et al., 2000; Gibson and Roselle, 2002; Gong et al., 2005). If the dimension of control variables is large and the number of observations is limited, full nonparametric estimation will suffer from the curse of dimensionality: the estimation precision of the nonparametric function decreases rapidly with the increase in the dimension of nonlinear variables (Hardle et al., 2000; Fox, 2000; Gong et al., 2005; Meng et al., 2009). In the case of nutrition transition, many other factors also have influence on this process in addition to income. Ignoring these factors will lead to biased estimation (Fox, 2000; Gong et al., 2005; Meng et al., 2009). Therefore, a semi-parametric approach, which allows full flexibility of some independent variables while simultaneously controls others in parametric form, is appropriate in the case that a lot of variables need to be controlled but most of them can be well modeled in a parametric function (Hardle et al., 2000; Fox, 2000; Gong et al., 2005; Meng et al., 2009). 
The class of semi-parametric specifications includes several subclasses such as partial linear model, partial parametric model and partial index model (Yatchew, 1998). This thesis only focuses on partial linear model.

A partial linear model is a semi-parametric regression model with the following form:

$$
Y=Z^{T} \beta+f(X)+\varepsilon
$$

Where $Z=\left(z_{1}, z_{2}, \mathrm{~L}, z_{p}\right)^{T}$ is the vector of explanatory variables, $\beta=\left(\beta_{1}, \beta_{2} \mathrm{~L}, \beta_{p}\right)^{T}$ is the corresponding coefficients vector, $Z^{T} \beta$ is the parametric part of this model in linear form. $\varepsilon$ is the error term which is uncorrelated with all independent variables $E(\varepsilon \mid Z, X)=0 . f(X)$ is the nonparametric part, which is an unknown function of $X=\left(x_{1}, x_{2} \mathrm{~L}, x_{m}\right)^{T}$. For simplicity, we only discuss the model with only one dimension in the nonparametric part $(m=1)$.

The analysis of partial linear model can be divided into two stages: first analyzing the parametric portion of the model using a standard econometric package such as OLS; then estimating the nonparametric portion of the model with nonparametric regression techniques such as kernel estimator and nonparametric least squares (Yatchew, 1998).

In the first stage, two methods are widely used to estimate the parameter $\beta=\left(\beta_{1}, \beta_{2} \mathrm{~L}, \beta_{p}\right)^{T}:$ the conditional expectation method proposed by Robinson (1988) and the differencing method developed by Yatchew $(1997,1998)$. Robinson removed the nonparametric function $f(X)$ by taking the conditional expectation of equation (1.4) on $X$ and subtracting these on both sides of the equation.

$$
Y-E(Y \mid X)=\left[Z^{T}-E\left(Z^{T} \mid X\right)\right] \beta+f(X)-E(f(X) \mid X)+\varepsilon-E(\varepsilon \mid X)=\left[Z^{T}-E\left(Z^{T} \mid X\right)\right] \beta+\varepsilon
$$


Robinson estimated the conditional mean of $Y$ and $Z$ using nonparametric estimators and substituted them in equation (1.5), then OLS would yield an estimate of the coefficient of parametric function $\beta$ which is asymptotically $N\left(\beta, \frac{\sigma_{\varepsilon}}{N \sigma_{z}}\right)$, where $N$ is the number of observations and $\sigma_{z}$ is the expected conditional variance of $Z$ given $X$.

On the other hand, Yatchew $(1997,1998)$ figured out that Robinson's method was quite onerous, because separate nonparametric regressions were required for each parametric variables and for the dependent variables. He thus proposed an elementary and asymptotically efficient estimator of $\beta$ by ranking the observations according to $X$ and taking the first order difference to remove the nonparametric function.

$$
Y_{\mathrm{i}}-Y_{i-1}=\left(Z_{i}^{T}-Z_{i-1}^{T}\right) \beta+f\left(X_{i}\right)-f\left(X_{i-1}\right)+\varepsilon_{i}-\varepsilon_{i-1}, i \in[2, N]
$$

As sample size increases, the typical difference $X_{i}-X_{i-1}$ shrinks at a rate close to $1 / N$. Assuming that the first derivative of the unknown function $f(X)$ is bounded by a constant, thus $f\left(X_{i-1}\right)$ tends to cancel $f\left(X_{i}\right)$. Therefore, the coefficients of parametric function can be estimated in the following function by OLS.

$$
\Delta Y=\Delta Z^{T} \beta+\Delta \varepsilon
$$

Yatchew proved that the estimated coefficient $\beta \sim N\left(\beta, 1.5 \frac{\sigma_{\varepsilon}}{N \sigma_{z}}\right)$, which was only $66.7 \%$ (1/1.5) efficient as Robinson's estimator. However, efficiency can be improved substantially by using higher order differences (Yatchew, 1997).

Once the parametric portion of the partial linear model has been estimated in the first stage, the nonparametric portion can be generated by substituting the estimated $\beta$ in equation (1.4) and rewriting the equation as follows: 


$$
Y-Z^{T} \beta=f(X)+\varepsilon
$$

The relationship between $Y$ and $X$ can be demonstrated by nonparametric regression estimators. This dissertation briefly discusses two estimators: kernel estimator and nonparametric least squares.

Kernel estimation generates the fitted value by a locally weighted average using a kernel as a weighting function. The widely used Nadaraya-Watson (1964) estimator is specified as follows:

$$
f\left(x_{0}\right)=\frac{\sum_{i=1}^{N} w_{i} Y_{i}}{\sum_{i=1}^{N} w_{i}}=\frac{\frac{1}{\lambda N} \sum_{i=1}^{N} K\left(\frac{x_{i}-x_{0}}{\lambda}\right) Y_{i}}{\frac{1}{\lambda N} \sum_{i=1}^{N} K\left(\frac{x_{i}-x_{0}}{\lambda}\right)}
$$

Here $w_{i}$ is the weighting function, $K\left(\frac{x_{i}-x_{0}}{\lambda}\right)$ is the kernel function which is symmetric and integrates to one, and $\lambda$ is a smoothing parameter called the bandwidth.

On the other hand, nonparametric least square produces the fitted value by locally regression (see equation 1.10). It is preferred to kernel estimation for several reasons: first, it corrects biases caused by asymmetric neighbourhoods in the interior; second, it can better model the slope effects particularly in the boundary regions.

$$
\min \sum_{i=1}^{N} w_{i}\left(Y_{i}-a-b_{1} x_{i}-b_{1} x_{i}^{2}-\mathrm{L}-b_{k} x_{i}^{k}\right)^{2}
$$

\subsubsection{A Simple Model Specification Test}

Once the coefficient has been estimated using both parametric and semiparametric estimators, it is necessary to test whether the functional form in parametric estimation is correctly specified. Yatchew $(1997,1998)$ proposed a simple differencing test for model specification. The null hypothesis is that the parametric model is correctly specified. Therefore, the error terms in two estimations should follow the same 
distribution and a test can be conducted by comparing the residual variance in two estimations.

$$
V=\frac{\sqrt{N}\left(S_{r e s}^{2}-S_{d i f f}^{2}\right)}{S_{d i f f}^{2}}
$$

Where $S_{\text {res }}^{2}$ is the average sum of squared residuals of the parametric model (linear model), and $S_{\text {diff }}^{2}$ is defined as:

$$
S_{\text {diff }}^{2}=\frac{\sum_{i=1}^{N}\left(\Delta \mathrm{Y}_{\mathrm{i}}-\Delta \mathrm{Z}_{i}^{T} \beta\right)^{2}}{2 N}
$$

Here $\Delta$ refers to the first difference after sorting the observations as described in Yatchew's differencing method (see equation 1.6), and $\beta$ is the estimated coefficients vector of the parametric portion.

Yatchew (1997) claimed that under the null hypothesis $V \sim N(0,1)$, which indicated a one-sided $t$ test.

\subsection{Empirical Contributions and Policy Implications}

This dissertation makes important empirical contributions to the analysis of the relationship between technological progress and economic development, and the impact of income growth on nutrition transition and gender discrimination, which are investigated in three case studies respectively. The first two case studies have strong policy implications not only for China, but also for other developing and emerging economies, the last case provides some implications for China and other countries that are believed to discriminate strongly against females.

\subsubsection{Case Study 1}


Case study one uses meta-analysis to investigate the controversies about productivity growth in China. By integrating 5308 observations from 150 primary studies, this case study finds that TFP growth contributes $24 \%$ to growth in China's nation-level aggregate economy during the reform period, and there is a cycle every 10 years after 1978. Moreover, the results show that TFPGs vary in different regions, sectors and periods, and can be affected by methodological factors such as peer-review process, paper language, model and specification. The empirical results uncover some potential problems in the current literature and clarify some misunderstandings of TFPG in China.

To my knowledge, this case study is the first piece of research to investigate the heterogeneity of TFPGs in China through meta-analysis. Given the success of China's economic development over the past three decades, these findings offer the reader a deeper understanding of the driving forces behind economic growth, and can also provide meaningful empirical findings and implications for other developing and transition countries that want to catch up with rich ones.

\subsubsection{Case Study 2}

The second case study explores the relationship between income growth and nutrition transition with China as the chosen country. Current literature shows that China is undergoing a nutrition transition in line with its rapid income growth (Popkin, 1993, 2001b; Guo et al., 2000; Du et al., 2002). However, most studies are limited to inspecting one aspect of nutrition transition such as calorie elasticity, and often use linear models to capture the change in nutrition transition along with income growth. To overcome these shortcomings, case study 2 develops 10 indices from different perspectives to measure nutrition improvement and dietary change during nutrition transition in a semi-parametric approach. Results show that linear model is too restrictive to capture the complex 
relationship between nutrition transition and income growth for most indices. Moreover, along with income growth, people value more about other attributes of food such as diversity and tastes rather than energy, and the demand for staple food and vegetables will be gradually replaced by fruits, meat and dairy products. I also find that nutrition transition will slow down.

Using a semi-parametric approach with several indicators from different perspectives, this case study contributes to the current literature by providing a deeper and more comprehensive understanding of the current nutrition transition in China, which also gives some implication to other developing countries that are undergoing a similar transition process in diet.

In addition, the method developed in this dissertation can also be used to project the nutrition transition in the long run. Policy makers aimed at eliminating malnutrition and improving the health status of people can glean useful implications from the projection.

\subsubsection{Case Study 3}

In the third case study, gender discrimination against girls is measured and tested by a simple but effective method from the perspective of welfare change.

Using China Health and Nutrition Survey data (CHNS) 2004, 2006, and 2009, this case study uses Engel's index as a proxy of family welfare, and measures gender inequality by comparing the compensations needed by the household to raising an additional boy and girl. The results show that families with a new boy usually need higher compensation to be as well off as before, but this difference is only statistically significant for teenage child in China and small child in rural area. These findings are confirmed by using a semi-parametric approach. Therefore, results from this case study 
indicate that gender inequality still exists in China, particularly in rural area.

In addition, well educated people might discriminate less against girls since they are usually more open-minded, and have more decent jobs. Thus case three also sheds some light on the impact of education on gender inequality. However, the results do not provide any clear evidence that education can help to reduce gender inequality in China, so policy makers interested in ending gender discrimination should consider finding some other means of reaching the public.

The method developed in this case study can also be used in other countries where females are believed to be discriminated against. 


\section{The Enigmas of TFP in China: A Meta-analysis ${ }^{1}$}

${ }^{1}$ This chapter is jointly written with Xiaohua Yu and has been published in China Economic Review, Vol. 23(2): 396414. 


\subsection{Introduction}

Since the market-oriented reform and the open-up policies were launched in 1978, China has experienced rapid economic growth with an average annual growth rate of $9.8 \%$ in the past three decades. GDP per capita increased rapidly from 381 Yuan in 1978 to 29678 Yuan (USD 4481) in 2010. It is called an economic miracle. Along with the remarkable performance in economic growth, a lot of arguments have been raised regarding the fundamental driving forces behind the economic miracle, particularly regarding the role of productivity growth (Hsieh and Klenow, 2009).

Some economists believe that the key driving force behind the economic miracle is the soaring input use (Krugman, 1994; Young, 2003) and the contribution of productivity growth is very limited. Many studies point out that the TFP growth rates in China are lower than $1.5 \%$ and the contribution to economic growth is less than $20 \%$ (e.g., Wang, 2000; Liang, 2000; Young, 2003), while the main contributors are the soaring increases in inputs, such as labor (increase in labor participation rate, rural-urban migration, and improvement of education) (Young, 2003), and capital. For instance, the nominal gross capital formation increased to more than 90 times as much as its initial value from 1978 through $2010^{2}$. In addition, China has benefited a lot from the demographic bonus during the past three decades resulting from a rise of the labor force ratio due to family planning and rural-urban migration (Cai and Wang, 1999; Chen and Feng, 2000). According to the estimate of Cai and Wang (1999), the contributions of the rise of the labor force ratio and of the rural-urban migration to economic growth in China from 1982 to 1997 are $24 \%$ and $20 \%$, respectively.

However, some other studies argue that the improvement of productivity or TFP

2 Data source: <China Statistical Yearbook>, (2009). 
plays a key role in China's rapid economic growth, and they claim that the TFP growth rates are more than $3 \%$ per year and contribute to more than $30 \%$ of the economic growth in China (e.g., Hu and Khan, 1997; Chow and Li, 2002; Zhang and Shi, 2003; Bosworth and Collins, 2008)

Why is there such a big divergence in the results regarding Chinese TFP growth rates in the current literature? What causes the differences? Which results are more credible? Given the importance of the Chinese economy in the whole world, these questions are very important both from a policy perspective and from an academic perspective. Unfortunately, the determinants of TFPG heterogeneities in China haven't been studied systematically and quantitatively. In this paper, we try to find out the causes of the differences in TFPG for China by conducting a meta-analysis, which is now made possible by a large number of studies on Chinese TFP in the current literature.

The paper is organized as follows: Section 2 discusses different approaches to TFPG estimation and other possible determinants that may affect TFPG; Section 3 then briefly introduces the approach of meta-analysis and discusses the problems with respect to data processing; Section 4 provides a brief introduction to the data on Chinese TFPG collected from the recent primary studies and presents a descriptive statistic analysis; Section 5 presents the results of the meta-analysis and has some discussion, which is followed by the conclusion in Section 6 .

\subsection{TFPG Measurement}

Economic growth can be decomposed into input contribution and productivity growth. Economists prefer the concept of total factor productivity (TFP) to measure the improvement of productivity with exclusion of input contribution. TFP is a measure of an economy's long-term productivity growth or the quality of growth, and regarded as the 
transformation ratio of total inputs into total outputs (Diewert and Nakamura, 2007).

There are two types of productivity growth: Embodied technical progress and disembodied technical progress. The former represents the technical progress or productivity growth stemmed from changes in input factors, such as an increase in the quality of inputs, whereas the latter refers to the productivity growth that does not stem from the inputs, but takes place like manna from heaven in the form of better methods and organization that improve the efficiency of both new and old factor inputs (Solow, 1957; Chen, 1997). However, the concept of TFP is only applicable to disembodied, exogenous and Hicks neutral technical progress in neoclassical economics. Furthermore, if inputs are not measured correctly, the TFP contains not only disembodied technical progress but also some embodied technical progress (Chen, 1997; Zheng, 1998; Felipe, 1999).

Several stages are required for measuring TFP and its growth rate: Model specification, variable selection, parameter setting, data processing and et al. Hence, the heterogeneities in final TFPG may emerge on each stage. Nadiri (1970) concludes several factors that may influence TFPG: first, specifications of the production function; second, the proper measurement of factor inputs; third, the weight assigned to different inputs; fourth, time period chosen in the study. Felipe (1999) suggests that the measurement of TFPG depends critically on assumptions about production function, measurement of output, measurement of capital, quality adjustment of inputs, cyclical smoothing, time period studied, errors of measurement in the variables, and so on. Chen (1997) also believes that the measurement of TFPG is quite sensitive to the measurement of factor inputs, especially to the extent and scope of the adjustments of quality improvements made to factor inputs. Similar argument can also be found in other studies (Sun and Ren, 2005; Zhang and Gui, 2008; Liu et al., 2009). 
Regarding the different results in primary studies, Alston et al. (2000) categorized all factors that might account for the variation in primary studies into five broad groups: (1) characteristics of the results in primary studies (e.g., real or nominal, marginal or average); (2) characteristics of the analysts (e.g., published or unpublished); (3) characteristics of the research (e.g., geographic region); (4) evaluation characteristics (e.g., ex post or ex ante, method); (5) random measurement errors. Nelson and Kennedy (2009) suggest that heterogeneities between primary studies can be attributed to two basic causes: Factual factors and methodological factors. Following their studies, we first discuss the methodological factors and then briefly introduce the factual factors in this section.

\subsubsection{Methodological Factors}

\subsubsection{Approaches to TFPG Measurement}

There are many different approaches to estimate TFPG and a lot of papers already present comprehensive reviews on this issue (e.g., Solow, 1957; Jorgenson and Griliches, 1967; Nadiri, 1970; Chen, 1997; Felipe, 1999; Hulten, 2000; Lipsey and Garlaw, 2004; Guo and Jia, 2005; Raa and Shestalova, 2011).

The first way to measure TFPG is the growth accounting approach, where TFP is estimated by removing the contributions of all inputs. The residual is then presumed to be attributable to technical progress. Two commonly used growth accounting approaches are the Arithmetic Index Number Approach (AINA) and the Solow Residual Method (SRM). When using the AINA, TFP is taken as the ratio of the output index and the input index, while the production function is not specified. The SRM is also called production function method. In this method, TFPG is the residual after subtracting the growth rates of all inputs from the growth rate of total output, so that a production function needs to be specified (Solow, 1957). Based on the assumptions of cost minimization for producers, 
perfect technical efficiency, constant return to scale and Hicks neutral technical progress, TFPG equals the technical progress.

In addition, two other approaches are also widely used in TFPG estimation: namely the Latent Variable Approach (LVA) and the Potential Output Approach (POA). In the LVA, TFPG is taken as a latent variable, and in the POA, also called Frontier Production Function Approach (FPFA), TFP change arises not only from technological innovation but also from the improvements in technical efficiency, allocative efficiency and the scale effect (Brummer et al., 2006; Jin et al., 2010; Brandt et al., 2011; Li and Liu, 2011).

The FPFA usually includes the non-parametric and the parametric approach. The former mainly refers to the data envelopment analysis (DEA) and the latter basically refers to the stochastic frontier approach (SFA). The non-parametric approach may be more flexible because it does not require specification of a production function and price information of the inputs. However, the SFA is more capable of distinguishing the effects of statistical noises from those of inefficiency, particularly when measurement errors are present (Lovell, 1996). Since it is impossible to eliminate all measurement errors, the parametric approach might be more reasonable. Consequently, the estimates of TFPG by means of the SFA would be smaller due to the elimination of some measurement errors. Meanwhile, SFA converges to SRM if all assumptions aforementioned hold.

While in practice, it is very difficult to satisfy the assumptions of perfect technical efficiency and constant returns to scale. If technical efficiency is considered, as in SFA and DEA, TFPG not only includes the technical progress, but also the efficiency change. As Nishimizu and Page (1982) suggested, technical efficiency change in developing country is quite obvious and important for TFP growth. In the case of China, as some studies (e.g., Kalirajan et al., 1996; Wu, 2000; Meng and Li, 2004; Zhang and Gui, 2008) 
find, the technical efficiency deteriorated from 1952 to 1978, while the success of economic reform started in 1978 helped regional economies to catch up with the frontier producers, which indicates a significant increase in technical efficiency from 1978 to 1985; after 1985, technical efficiency improvement slowed down, even became negative in agricultural sector after the mid of 1990s, mainly due to the deterioration of extension system and land infrastructure, particularly with regard to the existing water conservation systems that prevent farmers from applying the best practice production techniques (Bruemmer et al., 2006), as well as the disequilibrium that occurs during the expansion of crop production (Jin et al., 2010). The efficiency change in China implies that TFPG calculated by SFA and DEA should be relatively smaller before 1978 and larger at the beginning of the reform than those calculated by other approaches with an assumption of perfect technical efficiency. Similarly, we can also argue that if the assumption of constant return to scale does not hold in China, TFPG estimated by SRM may be biased. Jefferson et al. (1992) finds a slightly increasing return to scale in state and collective industries in 1980s, while Zhang and Gui (2008) think the scale economy is deteriorating after 1978. Similarly, Bruemmer et al. (2006) also find a decreasing return to scale in Chinese agriculture sector after the economic reform in 1978. In this paper we use a dummy variable to distinguish these studies with an assumption of constant return to scale from those without the assumption in SRM.

\subsubsection{Inputs}

Since TFP is the residual by removing the contribution of all inputs from the output, the measurement of inputs is critical in estimating TFPG. Here, three issues arise: (1) how many inputs are included in the production function; (2) how to weight each input (or output elasticity with respect to inputs appropriately); and (3) how to deal with the heterogeneity of inputs. 
In most TFP studies on the aggregate economy, only labor and capital are included in production function, such as Li (1992), Woo (1998), Chow and Li (2002) and Zhang and Shi (2003). Others, such as Bosworth and Collins (2008), Zheng and $\mathrm{Hu}(2005,2008)$ and Liu and $\mathrm{Hu}$ (2008), also take human capital as an additional input by separating it from physical inputs. Particularly, Fleisher et al. (2010) find that education can contribute to TFP growth both at regional level and at firm level. For the studies on sector-specific TFPG, more inputs are often included in the econometric exercises. For instance, Tang (1986) uses four inputs to estimate agricultural TFPG: Labor, capital, land and intermediate inputs. Lin (1992) uses fertilizer as an intermediate input, and Fan (1997) even includes 7 inputs, namely labor, land, fertilizer, machinery, animal power, irrigation and organic fertilizer. However, most studies for calculating TFPG in manufacturing still use the three main inputs: labor, capital and intermediate inputs, such as in Zhu and Li (2005), Wang and Gu (2005), and $\mathrm{Li}$ and Li (2008). Obviously, more inputs included in production functions often result in a lower TFPG. In this paper, we use a dummy variable to distinguish the studies using more than two inputs from those only using labor and capital.

In the recent literature, three ways are presented to construct the output elasticities of inputs: (1) calculating: under the assumption of cost minimization, producers will equate an input's output elasticity to the product of that input's cost share and the scale elasticity, which implies that all factors including education are paid at their marginal productivity (Fleisher and Wang, 2004, 2005; Fleisher et al., 2010; Fleisher et al., 2010); (2) regressing: output elasticity can also be estimated by regressing the production function, which implies that elasticity is constant over time; (3) assuming: some literature assigns the input share subjectively. As aforementioned, output elasticities are not required in DEA and AINA; and in SFA and LVA, They are estimated by regressing the 
production function. While in SRM, all three ways are used. It is not easy to conclude the general impacts of the methods on estimated TFPG. However, the only thing we know is that calculating and assuming approaches automatically assume constant return to scale, while if the input share is measured independently (such as regression without restriction or adjustment), TFPG can be derived without the assumption of constant return (Hulten, 2000). This paper uses also dummy variables to control for the influence of the estimating methods for output elasticities on TFPG.

Strictly speaking, the definition of an input, for example, the quality and utilization efficiency, should be consistent across a study, which is not yet satisfied in the current literature. Nadiri (1970) notes that labor and capital as aggregate elements, are heterogeneous in longevity, impermanence, productive quality, mobility, etc. Consequently, inconsistent definitions are used in the previous studies which lead to diverse TFPG results. In particular, we take a brief look at the definitions of labor and capital.

First, labor input should be defined as the working time with standard labor intensity, not as the number of workers, because the latter doesn't reflect heterogeneities in working hours per worker (Solow, 1957; Jorgenson and Griliches, 1967; Owyong, 2000). Additionally, the contributions of labor input for different occupations are also different, so that in order to calculate the labor input precisely we should sum up individual labor input time and assign different weights to the heterogeneous quality, such as occupations. However, this cannot be realized in practice due to data limitations. The most commonly used approach is to use labor's marginal output value to measure the quality, and labor heterogeneity can be mirrored by education and work experiences which then are used as the weights for calculating labor input. Nevertheless, information on these variables is not widely available in China, and labor input usually is just 
measured by the number of labor forces or just by population in most studies. For instance, Wang and Yao (2003), and Zhang and Shi (2003) use the total number of workers as a proxy for labor inputs, while Graham and Wada (2001) use population. Other measures include working time (Kong et al., 1999), total wage (Lu and Jin, 2005), and a labor index calculated from working time and wage (Sun and Ren, 2005).

On the other hand, the ratio of working forces in the total population of China has increased sharply from $61.50 \%$ in 1982 to $73.14 \%$ in 2008 due to the so-called demographic bonus ${ }^{3}$. In other words, working forces grew faster than the population during this period, so that the labor input will be underestimated when the population is used as a proxy for labor input, and consequently the TFPG will be overestimated. However, the TFPG will be underestimated if the wage is used as a proxy for labor input, because the wage increased much faster than labor input ${ }^{4}$. For instance, the real wage in China in 2008 is about 8-fold higher than that in $1978^{5}$.

Second, the measurement of capital input is also very crucial for TFPG estimation particularly in China where there are no official statistics for it. Jorgenson and Griliches (1967) as well as Norsworthy et al. (1979) made important contributions in this field. Following Diewert's (1980) definition, capital consists of constructions, land, natural resources, machinery equipment, other durable facilities and the private inventories. Chen (1997) introduces a three-step method to calculate capital input index: first, decide what kind of the capital inputs should be taken into account; second, adjust capital input for capacity utilization; third, adjust capital for physical depreciation. While most researchers, such as Li et al. (1996), Li (1997) and Ezaki and Sun (1999) use capital stock as capital input because of lacking necessary data on capital quality and utilization efficiency; some

\footnotetext{
${ }^{3}$ Data source: China Population and Employment Statistics Yearbook, 2009.

${ }^{4}$ Young (2003) finds that the weighted wages grow at $12.5 \%$ per year from 1978 to1998, which is 1.5 times higher than implied employment growth rate.

5 Data source: China Population and Employment Statistics Yearbook, 2009.
} 
other researchers, including Wen (2005) and Zhao et al. (2005), use total investment in fixed assets as a proxy for capital input. To calculate capital stock, three steps are introduced in the prevalent perpetual inventory approach: (1) selection of a base period; (2) calculation of investment in each year; and (3) use of constant prices to calculate the capital stock in each year under an appropriate depreciation rate. Different base periods, depreciation rates and price indices can lead to different results for capital stocks calculation, which obviously affects the final TFPG estimates.

However, such information is not available in most studies, so that we cannot control for these variables in our meta-analysis even we know they are important. What we can do here is to add a dummy variable to control for the differences caused by the adjustment of input quality. As discussed earlier in the paper, once quality of input is adjusted, some technological progress embodied in input will be taken away from the residual, hence the TFPG will be possibly biased downward.

\subsubsection{Dummy Variables}

In order to control for unobserved heterogeneities and structural changes in the data, some primary studies include dummy variables in the production function (SRM, SFA and LVA). For instance, Kong et al. (1999) and Zhao and Zhang (2006) add regional dummies; Sheng and Zhao (2006), and Wang et al. (2009) add time dummies; and Lin (1992) and Mead (2003) include both regional and time dummies. Obviously, dummy variables also influence the TFPG estimations. In General, inclusion of dummy variables usually lowers the TFPG estimates because they capture some effects of the TFPG.

\subsubsection{Price and Discounting}

TFPG estimates can also be influenced by the prices of inputs and outputs. In particular, both real and nominal values for inputs and outputs are used in the current 
literature. For instance, Liu and Wang (2003) and Jin (2006) use nominal values, while most others use real values (e.g., Kalirajan et al., 1996; Woo, 1998; Coelli and Rao, 2005; Sun and Ren, 2005). In order to capture the impacts of prices on final TFPG estimates, we include a dummy variable to compare the studies using real values with those using nominal values.

\subsubsection{Peer-Review Process and Published Journals}

Peer-review process and the flavor of an academic journal might also account for the variation in estimated TFPG (Alston et al., 2000). For instance, the studies that generate TFPGs that fall outside the range of "conventional wisdom" prevailing in the profession at the time may be discriminated in the publication process, thus published work and unpublished work may have different estimations.

Accordingly, variation of the TFPGs might also be attributed to the characteristics of an academic journal. For instance, Chinese journals may get some pressure from the government and the Chinese scientific community, such that the studies with low TFPG or with politically sensitive contents might not be allowed to be published, while English journals usually have more freedom.

To control for the potential biases resulting from peer-review process and the flavor of an academic journal, we include two dummy variables respectively to distinguish published studies from unpublished paper, and to distinguish Chinese paper from English ones.

\subsubsection{Factual Factors}

After discussing the methodological factors, we now shed some light on the factual factors. A large body of literature has estimated Chinese TFPGs for different periods, different regions, and different economic sectors, which of course have 
heterogeneous TFPGs, particularly given the fact that China is a huge country.

\subsubsection{Time Difference}

TFPG is a dynamic concept measuring the technological changes over time. Most studies show that TFPG is very low or even negative in China before 1978 (e.g., Kalirajan et al., 1996; Chow and Li, 2002; Wang and Yao, 2003), but becomes positive and significantly contributes to economic growth only after 1978 (e.g., Hu and Khan, 1997; Chow and Li, 2002).

\subsubsection{Regional Difference}

China is a huge country with a lot of regional heterogeneities. The current literature indicates that the TFPG values in different regions are quite heterogeneous even in the same period (Li and Meng, 2006). Fu et al. (2009) find that the average TFP growth rate in the central region is lower than that in the eastern region, but higher than that in the western region, consistent with our common wisdom, and however, it is still below the nation average level. Fleisher et al. (2010) and Fleisher et al. (2010) suggest that human capital might be related to the regional inequality.

\subsubsection{Sectoral Difference}

The TFPG significantly varies in different economic sectors. For instance, Dekle and Vandenbroucke (2010) point out that agricultural labor productivity is much lower than non-agricultural labor productivity.

In order to analyze heterogeneities of TFPG in different economic sectors, together with aggregation-economy level, this paper classifies economic activities into three sectors according to the standards of the Chinese National Bureau of Statistics 
$(\mathrm{CNBS})^{6}:$ Agriculture, manufacturing, and service sector.

\subsubsection{Data Difference}

Data sources also play a significant role when estimating TFPG. Both time series data and panel data have been widely used in the current literature. It is however worth to note that the SFA and DEA can only be applied with panel data. Different types of data sources may lead to different results. For instance, panel data would be better for capturing unobservable heterogeneities than time series data.

In addition, some studies use microeconomic data while others employ macroeconomic data. This could also lead to TFPG heterogeneities in the current literature.

\subsection{Meta-Analysis}

A meta-analysis is a qualitative analysis of a body of similar related studies and is used to summarize them or to evaluate the reliability of their findings (Card and Krueger, 1995). This technique has been widely used in the economics literature (Nelson and Kennedy, 2009).

In a standard regression model for a meta-analysis, the dependent variable is given by the results from primary empirical studies (effect size), which is TFPG in this paper. The independent variables are all factors that could cause differences in the results in the primary studies. As aforementioned, these factors could include sectors, time, region, data characteristics, model specifications, sample size and other quality variables, such as the time of publication and the origin of the published journals.

\footnotetext{
${ }^{6}$ The agricultural sector includes plantations, forestry, animal husbandry and fishery as well as services supporting these industries. The manufacturing sector comprises mining and quarrying, manufacturing, electricity production, water and gas supply, and construction. The service sector in turn includes all other economic activities not included in the agricultural and manufacturing sectors.
} 
In particular, Nelson and Kennedy (2009) point out that the three characteristics of the primary studies have strong implications for the choice of a meta-analysis model: (1) Sample heterogeneity, which could be handled by adding dummies to capture those effects; (2) heteroskedasticity of effect-size variances, which can be eliminated by taking sample sizes as proxies for the weights in Weighted Least Squares Regression (WLS); and (3) non-independence of primary studies, which can be controlled by employing fixed-effects or random-effects regression models. In this paper, WLS model is chosen to deal with heteroskedasticity because the variance of a sample would decrease as the sample size increases. .

In addition, Walker et al. (2008) point out that the selection criteria of the primary studies could cause a sample selection bias problem, which makes the results of the metaanalysis inconsistent and unreliable. In this study, we try our best to include all related papers we could find to avoid such bias.

\subsection{Data and Summary Statistics}

\subsubsection{Sources of Primary Studies}

The sources of economic growth in China have been of particular interest for economists since the 1980s, as China achieved a prolonged period of rapid economic growth after the reforms in 1978 . We have endeavored to collect 150 papers with 5308 TFPG observations using Google scholar and from the database of the China National Knowledge Infrastructure (CNKI). The detailed information of the primary studies can be found in Appendices A.

Note that if the TFPG is measured for a period with more than one year, we assume that it is the TFPG of the medium year in that period. In order to distinguish these observations from the estimates for each single year, we define them as Period TFPGs 
and Single-year TFPGs, respectively. Finally, 3292 observations are single-year TFPG, and 2016 are TFPGs in a period.

\subsubsection{Summary Statistics of TFPGs}

Since TFPGs are of particular interest in our study, we now present the summary statistics of TFPGs from different aspects.

\subsubsection{TFP Growth Trend}

Table 2.1 shows the summary statistics for all single-year TFPG observations by 5-year period between 1950 and 2009. The mean of all single-year TFPGs between 1950 and 2009 is 0.0288 , which is a substantial growth rate. Particularly, the average TFPG before the reform in 1978 is -0.008 , indicating that there were basically no technological progress during the planned economic system; the average TFPG after the reform reaches 0.0345, which is an remarkable figure, and the contribution to economic growth would be more than 30\% according to the research of $\mathrm{Hu}$ and Khan (1997) and Chow and Li (2002).

Table 2.1: TFPGs in Different Periods

\begin{tabular}{cccccc}
\hline Period & Obs. & Mean & Std. Dev. & Min & Max \\
\hline $1950-1954$ & 35 & -0.0149 & 0.0704 & -0.2470 & 0.1234 \\
$1955-1959$ & 80 & -0.0032 & 0.0812 & -0.2670 & 0.1997 \\
$1960-1964$ & 86 & -0.0313 & 0.1098 & -0.3346 & 0.1740 \\
$1965-1969$ & 90 & 0.0068 & 0.0592 & -0.1139 & 0.1769 \\
$1970-1974$ & 90 & 0.0016 & 0.0536 & -0.0980 & 0.2058 \\
$1975-1979$ & 147 & 0.0167 & 0.0512 & -0.1160 & 0.2020 \\
$1980-1984$ & 301 & 0.0479 & 0.0715 & -0.0791 & 0.9430 \\
$1985-1989$ & 349 & 0.0122 & 0.0534 & -0.5229 & 0.2708 \\
$1990-1994$ & 430 & 0.0550 & 0.0986 & -0.1867 & 0.9603 \\
$1995-1999$ & 678 & 0.0127 & 0.0716 & -0.2560 & 0.7670 \\
$2000-2004$ & 825 & 0.0436 & 0.0931 & -0.3990 & 0.9760 \\
$2005-2009$ & 181 & 0.0456 & 0.0821 & -0.3330 & 0.4320 \\
\hline $1950-1977$ & 437 & -0.0080 & 0.0748 & -0.3346 & 0.2058 \\
$1978-2009$ & 2855 & 0.0345 & 0.0828 & -0.5229 & 0.9760 \\
$1950-2009$ & 3292 & 0.0288 & 0.0830 & -0.5229 & 0.9760 \\
\hline
\end{tabular}

Note: Only single-year TFPGs are included. 
Figure 2.1 demonstrates the annual changes in TFPG between 1950 and 2009 both for the full sample (regardless of sectors and regions) and for the national-level aggregate economy. It indicates that they have quite similar trends. We find that (1) The TFPG in China fluctuates drastically around zero before the 1978 economic reform; and (2) The TFPGs are generally positive after 1978, and there are three cycles and each circle is about 10 years (namely 1978-1988, 1989-1998, and 1998-now). Even though we cannot give a specific explanation to this cyclic phenomenon, it might be linked to the conjectures of business cycles in China: Institutional reform cycle, state-owned enterprise reform, and WTO and housing boom cycle.

Figure 2.1: Average TFPG from 1950 to 2009

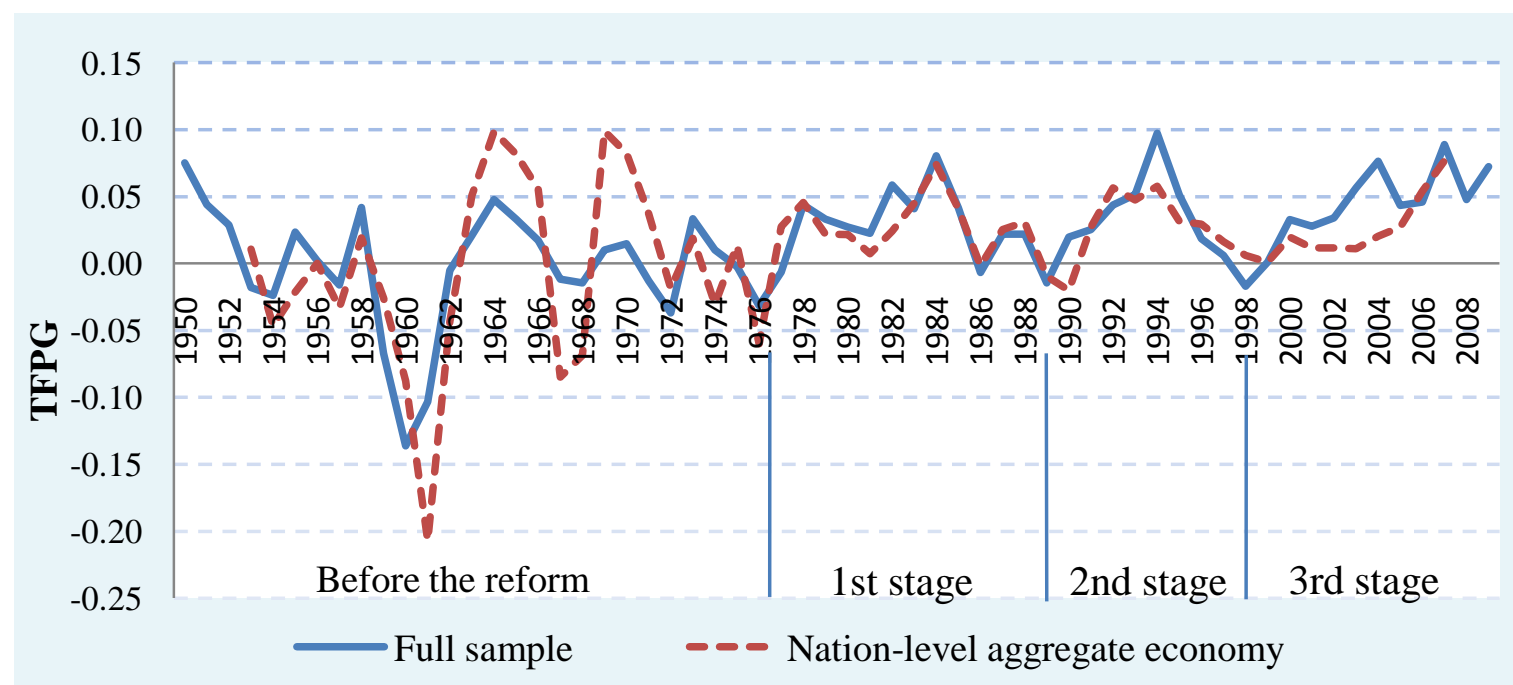

Note: Only single-year TFPGs are included. The total number of observations is 3292.

\subsubsection{Sectoral Difference}

As aforementioned, the TFPGs vary across different sectors and regions, as is indicated in Table 2.2. Particularly, we find the average TFPG for manufacturing sector between 1950 and 2009 is 0.0759 , significantly higher than other sectors: The figures for service sector and agricultural sector respectively are 0.055 and 0.020 . The mean TFPG for the aggregate-economy during this period is only about 0.023 . 
Table 2.2: TFPGs in Different Sectors, Regions and Approaches

\begin{tabular}{cccccc}
\hline Category & Obs. & Mean & Std. Dev. & Min & Max \\
\hline East China & 1145 & 0.0418 & 0.0763 & -0.3500 & 0.9430 \\
Central China & 964 & 0.0264 & 0.0790 & -0.3990 & 0.7670 \\
West China & 950 & 0.0283 & 0.0835 & -0.5185 & 0.9760 \\
Whole Nation & 2249 & 0.0215 & 0.0616 & -0.5229 & 0.9603 \\
\hline Agriculture & 2357 & 0.0203 & 0.0714 & -0.5185 & 0.9430 \\
Manufacturing & 583 & 0.0759 & 0.1213 & -0.5229 & 0.9760 \\
Service & 88 & 0.0538 & 0.0551 & -0.0350 & 0.2848 \\
Aggregate-economy & 2281 & 0.0227 & 0.0500 & -0.3346 & 0.4320 \\
\hline SRM & 1769 & 0.0276 & 0.0588 & -0.5229 & 0.9603 \\
DEA & 2634 & 0.0328 & 0.0819 & -0.3990 & 0.9760 \\
SFA & 593 & 0.0164 & 0.0719 & -0.5185 & 0.5800 \\
AINA & 250 & 0.0089 & 0.0593 & -0.1776 & 0.1889 \\
Others & 62 & 0.0249 & 0.0509 & -0.0594 & 0.2130 \\
\hline Full sample & 5308 & 0.0280 & 0.0728 & -0.5229 & 0.9760 \\
\hline
\end{tabular}

Figure 2.2 presents the trends of national-level TFPGs by different sectors: aggregate-economy, agriculture, and the manufacturing ${ }^{7}$.

Figure 2.2: Nation-level Average TFPGs by Sectors (1950-2009)

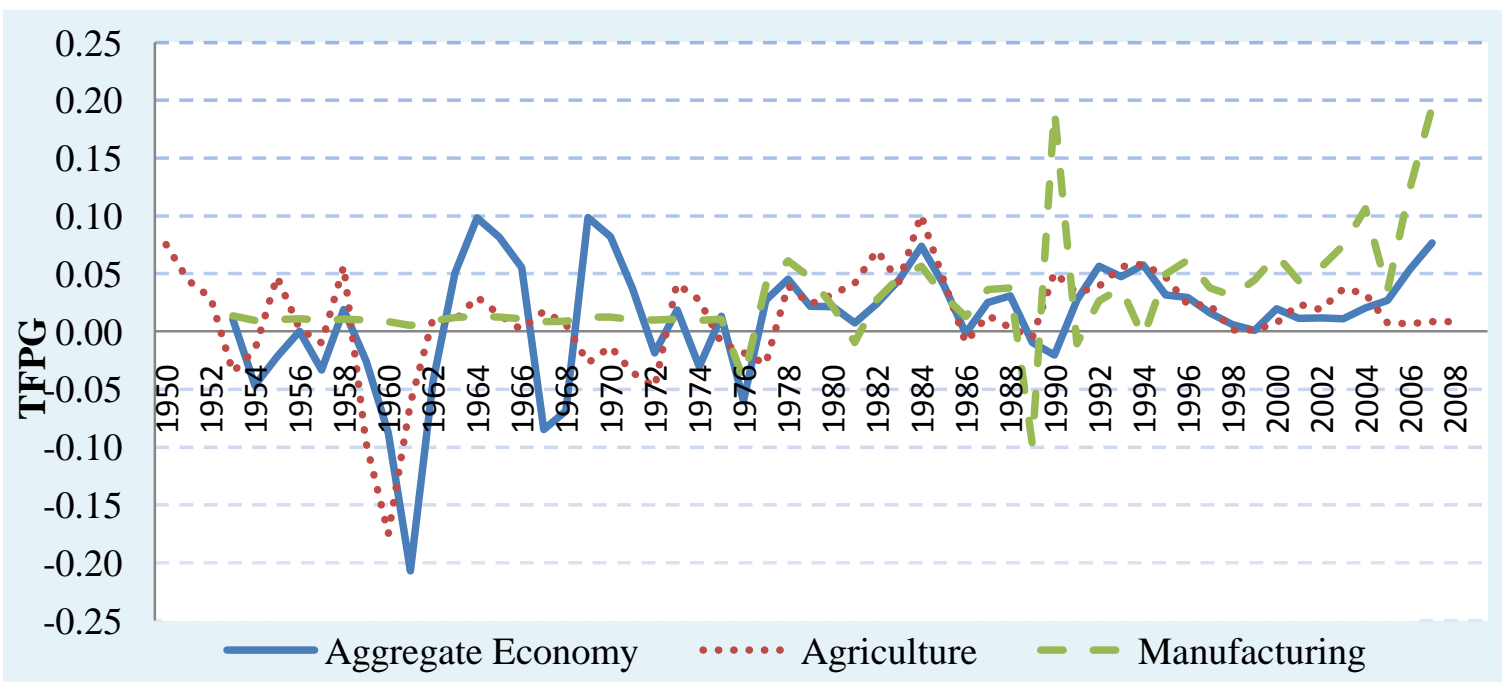

Before the reform in 1978, we observed that the TFPG of the manufacturing sector is quite stable and barely over zero, significantly different from the aggregate-economy and agriculture which were drastically fluctuating around zero. Then, the period between

\footnotetext{
${ }^{7}$ The service sector is not demonstrated due to small number of observations.
} 
1978 and 1995 generally sees indifference of TFPG between different sectors. However, the TFPG in manufacturing sector then overtakes other sectors after 1995, which makes China "the World Factory" now.

\subsubsection{Regional Difference}

Table 2.2 also indicates that TFPG differences between regions are substantial. The means of TFPG for East China, Central China, West China, and the whole nation respectively are $0.042,0.026,0.028$, and 0.022 from 1950 to 2009 . It indicates that (1) the TFPG in East China is higher than the rest of China, which does make sense, (2) and the TFPG in the whole nation however is lower than that in each region, which is contradictory to our common wisdom. It is plausible that some regional-level economic data are manipulated or that intermediate inputs across regions are not captured, or the economic sectors in different regions are different.

In order to consistently compare TFPG between different regions, we now only shed light on the TFPGs of the aggregate economies for different regions between 1978 and 2009, which are reported in four panels of Figure 2.3. In general, results indicate that average TFPGs in the East is the highest (Panel B \& C \& D). However, West China has the highest TFPG in the period between 1978 and 1989, as shown in Panel A. It is plausible that the economic reform starts from west and central rural China. Also, that the "Third-Line Movement" in 1960s moved a lot of manufacturing industries from the east to the west in order to prepare for the possible wars in the East could be another reason. However, the trend changes dramatically after 1989. Both Panel B and C demonstrate that TFPGs in the East and Central surpass that in West China and the East outperforms the Central and West after 1989. The average TFPGs of the aggregate economies during the period 1978-2009 for the East, the Central, the West and the whole nation respectively are $0.0188,0.0205,0.0339$, and 0.0242 . The results are consistent with our common wisdom 
that the TFPG is highest in the eastern and coastal rich areas. More importantly, the results indicates that the average TFPG of the aggregate economy at the national level after the 1978 reform is only about $2.42 \%$, which is a moderate high speed of technological progress, so that the contribution rate to economic growth is about $24 \%{ }^{8}$ in whole China.

Figure 2.3: TFPGs of the Aggregate Economy for Different Regions After 1978

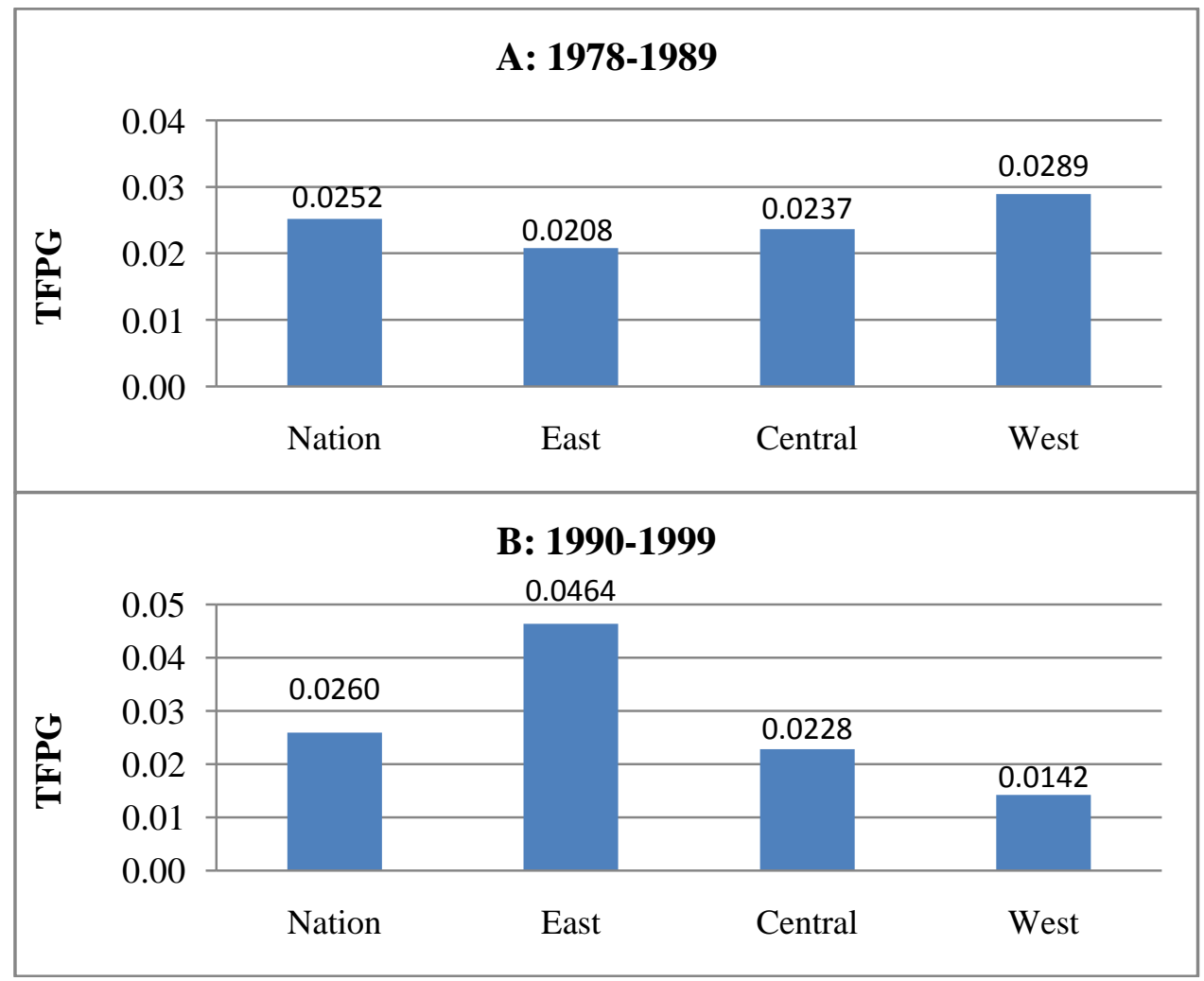

\footnotetext{
${ }^{8}$ The average annual economic growth rate in the past three decades is about $9.8 \%$, as indicated in the beginning of the paper.
} 


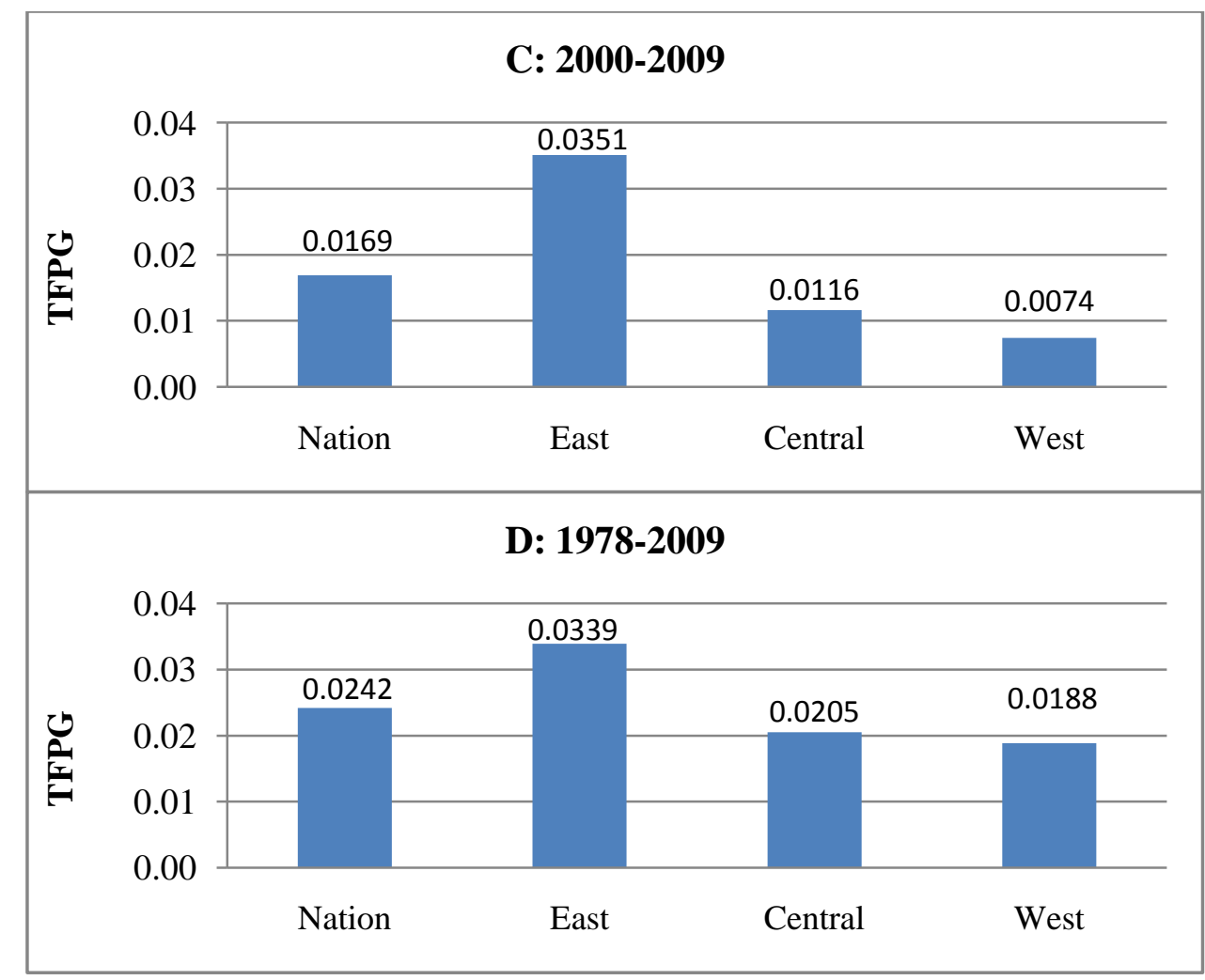

Note: Only TFPGs of aggregate economy are included. The total number of observations is 2113.

\subsubsection{Summary Statistics of the Primary Studies}

The selected 150 primary studies can be classified by the characteristics of the published journal and paper, region, sector, data type, model specification, price and input, which are reported in Table 2.3. For instance, within the 150 papers, 103 are written in the Chinese language, and the remaining 47 are written in English; 136 are published by peer-review process, and the remaining 14 are unpublished working papers.

Table 2.3: Summary of Primary Studies

\begin{tabular}{ccccccc}
\hline Journal/Paper & Region & Sector & Data & Method & Price & Inputs \\
\hline English 47 & Nation 130 & Aggregate 69 & Panel data 80 & AINA 8 & Constant 126 & Capital and labor 86 \\
Chinese 103 & East 48 & Agriculture 41 & Time series 70 & SRM 72 & Current 17 & More inputs 64 \\
& Central 40 & Manufacturing 38 & & DEA 55 & & \\
& West 38 & Service 6 & & SFA 14 & & \\
Published 136 & & Non-agriculture 1 & Micro-data 141 & & & \\
Unpublished 14 & & & Micro-data 9 & Others 4 & Unknown 7 & Quality-adjusted 23 \\
\hline
\end{tabular}

Notes: 1. Numbers denote the numbers of primary studies.

2. There are more primary studies than papers because some papers have more than one study.

3. In the last column, Single-year refers to the TFPG estimated for each year, while Period refers to the TFPG reported for a period. 
In the next section, taking all these factors into consideration, we use econometric models to quantitatively study the heterogeneities of TFPGs in China.

\subsection{Empirical Results}

Similar to other meta-analyses, the dependent variable is the TFPGs in primary studies and the independent variables include region, sector, approaches to estimate TFPG, characteristics of the paper and journal, data type, measures of capital and labor, number of inputs, price information, inclusion of dummies and time. The definitions of the variables are presented in Table 2.4.

Table 2.4: Definition of Variables

\begin{tabular}{ll}
\hline Variables & Definition \\
\hline Published & Dummy for published studies with peer-review process. \\
English & Dummy for primary studies written in English language. \\
Region & Dummy for region-level studies. \\
East & $\begin{array}{l}\text { Dummy for East China, including Hebei, Beijing, Tianjin, Guangdong, Jiangsu, } \\
\text { Liaoning, Shandong, Shanghai, Zhejiang, Fujian and Hainan. }\end{array}$ \\
Central & Dummy for Central China, including Anhui, Henan, Heilongjiang, Jilin, Hubei, \\
& Hunan, Jiangxi, Inner Mongolia and Shanxi. \\
West & Dummy for West China, including Guangxi, Guizhou, Yunnan, Sichuan, \\
Sector & Chongqing, Tibet, Ningxia, Qinghai, Gansu, Shaanxi and Xinjiang. \\
Agriculture & Dummy for sector-specific economy study. \\
Manufacturi & Dummy for primary sector, including plantation, forestry, animal husbandry, \\
ng & Dummy for secondary sector, including mining and quarrying, manufacturing, \\
production and supply of electricity, water and gas, and construction. \\
Service & Dummy for tertiary sector, refers to all other economic activities not included in \\
SRM & agriculture or manufacturing. \\
DEA & Solow Residual Method used in primary studies. \\
SFA & Data Envelopment Analysis used in primary studies. \\
AINA & Stochastic Frontier Analysis used in primary studies. \\
Others & Arithmetic Index Number Approach used in primary studies. \\
Micro data & Other approaches used in primary studies. \\
Quality- & Dummy for primary studies using micro data. \\
adjust & Dummy for primary studies adjusting the quality of inputs. \\
Inputs & Additional inputs except for labor and capital are included in primary studies. \\
Current price & Nominal value is used in primary studies. \\
Time & Year (1949 is set to be 1). \\
Time & Year Squared. \\
\hline &
\end{tabular}


squared

Reform 1= after $1978,0=$ others.

Panel Panel data is used in primary studies.

Scale Restriction of constant return to scale is held in primary studies.

Reg-

elasticity

Output elasticity with respect to input is estimated by regressing.

Dummies Dummy variables are used in primary studies.

\subsubsection{Full Sample}

We pooled all observations together and estimated four different econometric models, including an OLS model with time trend and time squared, a WLS model with time dummy, a WLS model with time trend and a WLS model with time trend and time squared. The results are reported in Table 2.5, and quite consistent, as there is no substantial difference among the four models. We prefer WLS models because they can deal with heteroskedasticity of the effect-size variance (Nelson and Kennedy, 2009). However, we also find that both time and time squared are significant at the $1 \%$ level in the respective model, which makes the WLS model with linear and quadratic time variables the best. Hence our discussion is based on it.

Table 2.5: Results Based on the Full Sample

\begin{tabular}{c|c|ccc}
\hline \multirow{2}{*}{ Variables } & OLS & \multicolumn{3}{|c}{ WLS } \\
\cline { 2 - 5 } East & Time square & Reform & Time & Time square \\
\hline \multirow{4}{*}{ Central } & 0.0221 & 0.0174 & 0.0181 & 0.0179 \\
& $(7.58)^{* * *}$ & $(6.30)^{* * *}$ & $(6.52)^{* * *}$ & $(6.45)^{* * *}$ \\
& 0.0054 & -0.0001 & 0.0008 & 0.0004 \\
West & $(1.75)^{*}$ & $(-0.04)$ & $(0.25)$ & $(0.14)$ \\
& 0.0087 & 0.0029 & 0.0039 & 0.0035 \\
Agriculture & $(2.84)^{* * *}$ & $(0.91)$ & $(1.24)$ & $(1.12)$ \\
& 0.0201 & 0.0111 & 0.0112 & 0.0113 \\
Manufacturing & $(4.96)^{* * *}$ & $(3.34)^{* * *}$ & $(3.34)^{* * *}$ & $(3.37)^{* * *}$ \\
& 0.0601 & 0.0332 & 0.0303 & 0.0314 \\
Service & $(16.87)^{* * *}$ & $(11.34)^{* * *}$ & $(10.17)^{* * *}$ & $(10.44)^{* * *}$ \\
& 0.0299 & 0.0290 & 0.0243 & 0.0262 \\
SRM & $(3.90)^{* * *}$ & $(5.02)^{* * *}$ & $(4.15)^{* * *}$ & $(4.45)^{* * *}$ \\
& 0.0045 & 0.0014 & 0.0053 & 0.0036 \\
DEA & $(0.84)$ & $(0.30)$ & $(1.16)$ & $(0.77)$ \\
& -0.0049 & -0.0020 & -0.0005 & -0.0017 \\
SFA & $(-0.90)$ & $(-0.45)$ & $(-0.11)$ & $(-0.35)$ \\
\hline \hline
\end{tabular}




\begin{tabular}{|c|c|c|c|c|}
\hline \multirow{3}{*}{ Others } & $(-2.18) * *$ & $(0.21)$ & $(0.36)$ & $(0.10)$ \\
\hline & 0.0005 & 0.0084 & 0.0110 & 0.0096 \\
\hline & $(0.05)$ & $(0.97)$ & $(1.26)$ & (1.09) \\
\hline \multirow{2}{*}{ Published } & 0.0193 & 0.0107 & 0.0116 & 0.0111 \\
\hline & $(6.32) * * *$ & $(3.27) * * *$ & $(3.52) * * *$ & $(3.37) * * *$ \\
\hline \multirow{2}{*}{ English } & 0.0068 & 0.0070 & 0.0075 & 0.0071 \\
\hline & $(2.57) * * *$ & $(2.84) * * *$ & $(3.01)^{* * *}$ & $(2.86) * * *$ \\
\hline \multirow{2}{*}{ Micro data } & -0.0245 & -0.0091 & -0.0061 & -0.0071 \\
\hline & $(-3.13) * * *$ & $(-1.64)$ & $(-1.11)$ & $(-1.24)$ \\
\hline \multirow{2}{*}{ Quality adjust } & 0.0004 & -0.0011 & -0.0016 & -0.0016 \\
\hline & $(0.12)$ & $(-0.39)$ & $(-0.55)$ & $(-0.57)$ \\
\hline \multirow{2}{*}{ Inputs } & -0.0178 & -0.0143 & -0.0152 & -0.0151 \\
\hline & $(-4.77)^{* * *}$ & $(-4.83) * * *$ & $(-5.11) * * *$ & $(-5.07) * * *$ \\
\hline \multirow{2}{*}{ Current price } & -0.0111 & -0.0022 & 0.0001 & -0.0008 \\
\hline & $(-3.20) * * *$ & $(-0.72)$ & $(0.03)$ & $(-0.26)$ \\
\hline \multirow{2}{*}{ Time/Reform } & 0.0028 & 0.0375 & 0.0009 & 0.0019 \\
\hline & $(6.64) * * *$ & $(11.18)^{* * *}$ & $(9.07) * * *$ & $(4.86) * * *$ \\
\hline \multirow{2}{*}{ Time squared } & -0.00003 & & & -0.00001 \\
\hline & $(-4.82) * * *$ & & & $(-2.66) * * *$ \\
\hline \multirow{2}{*}{ Intercept } & -0.0666 & -0.0225 & -0.0299 & -0.0435 \\
\hline & $(-7.38) * * *$ & $(-3.79)^{* * *}$ & $(-4.63) * * *$ & $(-5.28) * * *$ \\
\hline $\mathrm{R}^{2}$ & 0.0987 & 0.0745 & 0.0671 & 0.0684 \\
\hline Adjusted $\mathrm{R}^{2}$ & 0.0957 & 0.0715 & 0.0641 & 0.0652 \\
\hline $\mathrm{F}$ & $32.19 * * *$ & $25.05^{* * *}$ & $22.39 * * *$ & $21.57 * * *$ \\
\hline Observations & 5308 & 5308 & 5308 & 5308 \\
\hline
\end{tabular}

Notes: 1. The first column uses OLS models, and the last three use WLS with the squared root of the sample size as weight.

2. *, ** and $* * *$ denote statistical significance at the $10 \%, 5 \%$ and $1 \%$ levels, respectively.

3. We take the whole nation and the aggregate economy as the control region and the control sector, respectively. Therefore, the benchmark group is the nation-level aggregate-economy TFPG using constant price and macro-data without quality adjustment, and it is estimated by arithmetic index number approach with only two inputs. Moreover, it is written in Chinese and has not been published.

4. If price information is not available in the primary study, we assume a constant price.

First, our estimation results indicate that the coefficient for East China is 0.018 and statistically significant at the $1 \%$ level in all models. It implies that the results are quite robust and not overly affected by model specifications, and TFPGs in the eastern areas is on average 0.018 higher than the national-level TFPG, while the central and western areas are not significantly different from the national level, after controlling for the above-mentioned factors.

Regarding the sectoral difference, TFPGs in agriculture, manufacturing and service are $0.011,0.031$ and 0.026 higher than the aggregate-economy TFPG, 
respectively. The results are all statistically significant and robust, and not affected by model specifications. That the sector-specific TFPGs are considerably larger than those of the aggregate economy is contradictory to our common wisdom. The reasons might be that some sectoral-level economic data are manipulated or that intermediate inputs across sectors are not captured.

Second, we find that peer-review process and paper language significantly influence the estimates. TFPGs with peer-review process are 0.011 higher than those in working papers; and English studies have higher TFPGs than Chinese ones by 0.007. It is plausible that there is a sample-selective bias in the peer-review process that low TFPG estimates are dropped out. Regarding the higher estimates in English papers, further research is needed to identify the reasons.

Third, the number of inputs included in econometric models of primary studies also affects the results. If more inputs are included in the regression besides labor and capital, TFPG will fall by 0.015 , implying that more inputs will result in smaller TFPGs. It is obvious that more inputs will result in less unexplained factors in error terms which are looked as technological progress in the context of Solow models (Solow, 1957).

Fourth, the following methodological factors, such as TFP estimation approaches, data type, quality adjustment and price have no significant impact on TFPG.

Finally, we also find an increasing trend for TFPG, and the TFP growth rate is significantly higher after 1978. As the coefficient for the term of time squared is negative, it implies that TFP grows with a diminishing rate.

\subsubsection{Subsamples and Sensitivity Analysis}

In the previous section we pooled all data and obtained some general results. Now we take a close look at the heterogeneity of subsamples. It is possible that there are 
structural differences between different subsamples, which can be tested by Likelihood Ratio Tests.

Our tests reveal that there are indeed significant differences between regionspecific samples and the national sample, as well as between sector-specific samples and the aggregate-economy sample. Therefore, it is necessary to estimate each subsample separately. The estimation results for national sample, the region-specific samples, the aggregate-economy sample and the sector-specific samples are reported in Table 2.6 from column 1 to 4 .

Table 2.6: Results Based on Subsamples

\begin{tabular}{|c|c|c|c|c|c|c|c|c|}
\hline Variables & $\begin{array}{c}\text { Nation- } \\
\text { level }\end{array}$ & Region & $\begin{array}{l}\text { Aggregate- } \\
\text { economy }\end{array}$ & Sectors & $\begin{array}{l}\text { Single } \\
\text { year }\end{array}$ & $\begin{array}{c}\text { Nation- } \\
\text { single year }\end{array}$ & $\begin{array}{c}\text { Nation- } \\
\text { aggregate }\end{array}$ & $\begin{array}{l}\text { Nation- } \\
\text { aggregate- } \\
\text { single year }\end{array}$ \\
\hline East & & & $\begin{array}{c}0.0148 \\
(4.80)^{* * *}\end{array}$ & $\begin{array}{c}0.0204 \\
(4.51)^{* * *}\end{array}$ & $\begin{array}{c}0.0268 \\
(5.88)^{* * *}\end{array}$ & & & \\
\hline Central & & $\begin{array}{c}-0.0174 \\
(-5.62)^{* * *}\end{array}$ & $\begin{array}{c}0.0008 \\
(0.22)\end{array}$ & $\begin{array}{c}0.0004 \\
(0.08)\end{array}$ & $\begin{array}{l}0.0102 \\
(1.76)^{*}\end{array}$ & & & \\
\hline West & & $\begin{array}{c}-0.0132 \\
(-4.22)^{* * *}\end{array}$ & $\begin{array}{c}-0.0028 \\
(-0.78)\end{array}$ & $\begin{array}{c}0.0069 \\
(1.39)\end{array}$ & $\begin{array}{c}0.0166 \\
(2.75)^{* * *}\end{array}$ & & & \\
\hline Agriculture & $\begin{array}{c}0.0077 \\
(1.54)\end{array}$ & $\begin{array}{c}0.04443 \\
(7.90)^{* * *}\end{array}$ & & & $\begin{array}{c}0.0168 \\
(3.42)^{* * *}\end{array}$ & $\begin{array}{l}0.0117 \\
(1.85)^{*}\end{array}$ & & \\
\hline Manufacturing & $\begin{array}{c}0.0092 \\
(2.13)^{* *}\end{array}$ & $\begin{array}{c}0.0757 \\
(15.19)^{* * *}\end{array}$ & & $\begin{array}{c}0.0110 \\
(2.41)^{* *}\end{array}$ & $\begin{array}{c}0.0350 \\
(8.02)^{* * *}\end{array}$ & $\begin{array}{c}0.0186 \\
(3.29)^{* * *}\end{array}$ & & \\
\hline Service & $\begin{array}{c}0.0273 \\
(3.12)^{* * *}\end{array}$ & $\begin{array}{c}0.0328 \\
(3.95)^{* * *}\end{array}$ & & $\begin{array}{c}0.0034 \\
(0.45)\end{array}$ & $\begin{array}{c}0.0716 \\
(5.86)^{* * *}\end{array}$ & $\begin{array}{c}0.0967 \\
(5.92)^{* * *}\end{array}$ & & \\
\hline SRM & $\begin{array}{c}0.0004 \\
(0.07)\end{array}$ & $\begin{array}{c}0.0312 \\
(4.73) * * *\end{array}$ & $\begin{array}{c}0.0141 \\
(1.96)^{* *}\end{array}$ & $\begin{array}{l}-0.0040 \\
(-0.70)\end{array}$ & $\begin{array}{c}0.0009 \\
(0.16)\end{array}$ & $\begin{array}{c}0.0024 \\
(0.40)\end{array}$ & $\begin{array}{l}-0.0106 \\
(-1.05)\end{array}$ & $\begin{array}{l}-0.0009 \\
(-0.06)\end{array}$ \\
\hline DEA & $\begin{array}{c}0.0015 \\
(0.25)\end{array}$ & $\begin{array}{c}0.0120 \\
(2.12)^{* *}\end{array}$ & $\begin{array}{c}0.0021 \\
(0.29)\end{array}$ & $\begin{array}{l}-0.0012 \\
(-0.20)\end{array}$ & $\begin{array}{c}0.0017 \\
(0.29)\end{array}$ & $\begin{array}{l}-0.0005 \\
(-0.08)\end{array}$ & $\begin{array}{c}-0.0040 \\
(-0.39)\end{array}$ & $\begin{array}{c}0.0073 \\
(0.50)\end{array}$ \\
\hline SFA & $\begin{array}{c}0.0176 \\
(2.34)^{* *}\end{array}$ & & $\begin{array}{c}0.0157 \\
(1.47)\end{array}$ & $\begin{array}{c}-0.0025 \\
(-0.36)\end{array}$ & $\begin{array}{c}0.0022 \\
(0.29)\end{array}$ & $\begin{array}{c}0.0186 \\
(2.00)^{* *}\end{array}$ & & \\
\hline Others & $\begin{array}{c}0.0110 \\
(1.04)\end{array}$ & $\begin{array}{c}-0.0273 \\
(-1.19)\end{array}$ & & $\begin{array}{c}0.0387 \\
(2.32)^{* *}\end{array}$ & $\begin{array}{c}0.0184 \\
(1.55)\end{array}$ & $\begin{array}{c}0.0178 \\
(1.41)\end{array}$ & $\begin{array}{c}-0.0192 \\
(-1.52)\end{array}$ & $\begin{array}{l}-0.0115 \\
(-0.64)\end{array}$ \\
\hline Published & $\begin{array}{c}-0.0031 \\
(-0.48)\end{array}$ & $\begin{array}{c}0.0118 \\
(3.08) * * *\end{array}$ & $\begin{array}{c}0.0009 \\
(0.23)\end{array}$ & $\begin{array}{c}0.0237 \\
(4.44) * * *\end{array}$ & $\begin{array}{c}0.0355 \\
(6.46)^{* * *}\end{array}$ & $\begin{array}{c}0.0158 \\
(1.81)^{*}\end{array}$ & $\begin{array}{l}0.0162 \\
(1.72)^{*}\end{array}$ & $\begin{array}{c}0.0234 \\
(1.83)^{*}\end{array}$ \\
\hline English & $\begin{array}{c}0.0081 \\
(2.19)^{* *}\end{array}$ & $\begin{array}{c}0.0110 \\
(3.09)^{* * *}\end{array}$ & $\begin{array}{c}0.0146 \\
(5.14)^{* * *}\end{array}$ & $\begin{array}{c}0.0099 \\
(2.41)^{* *}\end{array}$ & $\begin{array}{c}0.0171 \\
(4.16)^{* * *}\end{array}$ & $\begin{array}{c}0.0155 \\
(3.35)^{* * *}\end{array}$ & $\begin{array}{c}0.0173 \\
(3.78)^{* * *}\end{array}$ & $\begin{array}{c}0.0335 \\
(4.61)^{* * *}\end{array}$ \\
\hline Micro data & $\begin{array}{c}0.0010 \\
(0.14)\end{array}$ & $\begin{array}{c}-0.0127 \\
(-1.06)\end{array}$ & $\begin{array}{c}-0.0273 \\
(-3.19)^{* * *}\end{array}$ & $\begin{array}{c}-0.0043 \\
(-0.55)\end{array}$ & $\begin{array}{c}-0.0126 \\
(-1.39)\end{array}$ & $\begin{array}{c}-0.0071 \\
(-0.65)\end{array}$ & $\begin{array}{c}-0.0268 \\
(-2.60)^{* * *}\end{array}$ & \\
\hline Quality adjust & $\begin{array}{c}0.0004 \\
(0.09)\end{array}$ & $\begin{array}{c}-0.0016 \\
(-0.36)\end{array}$ & $\begin{array}{c}0.0040 \\
(1.29)\end{array}$ & $\begin{array}{c}-0.0150 \\
(-2.87)^{* * *}\end{array}$ & $\begin{array}{c}-0.0037 \\
(-0.66)\end{array}$ & $\begin{array}{c}-0.0035 \\
(-0.50)\end{array}$ & $\begin{array}{c}0.0090 \\
(2.20)^{* *}\end{array}$ & $\begin{array}{c}0.0083 \\
(1.26)\end{array}$ \\
\hline Inputs & $\begin{array}{c}-0.0105 \\
(-2.44)^{* *}\end{array}$ & $\begin{array}{c}-0.0393 \\
(-8.23)^{* * *}\end{array}$ & $\begin{array}{c}-0.0025 \\
(-0.69)\end{array}$ & $\begin{array}{c}-0.0254 \\
(-5.69) * * *\end{array}$ & $\begin{array}{c}-0.0273 \\
(-5.95)^{* * *}\end{array}$ & $\begin{array}{c}-0.0177 \\
(-2.77)^{* * *}\end{array}$ & $\begin{array}{l}-0.0088 \\
(-1.72)^{*}\end{array}$ & $\begin{array}{l}-0.0153 \\
(-1.71)^{*}\end{array}$ \\
\hline
\end{tabular}




\begin{tabular}{ccccccccc}
\hline \hline \multirow{2}{*}{ Current price } & 0.0091 & -0.0189 & 0.0110 & -0.0026 & -0.0072 & 0.0014 & 0.0118 & 0.0095 \\
& $(2.04)^{* *}$ & $(-3.81)^{* * *}$ & $(2.19)^{* *}$ & $(-0.65)$ & $(-1.64)$ & $(0.25)$ & $(2.04)^{* *}$ & $(1.35)$ \\
Time & 0.0021 & 0.0036 & 0.0035 & 0.0012 & 0.0024 & 0.0026 & 0.0040 & 0.0044 \\
& $(4.29)^{* * *}$ & $(2.12)^{* *}$ & $(7.16)^{* * *}$ & $(2.02)^{* *}$ & $(4.60)^{* * *}$ & $(4.51)^{* * *}$ & $(6.63)^{* * *}$ & $(5.92)^{* * *}$ \\
Time squared & -0.00002 & -0.00004 & -0.00004 & -0.0000 & -0.00002 & -0.00002 & -0.00005 & -0.0001 \\
& $(-2.38)^{* *}$ & $(-2.20)^{* *}$ & $(-5.94)^{* * *}$ & $(-0.02)$ & $(-2.91)^{* * *}$ & $(-2.84)^{* * *}$ & $(-5.59)^{* * *}$ & $(-5.11)^{* * *}$ \\
Intercept & -0.0321 & -0.0776 & -0.0627 & -0.0286 & -0.0719 & -0.0581 & -0.0649 & -0.0883 \\
& $(-2.87)^{* * *}$ & $(-2.20)^{* *}$ & $(-5.23)^{* * *}$ & $(-2.27)^{* *}$ & $(-6.18)^{* * *}$ & $(-4.30)^{* * *}$ & $(-3.74)^{* * *}$ & $(-3.70)^{* * *}$ \\
\hline $\mathrm{R}^{2}$ & 0.0637 & 0.1146 & 0.0705 & 0.0898 & 0.0903 & 0.0766 & 0.0695 & 0.0770 \\
Adjusted $\mathrm{R}^{2}$ & 0.0574 & 0.1100 & 0.0648 & 0.0846 & 0.0853 & 0.0693 & 0.0605 & 0.0667 \\
$\mathrm{~F}$ & $10.12 * * *$ & $24.61 * * *$ & $12.28 * * *$ & $17.46 * * *$ & $18.06 * * *$ & $10.37 * * *$ & $7.70 * * *$ & $7.48 * * *$ \\
Observation & 2249 & 3059 & 2281 & 3027 & 3292 & 1890 & 1145 & 908 \\
\hline
\end{tabular}

Notes: $1 . * * *$ and $* * *$ respectively denote significance at the $10 \%, 5 \%$ and $1 \%$ levels.

2. We set East China as the control region in region subsamples and agriculture as the control industry in sectoral subsamples.

The main results of these regressions can be summarized as follows:

(1) TFPGs in East China are significantly higher than those at the national level in all regressions, and also higher than the TFPGs in Central and West China by 0.017 and 0.013 , respectively.

(2) TFPGs in all sectors are still significantly higher than the aggregate-economy TFPGs. Furthermore, TFPGs in manufacturing sector are 0.011 higher than that in agriculture, which is consistent with the fact of shrinking share of agriculture in national output.

(3) Model specifications now have substantial impacts on TFPG estimates in some subsample estimations, but the effect varies across sub-samples. For instance, the result obtained by employing the DEA is higher than the AINA in region-specific sample, and the SFA yields a higher TFPG in nation-level sample than the AINA. It could be explained by the fact that the DEA and the SFA take technical efficiency into account and there is an improvement in technical efficiency.

(4) Consistent with the results in full sample, the selection bias from peer-review process and journal characteristics can still be found here. Particularly, the studies with 
peer-review process have higher TFPG estimates than the unpublished working papers in region-specific and sector-specific samples, and TFPGs in English papers are significantly higher than those in Chinese ones in all sub-samples.

(5) In the aggregate-economy model, TFPGs estimated by micro data are 0.027 lower than those by macro data. That could be explained by the following reasons: first, the micro data is more precise than macroeconomic data, and might be less manipulated; second, the technical progress for firms is indeed slower than that of the whole economy; third, if the statistical data is not distorted and technical level is identical between firms and the whole economy, it is possible that inputs in firm-level data (micro data) is adjusted by quality; fourth, it is also possible that most studies of firms' TFP use stateowned firms and their TFP growth rates could be lower due to misallocation (Hsieh and Klenow, 2009).

(6) Unlike the insignificant negative coefficients found in the full sample, TFPGs decline in the sector-specific subsample after quality-adjustment, which can be explained by that quality adjustment captures some embodied technical progress and thus lowers the estimated TFPG.

(7) The impact of the number of inputs on TFPGs is also statistically significant. If more inputs are added in the model, TFPG decreases by 0.003 to 0.039 , though the results are not as robust as in the full sample.

(8) The influence of the price used to measure output and input on TFPG is uncertain. TFPG estimates using nominal values are lower in region-specific studies, while higher in nation-level and aggregate-economy samples. Further research is needed to look into this effect.

(9) Similar to the full sample regression, TFPG grows with a diminishing rate. 
In addition, in the previous regressions we made a strong assumption that the TFPG in each year for period-observations is identical. Now we separate out all singleyear observations and conduct the econometric exercises. The results are reported in column 5 of Table 2.6. Compared with the results from the full sample, the main differences are related to the estimated coefficients for regional dummies. Together with East China, TFPGs in Central and West China are also significantly higher than the nation level.

Moreover, most studies are more interested in TFPGs at the national level and for the aggregate-economy, as they are heavily hinged with policy implications. In order to shed some light on this, we also separately conduct econometric exercises on these subsamples. The corresponding results are reported in Table 2.6 from column 6 to 8 . However, we find that these results are quite similar to those in the first 5 columns, which implies that our main conclusions are quite robust.

\subsubsection{Subsample after 1978}

According to the results in the previous section, we find that the TFPG after 1978 is quite different from that before 1978 (Table 2.1 and Figure 2.1). Since China's economy performed impressively after the reform in 1978, it has significant policy implications to separate out the observations after 1978.

We conducted an LR test to check if there is a structural difference between the samples before and after 1978. The result rejects the null hypothesis of no difference. After sorting out all observations after 1978, we lead new regressions and the results are reported in Table 2.7. Since no substantial difference is found between these results and those of the full samples in Table 2.5, we will not repeat the above discussions here. In addition, it also confirms that our main results are quite robust. 
Table 2.7: Results after 1978

\begin{tabular}{|c|c|c|c|c|c|c|c|}
\hline Variables & Full sample & $\begin{array}{c}\text { Single } \\
\text { year }\end{array}$ & $\begin{array}{c}\text { Nation- } \\
\text { level }\end{array}$ & $\begin{array}{l}\text { Aggregate } \\
\text { economy }\end{array}$ & Agriculture & Manufacturing & Service \\
\hline \multirow{2}{*}{ East } & 0.0172 & 0.0245 & & 0.0135 & 0.0206 & 0.0335 & 0.0188 \\
\hline & $(6.30) * * *$ & $(5.35)^{* * *}$ & & $(4.90) * * *$ & $(4.87)^{* * *}$ & $(2.26)^{* *}$ & $(1.00)$ \\
\hline \multirow{2}{*}{ Central } & -0.0004 & 0.0077 & & -0.0004 & -0.0077 & 0.0381 & 0.0009 \\
\hline & $(-0.12)$ & $(1.32)$ & & $(-0.13)$ & $(-1.70)^{*}$ & $(2.53)^{* *}$ & $(0.04)$ \\
\hline \multirow{2}{*}{ West } & 0.0034 & 0.0135 & & -0.0040 & -0.0025 & 0.0618 & -0.0049 \\
\hline & $(1.08)$ & $(2.23)^{* *}$ & & $(-1.22)$ & $(-0.56)$ & $(3.32) * * *$ & $(-0.26)$ \\
\hline \multirow{2}{*}{ Agriculture } & 0.0120 & 0.0159 & 0.0075 & & & & \\
\hline & $(3.59) * * *$ & $(3.19) * * *$ & $(1.44)$ & & & & \\
\hline \multirow{2}{*}{ Manufacturing } & 0.0314 & 0.0336 & 0.0091 & & & & \\
\hline & $(10.41)^{* * *}$ & $(7.41)^{* * *}$ & $(2.06)^{* *}$ & & & & \\
\hline \multirow{2}{*}{ Service } & 0.0243 & 0.0634 & 0.0264 & & & & \\
\hline & $(4.21)^{* * *}$ & $(5.09) * * *$ & $(3.03) * * *$ & & & & \\
\hline \multirow{2}{*}{ SRM } & 0.0052 & -0.0005 & 0.0010 & -0.0009 & -0.0034 & -0.0260 & -0.0465 \\
\hline & $(0.84)$ & $(-0.06)$ & $(0.13)$ & $(-0.12)$ & $(-0.54)$ & $(-1.00)$ & $(-2.31)^{* *}$ \\
\hline \multirow{2}{*}{ DEA } & 0.0032 & 0.0080 & 0.0076 & -0.0101 & -0.0067 & -0.0330 & \\
\hline & $(0.51)$ & (1.04) & $(1.01)$ & $(-1.33)$ & $(-1.05)$ & $(-1.17)$ & \\
\hline \multirow{2}{*}{ SFA } & 0.0083 & 0.0052 & 0.0208 & & -0.0096 & 0.0317 & \\
\hline & $(1.20)$ & $(0.58)$ & $(2.32)^{* *}$ & & $(-1.35)$ & $(1.06)$ & \\
\hline \multirow{2}{*}{ Others } & 0.0125 & 0.0173 & 0.0130 & -0.0155 & -0.0047 & 0.0821 & \\
\hline & $(1.31)$ & (1.34) & $(1.11)$ & $(-1.61)$ & $(-0.23)$ & $(1.73)^{*}$ & \\
\hline \multirow{2}{*}{ Published } & 0.0132 & 0.0381 & -0.00005 & 0.0006 & 0.0080 & 0.0731 & \\
\hline & $(3.91)^{* * *}$ & $(6.40)^{* * *}$ & $(-0.01)$ & $(0.17)$ & $(1.46)$ & $(2.81)^{* * *}$ & \\
\hline \multirow{2}{*}{ English } & 0.0095 & 0.0230 & 0.0120 & 0.0130 & 0.0043 & 0.0553 & -0.0723 \\
\hline & $(3.62) * * *$ & $(4.95) * * *$ & $(2.92) * * *$ & $(4.85)^{* * *}$ & (1.11) & $(2.62) * * *$ & $(-2.86) * * *$ \\
\hline \multirow{2}{*}{ Micro data } & -0.0089 & -0.0108 & -0.0011 & -0.0263 & -0.0040 & -0.0565 & \\
\hline & $(-1.64)$ & $(-1.18)$ & $(-0.15)$ & $(-3.44) * * *$ & $(-0.28)$ & $(-2.86)^{* * *}$ & \\
\hline \multirow{2}{*}{ Quality adjust } & -0.0044 & -0.0133 & -0.0039 & 0.0025 & -0.0090 & -0.0770 & \\
\hline & $(-1.47)$ & $(-2.15)^{* *}$ & $(-0.83)$ & $(0.83)$ & $(-2.08) * *$ & $(-2.99) * * *$ & \\
\hline \multirow{2}{*}{ Inputs } & -0.0146 & -0.0280 & -0.0090 & 0.0002 & 0.0004 & -0.0516 & 0.0545 \\
\hline & $(-4.90) * * *$ & $(-6.00) * * *$ & $(-2.04)^{* *}$ & $(0.06)$ & $(0.46)$ & $(-5.05)^{* * *}$ & $(5.08) * * *$ \\
\hline \multirow{2}{*}{ Current price } & -0.0014 & -0.0079 & 0.0098 & 0.0092 & 0.0056 & -0.0094 & \\
\hline & $(-0.46)$ & $(-1.68)^{*}$ & $(1.98)^{* *}$ & $(1.92)^{*}$ & $(1.37)$ & $(-0.68)$ & \\
\hline \multirow{2}{*}{ Time } & -0.0076 & -0.0056 & -0.0073 & -0.0004 & -0.0044 & -0.0093 & -0.0059 \\
\hline & $(-4.75)^{* * *}$ & $(-2.45)^{* *}$ & $(-3.04) * * *$ & $(-0.27)$ & $(-1.84)^{*}$ & $(-0.99)$ & $(-0.56)$ \\
\hline \multirow{2}{*}{ Time squared } & 0.0001 & 0.0001 & 0.0001 & 0.0000 & 0.00004 & 0.0001 & 0.00004 \\
\hline & $(4.90) * * *$ & $(2.46)^{* * *}$ & $(3.11)^{* * *}$ & $(0.19)$ & $(1.51)$ & $(1.27)$ & $(0.40)$ \\
\hline \multirow{2}{*}{ Intercept } & 0.1645 & 0.1050 & 0.1706 & 0.0376 & 0.1338 & 0.2499 & 0.1356 \\
\hline & $(4.73) * * *$ & $(2.12)^{* *}$ & $(3.34) * * *$ & $(1.05)$ & $(2.62) * * *$ & $(1.25)$ & $(0.53)$ \\
\hline $\mathrm{R}^{2}$ & 0.0531 & 0.0751 & 0.0383 & 0.0430 & 0.0514 & 0.1559 & 0.4232 \\
\hline Adjusted $\mathrm{R}^{2}$ & 0.0495 & 0.0692 & 0.0300 & 0.0366 & 0.0443 & 0.1325 & 0.3647 \\
\hline $\mathrm{F}$ & $14.85 * * *$ & $12.79 * * *$ & $4.63 * * *$ & $6.73 * * *$ & $7.27 * * *$ & $6.65 * * *$ & $7.24 * * *$ \\
\hline Observation & 4787 & 2855 & 1761 & 2113 & 2031 & 556 & 88 \\
\hline
\end{tabular}

Note: $* * *$ and $* * *$ respectively denote the significance at the $10 \%, 5 \%$ and $1 \%$ level.

\subsection{Conclusion}

This paper collected 5308 observations of total factor productivity growth rates 
(TFPG) for China from 150 primary studies and used a meta-analysis to analyze the impacts of a number of related factors on the heterogeneities of TFPG in the primary studies. Our results show that both factual factors and methodological factors can cause heterogeneities in TFPG in China. The sensitive analyses also indicate that the main results are quite robust with respect to different models and subsamples.

First, we find that the TFPG before the 1978 economic reform is quite close to zero, and hence most technical progress takes place after 1978. In particular, we find that the average TFPG for the aggregate economy at the national level is about $2.42 \%$, which barely contribute to about $24 \%$ of economic growth in China.

Second, the TFPGs are quite heterogeneous between regions and between sectors. Particularly, the TFPGs in East China are higher than those in West and Central China, which might help explain the increasing regional inequality in China. The TFPG in the manufacturing sector is significantly higher than that in other sectors, and ironically, the TFPGs in all sectors are generally higher than that of the aggregate economy, which are obviously contradictory to our common wisdom and more studies are needed for identifying the reasons.

Third, some methodological factors can significantly affect the TFPGs. Particularly, peer-review process and paper language can significantly influence the estimation of TFPGs. The TFPGs with peer-review process and written in the English language respectively are higher than those without peer-review process and written in the Chinese language. The number of inputs included in econometric models of primary studies also affects the results, and specifically, more inputs often lead to less TFPGs. While the following methodological factors, such as TFP estimation approaches, data type, quality adjustment and price generally have no significant impact on TFPGs. 
We uncover some potential problems in the current literature of empirical TFPG studies for China and find some factors that cause heterogeneities among previous studies, which is helpful to clarify some misunderstandings regarding the TFPG in China. Future studies should pay attention to these factors in order to make the research more convincing.

In addition, the measurement of capital input is also vital for TFPG studies, but we can't take a deeper look at how capital measurement affects TFPGs due to data limitations. This issue should be taken up by future research. 


\title{
3 Using Semi-parametric Model to Study
}

Nutrition Transition with Different Indices: The

\author{
Case of China ${ }^{9}$
}




\subsection{Introduction}

Many economies, particularly emerging ones, are experiencing a nutrition transition running parallel with rapid income growth (Monteiro et al., 1995; Popkin et al., 2001; Popkin, 2001a). Current literature shows that as income increases, people's diets which were traditionally high in complex carbohydrates and fiber are evolving into diets with a higher proportion of fats, saturated fats, sugar, refined foods and low fiber foodstuffs, which are collectively termed as "Western diet" (Drewnowski and Popkin, 1997; Guo et al., 2000; Popkin, 2003). This type of dietary change is always accompanied by two historic processes. One is the demographic shifts associated with higher life expectancy and reduced fertility rates, and the second is the epidemiological transition: Patterns of disease shift away from infectious and nutrient deficiency diseases toward higher rates of coronary heart disease and some types of cancer, and a higher prevalence of obesity, particularly childhood obesity, and non-insulin-dependent diabetes (Drewnowski and Popkin, 1997; Omran, 1971; Popkin, 2003). Popkin (1993) divides nutrition transition into 5 steps, namely collecting food, famine, receding famine, degenerative diseases, and behavioral change. A lot of studies (e.g., Du et al., 2002; Gao et al., 2013; Monteiro et al., 1995; Popkin, 2001b, 2003; Popkin et al., 2001; Wang et al. 2007) show that the developing world is transforming rapidly from the stage of receding famine to that of degenerative diseases, which is characterized by an increase in dietrelated, non-communicable diseases (DR-NCD) such as obesity, diabetes mellitus, cardiovascular disease, and cancer. Consequently, nutrition improvement results in a decline in under-nutrition accompanied by a rapid increase in obesity.

The current mainstream literature on nutrition transition mainly focuses on the estimation of calorie elasticities with respect to income or expenditure (Aromolaran, 2004; Behrman and Deolalikar, 1990; Behrman et al., 1997; Bouis, 1994; Dawson, 1997; 
Dawson and Tiffin, 1998; Gibson and Rozelle, 2002; Kochar, 2005; Ogundari and Abdulai, 2013; Shimokawa, 2010; Skoufias, 2003; Subramanian and Deaton, 1996). Empirical studies have revealed contradictory results with regard to the income elasticity of nutrient demand, but the extent to which nutrition responds to income, and the extent to which hunger and malnutrition can be eliminated by economic growth, are still controversial (Behrman and Deolalikar, 1987; Gibson and Rozelle, 2002; Ravallion, 1990; Skoufias et al., 2009; Subramanian and Deaton, 1996; Tian and Yu, 2013; Ye and Taylor, 1995). Some studies (e.g., Behrman and Deolalikar, 1987; Tian and Yu, 2013) assert that the contradiction in results is caused by different ways of converting food consumption into nutrient intake, while others (e.g., Bouis, 1994; Bouis and Haddad, 1992) figure out that measurement error might be the culprit. Both make sense only if the assumed functional form can correctly capture the complex relationship between calorie and income. However, most literature on the subject, except for a few studies (e.g., Gibson and Rozelle, 2002; Meng et al., 2009; Strauss and Thomas, 1995), uses parametric methods to estimate the elasticities. A comprehensive review of literature on the subject can be read in the work of Strauss and Thomas (1995). It is a well known fact that the relationship between nutrition intake and income (or expenditure) is typically nonlinear (Gibson and Rozelle, 2002; Jensen and Miller, 2010; Strauss and Thomas, 1995). Parametric methods are too restrictive to model the exact relationship, and the results often tend to be biased if the model is mis-specified. In light of this, nonparametric models can capture this complex relationship more effectively, and the results can be directly used for projection without estimation of nutrition elasticities. In addition, the projection based on elasticities is only applicable for the short run, and hence might not be suitable for an economy with rapid economic growth, such as the emerging economies. Another limitation in the current literature is that most studies only focus on the 
relationship between calorie intake and income. Undoubtedly, calorie intake is a very important aspect of nutrition transition, but it is certainly not the sole constituent. As abovementioned, nutrition transition also implies dietary change such as increasing consumption of meat, fruit and dairy products, and declining consumption of grain, because consumers care more about non-nutritional attributes such as taste when their income increases. In addition to calorie intake, many other indices with different merits hence can be proposed to measure nutrition transition. For instance, Jensen and Miller (2010) use the share of calories from staple food to measure hunger and nutrition improvement.

To overcome the problems in the current literature, we primarily develop 8 aggregate indices to measure nutrition transition and its corresponding outcomes from different angles to fill in the gaps in current work, namely (1) per capital calorie intake, (2) share of calorie obtained from protein, (3) share of calorie obtained from fat, (4) unit value of food, (5) unit value of calorie, (6) food diversity, (7) average calorie density (unit calorie) and (8) body mass index (BMI). In order to model dietary change, we additionally propose (9) calorie shares and (10) expenditure shares of specific food groups, to capture changes in the structure of food consumption. These ten measurements have different data requirements, and can capture nutrition transition from different perspectives. The first three indices are used to measure total calorie intake and energy sources; the next two indicators reflect the unit value of food and calorie, which are commonly used to measure quality; the food diversity index measures how many choices consumer have, more consumption bundle are usually related to higher welfare level; average calorie density of food indicates the change of consumer's preference for food energy, and BMI is a measure of consequence of nutrition transition. In addition, dietary change is an intuitive way to demonstrate the changes in food demand. Therefore we 
choose several specific food groups and calculate the corresponding calorie and expenditure shares. Moreover, to avoid the restrictive assumptions of the functional form of the parametric model, we introduce a semiparametric model, which allows full flexibility for the functional form of income and simultaneously controls other covariates in a parametric form, to identify the complex relationship between income and nutrition transition. The model can be further used to directly project the nutrition transition at different income levels from different perspectives.

At the end of this paper, we take China as a case study by using the data available from the China Health and Nutrition Survey (CHNS), which has detailed information for developing the abovementioned indices, and to empirically study nutrition transition in tandem with rapid economic growth.

\subsection{Measuring Nutrition Transition}

Nutrition transition implies both nutrition improvement and dietary changes. Here we propose 10 different measurements to study nutrition transition: 8 for the former and 2 for the latter.

\subsubsection{Measuring Nutrition Improvement}

\section{- Daily Calorie Intake Per Capita ( PKcal )}

Calorie intake may be the most widely used index for measuring malnutrition in developing countries. Food energy is the first necessity for consumers, and people usually spend most of their budget on food in order to get enough calories to survive when the budget constraint is very stringent. Therefore, the estimated income elasticity of calorie intake is usually positive in current literature (e.g., Gibson and Rozelle, 2002; Meng et al., 2009; Strauss and Thomas, 1995; Ogundari and Abdulai, 2013). First, we use daily calorie intake per capita ( $P K$ cal ) to measure calorie intake. 


\section{(3.1) $\quad P K \mathrm{cal}=C^{*} M$}

Where $C$ is the food consumption vector, $M$ is the food-calorie conversion vector, and the mark of $*$ denotes the inner product. A minimum calorie intake threshold is found for people regarding their different sex, weight, height, age and physical activities (Whitney and Rolfes, 2005; Jensen and Miller, 2010). However, energy requirement is not equal to real calorie intake. The former is based on the basal metabolic ratio (BMR), which mainly depends on body composition, body size, gender, age, health status and physical activity; while the latter is determined by food consumption, which is related to preference and income constraints. In practice, the real calorie intake can be estimated from food consumption data by using the food composition table.

\section{- Share of Calorie Obtained from Protein (Protein)}

Per capita calorie intake measures the total energy obtained from all sources of food. However, if there is a strong substitution effect, that is, people consuming better quality food but fewer calories, per capita calorie intake could decrease with income growth and the results might be misleading. Therefore, the source of calorie intake is also quite important for understanding nutrition transition. In this study, we use the share of calorie obtained from protein and fat to measure the structure of calorie intake.

$$
\text { Protein }=\frac{C * M_{P} * 4}{P \text { Kcal }}
$$

Here $M_{P}$ is the food-protein conversion vector, $C$ and $P K c a l$ are the same as aforementioned. We time numerator by 4 because 1 gram protein can provide 4 kilogram calories.

\section{- Share of Calorie Obtained from Fat ( Fat)}

Similarly, we also propose an indicator to measure the share of calorie obtained from fat. 


$$
F a t=\frac{C^{*} M_{F} * 9}{P K c a l}
$$

Here $M_{F}$ is the food-fat conversion vector, $C$ and PKcal are the same as aforementioned. Because 1 gram fat can provide 9 kilogram calories, we time the numerator by 9 . According to the findings in current literature (e.g., Popkin, 2003), as income increases, the diet will shift away from carbohydrate to fat and protein, particularly animal fat and protein. Therefore, we can expect that the share of fat and protein in total calorie intake will go up along with income growth.

\section{- Unit Value of Food (UnitV)}

Food price is determined by many attributes such as energy density, taste, appearance and so on. Energy is just one of many attributes that determine food price, so that the link between calories intake and food price might not be much stronger, and the dietary changes revealed by calories intake and food price may have different implications. Therefore we propose two indicators to measure food price: unit value of food (average price of food) and calorie (average price of calorie). The unit value of food can be defined as:

$$
\operatorname{Unit} V=\frac{E}{Q}=\frac{P^{*} C}{Q}
$$

Where $E$ and $Q$ are the total expenditure and quantity of food consumed, and $P$ is the price vector. It is an index widely used for measuring food quality (Yu and Abler, 2009) which often increases with income, because the rich prefer to purchase more expensive food. The unit value of the consumed food is expected to increase with income as rich people are more likely to substitute cheap staple food with more expensive cuisine when their income grows. Therefore the substitution between and within food groups with different prices can be captured by this index.

\section{- Unit Value of Calorie (UnitVK)}


Similar to the unit value, unit value of calorie (UnitVK) can capture the substitution between calorie sources regarding the calorie price.

$$
\text { UnitVK }=\frac{E}{P K c a l}
$$

People usually switch from cheap sources of calories (staple food) to more expensive sources (non-staple food) as their income increases, indicating that rich people have higher UnitVK (Behrman and Doelalikar, 1987).

\section{- Food Diversity ( Diversity)}

In general, poor people only consume several cheap staple food products due to limited budget constraint, while rich people have more choices and can choose more diverse food products due to a larger budget set. A greater diversity often increases consumer welfare because people can benefit from enjoying quality on characteristics that they had not experienced (Bar-Isaac et al., 2004). Therefore, the diversity of food products can be used as a measure of household welfare and it is expected to increase with income growth. In this study, we specifically calculate the total number of food categories consumed in the household during the survey time as the measure of food diversity.

\section{- Unit Calorie (UnitK)}

Calorie is one of the most important attributes of food, particularly for the poor people. However, once people are released from hunger, they start to care more about other attributes, implying the calorie density of food might change along with income growth. We use unit calorie (UnitK) to measure the average calorie density of the total amount of consumed food. It is expressed as follows:

$$
\text { UnitK }=\frac{P K c a l}{Q}
$$

PKcal is the calorie intake mentioned before and $Q$ is the total quantity of food 
consumption for this person measured by weight (e.g., gram). It is well known that calorie density varies between and within food groups. For instance, 100 grams of rice (uncooked) can provide 340-360 kilocalories of energy, while most edible oil can provide more than 800 kilocalories for the same weight (Institute of Nutrition and Food Safety and Chinese Center for Disease Control and Prevention, 2002 and 2004). Since diets which are high in carbohydrates and fiber are usually replaced by ones with a higher proportion of fat and sugar during the nutrition transition (Drewnowski and Popkin, 1997; Popkin, 1993), the average calorie density alters as well. But we must be very cautious before drawing a conclusion. The relationship between this index and income is neither obvious nor clear, because there is a large variation between calorie densities. On the one hand, if people switch from a diet with a lot of cereals and vegetables and a small amount of animal products, to a high-fat diet as their income grows (Du et al., 2002; Popkin, 1999; Popkin et al. 2002), the unit calorie is likely to increase. On the other hand, if people replace cereals and animal products with fresh fruit and dairy products, which have a lower calorie density, UnitK may be inclined to fall.

\section{- Body Mass Index ( BMI)}

Body mass index ( $B M I$ ) is a widely used anthropometric proxy for human body fat based on an individual's weight and height.

$$
B M I=\frac{\text { weight }}{(\text { height })^{2}}
$$

Where weight is measured in kilograms and height in meters. BMI provides a simple numeric measure of a person's "fatness" or "thinness", as a consequence of nutrition transition, which is strongly linked to nutrition intake, and allows health professionals to discuss weight problems more objectively with their patients (WHO, 1995). The BMI values are valid only when applied to adults, and do not predict health. 
In this paper, we use the $B M I$ of household head to representatively measure the nutrition statue of the family from an anthropometric perspective. Strauss and Thomas (1995) provide a deep discussion regarding the link between BMI and income. On the one hand, BMI is related to maximum physical capacity since energy can be stored in the body and some jobs may require stress activity, thus higher BMI may increase labor productivity and income. Behrman and Deolalikar (1989) confirm that BMI has a significant positive effect on the wage of male. On the other hand, income growth usually increases calorie intake, which may result in a higher BMI. Therefore, rich people are expected to have higher BMI.

\subsubsection{Measuring Dietary Changes}

Staple food often dominates the diet for extremely poor people, because it is the cheapest source of calories. Once people are relieved from hunger, they care more about other attributes such as taste, appearance, odour, status value, and degree of processing rather than energy (Behrman and Doelalikar, 1987; Jensen and Miller, 2010), and tend to replace staple food with more delicious animal food as their economic status increases, which implies that the consumption of different food groups differs across different income levels. To measure the structure change in the diet, we can select several representative food groups and calculate the calorie shares and expenditure shares of these food groups for comparison.

\section{- Calorie Shares $\left(C S_{i}\right)$}

The calorie share of a specific food group is defined as the share of calorie for this food group in total calorie intake.

$$
C S_{i}=\frac{\text { Calorie }_{i}}{\text { PKcal }}
$$

Where Calorie $_{i}$ and PKcal denote calorie intake from food group $i$ and all food 
sources, respectively. As a new approach to measuring food consumption behaviour during nutrition transition, calorie share avoids the heterogeneity of energy requirement across consumers and the imperfect absorption of nutrients. It is also consistent with the revealed consumer preference. Jensen and Miller (2010) find that calorie share of staple food among the poorest is quite high (80\%) and does not respond to income growth until reaching an income threshold, then consumers switch to more delicious food such as meat and fruit. Drewnowski and Popkin (1997) also find that the proportion of energy from carbohydrates diminishes sharply as income grows, while that from animal fats and sugar increases rapidly. Thus, we can speculate that calorie share of staple food will decrease with income, while the calorie share of animal food (meat, dairy) and fruit will increase.

\section{- Expenditure Share $\left(E S_{i}\right)$}

In some household surveys, prices and quantities of food products are not available, but expenditures are, so that expenditure share can be easily calculated without any further information. Such an index is very convenient for providing information about welfare and nutrition change.

$$
E S_{i}=\frac{E_{i}}{E}
$$

Where $E_{i}$ and $E$ denote food expenditure for food group $i$ and all food, respectively. Similar to the reason for the $C S_{i}$, the members of the lower social classes first take more calories from cheaper food and then switch to more expensive calorie sources when their income is higher than the subsistence level (Jensen and Miller, 2010).

\subsubsection{Comparison of Different Indices}

Different indices have different advantages, and a comparison, including the data requirements, shown in Table 3.1, is necessary for us to understand each one's advantages and disadvantages. 
Table 3.1: Comparison of Different Indices

\begin{tabular}{|c|c|c|c|c|c|c|c|}
\hline \multirow[b]{2}{*}{ Indices } & \multirow[b]{2}{*}{ Definition } & \multirow[b]{2}{*}{ Implication } & \multirow[b]{2}{*}{ Merits and Odds } & \multicolumn{4}{|c|}{ Information needed } \\
\hline & & & & Quantity & Price & $\begin{array}{l}\text { Expend } \\
\text { iture }\end{array}$ & Others \\
\hline Pkcal & Total calorie intake & $\begin{array}{l}\text { Whether people } \\
\text { have sufficient } \\
\text { energy }\end{array}$ & $\begin{array}{l}\text { Suffer from heterogeneity } \\
\text { in energy requirement } \\
\text { across individuals }\end{array}$ & yes & no & no & no \\
\hline Protein & $\begin{array}{l}\text { Share of calorie } \\
\text { obtained from } \\
\text { protein }\end{array}$ & $\begin{array}{l}\text { Quality or structure } \\
\text { of energy }\end{array}$ & $\begin{array}{l}\text { Measure the sources of } \\
\text { energy }\end{array}$ & yes & no & no & no \\
\hline Fat & $\begin{array}{l}\text { Share of calorie } \\
\text { obtained from fat }\end{array}$ & $\begin{array}{l}\text { Quality or structure } \\
\text { of energy }\end{array}$ & $\begin{array}{l}\text { Measure the sources of } \\
\text { energy }\end{array}$ & yes & no & no & no \\
\hline UnitV & $\begin{array}{l}\text { Average price of } \\
\text { food consumed }\end{array}$ & Quality of food & $\begin{array}{l}\text { Capture the substitution } \\
\text { between food groups with } \\
\text { different prices }\end{array}$ & yes & yes & no & no \\
\hline UnitVK & $\begin{array}{l}\text { Average price of } \\
\text { calorie }\end{array}$ & Quality of calorie & $\begin{array}{l}\text { Capture the substitution } \\
\text { between calorie sources } \\
\text { with different prices }\end{array}$ & yes & yes & no & no \\
\hline Diversity & Diversity of food & Welfare level & $\begin{array}{l}\text { Reflect the budget } \\
\text { constraint }\end{array}$ & yes & no & no & no \\
\hline UnitK & $\begin{array}{l}\text { Average calorie } \\
\text { density of food } \\
\text { consumed }\end{array}$ & $\begin{array}{l}\text { Importance of } \\
\text { energy in food } \\
\text { attributes }\end{array}$ & $\begin{array}{l}\text { Capture the substitution } \\
\text { between food groups with } \\
\text { different calorie densities }\end{array}$ & yes & no & no & no \\
\hline BMI & $\begin{array}{l}\text { Human body mass } \\
\text { index }\end{array}$ & Obesity & Anthropometric index & no & no & no & yes \\
\hline $\begin{array}{l}\text { Calorie } \\
\text { share }\end{array}$ & $\begin{array}{l}\text { Share of calorie } \\
\text { obtained from } \\
\text { specific food group }\end{array}$ & $\begin{array}{l}\text { Food composition } \\
\text { change }\end{array}$ & $\begin{array}{l}\text { Avoid the heterogeneity } \\
\text { of energy intake across } \\
\text { individuals }\end{array}$ & yes & no & no & no \\
\hline $\begin{array}{l}\text { Expenditure } \\
\text { share }\end{array}$ & $\begin{array}{l}\text { Share of expenditure } \\
\text { spend on specific } \\
\text { food group }\end{array}$ & $\begin{array}{l}\text { Food composition } \\
\text { change }\end{array}$ & $\begin{array}{l}\text { Avoid the heterogeneity } \\
\text { of food demand across } \\
\text { individuals }\end{array}$ & no & no & yes & no \\
\hline
\end{tabular}

As abovementioned, $P K$ cal can measure calorie intake by using the food quantity and food composition table. However, it cannot capture structure change and suffers from the heterogeneity in energy requirement. Protein and Fat are thus proposed to measure the structure of calorie intake. UnitV and UnitVK are used to measure food quality and can capture the substitution between food groups and calorie sources, while both of them need price or expenditure information in addition to quantity. Diversity is used to measure the food diversity which usually implies a higher utility due to more choices. UnitK $\mathrm{is}$ developed to measure the average calorie density.

$B M I$ is an anthropometric index to measure human body fat which is a consequence of nutrition transition. $C S_{i}$ can avoid the heterogeneity across individuals by 
using the share of calorie from a specific food group when price information is not available. Finally, $E S_{i}$ is more suitable when only expenditure data is available.

\subsection{Semiparametric Model}

The relationship between nutrition transition and income might be nonlinear (Gibson and Rozelle, 2002; Jensen and Miller, 2010; Strauss and Thomas, 1995). Using parametric specification to model the relationship may suffer from the bias of incorrect specification and may generate inconsistent estimates. Therefore, nonparametric regressions may be appropriate to explore the nonlinear relationship between nutrition transition and income, because they allow the data to speak for themselves and make no assumptions about functional form. However, nonparametric regressions are restricted to low dimensional relationships (Gibson and Rozelle, 2002). Unfortunately, income is not the sole determinant of nutrition transition; other factors such as household size and demographic composition also play important roles in this process. Ignoring these covariates might lead to biased estimation as well. It would be ideal to specify the whole model nonparametrically, when there is little a priori knowledge of the shape of the function to be estimated (Strauss and Thomas, 1995). This, however, will suffer from the “curse of dimensionality", requiring very large samples to estimate and making it difficult to visualize a regression surface in more than three dimensions (Fox, 2000; Gong et al., 2005; Meng et al., 2009). Therefore, a semiparametric model, which allows full flexibility of the relationship between nutrition indices and income, and simultaneously controls for other factors that also influence these indicators in a parametric function, is appropriate in studying nutrition transition. The class of semi-parametric specifications includes several subclasses such as partial linear model, partial parametric model and partial index model (Yatchew, 1998). The partial linear model is commonly used in nutrition study(Gibson 
and Rozelle, 2002). The functional form of a partial linear model can be written as

$$
N I_{j}=f_{j}(Y)+\sum X_{j} \beta_{j}+\varepsilon_{j}
$$

where $N I_{j}$ denotes the index $j$ developed in this paper; $Y$ denotes per capita income, and $f_{j}(Y)$ is the unknown income function with nonparametric specification; $\varepsilon_{j}$ is the error term following a normal distribution; $X_{j}$ and $\beta_{j}$ respectively stand for other exogenous factor and the corresponding coefficient, such as household characteristics (e.g., demographic ratio, household size, age), and this part is a parametric specification.

We assume that income is exogenous, because Gibson and Rozelle (2002) argue that: (1) The feedback from nutrition to income is likely to be small given the trivial cost of purchasing additional calories needed for physical activity; (2) Measurement errors in income also should be uncorrelated with errors in nutrition indices because the two types of data were collected in separate sections of the survey and refer to different time periods. In addition, we use income rather expenditure for projection.

Two methods are widely used to estimate the partial linear model: the conditional expectation method proposed by Robinson (1988) and the differencing method developed by Yatchew $(1997,1998)$. Robinson removes the nonparametric function by taking the conditional expectation of equation (3.10) on income and subtracting these on both sides of the equation, while Yatchew removes the income function by taking difference. This study employs Yatchew's method for its simplicity. In practice, Yatchew's method (1997) is conducted in a two-step process:

In the first step, we sort all observations according to income and take the first order difference of all variables.

$$
N I_{j, n+1}-N I_{j, n}=\sum \beta_{j}\left(X_{j, n+1}-X_{j, n}\right)+f_{j}\left(Y_{n+1}\right)-f_{j}\left(Y_{n}\right)+\varepsilon_{j, n+1}-\varepsilon_{j, n}
$$

Where $n$ denotes the order of observations. Because the observations are 
rearranged so that $Y_{1} \leq Y_{2} \leq \ldots \leq Y_{n}$. As sample size increases, $f_{j}\left(Y_{n}\right)$ is asymptotically equal to $f_{j}\left(Y_{n+1}\right)$ (Yatchew, 1997). We can rewrite the model as follows and use OLS to estimate $\beta_{j}$.

$$
d N I_{j}=\sum \beta_{j} * d X_{j}+d \varepsilon_{j}
$$

$d N I_{j}$ and $d X_{j}$ denotes the first order differences of $N I_{j}$ and $X_{j}$ respectively.

In the second step, the estimated coefficient $\beta_{j}$ is substituted into equation (3.10) so that we can calculate $f_{j}(Y)$ as

$$
f_{j}(Y)=N I_{j}-\sum \beta_{j}^{\prime} * X_{j}
$$

Finally, we can use nonparametric regression to uncover the relationship between nutrition indicators and income directly.

Different from a parametric regression which specifies the model globally, nonparametric regression methods estimate the relationship between variables locally. Local polynomial regression, locally weighted regression (LOWESS) and smoothing splines are three commonly used smoothing methods. Even though LOWESS could overcome the problem of large intervals in the sample, it is not easy to obtain the confidence interval, which has important policy implications for this research. Fox (2000) shows that local polynomial regression and smoothing splines methods with comparable smoothing parameters will produce similar results in practice when sample size is relatively large.

Different from Strauss and Thomas (1995), and Gibson and Rozelle (2002) who used a locally weighted regression (LOWESS) to study the relationship between income and nutrition intakes, we propose a Kernel-weighted local polynomial estimation, because it provides a simple and intuitive way to correct biases caused by asymmetric neighbourhoods in the interior, can better model the slope effects particularly in the 
boundary regions, and can more straightforwardly provide confidence intervals and optimal bandwidth from the sample itself (Fox, 2000; Hastie and Loader, 1993; Fan et al., 1997).

Yatchew (1997) also proposed a specification test to test the semiparametric model against its parametric counterpart (linear model) in the following equation:

(3.14) $\quad N I_{j}=\alpha+\gamma Y+\sum \beta_{j}^{*} X_{j}+e_{j}$

Where $\alpha$ is the intercept and $\gamma$ is the coefficient for $Y$. If equation (3.14) is correctly specified, $e_{j}$ and $\varepsilon_{j}$ should following the same distribution, so that we can give the following test,

(3.15) $V=\frac{\sqrt{N}\left(S_{\text {res }}^{2}-S_{\text {diff }}^{2}\right)}{S_{\text {diff }}^{2}}$

with $S_{\text {diff }}^{2}=\frac{\sum\left(\Delta \mathrm{y}_{\mathrm{i}}-\beta^{\prime} \Delta \mathrm{x}_{\mathrm{i}}\right)^{2}}{2 N}$.

Where $S_{r e s}^{2}$ is the average sum of squared residuals in the linear model Equation (3.13), and $\beta_{j}^{\prime}$ is the estimated coefficient in Equation (3.12), the first difference function. Yatchew (1997, 1998) shows that $V \sim N(0,1)$ under the null hypothesis that the parametric model is correctly specified. This allows us to perform a one-sided $t$ test.

\subsection{Projection}

One important purpose of studying nutrition transition is the ability it gives to project future nutrition intake and dietary change, particularly for emerging economies with rapid economic growth. In contrast to the parametric models, which are too restrictive to project in the long run, the results of the semiparametric models can directly project the nutrition transition in the long run with greater accuracy. To conduct the projection in the aforementioned model, we can first generate a new income variable that 
is higher than the current one, ceteris paribus, and then use local polynomial regression to predict the nutrition transition basing on the new income level.

$$
\tilde{N I}_{j}=\tilde{f}_{j}(Y)+\sum \beta_{j}^{\prime} * \bar{X}_{j}
$$

$\tilde{N I}_{j}$ and $\tilde{f}_{j}(Y)$ are the predicted value of nutrition indices and income function,

$\bar{X}_{j}$ is the mean of other covariates, or the values ceteris paribus.

\subsection{An Illustrative Case Study}

\subsubsection{Data Description}

China, the largest emerging country in the world, is chosen in this thesis as a case study. After three decades of remarkable economic growth, the dietary pattern in China is switching from a low-fat traditional Chinese diet, mainly based on cereals and vegetables with few animal products, to a "western diet", which is high in both saturated fat and sugar, and includes refined food which is low in fiber (Du et al., 2002; Guo et al., 2000; Popkin, 1993, 2001b). The data used in this study has been extracted from the China Health and Nutrition Survey (CHNS) 2004, 2006, and 2009. The sample consists of data obtained from more than 4000 households in each year through the use of a multi-stage, random cluster strategy for 9 provinces. Details on household food consumption were collected for three consecutive days, which were randomly allocated from Monday to Sunday. Further discussion about the data is shown in the Appendix 3.1.

To measure the dietary change, 6 food groups are selected based on the Chinese Food Classification Table: (1) staple food (cereals and cereal products), (2) vegetable (vegetables and vegetable products), (3) fruit (fruit and fruit products, nuts and seeds), (4) meat (meat and meat products, poultry and poultry products), (5) dairy products (milk and dairy products) and (6) oil (edible oil). The descriptive statistics of these nutrition 
indicators are shown in Appendix 3.2.

In order to estimate the nonparametric relationship between income and nutrition transition or dietary change, we control household heterogeneity using household size, characteristics of household head (gender, age, education and physical activity level which is measured by the category of professions), characteristics of people who cooked during the survey time (average education and activity level), demographic ratio of specific age-gender cohort, and two year-dummies. In order to control the regional variation in the preference of diet and regional price difference in the first stage, we also add a dummy variable for each city and county. The definition and descriptive analysis of these control variables are shown in Appendix 3.3. We pool three year data together and use two time dummies to control the variation over time. We only show the results for the pooled regression to save space.

After taking the difference, we use OLS to estimate the non-income effect according to equation (3.12). The results are shown in Appendix 3.4 and 3.5. Even though we find that the aforementioned covariates have significant impact on the nutrition indices, implying that we should control these variables, they are of no interest to us, and therefore will not be further discussed here.

\subsubsection{Estimation Results}

To compare the semiparametric models with their linear counterparts, we conduct Yatchew's test according to equation (3.15). The results are reported in Table 3.2. We compare the partial linear model with two linear models: one uses logarithm of income and the other uses income. We find that about half of linear models are rejected. In particular, the relationships between income (logarithm of income) and protein share, unit value of calorie (UnitVK ), unit calorie (UnitK ), and expenditure and calorie share of fruit, dairy, vegetable, and oil can be well captured by linear model, while all others cannot, 
indicating traditional linear models are too restrictive to capture the changing patterns of different nutrition indices. Therefore, we prefer semiparametric models to parametric ones (linear model).

Table 3.2: Specification Test for Income Function

\begin{tabular}{|c|c|c|c|c|c|}
\hline \multirow{2}{*}{ Model } & \multicolumn{2}{|l|}{ Linear } & \multirow{2}{*}{$\begin{array}{l}\text { Partial Linear } \\
\text { S square }\end{array}$} & \multicolumn{2}{|l|}{ t test } \\
\hline & RMS-Inincome & RMS-income & & lnincome & income \\
\hline PKcal & 594940.3140 & 596311.9520 & 560456.5838 & $6.8141 * * *$ & $7.0851 * * *$ \\
\hline Protein & 0.0009 & 0.0009 & 0.0009 & 0.9521 & 0.9799 \\
\hline Fat & 0.0115 & 0.0115 & 0.0113 & $1.6172 *$ & $2.0702 * *$ \\
\hline UnitV & 13.3167 & 13.3462 & 13.1292 & $1.5822 *$ & $1.8307 * *$ \\
\hline UnitVK & 3.7345 & 3.7382 & 3.7140 & 0.6100 & 0.7203 \\
\hline Diversity & 19.0320 & 19.2985 & 18.9088 & 0.7216 & $2.2827 * *$ \\
\hline UnitK & 0.1863 & 0.1863 & 0.1842 & 1.2399 & 1.2553 \\
\hline BMI & 9.7415 & 9.7736 & 9.5641 & $2.0548 * *$ & $2.4260 * * *$ \\
\hline CS-Staple & 0.0187 & 0.0187 & 0.0183 & $2.0949 * *$ & $2.3820 * * *$ \\
\hline CS-Fruit & 0.0007 & 0.0007 & 0.0007 & 0.1783 & 0.1674 \\
\hline CS-Meat & 0.0078 & 0.0079 & 0.0077 & $2.7086 * * *$ & $3.5041 * * *$ \\
\hline CS-Dairy & 0.0003 & 0.0003 & 0.0003 & 0.6966 & 0.5537 \\
\hline CS-Vegetable & 0.0010 & 0.0010 & 0.0010 & 1.0229 & 1.0261 \\
\hline CS-Oil & 0.0098 & 0.0098 & 0.0097 & 0.9655 & 0.9498 \\
\hline ES-Staple & 0.0135 & 0.0136 & 0.0133 & $1.3187 *$ & $2.2469 * *$ \\
\hline ES-Fruit & 0.0046 & 0.0046 & 0.0046 & 0.4358 & 0.4645 \\
\hline ES-Meat & 0.0282 & 0.0285 & 0.0276 & $2.2200 * *$ & $3.2703 * * *$ \\
\hline ES-Dairy & 0.0023 & 0.0023 & 0.0023 & 0.5766 & 0.3804 \\
\hline ES-Vegetable & 0.0062 & 0.0062 & 0.0062 & 0.8227 & 1.1366 \\
\hline ES-Oil & 0.0052 & 0.0052 & 0.0051 & 0.8236 & 0.9245 \\
\hline
\end{tabular}

Notes: 1. Linear and Partial Linear refer to the linear model and partial linear model respectively. There two linear models, the first one uses logarithm of per capita net income as income variable, while the second one does not take the logarithm form. RMS refers to the root mean of squared error.

2. *,**, *** refer to significant levels at $10 \%, 5 \%$, and $1 \%$ respectively.

Our primary interest is to use the kernel-weighted local polynomial regression to display the relationships between nutritional indices and income, as shown in equation (3.13). To remove the skew in the distribution of income, we take the logarithm of income and map the indices against it. Moreover, following the suggestions by Heckman et al. (1998), we trim the lowest $2 \%$ to remove the low-density samples, and then use the optimal bandwidth for the estimations. The results, including a fitted curve and $95 \%$ confident intervals, are shown in Figures 3.1, 3.2 and 3.3. 
Figure 3.1: Local Polynomial Smooth for Nutrition Improvement Indices
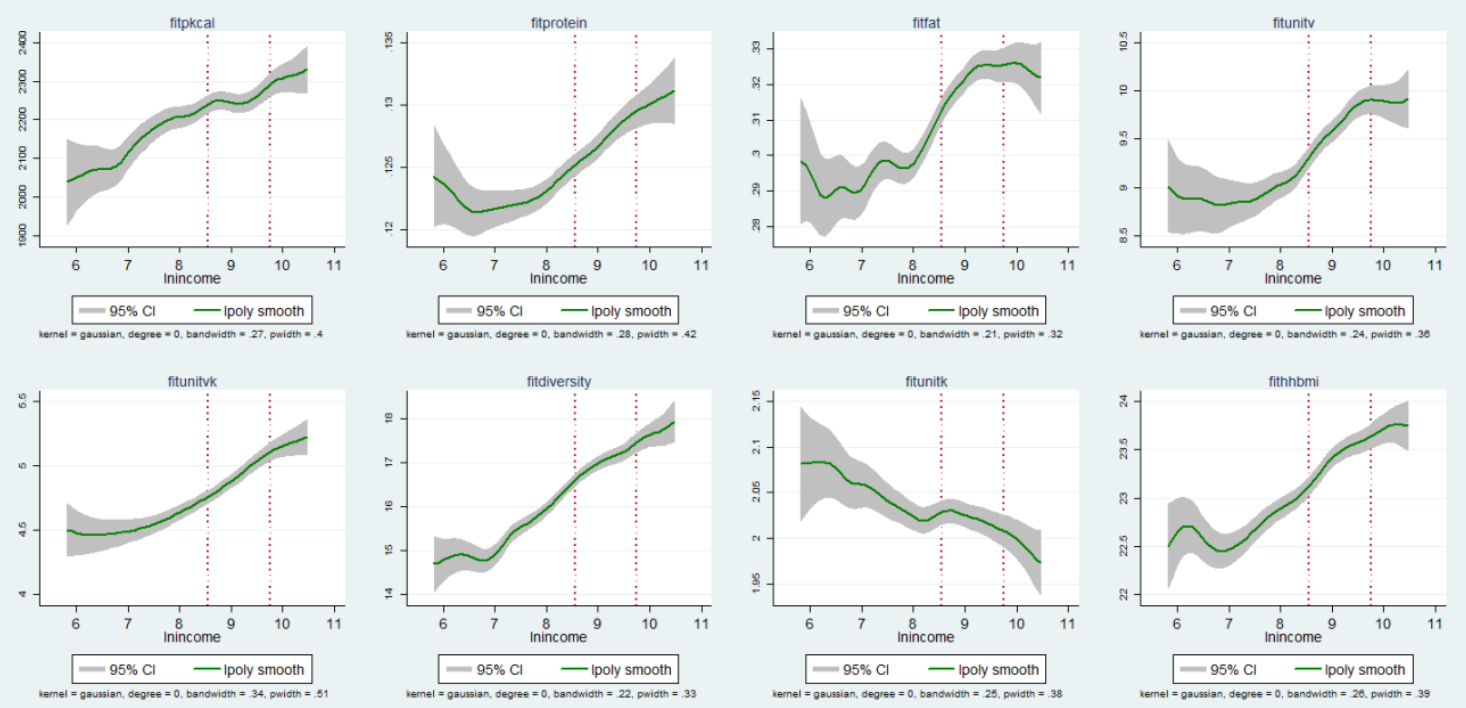

Notes: 1 . The solid lines refer to the fitted value of each nutrition index.

2. The two vertical dotted lines stand for the per capita disposable income in China in 2009: The left one (income=5153.2 Yuan) denotes that in rural area and the right one (income=17174.7 Yuan) in urban area.

\section{Figure 3.2: Local Polynomial Smooth for Calorie Share of Specific Food Groups}
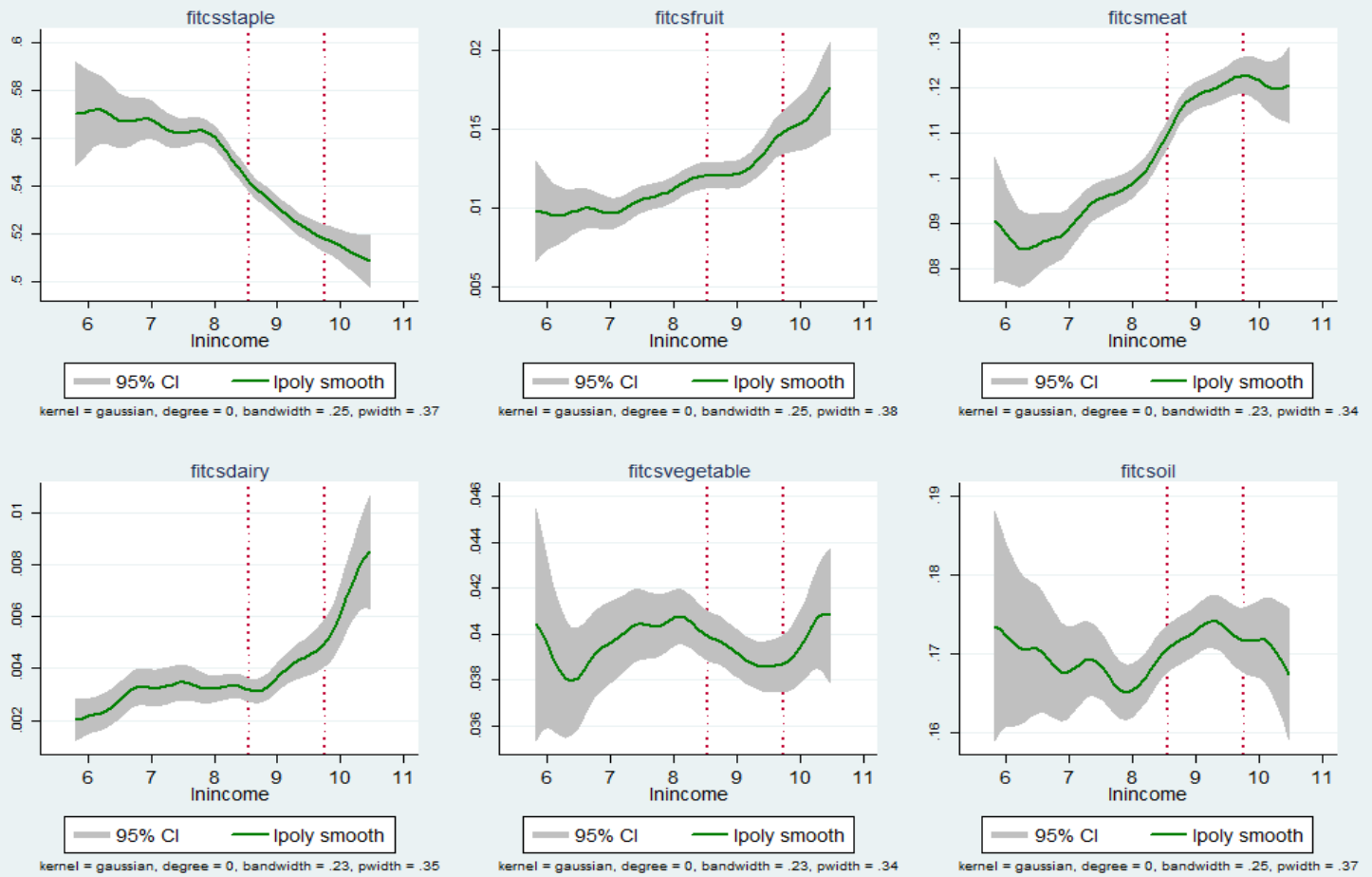

Notes: 1 . The solid lines refer to the fitted value of each nutrition index.

2. The two vertical dotted lines stand for the per capita disposable income in China in 2009: The left one (income $=5153.2$ Yuan) denotes that in rural area and the right one (income=17174.7 Yuan) in urban area. 
Figure 3.3: Local Polynomial Smooth for Expenditure Share of Specific Food Groups
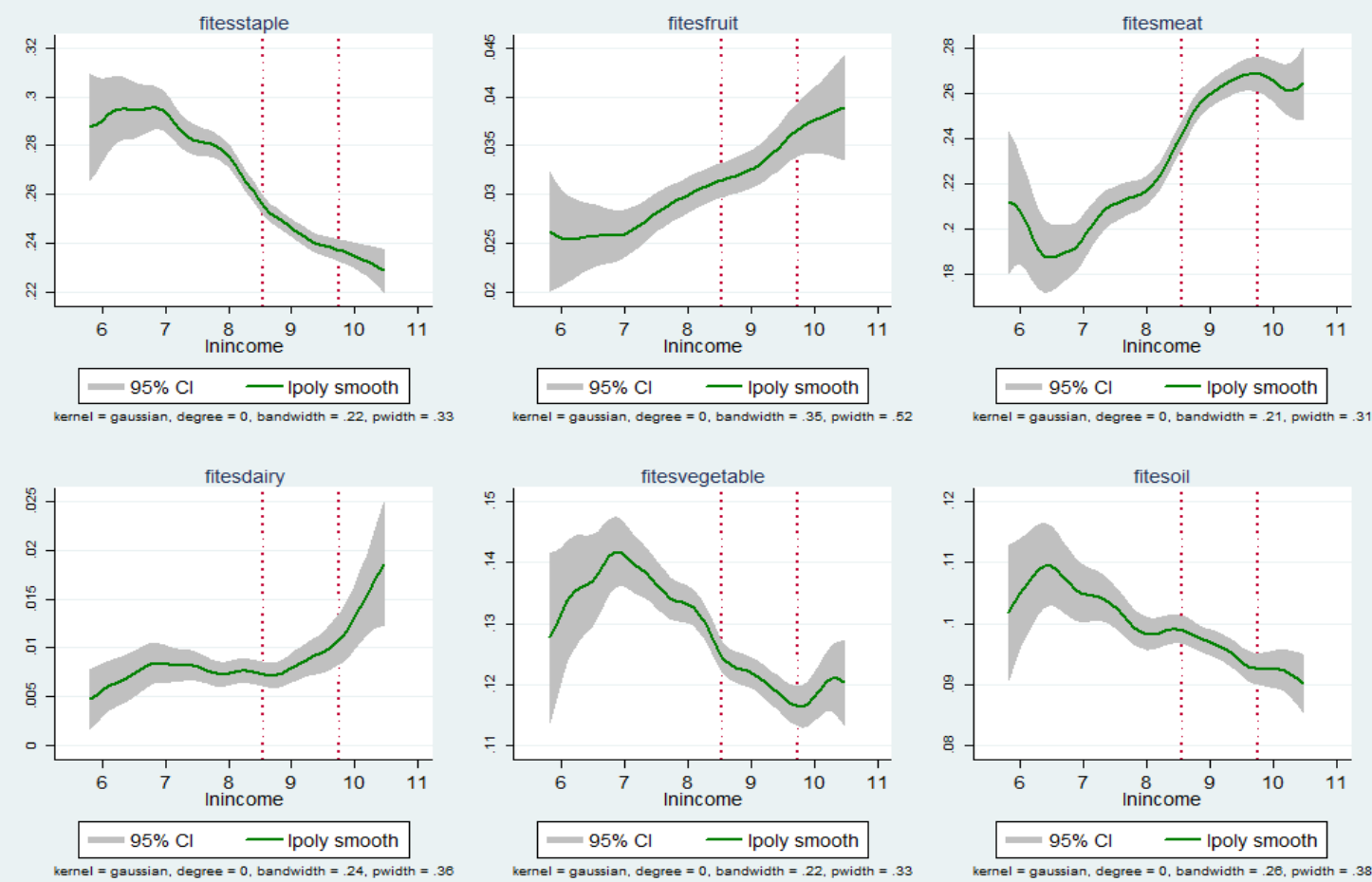

Notes: 1. The solid lines refer to the fitted value of each nutrition index.

2. The two vertical dotted lines stand for the per capita disposable income in China in 2009: The left one (income $=5153.2$ Yuan) denotes that in rural area and the right one (income=17174.7 Yuan) in urban area.

Several conclusions can be drawn from these figures:

First, the relationship between calorie intake and log of income is nonlinear. Per capita calorie intake increases monotonically with logarithm of income in China, but the growth rate slows down at a high income level, implying a positive but decreasing income elasticity of calorie. Our findings are consistent with a number of previous studies (Behrman and Doelalikar, 1987, 1988; Strauss and Thomas, 1995; Subramanian and Deaton, 1996). In particular, the share of calorie obtained from protein and fat follow a Ushaped relationship. As income increases, those two indices first go down and then go up. The U-shaped trend is also consistent with Jensen and Miller's finding that the very poor people would spend additional income mostly on the cheapest calorie sources such as staple food which is high in carbohydrate, and once they are released from hunger, they will shift to high quality calorie sources such as protein and fat. However, at very high 
income level, the share of calorie obtained from fat tends to fall down, implying a return of high-carbohydrate food in the diet.

Second, rich people tend to consume more high-valued food. We find that both unit value of food (UnitV) and unit value of calorie (UnitVK) increase with income growth. It is plausible that people switch to more expensive and high-valued food, but not necessarily food with higher calorie density as their income status improves (Behrman and Doelalikar, 1987; Jensen and Miller, 2010).

Third, the diversity of food also increases with income growth. Consistent with consumer theory, people have larger consumption bundles as their budget increases.

Fourth, people are shifting to low-calorie density food as income increase, but their body mass index continue going up due to increasing intake of calories.

Fifth, different food groups have different trends which accompany income growth. In general, staple food's role in the diet increases slightly with income for the extremely poor people due to the high demand for energy. Once people are released from hunger, staple food becomes less important and accounts for a decreasing share in the diet both in terms of calories and expenditure as income increases. On the contrary, fruits, meat and dairy products play a more and more important role. Particularly, the shares of fruits and dairy products increase at an accelerating rate, while the growth rate of meat products slows down at higher income levels. Similar to staple food, the shares of vegetables in calories and expenditure also increase at first and then decrease along with income growth, but they tend to play an increasing role in the diet for the very rich people. In addition, the expenditure share of edible oil decreases in tandem with income growth, but the calorie share shows a more complicated picture, implying that the quality (price) of oil differs for different income groups.

\subsubsection{Projection Results}


We use the method presented in equation (3.16) to project the nutrition transition at different income levels. Other things being equal, we select 10 income levels and project the 20 measures of nutrition transition in China by using the semiparametric results. The lowest income level is the average per capita disposable income in 2009 , and the highest ones are set to be 50000 Yuan (around 8000 USD). The projected results are reported in Table 3.3.

Table 3.3: Projections of Nutrition Transition in China at Different Income Levels

\begin{tabular}{|c|c|c|c|c|c|c|c|c|c|c|}
\hline Income & 8400 & 10000 & 15000 & 20000 & 25000 & 30000 & 35000 & 40000 & 45000 & 50000 \\
\hline Pkcal & 2244 & 2242 & 2275 & 2303 & 2312 & 2320 & 2329 & 2337 & 2343 & 2347 \\
\hline Protein & $12.69 \%$ & $12.76 \%$ & $12.91 \%$ & $12.99 \%$ & $13.04 \%$ & $13.08 \%$ & $13.11 \%$ & $13.14 \%$ & $13.17 \%$ & $13.19 \%$ \\
\hline Fat & $32.24 \%$ & $32.49 \%$ & $32.53 \%$ & $32.61 \%$ & $32.53 \%$ & $32.33 \%$ & $32.20 \%$ & $32.13 \%$ & $32.08 \%$ & $32.01 \%$ \\
\hline UnitV & 9.60 & 9.70 & 9.89 & 9.90 & 9.88 & 9.88 & 9.92 & 9.98 & 10.06 & 10.13 \\
\hline UnitVK & 4.89 & 4.94 & 5.07 & 5.14 & 5.17 & 5.20 & 5.22 & 5.24 & 5.26 & 5.28 \\
\hline Diversity & 17.02 & 17.11 & 17.34 & 17.58 & 17.68 & 17.79 & 17.93 & 18.06 & 18.18 & 18.28 \\
\hline UnitK & 2.02 & 2.02 & 2.01 & 2.00 & 1.99 & 1.98 & 1.97 & 1.97 & 1.97 & 1.97 \\
\hline BMI & 23.43 & 23.50 & 23.60 & 23.69 & 23.75 & 23.76 & 23.74 & 23.72 & 23.70 & 23.69 \\
\hline CS-Staple & $53.05 \%$ & $52.66 \%$ & $51.95 \%$ & $51.60 \%$ & $51.28 \%$ & $51.03 \%$ & $50.88 \%$ & $50.82 \%$ & $50.84 \%$ & $50.91 \%$ \\
\hline CS-Fruit & $1.22 \%$ & $1.25 \%$ & $1.44 \%$ & $1.52 \%$ & $1.58 \%$ & $1.67 \%$ & $1.76 \%$ & $1.84 \%$ & $1.90 \%$ & $1.95 \%$ \\
\hline CS-Meat & $11.84 \%$ & $11.93 \%$ & $12.21 \%$ & $12.23 \%$ & $12.02 \%$ & $11.97 \%$ & $12.06 \%$ & $12.17 \%$ & $12.25 \%$ & $12.30 \%$ \\
\hline CS-Dairy & $0.38 \%$ & $0.41 \%$ & $0.47 \%$ & $0.56 \%$ & $0.70 \%$ & $0.80 \%$ & $0.85 \%$ & $0.86 \%$ & $0.87 \%$ & $0.86 \%$ \\
\hline CS-Vegetable & $3.91 \%$ & $3.88 \%$ & $3.87 \%$ & $3.90 \%$ & $4.00 \%$ & $4.08 \%$ & $4.08 \%$ & $4.05 \%$ & $4.00 \%$ & $3.95 \%$ \\
\hline CS-Oil & $17.32 \%$ & $17.41 \%$ & $17.23 \%$ & $17.17 \%$ & $17.16 \%$ & $16.98 \%$ & $16.75 \%$ & $16.56 \%$ & $16.43 \%$ & $16.34 \%$ \\
\hline ES-Staple & $24.56 \%$ & $24.23 \%$ & $23.81 \%$ & $23.57 \%$ & $23.33 \%$ & $23.09 \%$ & $22.87 \%$ & $22.69 \%$ & $22.57 \%$ & $22.48 \%$ \\
\hline ES-Fruit & $3.27 \%$ & $3.34 \%$ & $3.60 \%$ & $3.73 \%$ & $3.79 \%$ & $3.84 \%$ & $3.88 \%$ & $3.93 \%$ & $3.96 \%$ & $3.99 \%$ \\
\hline ES-Meat & $26.02 \%$ & $26.33 \%$ & $26.84 \%$ & $26.70 \%$ & $26.25 \%$ & $26.14 \%$ & $26.42 \%$ & $26.79 \%$ & $27.12 \%$ & $27.36 \%$ \\
\hline ES-Dairy & $0.81 \%$ & $0.87 \%$ & $1.01 \%$ & $1.22 \%$ & $1.47 \%$ & $1.69 \%$ & $1.86 \%$ & $1.97 \%$ & $2.06 \%$ & $2.13 \%$ \\
\hline ES-Vegetable & $12.18 \%$ & $12.05 \%$ & $11.70 \%$ & $11.69 \%$ & $11.96 \%$ & $12.10 \%$ & $12.03 \%$ & $11.88 \%$ & $11.72 \%$ & $11.58 \%$ \\
\hline ES-Oil & $9.67 \%$ & $9.60 \%$ & $9.30 \%$ & $9.25 \%$ & $9.24 \%$ & $9.15 \%$ & $9.02 \%$ & $8.91 \%$ & $8.82 \%$ & $8.75 \%$ \\
\hline
\end{tabular}

In general, the estimated values for all indices are reasonable and several implications can be drawn as follow: First and foremost, nutrition transition will last for a long time but the changes will slow down. Second, calorie intake will continue going up in the future but the growth rate will decelerate. Third, protein will account for an increasing role in total calorie intake, while carbohydrate's role will decrease, and the share of energy obtained from fat will increase in the near future but tends to fall down in the long run. Fourth, people will care more about other attributes of food such as value 
and diversity rather than energy along with income growth, so that the unit values and diversity of food will keep increasing in the long run while the average calorie density of food will keep lowering. Fifth, we have an optimistic future for the obesity concern in China from our projection that the BMI will fall down in the long run. Sixth, the structure of diet will change slowly with income growth, and particularly staple food and edible oil will be replaced by high-value and more healthy food such as fruits and dairy, and an increasing demand for vegetables will be foreseeable in the long run, while meat consumption will follow an inverse U-shaped pattern.

Our projection is different from current literature in several ways: (1) The current studies (e.g. Guo et al., 2000; Popkin, 1999, 2002) find an increasing proportion of highfatted food such as meat and edible oil in diet in the past decades, while our projection show an inverse U-trend which indicates that the high-fatted food will be replaced by more healthy food in the long run. (2) The traditional Chinese diet that is mainly composed by staple food and vegetable will be replaced by western-style food that is high in saturated fat and sugar (Du et al., 2002; Gale and Huang, 2007; Guo et al., 2000; Popkin, 1993, 2001); however, the transition will slow down in the future and staple food will still contribute half of the total calorie intake even at very high income level (such as at 50000 yuan). (3) China experienced a blowout growth of obesity prevalence in the past years (e.g. Popkin, 2002, 2003), which raises a great concern about the diet-related diseases. But our projection is less pessimistic and indicates that obesity prevalence might drop in the long run due to the increasing consumption of low calorie density and healthy food. This suggests that China may be able to avoid the high burden caused by obesity prevalence in other countries such as USA and Mexico. This difference might be attributed to the variation in cooking culture between China and other countries.

\subsection{Conclusion}


The current literature mainly uses the parametric model to study nutrition transition, and only focuses on the relationship between calorie intake and income in a short run. However, nutrition transition might not be a linear function of income, and it might not be limited to calorie intake but also dietary change and epidemiological transition. This paper first proposes 10 different indices from different perspectives to reveal the nutrition improvement and dietary changes during nutrition transition. Then we present a brief discussion over the approaches used in studying nutrition transition, and conclude that neither a parametric model nor a full nonparametric model is appropriate in exploring the complex relationship between nutrition transition and income. Thus we introduce a semiparametric model, using locally polynomial smoothing to deal with the nonlinearity between nutrition transition and income and simultaneously control for other factors that might also have some impact on these indicators. Such a semi-parametric model can also be used for a long-run projection.

We further conducted a case study using three cohorts of CHNS data. The important findings include: First, multi-dimension indicators are needed to study nutrition transition from different perspectives since it is not limited to calories intake but also many other changes; Second, linear model is too restrictive to capture the complex relationship between nutrition transition and income growth for most indices; Third, staple food and vegetables will be replaced by fruits, meat and dairy products, but they will still play a prominent role in the diet in the long run; Fourth, people will value more about other attributes of food such as diversity and tastes rather than energy, thus the rising obesity concern might be not so pessimistic as we expected before; Fifth, the transition process will continue for a long time and the change will slow down.

Our paper contributes to the current literature from three perspectives: First, we introduce a semiparametric model, which has obvious advantages over parametric and 
full nonparametric models, to study nutrition transition; Second, we propose and compare 10 indices from different perspectives to capture the nutrition improvement and dietary change which deepen our understanding of nutrition transition; Third, we project the transition in the long run and show several new findings that are different with the findings in current literature. Our paper overcomes the limitations in the current literature whilst adding a new and increased level of depth to our understanding of nutrition transition from a more comprehensive perspective. 


\section{A Comparison of Gender Discrimination in}

\section{Rural and Urban China: The Engel's Method ${ }^{10}$}




\subsection{Introduction}

Gender discrimination has been of particular concern and a large volume of empirical studies have worked on this issue with different approaches (Deaton, 1989). However, it is still a controversial topic. Even in China, a country usually labeled as having strong discrimination against female, empirical results have not reached a consensus. On the one hand, the son preference in China has been confirmed by some literature from different perspectives. For instance, Knight and Song (1993) denote that men received more education than women in both rural and urban areas in China. Burgess and Wang (1995) show that households spend more than twice as much on health care on very young boys (0-4) as on very young girls in Sichuan. Yu and Sarri (1997) also argue that the opportunities in education and health status is unequal for females, and the gender-related development index of China is still quite low even compared with some middle-income countries such as Brazil and Malaysia. Furthermore, Graham et al. (1998) claim that girls are breastfed for a significantly shorter duration than boys in central China. Park and Rukumnuaykit (2004) use the nutrient intake as adult good in Deaton's method and find that fathers in rural China have a preference for sons and reduce their intake of nutrients more for additional boys. Song (2008) also argues that men sacrifice more for very young boys than for very young girls. According to the study of Qian (2008), increasing female income improves survival rates for girls, whereas increasing male income deteriorates survival rates for girls. Moreover, increasing female income increases educational attainment for all children, whereas increasing male income decreases educational attainment for girls and has no significant effects on boys' educational attainment in China. In addition, $\mathrm{Li}$ and $\mathrm{Wu}$ (2011) find that a woman with a first-born son has a 3.9 percentage greater power in household decision-making than a woman with a first-born daughter, and having a first-born son increases mother's role in household 
decision-making, especially in rural, one-child and low-income family. Moreover it also improves mother's nutrition intakes and reduces her likelihood of being underweight. All aforementioned studies find some evidence of gender discrimination against females in China.

However, there are also some studies that do not find significant discrimination against females in China. For instance, Lee (2008) uses Deaton's methodology (1987), which tests gender inequality by comparing the impacts of adding a boy and a girl on the expenditure on adult goods, does not find any strong evidence to support the hypothesis that boys are favored in rural China. Furthermore, Gong et al. (2005) also do not detect any strong evidence that boys are favored in rural China by using a flexible, partially linear specification.

The controversial conclusion regarding gender inequality could be attributed to several reasons. First, female is discriminated in some aspects, but may be compensated in other aspects (Lee, 2008), thus the measurement from different perspectives might lead to various results. Second, female and male have different demands and it is difficult to compare them. For instance, male may consume more alcohol and cigarette, while female often spend more money on cosmetic. Third, gender bias exists in some regions but not in others (Gibson and Rozelle, 2004). Fourth, female and male have different biologic characteristics. Given similar health care and other forms of attention, women tend to have a lower mortality rate than men (Sen, 1998), while men are generally taller than women. Therefore, biologic indicators might be misleading. Fifth, much of discrimination against girls has been removed for pre-birth in the form of sex-selective abortion, thus those girls that are born no longer face discrimination. Sixth, different approaches might lead to different results.

In general, three methods are commonly used in the current literatures to identify 
gender inequality: (1) Detecting the unequal distribution of resources such as food, nutrient, investment on education and medical care within household; (2) Using biologic indicators to identify gender bias, such as the anthropometric indicators (e.g., BMI, height, weight), mortality rate, morbility rate, gender ratio (or missing women); (3) Unequal opportunity and bargaining power for male and female, for instance, job discrimination, wage difference, unequal allocation of housework and bargaining power in household consumption decision. There are shortcomings and limitations of these three approaches. For instance, resource allocation within family is very difficult to measure comprehensively and accurately regarding the limited data and the difference in demand (Gibson and Rozelle, 2004). On the other hand, biologic indicators are easy to collect, but might be misleading since female and male have different biological characteristics. Moreover, serious measurement error can be expected because some reported data depend overwhelmingly on parental judgments (Lee, 2008). In addition, unequal opportunity and bargaining power might be partly caused by the gender difference rather than discrimination.

Regarding the difficulty in testing gender bias, Deaton (1987, 1989, 1997) proposes an alternative approach using only household expenditure data. As we know, most household survey only report total consumption for each family rather than each individual, thus we cannot compare consumption patterns between individuals directly. However, Deaton $(1987,1989,1997)$ develops a test to identify gender discrimination by comparing the outlay equivalent ratios of male and female, which is calculated by regressing the expenditure on adult goods on demographic ratios of specific age-gender cohort. This inferential method, which only uses standard household expenditure data, is attractive and widely used in empirical analysis since it overcomes the aforementioned shortcomings in other approaches. However, Deaton (1997) points out that it is very 
difficult to find goods that are consumed only by adults and children could also change the consumption pattern of the family rather than substitution effects. Therefore, it is necessary to develop a new approach which can avoid these limitations.

Different from Deaton's method, this paper goes back to the original idea of Deaton' methodology and uses the Engel's food share function, which is originally used to estimate the equivalent scale of families with varying compositions, to measure and test gender inequality. In the context of this method, Engel's index is a measure of family welfare and the key point of the method used in this article is to compare the compensations needed by families with the arrival of a new child with different genders, to restore to their original welfare level. We choose China, the largest developing country with a tradition of strong son preference, as our research objective. Using both linear Engel food share function and partial linear function, we shed some light on the gender inequality in China. Regarding the enormous difference in urban and rural China, we investigate the gender inequality in urban and rural region separately and try to show whether there is any regional difference. Furthermore, Sen (1998) argues that education has played a major part in improving the social status of female, thus we also analyze the effect of education on gender bias, to see whether education can help controlling the gender discrimination in China.

The rest of this paper is organized as follows: we first give a brief review of the reasons for son preference and the rising role of women in China. Then we will develop the methodology used in this paper, followed by an introduction of the data and empirical analysis. A brief conclusion is presented at the end of this paper.

\subsection{Background}

The son preference in China, which has a long history, could be traced back to the 
origins of ancestral worship in the second and third millennia B.C. (Lee and Wang, 1999). Bray (1997) further claims that the patrilocal and patrilineal familial systems developed during imperial state reinforced this preference. In this society, children are named with their father's last name, not mother's, thus, only male can continue the family name and carry the practice of ancestor worship (Ahn, 1994; Graham et al., 1998; Lee, 2008; Li and $\mathrm{Wu}, 2011)$. Women are merely biological reproducers for a lineage other than their lineage of birth, and men are the social reproducers who confer an identity to the newborn child (Gupta and Li, 1999). Furthermore, only sons and their wives are expected to live with sons' parents, while daughters are married out and become member of another family ( $\mathrm{Li}$ and $\mathrm{Wu}, 2011$ ), just like the old saying states "a married daughter is like spilling water on the ground". Girls' rights are transferred to the husband's family at the time of marriage, and their future productivity and services only belong to the husband's family, whatever her parents' needs may be (Gupta and Li, 1999). Therefore, only sons can take care of the old parents and offer financial support for them (Aha, 1994; Graham et al., 1998; Li and $\mathrm{Wu}, 2011)$.

In addition, on the economic ground, boys are favored because they can earn more money for the family. In rural area, men are thought to have a higher productivity in the heavy farm work and have more opportunity to find an off-farm job, and in the cities, female's wages are substantially lower than males with similar reason (Rozelle et al., 2002; Knight et al., 2010; $\mathrm{Li}$ and $\mathrm{Wu}, 2011)$. In another word, the higher expected value of boys provides economic incentives for parental preference for son ( $\mathrm{Li}$ and $\mathrm{Wu}, 2011)$. On the other hand, Knight et al. (2010) prove that parents in favor of son want to obtain more income in order to provide for the son in various ways, and the arrival of a son increases their incentive to engage in financial activities (Ding and Zhang, 2011; Wei and Zhang, 2011). 
Another issue we must mention regarding the gender discrimination in China is the family planning system. The limitation on the number of children that one couple can have deteriorated the status of girls in the family with strong son preference. Empirical results also confirm this notation. For instance, Graham et al. (1998) show that couples with only girls are more likely to have another child and the breastfeeding period of girls is shorter than boys'. Moreover, girls with elder sisters would have particularly shorter breastfeeding period compared with boys who have older sisters or brothers. The effect of policy intervention on gender bias can also be revealed by the huge number of missing women in China. Johansson and Nygren (1991) claim that the average number of missing girls is about 0.5 million each year from 1985 through 1987 in China. Sen (1998) denotes that there are about 48 million missing women in China in 1992. According to the study of Klasen and Wink (2002), the estimated number is 34.6 million in 1990 and 40.9 million in 2000. A recent study by Wei and Zhang (2011) also claims that men outnumber women at age 25 or below by about 30 million in China.

However, there are always two sides to a coin. The rising sex ratio imbalance caused by cultural factor, economic incentives, and political intervention exerts an increasing pressure on men in the marriage market that men are progressively more difficult to get married since there is a great shortage of women at marriage age (Wei and Zhang, 2011a, 2011b). On the one hand, household with a son are more likely to accept relatively dangerous or unpleasant jobs and save more money in order to improve their sons' relative attractiveness for marriage (Wei and Zhang, 2011a, 2011b). On the other hand, female become scare and their "economic value" are bidden up by the competition between males (Chu, 2001). Moreover, the increasing job opportunities available for females have raised the bargaining power of female (Lee, 2008), which further helps women to increasingly participate in decision-making in household resource allocation 
(Li and Wu, 2011). As Thomas (1990) argues, women usually have lower discrimination against girls, thus the allocation of household resource might be more equal after the involvement of female in the decision-making process. In addition, the female emancipation been inspired in the May $4^{\text {th }}$ movement and the egalitarian movement been launched during Mao's time challenges the son preference tradition and increases the status of women in the family (Leung, 2003; Shu, 2004). Furthermore, the rising prevalence of core family and improving pension system further weaken parents' dependence on their sons. After marriage, most new couple will no longer live with their parents, and cannot give much economic support to their parents. Moreover, they rely on their parents and need financial support from them to raise a baby or buy house, indicating a rising cost for raising sons.

In summary, the rapid change of cultural, economic, political and social factors and the interaction between them make the gender discrimination in China very complicated and ambiguous. There is a call for a study of gender inequality for China.

\subsection{Methodology}

Engel's food share method is one of the most straightforward and widely used approaches to construct the equivalent scales, which are used for welfare comparison between households with different structures (Deaton, 1997). Unlike other head counting indicators that are unable to deal with the variation resulting from age and the economies of scale in consumption, equivalent scales can convert the budgets of different household types to a needs-corrected basis (Deaton and Muellbauer, 1980). Therefore, comparing the welfare level of households with different size and composition become possible. In the Engel's framework, a large family needs a higher budget to be as well-off as the small one, and the cost of additional members in the large family can be measured by the total 
compensation in a food Engel curve.

The indentifying assumption of Engel's method is that the share of the budget devoted to food expenditure correctly indicates welfare between households of different demographic composition. It means a large household and a small household are equally well-off if, and only if, they spend the same fraction of total expenditure on food (Deaton, 1997). The reliability of this assumption further bases on two empirical evidence: the first is Engel's law, that the food share in the budget declines as income or total outlay increases; the second is that for households with the same income or total expenditure level, the food share is an increasing function of the number of children (Deaton and Muellbauer, 1980, 1986; Deaton, 1987, 1997). Therefore, the compensation required by a household to maintain their welfare level due to the additional child can be detected by the change in food share, which suggests a straightforward way to test gender inequality by comparing the marginal effects of an additional boy and girl on food share.

In empirical practice, we follow the studies of Deaton and Muellbauer (1986) and Deaton (1997), and write the Engel equation in Working (1943)-Leser (1963) form.

(4.1) $\quad w=\alpha+\beta \ln \left(\frac{x}{n}\right)+\sum_{j=1}^{J} \gamma_{j} n_{j}+\delta Z+\varepsilon$

Here $w$ is the food share, $x$ is the total expenditure, $n$ is the family size, $n_{j}$ is the number of person in category $j(j=1,2 \mathrm{~L} \mathrm{~L} J)$, and $Z$ denotes all other control variables. The marginal effect of an additional boy or girl on the food share is the corresponding coefficients of them.

We propose two different ways to identify gender inequality. First, we develop an intuitive index to measure gender inequality by comparing the equivalent scales of families with different compositions. Nicholson (1976) provides an example to show that 
the equivalent scale estimated in Engel's method is overestimated. He argues that the children's consumption patterns are different from their parents. In particular, children's consumption usually bias toward food, at least for very young children. As a result, restoration of the food share to its original level after the arrival of a child would cause overcompensation. However, if the consumption pattern of boys is similar to that of girls', we can still use the equivalent scales estimated by the Engel's methodology to proxy the gender inequality, because we only need to know the relative magnitude of these equivalent scales. In practice, we initially take the family with a childless couple (two adults) as the reference family, and the equivalent scale can be calculated from the coefficients estimated in the food Engel curve. As we aforementioned, other thing being equal, families with different demographic compositions have the same welfare levels if they have the same food shares. Therefore, the equivalent scale of a family with an additional boy (girl) can be calculated as follows:

$$
\begin{aligned}
& E S_{b}=\frac{x_{b}}{x_{0}}=\frac{3}{2} e^{\frac{\gamma_{b}}{-\beta}} \\
& E S_{g}=\frac{x_{g}}{x_{0}}=\frac{3}{2} e^{\frac{\gamma_{g}}{-\beta}}
\end{aligned}
$$

where $x_{b}\left(x_{g}\right)$ is the total outlay for the family with two adults and a boy (girl), $\gamma_{b}\left(\gamma_{g}\right)$ is the coefficient for boy (girl). The equivalent scale of families with an additional adult can be calculated similarly. We can further calculate the equivalent scale of a boy and a girl relative to a couple, which are $E S_{b}-1$ and $E S_{g}-1$ respectively. In order to deal with the potential economies of scale, we take the ratio of equivalent scales of an additional child to that of an additional adult.

To measure gender inequality, we use the ratio of the two equivalent scales to 
measure the "gender price" of a girl relative to a boy.

(4.3) $G P=\frac{E S_{g}-1}{E S_{b}-1}$

The lower the "gender price" GP, the stronger the gender inequality.

Second, we test gender inequality using a simple $\mathrm{t}$ test. The first method is straightforward and easy to calculated, but cannot tell us whether the gender inequality is statistically significant. Therefore, we propose a simple test to identify gender inequality by comparing the needed compensation to restore to the original welfare level caused by the new child, which can be detected by the marginal effects of an additional girl and boy on food share.

(4.4) $t=\frac{\gamma_{b}-\gamma_{g}}{\sqrt{\operatorname{Var}\left(\gamma_{b}-\gamma_{g}\right)}}$

The null hypothesis is that girls are discriminated, thus families with an additional boy need higher compensation than that with an additional girl to be as well off as before, indicating the marginal effect of boys should be greater than that of girls. Therefore, gender bias can be detected by a one-sided t test: if $\mathrm{t}$ test is statistically significant, gender discrimination against girls can be announced.

The linear function is easy to estimate, but too restrictive to model the complicate relationship between Engel index and income, and the results tend to be biased if the true relationship is nonlinear (Gong et al., 2005). In light of this, nonparametric models can capture this complex relationship more effectively, and is extremely useful when there is little a priori knowledge of the shape of the function to be estimated (Strauss \& Thomas, 1995). However, fully nonparametric estimators suffer from the curse of dimensionality: multidimensional spaces grow exponentially with the number of dimensions, requiring very large samples to estimate and difficult to visualize a regression surface in more than 
three dimensions (Fox, 2000; Gong et al., 2005; Meng et al., 2009). An alternative to avoid the bias in model specification and the curse of dimensionality is to use a semiparametric approach, which allows full flexibility of some variables and simultaneously control for other factors in a linear function. Therefore, the semiparametric approach, which control income in a nonparametric function and other factors in a parametric function as shown below, is specified in our paper because gender discrimination can still be identified by comparing the coefficients for specific age-gender cohorts.

$$
w=\alpha+F\left[\ln \left(\frac{x}{n}\right)\right]+\sum_{j=1}^{J} \gamma_{j} n_{j}+\delta Z+\varepsilon
$$

The semiparametric model presented above is a partial linear model, which includes an unknown income function and a linear function of demographic ratios and other control variables. In practice, two methods are commonly used to estimate the partial linear model: the conditional expectation method proposed by Robinson (1988) and the differencing method developed by Yatchew (1997, 1998). Robinson (1988) removes the nonparametric function by taking conditional expectations of each variable given $\ln \left(\frac{x}{n}\right)$ in equation (4.5), subtracting them on both sides of the equation. As a result, the nonparametric income function is cancelled out and we can estimate the model by an OLS. On the other hand, Yatchew (1997) removes the income function by taking difference. This study chooses Yatchew's method for its simplicity. To estimate this model, we follow the procedure developed by Yatchew (1997).

We first reorder all observations according to $\ln \left(\frac{x}{n}\right)$ and take the first order difference of all variables. 
$w_{n+1}-w_{n}=F\left[\ln \left(\frac{x}{n}\right)_{n+1}\right]-F\left[\ln \left(\frac{x}{n}\right)_{n}\right]+\sum_{j=1}^{J} \gamma_{j}\left(n_{j, n+1}-n_{j, n}\right)+\delta\left(Z_{n+1}-Z_{n}\right)+\varepsilon_{n+1}-\varepsilon_{n}$

Where $n$ denotes the order of observations. Because the observations are rearranged so that $\ln \left(\frac{x}{n}\right)_{1} \leq \ln \left(\frac{x}{n}\right)_{2} \leq \mathrm{LL} \ln \left(\frac{x}{n}\right)_{n}$. As sample size increases, $F\left[\ln \left(\frac{x}{n}\right)_{n}\right]$ is asymptotically equal to $F\left[\ln \left(\frac{x}{n}\right)_{n+1}\right]$ if the first derivative of $F\left[\ln \left(\frac{x}{n}\right)\right]$ is bounded (Yatchew, 1997). Therefore equation (4.6) can be rewritten as follows and estimated by OLS.

$$
\Delta w=\sum_{j=1}^{J} \gamma_{j} \Delta n_{j}+\delta \Delta Z+\Delta \varepsilon
$$

$\Delta$ denotes the first order differences. The estimated coefficients of demographic variables are then used to test gender bias in the similar way as in the linear function case.

Furthermore, Yatchew (1998) develops a simple test of the model specification by comparing the residual variance of the parametric model and the semiparametric model. The test procedure used in this paper is conducted as follows: first, conduct a regression of the linear model and save the average sum of squared residuals $\left(S_{\text {res }}^{2}\right)$; second, calculate the average sum of squared residuals for the semiparametric model $\left(S_{\text {diff }}^{2}\right)$ as shown in equation (4.8). The statistic is calculated as follows:

(4.8) $\quad V=\frac{\sqrt{N}\left(S_{\text {res }}^{2}-S_{\text {diff }}^{2}\right)}{S_{\text {diff }}^{2}}$

with $S_{\text {diff }}^{2}=\frac{\sum\left(\Delta \mathrm{w}_{\mathrm{i}}-\sum_{j=1}^{J} \gamma / g_{j} \Delta n_{j}-\delta / \Delta \mathrm{Z}\right)^{2}}{2 N}$. 
Yatchew $(1997,1998)$ shows that $V \sim N(0,1)$ under the null hypothesis that the parametric model is correctly specified. This allows us to perform a one-sided t test.

\subsection{Data}

The data used in this paper are taken from the China Health and Nutrition Survey (CHNS) 2004, 2006 and 2009. The sample consists of around 4000 households in each year by using a multi-stage, random cluster strategy for 9 provinces. The data provide us with very detailed consumption information and household structure which allow us to calculate the Engel's curve, and to compare the equivalence scale of a child for different genders respectively in rural and urban areas. Household food consumption data was collected for three consecutive days, which was randomly allocated from Monday to Sunday, and calculated by the changes in food inventory from the beginning to the end of this period. On the other hand, individual dietary intake data (24-h recall) away from home and at-home, and the number of meals eating at home for the same three consecutive days are also collected for all family members (Du et al., 2002; Popkin et al., 2002; Guo et al., 2000).

Food consumption, rather than individual dietary recall data, is used in our analysis for the following reasons. First, edible oil and condiments (salt, sugar, sauces, etc.), which also provide a lot of nutrients and are very important in Chinese cuisine, are only reported in household food consumption. Second, waste (e.g., spoiled rice, discarded cooked meals fed to pets or animals) is deducted from the change of food inventories to avoid the potential bias that rich families usually produce more waste, as is argued by Bouis and Haddad (1992), Bouis (1994) and Strauss and Thomas (1995, 1998). While food waste generated from eating away from home in individual dietary intake data, which is usually more common and severe, is not reported. Third, food fed to workers and 
guests at home is not reported in the survey, the real consumption of food could be lower than the reported change in food inventory for these households, and the nutrient intake would bias upward in this case (Bouis and Haddad, 1992). However, this food leakage is presumably not an important phenomenon, since most families in China serve their guests and workers in a restaurant, not at home. In addition, 24-hour recall may suffer more from random measurement errors because of day-to-day dietary variation, which is reduced in food consumption data by averaging the change in food inventory over three days (Strauss and Thomas, 1998). Thus, the change of the food inventory in our study is more reliable than the individual dietary recall data suggested by Bouis and Haddad (1992).

Finally, the food consumption data used in this paper is calculated as follows: We first calculate the changes in food inventory during the survey period; On the other hand, the number of meals eating at home for the same three consecutive days is also collected for all family members; Furthermore, different weights are assigned to three meals (breakfast, lunch and dinner) according to each person's dietary habit, which are further multiplied by the number of meals eaten at home during this period to calculate the total number of person-days. Food consumption per person per day is generated by dividing the household inventory change during these days by total number of person-days (Guo et al., 2000; Du et al., 2002; Popkin et al., 2002; Du et al., 2004).

Prices are only collected for 45 specific food and beverage products in each surveyed community, while more than 1500 different food products are reported in the household consumption. In this paper we follow McKelvey's method (2011) by using the price of one representative food product to stand for the price level in the corresponding food group, which implies little within food group price variation. In addition, both supermarket and free shop prices are collected, while only free shop prices are cleaned for these three years. Therefore we follow the suggestion of the research team and use the 
free shop prices as the price variable. Finally, food expenditure is not reported in the survey and we calculate it by multiplying the food consumption and price.

The income variable used in this paper is the generated per capita gross income in the survey, both market and nonmarket activities were accounted for (Du et al., 2004). We did not use the total expenditure, as suggested by Bouis and Haddad (1992), because the total expenditure data in this survey is not the living cost but the total operating cost in household business, farming, fishing, gardening, and livestock.

In total there are 12676 observations for the three cohorts of survey, but some observations with obvious measurement errors are excluded, such as those with Engel index greater than 1 . Finally, only 8837 observations (about $70 \%$ of the total sample) with food share less than 0.9 are used for analysis. Regarding the potential sample selection bias, we use Heckman (1979) procedure to detect it. The descriptive analysis of the data and variables are presented in Appendix 4.1.

\subsection{Empirical Results}

\subsubsection{Linear Model}

We first estimate the linear model as in equation (4.1). The empirical results are shown in the first two columns of Appendix 4.2. Sample selection bias is detected in both samples (presented in the bottom of the table). Therefore, we add the inverse Mill's ratio as an additional control variable in the OLS model.

We first use the straightforward index to measure gender inequality. We calculate the equivalent scales for three age cohorts, which are shown in Table 4.1. We begin with calculating the equivalent scale of children. To see how much one child is compared with one couple, we calculate the equivalent scale of each demographic cohort according to 
equation (4.2). The numbers are the estimated equivalent scale of a family of two adults plus one additional person of various ages and genders relative to that of a childless couple. In urban areas, for instance, a girl aged between 0 and 5 years is equivalent to $60.76 \%$ of a childless couple. The ratio drops to $52.17 \%$ for a girl aged 6 to 10 and further decrease to $50.00 \%$ for a girl aged 11 to 18 , implying that a teenage girl consumes the same resources as an adult.

However, the estimated equivalent scales are also influenced by the degree of economies of scale. In our sample, the third adult is $48.93 \%$ of the childless couple in urban areas; while in rural areas, the additional adult is about $52.43 \%$ of the reference pair. Two areas yield different economies of scale for an additional adult, suggesting the estimated equivalence scales for children might be biased. To eliminate the effect of economies of scale from equivalent scale, we further estimate the adjusted equivalent scale of child by taking the ratio of equivalent scales of an additional child to that of an additional adult.

Two conclusions can be drawn from the results: First, in urban region, household with an additional child need higher compensation to be as well-off as before, than that with an additional adult; while in rural region, the compensation for an additional child is smaller than that of an additional adult in most cases. Second, families with an older child need higher compensation than that with a younger child. However, in urban area, the corresponding compensation of an older girl is lower than their younger counterparts.

In order to measure the gender inequality, we calculate the gender price according to equation (4.3), which is shown in the lower part of Table 4.1. The calculations show that the required compensations for an additional girl are only around 70\%-97\% as that of an additional boy on average, with a highest value of 97.19\% (rural girls aged 6 to 10) and lowest value $70.12 \%$ (urban girls aged 11 to 18). The difference in inequality 
between urban and rural area is shown in the last column by the ratios of the gender prices in urban areas to that in rural areas. The results show that gender inequality in small child (0-5 years old) is more serious in rural area, while that of young child (6-10 years old) and teenage child (11-18 year old) are greater in urban region.

Table 4.1 Equivalent Scale and Gender Price in Linear Model-Before Adjustment

\begin{tabular}{lllll}
\hline \multirow{2}{*}{ Demography } & \multicolumn{2}{l}{ Equivalent Scale } & \multicolumn{2}{l}{ Adjusted Equivalent Scale } \\
\cline { 2 - 5 } & Urban & Rural & Urban & Rural \\
\hline Girl 0-5 & 1.6076 & 1.3820 & 1.2418 & 0.7285 \\
Girl 6-10 & 1.5217 & 1.4739 & 1.0662 & 0.9038 \\
Girl 11-18 & 1.5000 & 1.5191 & 1.0219 & 0.9901 \\
Boy 0-5 & 1.6308 & 1.4804 & 1.2892 & 0.9161 \\
Boy 6-10 & 1.6441 & 1.4876 & 1.3164 & 0.9300 \\
Boy 11-18 & 1.7131 & 1.6162 & 1.4574 & 1.1753 \\
Adult 19+ & 1.4893 & 1.5243 & 1.0000 & 1.0000 \\
\hline Gender Price & Urban & Rural & urban/rural & \\
\hline 0-5 years old & 0.9632 & 0.7952 & 1.2113 & \\
6-10 years old & 0.8099 & 0.9719 & 0.8333 & \\
11-18 years old & 0.7012 & 0.8424 & 0.8323 & \\
\hline
\end{tabular}

To further test the statistical significance of the gender inequality, we conduct the $\mathrm{t}$ test according to equation 4.4. The difference between marginal effects of boys and girls on food share, and the corresponding $\mathrm{t}$ tests are shown in Table 4.2. We find that boys always have larger marginal effect on food share than girls, implying higher compensation is needed for the arrival of a boy than the arrival of a girl. However, $t$ tests are only statistically significant for teenage child in urban area, while in rural region, significant discriminations against girls are found for both small and teenage children.

Table 4.2 Gender Inequality Test in Linear Model-Before Adjustment

\begin{tabular}{lllll}
\hline \multirow{2}{*}{ Gender Bias } & \multicolumn{2}{c}{ Marginal Effects } & \multicolumn{2}{c}{ t test (one-sided) } \\
\cline { 2 - 5 } & Urban & Rural & Urban & Rural \\
\hline 0-5 years old & 0.0030 & 0.0141 & 0.17 & $1.43^{*}$ \\
6-10 years old & 0.0162 & 0.0019 & 0.99 & 0.19 \\
11-18 years old & 0.0278 & 0.0127 & $2.48^{* * *}$ & $2.02^{* *}$ \\
\hline
\end{tabular}

Notes: $1 . *, * *, * * *$ denote significant level at $10 \%, 5 \%$ and $1 \%$ respectively.

2. Marginal effects are the difference between marginal effects of one additional boy and girl on food share. 
Two implications can be drawn from the results: first, some girls are still discriminated in China; second, gender discrimination in rural region is more severe than that in urban region. The results can be explained as follows: (1) The bargaining power and social status of female have been increased by the increasing work opportunities available for females (Lee, 2008), the enlightened egalitarian politics launched by the communist party, and the improvements in female education and women's legal rights on property, which further weakened the son preference tradition in China, particularly in urban China. In addition, the huge gender imbalance causes a severe shortage of women in the marriage market which further bids up the economic value of girl (Chu, 2001; Wei and Zhang, 2011a, 2011b). These changes improved the gender equality in China. (2) In rural China, male still have higher income than female since most of men work in nonfarm sectors which have higher salary than agriculture sector. Moreover, the rural pension system is much worse than the urban one and most old people still depend on their sons. Thus, boys are still favored in rural areas for their high economic value. On the other hand, raising a boy becomes more expensive in urban region due to the rising housing price and other living cost. Therefore, gender inequality still exists in China and is more severe in rural area.

Our results are consistent with the general impression that girls are somehow discriminated in China but contrary to the findings in studies of Lee (2008) and Gong et al. (2005), both of whom do not find sexual bias in rural China. We will further discuss the robustness of the results in the following section.

\subsubsection{Adjusting for The Difference in Requirement for Food}

We find that families with an additional boy always need higher compensation to restore to their original welfare level. However, this result might be distorted by the fact 
that boys and girls have different requirement for resource. To eliminate this effect, we calculate the ratio of energy requirements (RER) between boys and girls according to the estimation in FAO and use it as a proxy for the ratio of requirement for food between different genders, which is presented in Table 4.3.

Table 4.3 The Ratio of Energy Requirement (RER)

\begin{tabular}{llll}
\hline Age & $0-5$ & $6-10$ & $11-18$ \\
\hline RER (girl/boy) & 0.9189 & 0.9196 & 0.8844 \\
\hline
\end{tabular}

Note: RER refers the ratio of energy requirement of boys and girls, which is calculated from daily energy requirement for children and adults in FAO/WHO/UNU, 2001, pp. 26-27, pp. 48.

The numbers show that girls need less energy than boys at each age cohort. To show whether gender inequality still exist after taking into account the difference in requirement for food, we further multiply the RER with the number of girls at each age cohort, and use these modified numbers in the Engel food share function to replace the original ones. We conduct the same regression and present the results in column 3 and 4 in Appendix 4.2. The equivalent scales, gender price and inequality test are shown in Table 4.4. The results are almost the same with the one before adjustment, boys still have a higher marginal effect on food share than girls, implying families with new boys need higher compensation, but the $t$ test suggests that these differences are only statistically significant for teenage children in both rural and urban China and for small child in rural area. The implication is that discrimination against girls still exists in China, particularly in rural region.

Table 4.4 Equivalent Scale, Gender Price and Gender Inequality Test in Linear Model-After Adjustment

\begin{tabular}{lllll}
\hline \multirow{2}{*}{ Demography } & \multicolumn{2}{c}{ Equivalent Scale } & \multicolumn{2}{l}{ Adjusted Equivalent Scale } \\
\cline { 2 - 5 } & Urban & Rural & Urban & Rural \\
\hline Girl 0-5 & 1.6168 & 1.3719 & 1.2607 & 0.7093 \\
Girl 6-10 & 1.5238 & 1.4710 & 1.0706 & 0.8983 \\
Girl 11-18 & 1.4993 & 1.5236 & 1.0204 & 0.9986 \\
Boy 0-5 & 1.6308 & 1.4804 & 1.2892 & 0.9161
\end{tabular}




\begin{tabular}{|c|c|c|c|c|}
\hline Boy 6-10 & 1.6441 & 1.4876 & 1.3164 & 0.9300 \\
\hline Boy 11-18 & 1.7131 & 1.6162 & 1.4574 & 1.1753 \\
\hline Adult 19+ & 1.4893 & 1.5243 & 1.0000 & 1.0000 \\
\hline Gender Price & Urban & Rural & urban/rural & \\
\hline $0-5$ years old & 0.9779 & 0.7742 & 1.2631 & \\
\hline $6-10$ years old & 0.8133 & 0.9660 & 0.8419 & \\
\hline $11-18$ years old & 0.7002 & 0.8497 & 0.8241 & \\
\hline \multirow{2}{*}{ Gender Bias } & \multicolumn{2}{|c|}{ Marginal Effects } & \multicolumn{2}{|c|}{ t test (one-sided) } \\
\hline & Urban & Rural & Urban & Rural \\
\hline $0-5$ years old & 0.0018 & 0.0156 & 0.10 & $1.51 *$ \\
\hline 6-10 years old & 0.0159 & 0.0023 & 0.93 & 0.23 \\
\hline 11-18 years old & 0.0279 & 0.0121 & $2.25 * *$ & $1.74 * *$ \\
\hline
\end{tabular}

Notes: $1 . *, * *, * * *$ denote significant level at $10 \%, 5 \%$ and $1 \%$ respectively.

2. Marginal effects are the difference between marginal effects of one additional boy and girl on food share.

\subsubsection{Partial Linear Model}

If the Engel function is mis-specified, the results might be biased and misleading. To further check the robustness of the results in the linear function, we use the aforementioned partial linear model. Following Yatchew (1997), we first reorder all observations according to per capita income and take the first difference to remove the income function, then we use OLS to estimate the coefficients for demographic ratios in equation 4.7. The original results are shown in the right half of Appendix B, and the model specification tests are presented in Table 4.5.

Table 4.5 Model Specification Test in Original Model

\begin{tabular}{lllll}
\hline & \multicolumn{2}{c}{ Before Adjustment } & \multicolumn{2}{c}{ After Adjustment } \\
\hline Region & Urban & Rural & Urban & Rural \\
\hline t test (one-sided) & $5.59 * * *$ & $7.00 * * *$ & $5.59 * * *$ & $7.00 * * *$ \\
\hline Note: ${ }^{* *}, * * *$ denote significant level at $10 \%, 5 \%$ and $1 \%$ & respectively.
\end{tabular}

We find that linear function is rejected for all samples. Therefore, we need to use a more flexible functional form, the partial linear model to retest the results. The gender bias test is presented in Table 4.6. Similar with the results in the linear model, gender inequality is found in both rural and urban regions regardless of the adjustment of the 
difference in the requirement for food. The differences are statistically significant for all age cohorts in rural areas and only the teenage cohort in urban areas.

Table 4.6 Gender Inequality Test in Partial Linear Model

\begin{tabular}{llllllllll}
\hline \multirow{3}{*}{ Age Cohort } & \multicolumn{2}{l}{ Before Adjustment } & \multicolumn{5}{l}{ After Adjustment } \\
\cline { 2 - 9 } & $\begin{array}{l}\text { Marginal } \\
\text { Effects }\end{array}$ & & t test (one-sided) & Marginal Effect & t test (one-sided) \\
\cline { 2 - 10 } & Urban & Rural & Urban & Rural & Urban & Rural & Urban & Rural \\
\hline 0-5 years old & -0.0034 & 0.0190 & -0.15 & $1.52^{*}$ & -0.0045 & 0.0217 & -0.20 & $1.66^{* *}$ \\
6-10 years old & 0.0005 & 0.0150 & 0.03 & 1.24 & -0.0008 & 0.0166 & -0.04 & $1.30^{*}$ \\
11-18 years old & 0.0210 & 0.0198 & $1.53^{*}$ & $2.50^{* * *}$ & 0.0197 & 0.0202 & $1.30^{*}$ & $2.31^{* *}$ \\
\hline
\end{tabular}

Notes: $1 . *, * *, * * *$ denote significant level at $10 \%, 5 \%$ and $1 \%$ respectively.

2. Marginal effects are the difference between marginal effects of one additional boy and girl on food share.

\subsubsection{Education and Gender Discrimination}

It is known that parent's education level might have some impact on the gender inequality for children, because well-educated people might be more open-minded and less stuck by the son-preference tradition, and usually have more decent jobs that provide endowment insurance. Therefore, they may have less psychological and economic incentives to discriminate against girls. To test whether this hypothesis is true, we can extend the Engel food share model by adding interaction term of education and demographic variables. We start from a linear model as follows:

$$
w=\alpha+\beta \ln \left(\frac{x}{n}\right)+\sum_{j=1}^{J} \gamma_{j} n_{j}+\sum_{j=1}^{J} \alpha_{j}\left(n_{j} * e d u\right)+\delta Z+\varepsilon
$$

Here $e d u$ is the education level of household head. The marginal effects of one additional boy and girl on the food share are $M E_{b}=\gamma_{b}+\alpha_{b} * e d u$ and $M E_{g}=\gamma_{g}+\alpha_{g} * e d u$, respectively. Both of them are a linear function of education, implying the gender bias, which is indicated by the difference of the marginal effects of boys and girls at the same age cohort on food share, is also a linear function of education. 


$$
M E_{b}-M E_{g}=\gamma_{b}-\gamma_{g}+\left(\alpha_{b}-\alpha_{g}\right) * e d u
$$

Therefore, the impact of education on gender bias can be detected by testing the significance of $\alpha_{b}-\alpha_{g}$. In the case $\alpha_{b}-\alpha_{g}$ is significantly negative, gender inequality can be eased by improving education. In order to test the statistical significance of gender inequality, we develop a similar $\mathrm{t}$ test as follows:

$$
\text { (4.11) } t=\frac{M E_{b}-M E_{g}}{\sqrt{\operatorname{Var}\left(M E_{b}-M E_{g}\right)}}
$$

The model specification test is the same as the one we used before.

Appendix 4.3 presents the original results of the extended model, and Table 4.7 shows the gender price in extended linear model. Consistent with the results in the original model, Table 4.7 shows that families with an additional boy still need higher compensation to keep their welfare level unchanged. Implying girls might be discriminated in China.

Table 4.7 Gender Price in Extended Linear Model

\begin{tabular}{lllllll}
\hline Model & \multicolumn{2}{c}{ Before Adjustment } & \multicolumn{3}{c}{ After Adjustment } \\
\hline Gender Price & Urban & Rural & urban/rural & Urban & Rural & urban/rural \\
\hline 0-5 years old & 0.9276 & 0.7926 & 1.1704 & 0.9430 & 0.7696 & 1.2252 \\
6-10 years old & 0.8066 & 0.9360 & 0.8617 & 0.8066 & 0.9340 & 0.8636 \\
11-18 years old & 0.7297 & 0.8494 & 0.8591 & 0.7266 & 0.8513 & 0.8536 \\
\hline
\end{tabular}

To test whether this gender inequality is statistically significant, we conduct the similar $t$ test and present the results in the upper half of Table 4.9. The results are consistent with that in original model, that gender bias still exist in some age cohort and rural region has stronger discrimination against girls than urban area. Similarly, to check the robustness of the results, we also develop a partial linear model similar to the one in equation 4.6 as follows: 
$w_{n+1}-w_{n}=F\left[\ln \left(\frac{x}{n}\right)_{n+1}\right]-F\left[\ln \left(\frac{x}{n}\right)_{n}\right]+\sum_{j=1}^{J} \gamma_{j}\left(n_{j, n+1}-n_{j, n}\right)+\sum_{j=1}^{J} \alpha_{j}\left(n_{j, n+1} * e d u-n_{j, n} * e d u\right)+\delta\left(Z_{n+1}-Z_{n}\right)+\varepsilon_{n+1}-\varepsilon_{n}$

We adopt the same procedure in empirical analysis as that described in section 4.5.2. The model specification test is presented in Table 4.8. Unfortunately, linear specification is rejected in all samples. Thus, we need to retest the aforementioned findings.

Table 4.8 Model Specification Test in Extended Model

\begin{tabular}{|c|c|c|c|c|}
\hline & \multicolumn{2}{|c|}{ Before Adjustment } & \multicolumn{2}{|c|}{ After Adjustment } \\
\hline Region & Urban & Rural & Urban & Rural \\
\hline t test (one-sided) & $5.32 *$ & $7.50 * * *$ & $5.32 *$ & $7.50 * * *$ \\
\hline
\end{tabular}

We first look at the difference between marginal effects of boys and girls and the corresponding $\mathrm{t}$ tests in the lower half of Table 4.9.

Table 4.9 Gender Inequality Test in Extended Model

\begin{tabular}{lllllllll}
\hline Model & \multicolumn{4}{l}{ Before Adjustment } & \multicolumn{7}{l}{ After Adjustment } \\
\hline \multirow{2}{*}{ Linear Model } & \multicolumn{2}{l}{ Marginal Effects } & $\mathrm{t}$ test (one-sided) & Marginal Effects & $\mathrm{t}$ test (one-sided) \\
\cline { 2 - 9 } & Urban & Rural & Urban & Rural & Urban & Rural & Urban & Rural \\
\hline 0-5 years old & 0.0098 & 0.0236 & 0.47 & $2.08^{* *}$ & 0.0089 & 0.0259 & 0.41 & $2.18^{* *}$ \\
6-10 years old & 0.0064 & 0.0085 & 0.34 & 0.75 & 0.0055 & 0.0098 & 0.28 & 0.83 \\
11-18 years old & 0.0283 & 0.0136 & $2.23^{* *}$ & $1.90^{* *}$ & 0.0283 & 0.0141 & $2.01^{* *}$ & $1.78^{* *}$ \\
\hline \multirow{2}{*}{ Partial Linear Model } & \multicolumn{2}{l}{ Marginal Effects } & $\mathrm{t}$ test (one-sided) & Marginal Effects & $\mathrm{t}$ test (one-sided) \\
\cline { 2 - 9 } & Urban & Rural & Urban & Rural & Urban & Rural & Urban & Rural \\
\hline 0-5 years old & 0.0058 & 0.0143 & 0.32 & $1.44^{*}$ & 0.0045 & 0.0160 & 0.24 & $1.53^{*}$ \\
6-10 years old & 0.0167 & 0.0046 & 1.02 & 0.47 & 0.0167 & 0.0048 & 0.97 & 0.46 \\
11-18 years old & 0.0250 & 0.0122 & $2.23^{* *}$ & $1.94^{* *}$ & 0.0253 & 0.0120 & $2.04 * *$ & $1.73^{* *}$ \\
\hline
\end{tabular}

Notes: $1 . *, * *, * *$ denote significant level at $10 \%, 5 \%$ and $1 \%$ respectively.

2. Marginal effects are the difference between marginal effects of one additional boy and girl on food share.

Consistent with the results in the original model, we find that boys always have a larger marginal effect on food share than girls, but this difference is only statistically significant in some cases. In particular, teenage girls who are supposed to get secondary 
education are discriminated in both regions. This significant gender bias might be attributable to the slightly higher return to education for male (Chen and Hamori, 2009), which is also consistent with the studies of Qian (2008), Gong et al. (2005), Song (2000), Yu and Sarri (1997), and Burgess and Zhuang (1999) that female children have lower opportunity to get education. In addition, small girls are also discriminated in rural area, implying a pre-school gender bias.

The impact of education on gender inequality is shown in Table 4.10. We do not find any evidence that education has a significant negative impact on gender inequality, implying that well educated household head not necessarily has lower discrimination against girls. It is plausible that the popularization of education have eliminated the link between parents' education and gender inequality.

Table 4.10 Education Effect

\begin{tabular}{lllllllll}
\hline \multirow{2}{*}{ Education Effect } & \multicolumn{3}{l}{ Linear Model } & \multicolumn{5}{l}{ Partial Linear Model } \\
\cline { 2 - 9 } & \multicolumn{2}{l}{ Before Adjustment } & \multicolumn{2}{l}{ After Adjustment } & Before Adjustment & \multicolumn{2}{c}{ After Adjustment } \\
\cline { 2 - 9 } & Urban & Rural & Urban & Rural & Urban & Rural & Urban & Rural \\
\hline 0-5 years old & -0.99 & -0.49 & -1.07 & -0.50 & -0.79 & -0.22 & -0.84 & -0.24 \\
6-10 years old & 0.05 & 1.00 & 0.05 & 0.99 & -0.15 & 1.15 & -0.13 & 1.13 \\
$11-18$ years old & 0.49 & 0.56 & 0.52 & 0.56 & 0.83 & 0.05 & 0.82 & 0.04 \\
\hline
\end{tabular}

Note: *,**,** denote significant level at $10 \%, 5 \%$ and $1 \%$ respectively.

Therefore, we can make a conclusion that there is some evidence of discrimination against girls in China, but no evidence shows that education helps to reduce gender inequality.

\subsection{Conclusion}

Gender discrimination is a controversial topic in the world and a large volume of literature has already worked on that from different perspectives. However, it is still difficult to draw a conclusion since female being discriminated in one aspect can be 
compensated in other aspects. In this paper, following the studies of Engel (1895) and Deaton $(1987,1989,1997)$, we develop an alternative approach to measure and test gender inequality by comparing the compensation required by households to maintain their welfare levels after the arrival of a new boy and girl. We choose China, a country with a long history of son preference, as our research target. Moreover, we compare the gender inequality in urban and rural regions and extend the original Engel model to shed some light on the impact of education of household head on gender inequality by adding interaction terms of education and demographic variables. Furthermore, we adopt a semiparametric model which allows fully flexibility for the function form of income and simultaneously control other factors to check the robustness of the results. We find families with a new boy usually need higher compensation to be as well off as before but this difference is only statistically significant for teenage child in China and small child in rural area. Moreover, we do not find any evidence that education can help to reduce the gender inequality. One possible explanation is that the rapid popularization of education decreases the inequality in education, which further weakens the link between parent's education and attitude toward girls.

Therefore, two major conclusions can be made from this study. First, gender inequality still exists in China. Particularly, rural girls are more likely to be discriminated than their urban counterparts. Second, no evidence supports that education plays a role in eliminating gender inequality in China. Thus, further research should pay attention to the determinants of the improving gender bias. 
5 Overall Conclusion 


\subsection{Conclusions from Empirical Studies}

During the past three decades China's successful economic development has attracted a great deal of attention. One body of literature has already tried to explore the driving force behind this economic miracle and corresponding changes in other aspects. However, empirical studies reveal a number of controversies on many topics, such as how much economic growth can be accounted for by technological progress, how nutrition transition coincides with income growth, and whether girls are still discriminated against after the rapid economic growth and associated social and institutional changes. This dissertation seeks to shed some light on these issues in three case studies.

To clarify the contribution share of technological progress to economic growth, this dissertation originally conducts a meta-analysis by collecting more than 5000 estimates from 150 primary studies. Results indicate that $24 \%$ of economic growth in China during the reform period can be attributed to TFP growth, which is neither too high nor too low compared with other examples in the current literature. Moreover, we also find three circles for TFPG after 1978 and each one lasts about ten years. Furthermore, we look specifically at the determinants of TFPG heterogeneity and find that both methodological factors (language of paper, peer-review process) and factual factors (regions, sectors, period) have an impact on TFPG estimation. This research contributes to the current literatures by providing a systematic and quantitative analysis on the heterogeneity of TFPG.

Rapid economic growth is usually accompanied by a dietary shift from staple food to high-fat food stuff such as meat and fish and processed food. The changes in food consumption and its corresponding outcomes in health are termed as nutrition transition. Current literature in this field mainly focuses on calorie elasticity with respect to income 
or expenditure using a parametric approach. However, nutrition transition is not limited to calorie intake and might not be a linear function of income. Therefore, this dissertation adopts a semi-parametric approach to revisit the undergoing nutrition transition in China using 10 indicators from different perspectives. We found that linear model is too restrictive to capture the complex relationship between nutrition transition and income for most indices. In particular, our results show that Chinese consumers are shifting from staple food to high-value food such as meat, fruit and dairy products, but staple food will still play a prominent role in Chinese diet in the future. Furthermore, we project the nutrition transition in the long run using the method developed in this dissertation. The projection shows that people care more about other attributes of the food rather than calorie at higher income levels, and shift to healthy food such as fruit, vegetables and diary products. Meanwhile, the demand for food with high-calorie density such as meat will decline in the long run while that for food diversity will increase. Our study helps the reader to understand nutrition transition from a deeper and more comprehensive perspective.

Economic development also changes the attitude toward girls in China. Inspired by the changing nature of food consumption and the pioneering work of Engel and Deaton, this dissertation provides an alternative to investigate the gender inequality from the perspective of food consumption. Using Engel's index (food share in total expenditure) to proxy household welfare level, we identify gender discrimination against girls by comparing the compensation needed by families with a new boy and girl to maintain their original welfare level. Gender bias is measured in two ways: first, comparing the compensation caused by the arrival of a new boy and girl; second, test the difference between boy's and girl's marginal effect on food share. We do find that small girls in rural area and teenage girls are discriminated. To test the robustness of the results, we 
also adopt a semi-parametric model which allows full flexibility for the function form of income and simultaneously controls other factors in a linear function. In general, the results are consistent. It is plausible that gender inequality has been weakened due to the decreasing demand for help from children after retirement, the increasing economic and social status of women, as well as the shortage of women in the marriage market. However, these changes cannot fully offset the traditional son preference. Moreover, we also test the impact of household head's education on gender inequality. There is no significant evidence to show that education level of household head can change the attitudes toward girls.

Taking the findings from three case studies, we establish an overall picture of the driving force of economic growth and the corresponding influence on nutrition transition and gender inequality.

First, moderate technological progress and soaring inputs lead to the economic miracle which began occurring in China after 1978. According to the estimation in section two, TFPG and an increase in inputs contribute one quarter and three quarters respectively to economic growth in China after the reform. However, the contribution share might differ across sectors, regions and periods, because the TFPG varies in different sectors and changes over time and regions. Particularly, TFPG in eastern China is higher than that in western and central regions, and the manufacturing sector has the highest rate of technological progress.

Second, rapid income growth speeds up the nutrition transition in a nonlinear way and people tend to consume more animal products and more calories after their income increases, which results in a higher weight to height ratio. However, once people are relieved from poverty, they may tend to care more about other attributes of food such as diversity, value, health, and variety rather than calorie. Thus, the consumption of meat 
will decrease in the long run while the demand for fruit, dairy products, and vegetables will increase and they will play a more important role in the diet.

Third, economic development also reduces the discrimination against girls in China. As discussed in the introduction, remarkable economic development significantly increases income, which strengthens parents' ability to take care of themselves after retirement, and would reduce the incentive for a family to raise a boy for old time. Moreover, increasing job opportunities and salary for females due to economic development also improve women's bargaining power in the household, particularly in urban area. In addition, economic development also changes the tradition of preference for sons. All these changes caused by economic development, as well as the huge shortage of females in the marriage market, jointly decreased gender discrimination against girls in China. However, these changes cannot fully offset the strong son preference. Thus, discrimination against girl still exists for some age cohorts, particularly in rural area.

\subsection{Policy Implications}

General policy implications and research commendations can be drawn from these findings.

First, China's economic success after the reform is jointly driven by technological progress and soaring input uses, which account for one quarter and three quarters of the growth respectively. In particular, East China and the manufacturing sector enjoy the highest TFP growth. Policies aimed at maintaining sustainable economic growth and narrowing the income gap between regions should try to encourage the flow of capital and labor from the east to the central and west, and eliminate the barriers that prevent technology spillover regarding the fact that the western and central regions lag far behind 
the eastern region in terms of TFPG. Other developing and transition countries that are catching up with rich ones should realize the importance of input accumulation as well as technological progress in economic development.

Second, nutrition transition will not change monotonically with income growth and the process will slow down in the future. For the very poor families that might still suffer from hunger, income growth will lead to an increase in the consumption of cheap and high calorie-density food such as staple food. Once people are relieved from hunger and poverty, they care more about other attributes of food such as diversity, taste, variety, and appearance rather than calorie content. As a result, high-value food such as meat and fruit will gradually replace staple food and play an increasingly important role in the diet. Finally, at higher income levels, rich people tend to care more and more about their health and prefer a healthy diet, consisting of food such as vegetables and dairy products, while the demand for meat will drop. Therefore, policy makers whose interests are eliminating hunger and improving the nutrition status of citizens should consider designing separate policies for different income groups. Particularly in the case of rich people, more direct nutrition intervention such as biofortification must be implemented to eradicate micronutrient deficiency. Further research should investigate whether the status of micronutrients will change in line with income and ways of eliminating the micronutrient deficiency in an effective way.

Third, economic development might play a central role on eliminating gender inequality. Successful economic development increases the economic and social status of females by providing more job opportunities and higher bargaining power in the household resources allocation. Increasing income and improvement in social pension insurance system decrease the incentive to raise boy for old time. These changes contribute to reduce discrimination against females. Feminists fighting to bring an end to 
gender discrimination should pay more attention to the role of economic development. However, we still find some evidence of discrimination against girls in China, particularly in rural area. Therefore, it is plausible that the son preference is so strong that the social and economic changes in the past decades cannot fully offset its effect. Future research should try to find more effective ways to fight against gender discrimination. 
References 
Abdullah, M. (1989). The Effect of Seasonality on Intra-Household Food Distribution and Nutrition in Bangladesh. In: D. Sahn (ed.) Seasonal Variability in Third World Agriculture: The Consequence for Food Security. Baltimore, Maryland: Johns Hopkins University Press.

Ahn, N. (1994). Effects of the One-child Family Policy on Second and Third Births in Hebei, Shaanxi and Shanghai. Journal of Population Economics, 7: 63-78.

Alston, J. M., M. C. Marra, P. G. Pardey and T. J. Wyatt (2000). Research Returns Redux: A Meta-Analysis of the Returns to Agricultural R\&D. Australian Journal of Agricultural and Resource Economics, 44(2): 185-215.

Aromolaran, A. B. (2004). Household Income, Women's Income Share and Food Calorie Intake in South Western Nigeria. Food Policy, 29: 507-530.

Behrman, J. R., A. D. Foster and M. R. Rosenzweig (1997). The Dynamics of Agricultural Production and the Calorie-Income Relationship: Evidence from Pakistan. Journal of Econometrics, 77: 187-207.

Behrman, J.R. and A. B. Deolalikar (1987). Will Developing Country Nutrition Improve with Income-A Case Study for Rural South India. Journal of Political Economics, 95 (3): $492-507$.

Behrman, J.R. and A. B. Deolalikar (1988). Health and Nutrition. In: Chenery, H. and T. N. Srinivasan (eds.). Handbook of Development Economics. Amsterdam, Holland: North-Holland.

Behrman, J.R. and A. B. Deolalikar (1990). The Intrahousehold Demand for Nutrition in Rural South India: Individual Estimates, Fixed effects, and Permanent Income. Journal of Human Resources, 25: 655-696.

Bhalotra, S. and C. Attfield (1998). Intrahousehold Resource Allocation in Rural Pakistan: A Semi-parametric Analysis. Journal of Applied Econometrics, 13: 463-480.

Borensztein, E. and J. D. Ostry (1996). Accounting for China's Growth Performance. American Economic Review, 86(2): 224-228. Papers and Proceedings of theHundredth and Eighth Annual Meeting of the American Economic Association San Francisco,CA.

Bosworth, B. and S. M. Collins (2008). Accounting for Growth: Comparing China and India. Journal of Economic Perspectives, 22(1): 45-66. 
Bouis, E. H. (1994). The Effect of Income on Demand for Food in Poor Countries: Are Our Food Consumption Databases Giving Us Reliable Estimates. Journal of Development Economics, 44 (1): 199-226.

Bouis, E. H. and L. J. Haddad (1992). Are Estimates of Calorie-income Elasticities too High?-A Recalibration of the Plausible Range. Journal of Development Economics, 39 (2): 333-364.

Brandt, L., J. Van Biesebroeck and Y. Zhang (2011). Creative Accounting or Creative Destruction? Firm-level Productivity Growth in Chinese Manufacturing. Journal of Development Economics, 30: 1-13.

Bray, F. (1997). Technology and Gender: Fabrics of Power in Late Imperial China. University of California Press, Berkeley, California.

Bruemmer, B., T. Glauben and W. Lu (2006). Policy Reform and Productivity Change in Chinese Agriculture: A Distance Function Approach. Journal of Development Economics, 81: 61-79.

Burgess, R. and P. P. Wang (1995). Chinese Rural Household Expenditure Analysis. In. London School of Economics, vol. 13. Suntory-Toyota International Centre for Economics and Related Disciplines.

Cai, F. and D. Wang (1999). The Sustainability of China's Economic Growth and Contribution of Labour to Economy. Economic Research Journal, 10: 62-68. (In Chinese)

Card, D. and A. B. Krueger (1995). Time Series Minimum-wage Studies: A MetaAnalysis. American Economic Review, Papers and Proceedings of the Hundredth and Seventh Annual Meeting of the American Economic Association Washington, DC, 85(2): 238-243.

Chen, B. and Y. Feng (2000). Determinants of Economic Growth in China: Private Enterprise, Education and Openness. China Economic Review, 11: 1-15.

Chen, E. K. Y. (1997). The Total Factor Productivity Debates: Determinants of Economic Growth in East Asian. Asian-Pacific Economic Literature, 11(1): 18-38.

Chow, G. C. (1993). Capital Formation and Economic Growth in China. Quarterly Journal of Economics, 108(3): 809-842. 
Chow, G. C. and K. Li (2002). China's Economic Growth: 1952-2010. Economic Development and Cultural Change, 51(1): 247-256.

Christensen, P. (2003). Topics in Meta-Analysis: A Literature Survey. Institute of Transport Economics, Oslo.

Chu, J. (2001). Prenatal Sex Determination and Sex-Selective Abortion in Rural Central China. Population and Development Review, 27(1): 259-281.

Coelli, T. J. and D.S. P. Rao (2005). Total Factor Productivity Growth in Agriculture: A Malmquist Index Analysis of 93 Countries: 1980-2000. Agricultural Economics, 32(supplement s1): 115-134.

Dawson, P. J. (1997). The Demand for Calories in Developing Countries. Oxford Development Studies, 25: 361-369.

Dawson, P. J. and R. Tiffin (1998). Estimating the Demand for Calories in India. American Journal of Agricultural Economics, 80: 474-481.

Deaton, A. (1987). The Allocation of Goods within the Household: Adults, Children, and Gender. In: Living Standards Measurement Study Working Paper. vol. 39. World Bank Development Research Department, Washington, D.C..

Deaton, A. (1989). Looking for Boy-girl Discrimination in Household Expenditure Data. World Bank Economic Review, 3(1): 1-15.

Deaton, A. (1997). The Analysis of Household Surveys: A Microeconometric Approach to Development Policy. Baltimore, MD: John Hopkins University Press.

Deaton, A. and J. Muellbauer (1980). Economics and Consumer Behaviour. New York: Cambridge University Press.

Deaton, A. and J. Muellbauer (1986). On Measuring Child Costs: with Applications to Poor Countries. Journal of Political Economy, 94(4): 720-744.

Dekle, R. and G. Vandenbroucke (2010). Whither Chinese growth? A Sectoral Growth Accounting Approach. Review of Development Economics, 14(3): 487-498.

Diewert, W. E. (1980). Aggregation Problems in the Measurement of Capital. In D. Usher, The Measurement of Capital (pp. 433-538). London: University of Chicago Press.

Diewert, W. E. and A. O. Nakamura (2007). The Measurement of Productivity for Nations. In J. J. Heckman and E. E. Leamer, Handbook of Econometrics (pp. 
4502-4586), Netherlands: North Holland.

Ding, W. and Y. Zhang (2011). When A Son Is Born: The Impact of Fertility Patterns on Family Finance in Rural China. Working paper.

Drewnowski, A. and B. M. Popkin (1997). The Nutrition Transition New Trends in the Global Diet. Nutrition Reviews, 55 (2): 31-43.

Du, S., B. Lu, F. Zhai and B. M. Popkin (2002). A New Stage of the Nutrition Transition in China. Public Health Nutrition, 5 (1A): 169-174.

Du, S., T. A. Mroz, F. Zhai, B. M. Popkin (2004). Rapid Income Growth Adversely Affects Diet Quality in China--Particularly for the Poor! Social Science Medicine, 59(7): 1505-1515.

Engel, E. (1895). Die Lebenkosten Beligischer Arbeiter-Familien Fruher und Jetzt. International Statistics, 1: 1-74.

Ezaki, M. and L. Sun (1999). Growth Accounting in China for National, Regional, and provincial economies: 1981-1995. Asian Economic Journal, 13(1): 39-71.

Fan, J., T. Gasser, I. Gijbels, M. Brockmann and J. Engel (1997). Local Polynomial Regression: Optimal Kernels and Asymptotic Minimax Efficiency. Annals of the Institute of Statistical Mathematics, 49(1): 79-99.

Fan, S. (1997). Production and Productivity Growth in Chinese Agriculture: New Measurement and Evidence. Food Policy, 22(3): 213-228.

FAO (2001). Human Energy Requirements. Report of a Joint FAO/WHO/UNU Expert Consultation, Rome.

Felipe, J. (1999). Total Factor Productivity Growth in East Asia: A Critical Survey. Journal of Development Studies, 35(4): 1-41.

Fleisher, B. M. and X. Wang (2004). Skill Differentials, Return to Schooling, and Market Segmentation in A Transition Economy: The Case of Mainland China. Journal of Development Economics, 73: 315-328.

Fleisher, B. M. and X. Wang (2005). Returns to Schooling in China under Planning and Reform. Journal of Comparative Economics, 33: 265-277.

Fleisher, B. M., H. Li and M. Q. Zhao (2010). Human Capital, Economic Growth, and Regional Inequality in China. Journal of Development Economics, 92: 215-231. 
Fleisher, B. M., Y. Hu, H. Li and S. Kim (2010). Economic Transition, Higher Education and Worker Productivity in China. Journal of Development Economics, 94: 86-94.

Fox, J. (2000). Nonparametric Simple Regression: Smoothing Scatterplots. CA: Sage, Thousand Oaks.

Fu, X., S. Zhu and Y. Gong (2009). Knowledge Capital, Endogenous Growth and Regional Disparities in Productivity: Multi-level Evidences from China. PTWD Working Paper No. 015. Programme for Technology and Management for Development at the University of Oxford, Oxford, UK.

Gao, Z., J. Lee and X. Yu (2010). Consumer Demand for Healthy Diet: New Evidence from Healthy Eating Index. Selected Presentation in Agricultural and Applied Economics Association (AAEA) 2010 Annual Meeting, July 25-27, 2010, Denver, Colorado.

Gibson, J. and S. Rozelle (2002). How Elasticitic is Calorie Demand? Parametric, Nonparametric and Semiparametric Eesults for Urban Papua New Guinea. Journal of Development Studies, 38(6): 23-46.

Gibson, J. and S. Rozelle (2004). Is It Better to Be A Boy? A Disaggregated Outlay Equivalent Analysis of Gender Bias in Papua New Guinea. Journal of Development Studies, 40(4): 115-136.

Glass, G. V. (1976). Primary, Secondary, and Meta-Analysis of Research. Educational Researcher, 5(10): 3-8.

Gong, X. D., A. van Soest and P. Zhang (2005). The Effects of the Gender of Children on Expenditure Patterns in Rural China: A Semiparametric Analysis. Journal of Applied Econometrics, 20, 509-527.

Graham, E. M. and E. Wada (2001). Foreign Direct Investment in China: Effects on Growth and Economic Performance. Institute for International Economics Working paper No. 01-03. Peterson Institute for International Economics, Washington, DC.

Graham, M. J., U. Larsen and X. Xu (1998). Son Preference in Anhui Province, China. International Family Planning Perspectives, 24(2): 72-77.

Guo, Q. and J. Jia (2005). A Study of TFP in China: 1979-2004. Economic Research Journal, 6: 51-60. (In Chinese) 
Guo, X. G., T. A. Mroz, B. M. Popkin and F. Zhai (2000). Structural Change in the Impact of Income on Food Consumption. Economic Development and Cultural Change, 48(4): 737-760.

Gupta, M. D. and S. Li (1999). Gender Bias in China, South Korea and India 1920-1990: Effects of War, Famine and Fertility Decline. Development and Change, 30: 619652 .

Haddad, L. and R. Kanbur (1990). How Serious is the Neglect of Intra-Household Inequality? The Economic Journal, 100(402): 866-881.

Hardle, W., H. Liang and J. Gao (2000). Partially Linear Models. Heidelberg, Germany: Physica-Verlag.

Hastie, T. and C. Loader (1993). Local Regression: Automatic Kernel Carpentry. Statistical Science, 8(2):120-143.

Heckman, J. J. (1979). Sample Selection Bias as A Specification Error. Econometrica, 47(1): 153-161.

Heckman, J. J., H. Ichimura, J. Smith and P. Todd (1998). Characterizing Selection Bias Using Experimental Data. Econometrica, 66(5): 1017-1098.

Hsieh, C. T. and P. J. Klenow (2009). Misallocation and Manufacturing TFP in China and India. Quarterly Journal of Economics, 124(4): 1403-1448.

Hu, Z. and M. S. Khan (1997). Why is China Growing So Fast. IMF working paper, Vol. 44, No.1. International Monetary Fund, Washington, DC.

Hulten, C. R. (2000). Total Factor Productivity: A Short Biography. NBER Working Paper, No. 7471. The National Bureau of Economic Research, Washington, DC.

Institute of Nutrition and Food Hygiene, Chinese Center for Disease Control and Prevention (2004). China Food Composition 2004. Beijing, China: Peiking University Medical Press.

Institute of Nutrition and Food Safety, Chinese Center for Disease Control and Prevention (2002). China Food Composition 2002. Beijing, China: Peiking University Medical Press.

Jefferson, G. H., T. G. Rawsiki and Y. X. Zheng (1992). Growth, Efficiency, and Convergence in China's State and Collective Industry. Economic Development 
and Cultural Change, 40(2): 239-266.

Jensen, R. T. and N. H. Miller (2010). A Revealed Preference Approach to Measuring Hunger and Undernutrition. NBER Working Paper.

Jin, S., J. Huang and S. Rozelle (2010). Agricultural Productivity in China. In J. Alston, B. Babcock and P. Pardey (eds.), The Shifting Patterns of Agricultural Production and Productivity Worldwide (pp. 229-277). Midwest Agribusiness Trade and Research Information Center, Iowa State University, Ames, Lowa.

Jin, X. (2006). A Study on TFP of Cities in China. Shanghai Economic Review, 7: 14-23. (In Chinese)

Johansson, S. and O. Nygren (1991). The Missing Girls of China: A New Demographic Account. Population and Development Review, 17(1): 35-51.

Jorgenson, D. W. and Z. Griliches (1967). The Explanation of Productivity Change. The Review of Economic Studies, 34(3): 249-283.

Kalirajan, K. P., M. B. Obwona and S. Zhao (1996). A Decomposition of TFP Growth: The Case of Chinese Agricultural Growth Before and After Reforms. American Journal of Agricultural Economics, 78(2): 331-338.

Klasen, S. and C. Wink (2002). A Turning Point in Gender Bias in Mortality? An Update on the Number of Missing Women. Population and Development Review, 28(2): 285-312.

Knight, J. and L. Song (1993). The Missing Girls in China: A New Demographic Account. Population and Development Review, 17: 35-51.

Knight, J., S. Li and Q. Deng (2010) Son Preference and Household Income in Rural China. Journal of Development Studies, 46(10): 1786-1805.

Kochar, A. (2005). Can Targeted Food Programs Improve Nutrition? An Empirical Analysis of India's Public Distribution System. Economic Development and Cultural Change, 54: 203-235.

Kong, X., R. E. Marks and G. H. Wan (1999). Technical Efficiency, Technological Change and Total Factor Productivity Growth in Chinese State-Owned Enterprises in the Early 1990s. Asian Economic Journal, 13(3): 267-281.

Krugman, P. (1994). The Myth of Asia’s Miracle. Foreign Affairs, 73(6): 62-78. 
Lee, J. and F. Wang (1999). One Quarter of Humanity: Malthusian Mythology and Chinese Realities. Cambridge: Harvard University Press.

Lee, Y.D. (2008). Do Families Spend More on Boys Than on Girls? Empirical Evidence from Rural China. China Economic Review, 19: 80-100.

Leser, C. E. V. (1963). Forms of Engel functions. Econometrica, 31: 694-703.

Leung, A. S. M. (2003). Feminism in Transition: Chinese Culture, Ideology and the Development of the Women's Movement in China. Asia Pacific Journal of Management, 20: 359-374 (2003).

Li, J. (1992). Productivity and China's Economic Growth. The Economic Studies Quarterly, 43(4): 337-350.

Li, J. and L. Meng (2006). The Empirical Study on the Growth and Decomposition of China's Agricultural Productivity from 1978 to 2004: Evidence from Nonparameter HMB Productivity Index. The Journal of Quantitative \& Technical Economics, 5: 11-19. (In Chinese)

Li, J., H. Gong and S. Ming (1996). TFP and Economic Growth in China. The Journal of Quantitative \& Technical Economics, 12: 27-40. (In Chinese)

Li, K. W. and T. Liu (2011). Economic and Productivity Growth Decomposition: An Application to Post-Reform China, Economic Modelling, 28(1-2): 366-373.

Li, L. and X. Wu (2011). Gender of Children, Bargaining Power, and Intrahousehold Resource Allocation in China. Journal of Human Resources, 46(2): 295-316.

Li, S. and D. Li (2008). China's Industrial Total Factor Productivity Fluctuations: 19862005. The Journal of Quantitative \& Technical Economics, 5: 43-54. (In Chinese)

Li, W. (1997). The Impact of Economic Reform on the Performance of Chinese State Enterprises, 1980-1989. Journal of Political Economy, 105(5): 1080-1106.

Liang, Z. (2000). An Analysis of the Main Factors of Continuous Economic Growth in China. The Journal of World Economy, 7: 50-56. (In Chinese)

Lin, J. Y. (1992). Rural Reforms and Agricultural Growth in China. American Economic Review, 82(1): 34-51.

Lin, J. Y. (2007). Needham Puzzle, Weber Question and China's Miracle: Long Term Performance since the Song Dynasty. Journal of Peking University (Philosophy 
and Social Sciences), 44(4): 5-22. (In Chinese)

Lipsey, R. G. and K. I. Carlaw (2004). Total Factor Productivity and the Measurement of Technological Change. Canadian Journal of Economics, 37(4): 1118-1150.

Liu, D., S. Tang and D. Li (2009). Technical Progress and Quality of China's Economic Growth: 1978-2007. On Economic Problems, 3: 30-33. (In Chinese)

Liu, X. and C. Wang (2003). Does Foreign Direct Investment Facilitate Technological Progress?-Evidence from Chinese industries. Research Policy, 32: 945-953.

Liu, Z. and Y. Hu (2008). An Empirical Study on TFP, Capital Accumulation and Regional Disparity. Statistics and Decision, 12: 67-70. (In Chinese)

Lovell, C. A. K. (1996). Applying Efficiency Measurement Techniques to the Measurement of Productivity Change. Journal of Productivity Analysis, 7: 329340.

Lu, X. and W. Jin, (2005). Factors Contributing to the Growth of China's Construction Industry. Journal of Shanghai University (Natural Science), 11(3): 320-325. (In Chinese)

Maddison, A. (2007). Chinese Economic Performance in the Long Run. Second Edition, OECD report.

McKelvey C. (2011). Price, Unit Value, and Quality Demanded. Journal of Development Economics, 95(2): 157-169.

Mead, R. W. (2003). A Revisionist View of Chinese Agricultural Productivity. Contemporary Economic Policy, 21(1): 117-131.

Meng, L. and J. Li (2004). Tendency of TFP in China-A Non-parameter Malmquist Index Approach. Conference Paper of China Economics Annual Meeting, Tianjin. (In Chinese)

Meng, X, X. Gong and Y. Wang (2009). Impact of Income Growth and Economic Reform on Nutrition Availability in Rrban China: 1986-2000. Economic Development and Cultural Change, 57(2): 261-295.

Monteiro, C. A., L. Mondini, A. L. de Souza and B. M. Popkin (1995). The Nutrition Transition in Brazil. European Journal of Clinical Nutrition, 49(2): 105-113.

Nadaraya, E.A. (1964). On Estimating Regression. Theory of Probability \& Its 
Application, 10: 186-190.

Nadiri, M. I. (1970). Some Approaches to the Theory and Measurement of Total Factor Productivity: A Survey. Journal of Economic Literature, 8(4): 1137-1177.

Nelson, J. P. and P. E. Kennedy (2009). The Use of Meta-Analysis in Environmental and Natural Resource Economics: An Assessment. Environmental and resource economics, 42: 345-377.

Nicholson, J. L. (1976). Appraisal of Different Methods of Estimating Equivalence Scales and Their Results. Review of Income and Wealth, 22: 1-11.

Nishimizu, M. and J. M. Page (1982). Total Factor Productivity Growth, Technological Progress and Technical Efficiency Change: Dimensions of Productivity Change in Yugoslavia, 1965-78. The Economic Journal, 92(368): 920-936.

Norsworthy, J. R., M. J. Harper and K. Kunze (1979). The Slowdown in Productivity Growth: Analysis of Some Contributing Factors. Brookings Papers on Economic Activity, 2: 387-421.

Ogundari, K., and A. Abdulai (2013). Examining the heterogeneity in calorie-income elasticities: A meta-analysis. Food Policy, 40 (0):119-128.

Omran, A. R. (1971). The Epidemiologic Transition: A Theory of the Epidemiology of Population Change. Milbank Memorial Fund Quarterly, 49(4, pt. 1): 509-538.

Owyong, D. T. (2000). Productivity Growth: Theory and Measurement. APO Productivity Journal, 19-29.

Park, A. and P. Rukumnuaykit (2004). Eat Drink Man Woman: Testing for Gender Bias in China Using Individual Nutrient Intake Data. Working Paper. Department of Economics, University of Michigan.

Popkin, B. M. (1993). Nutrition Patterns and Transitions. Population and Development Review, 19(1): 138-157.

Popkin, B. M. (1999). Urbanization, Lifestyle Changes and the Nutrition Transition. World Development, 27(11): 1905-1916.

Popkin, B. M. (2001a). Nutrition in Transition: The Changing Global Nutrition Challenge. Asia Pacific Journal of Clinical Nutrition, 10 (Supplement S): 13-18. 
Popkin, B. M. (2001b). The Nutrition Transition and Obesity in the Developing World. The Journal of Nutrition, 131(3): 871-873.

Popkin, B. M. (2003). The Nutrition Transition in the Developing World. Development Policy Review, 21(5-6): 581-597.

Popkin, B. M., B. Lu and F. Zhai (2002). Understanding the Nutrition Transition: Measuring Rapid Dietary Changes in Transitional Countries. Public Health Nutrition, 5(6A): 947-53.

Popkin, B. M., S. Horton, S. Kim, A. Mahal and S. Jin (2001). Trends in Diet, Nutritional Status, and Diet-related Noncommunicable Diseases in China and India: The Economic Costs of the Nutrition Transition. Nutrition Review, 59(12): 379-390.

Qian, N. (2008). Missing Women and the Price of Tea in China: The Effect of SexSpecific Earnings on Sex Imbalance. Quarterly Journal of Economics, 123(3): 1251-1285.

Raa, T. T. and V. Shestalova (2011). The Solow Residual, Domar Aggregation, and Inefficiency: A Synthesis of TFP Measures. Journal of Productivity Analysis, 30(3): 191-199.

Robinson, P. (1988). Root-N-Consistent Semi-parametric Regression. Econometrica, 56: 931-954.

Rozelle, S., X. Dong, L. Zhang and A. Mason (2002). Gender Wage Gaps in Post-Reform Rural China. Pacific Economic Review, 7(1): 157-179.

Sen, A. (1998). Mortality as An Indicator of Economic Success and Failure. The Economic Journal, 108: 1-25.

Shen, K. and B. Zhao (2006). TFP, Technological Choice and the Economic Growth of the Yangtze Delta. Jiangsu Social Sciences, 4: 59-66. (In Chinese)

Shimokawa, S. (2010). Asymmetric Intra-household Allocation of Calories in China. American Journal of Agricultural Economics, 92(3): 873-888.

Shu, X. (2004). Education and Gender Egalitarianism: The Case of China. Sociology of Education, 77: 311-336.

Skoufias, E. (2003). Is the Calorie-income Elasticity Sensitive to Price Changes? Evidence from Indonesia. World Development, 31: 1291-1307. 
Solow, R. M. (1957). Technical Change and The Aggregation Production Function. The Review of Economics and Statistics, 39(3): 312-320.

Song, L. (2008). In Search of Gender Bias in Household Resource Allocation in Rural China. In: IZA Discussion Papers. vol. 3464.

Stanley, T. D. and S. B. Jarrell (1989). Meta-Regression Analysis: A Quantitative Method of Literature Surveys. Journal of Economic Survey, 19(3): 299-308.

Strauss, J. and D. Thomas (1995). Empirical Modeling of Household and Family Decisions. In: Behrman JR, Srinivasan TN (eds.) Handbook of Development Economics, Holland: North-Holland.

Strauss, J. and D. Thomas (1998). Health, Nutrition, and Economic Development. Journal of Economic Literature, 36(2): 766-817.

Subramanian, S. and A. Deaton (1996). The Demand for Food and Calories. Journal of Political Economy, 104(1): 133-162.

Sun, L. and R. Ren (2005). An Estimation of Capital Input and TFP in China. The Journal of World Economy, 12: 3-13. (In Chinese)

Tang, A. M. (1986). An Analytical and Empirical Investigation of Agriculture in Mainland China: 1952-80. The China Quarterly, 106: 346-347.

Thomas, D. (1990). Intra-Household Resource Allocation: An Inferential Approach. Journal of Human Resources, 25(4), 635-664.

Tian, X. and X. Yu (2012). The Enigmas of TFP in China: A Meta-Analysis. China Economic Review, 23(2): 396-414.

Tian, X. and X. Yu (2013). The Demand for Nutrients in China. Frontier of Economics in China, forthcoming.

UN (1975). Report of the World Food Conference. 5-16 November 1974. United Nations, New York.

Walker, E., A.V. Hernandez and M. W. Kattan (2008). Meta-Analysis: Its Strengths and Limitations, Cleveland Clinic Journal of Medicine, 75(6): 431-439.

Wang, G. and J. Gu (2005). An Empirical Study on TFP of Manufacturing in Hunan Province. Statistics and Decision, 5: 63-66. (In Chinese) 
Wang, X. (2000). The Sustainability of Economic Growth and Institutional Renovation. Economic Research Journal, 7: 3-15. (In Chinese)

Wang, X., G. Fan and P. Liu (2009). The Change of Economic Growth Pattern and Sustainability of Economic Growth in China. Economic Research Journal, 1: 4-16. (In Chinese)

Wang, Y, J. Mi, X. Y. Shan, Q. J. Wang and K. Y. Ge (2007). Is China Facing An Obesity Epidemic and the Consequence? The Erends in Obesity and the Chronic Disease in China. International Journal of Obesity, 31: 177-188.

Wang, Y. and Y. Yao (2003). Sources of China's Economic Growth: 1952-1999. China Economic Review, 14(1): 32-52.

Wang, Y. F., M. E. Bentley, F. Y. Zhai and B. M. Popkin (2002). Traking of Dietary Intake Patterns of Chinese from Childhood to Adolescence over A Six-year Follow-up Period. The Journal of Nutrition, 132(3): 430-438.

Wang, Z. H., F. Y. Zhai, S. F. Du and B. M. Popkin (2008). Dynamic Shifts in Chinese Eating Behaviours. Asia Pacific Journal of Clinical Nutrition, 17(1): 123-130.

Watson, G.S. (1964). Smooth Regression Analysis. Sankhya: The Indian Journal of Statistics, Series A, 26: 359-372.

Wei, S. and X. Zhang (2011a). The Competitive Saving Motive: Evidence from Rising Sex Ratios and Savings Rates in China. Journal of Political Economy, 119(3): 511-564.

Wei, S. and X. Zhang (2011b). Sex Rratio, Entrepreneurship, and Economic Growth in the People's Republic of China. In: NBER Working Papers. No. 16800.

Wen, H. (2005). Difference Comparison and Inspiration of TFP in China-Taking Shanghai, Hubei and Sichuan as examples. On Economic Problems, 2: 31-33. (In Chinese)

Whitney, E. and S. R. Rolfes (2005). Understanding Nutrition. 10 ed. USA: Thomson Wadsworth.

WHO (1995). Phsical Status: The Use and Interpretation of Anthropometry. In WHO Techinical Report Series.

Woo, W. T. (1998). Chinese Economic Growth: Sources and Prospects. The Chinese 
Economy, 3: 1-19.

Working, H. (1943). Statistical Laws of Family Expenditure. Journal of the American Statistical Association, 38: 43-56 (1943).

Wu, Y. R. (2000). Is China's Economic Growth Sustainable?-A Productivity Analysis. China Economic Review, 11(3): 278-296.

Yatchew, A. (1997). An Elementary Estimator of the Partial Linear Model. Economics Letters, 57: 135-143.

Yatchew, A. (1998). Nonparametric Regression Techniques in Economics. Journal of Economic Literature, 36: 669-721 (1998).

Young, A. (2003). Gold into Base Metals: Productivity Growth in the People's Republic of China during the Reform Period. Journal of Political Economy, 111(6): 12201261.

Yu, M. and R. Sarri (1997). Women's Health Status and Gender Inequality in China. Social Science \& Medicine, 45: 1885-1898.

Yu, X. and D. Abler (2009). The Demand for Food Quality in Rural China. American Journal of Agricultural Economics, 91(1): 57-69.

Zhai, F, H. Wang, S. Du, Y. He, Z. Wang, K. Ge and B. M. Popkin (2009). Prospective Study on Nutrition Transition in China. Nutrition Review, 67(Suppl 1): 56-61.

Zhang, J. and S. Shi (2003). The Change of TFP in China: 1952-1998. World Economic Papers, 2: 17-24. (In Chinese)

Zhang, X. and B. Gui (2008). An Analysis of China's TFP: Comments and Application of Malmquist Index Approach. The Journal of Quantitative \& Technical Economics, 6: 111-122. (In Chinese)

Zhao, W., R. Ma and Y. He (2005). Decomposition of TFP-An Empirical Analysis Based on Malmquist Index. Statistical Research, 7: 37-42. (In Chinese)

Zhao, Z. and S. Zhang (2006). The Tendency and Contribution of Technical Progress in China' Agriculture in the Past 20 Years. Chinese Rural Economy, 3: 4-12. (In Chinese)

Zheng, J. and A. Hu (2005). An Empirical Analysis of Provincial Productivity in China (1979-2001). China Economic Quarterly, 4(2): 263-296. (In Chinese) 
Zheng, J. and A. Hu (2008). Can China's Growth be Sustained?-A Productivity Perspective. China Economic Quarterly, 7(3):777-803. (In Chinese)

Zheng, Y. (1998). Estimation of TFP and Economic Growth law-Begin from the debate of East Asia's Growth Pattern. The Journal of Quantitative and Technical Economics, 10: 28-34. (In Chinese)

Zhu, Z. and X. Li (2005). Capital Formation, TFP Change and Divergence: A Study Based on Industry-specific Panel Data. The Journal of World Economy, 9: 51-62. (In Chinese) 
Appendices 


\section{1: List of Primary Studies}

\begin{tabular}{|c|c|c|c|c|c|c|c|c|c|c|}
\hline Author & $\begin{array}{l}\text { Time } \\
\text { paper }\end{array}$ & Journal & Region & Sector & Method & Data & Inputs & Price & Period & TFPG \\
\hline Bai and Yin & 2008 & Chinese & $\begin{array}{l}\text { East, west } \\
\text { and central }\end{array}$ & Aggregate & SRM & $\begin{array}{c}\text { Panel } \\
\text { data }\end{array}$ & $\begin{array}{c}\text { Labor and } \\
\text { capital }\end{array}$ & $\begin{array}{l}\text { Constant } \\
\text { price }\end{array}$ & $\begin{array}{l}1979- \\
2005\end{array}$ & $\begin{array}{c}-0.1160, \\
0.4320\end{array}$ \\
\hline Bai and Zhang & 2010 & WP & China & Manufacturing & SRM & $\begin{array}{c}\text { Panel } \\
\text { data }\end{array}$ & $\begin{array}{c}\text { Labor and } \\
\text { capital }\end{array}$ & $\begin{array}{c}\text { Constant } \\
\text { price }\end{array}$ & $\begin{array}{l}1953- \\
2005\end{array}$ & $\begin{array}{c}-0.4702, \\
0.3452\end{array}$ \\
\hline $\begin{array}{l}\text { Bosworth and } \\
\text { Collins }\end{array}$ & 2008 & JEP & China & $\begin{array}{c}\text { Aggregate, agriculture, } \\
\text { Manufacturing and } \\
\text { service }\end{array}$ & SRM & $\begin{array}{l}\text { Time } \\
\text { series }\end{array}$ & More & $\begin{array}{c}\text { Constant } \\
\text { price }\end{array}$ & $\begin{array}{l}1978- \\
2004\end{array}$ & $\begin{array}{c}0.0090 \\
0.0610\end{array}$ \\
\hline Brandt et al. & 2011 & JDE & China & Manufacturing & SRM & $\begin{array}{c}\text { Panel } \\
\text { data }\end{array}$ & $\begin{array}{c}\text { Labor and } \\
\text { capital }\end{array}$ & $\begin{array}{c}\text { Constant } \\
\text { price }\end{array}$ & $\begin{array}{l}1998- \\
2007\end{array}$ & 0.0280 \\
\hline $\begin{array}{c}\text { Bruemmer et } \\
\text { al. }\end{array}$ & 2006 & JDE & East & Agriculture & SFA & $\begin{array}{c}\text { Panel } \\
\text { data }\end{array}$ & More & $\begin{array}{c}\text { Constant } \\
\text { price }\end{array}$ & $\begin{array}{l}1986- \\
2000\end{array}$ & $\begin{array}{l}0.0010 \\
0.1120\end{array}$ \\
\hline $\begin{array}{c}\text { Cao and } \\
\text { Birchenall }\end{array}$ & 2011 & WP & China & Agriculture & SRM & $\begin{array}{l}\text { Time } \\
\text { series }\end{array}$ & More & $\begin{array}{c}\text { Constant } \\
\text { price }\end{array}$ & $\begin{array}{l}1991- \\
2009\end{array}$ & 0.0650 \\
\hline Cao and liu & 2011 & WP & China & Manufacturing & LVA & $\begin{array}{c}\text { Panel } \\
\text { data }\end{array}$ & $\begin{array}{c}\text { Labor and } \\
\text { capital }\end{array}$ & $\begin{array}{c}\text { Constant } \\
\text { price }\end{array}$ & $\begin{array}{l}1999- \\
2007\end{array}$ & $\begin{array}{c}-0.0260, \\
0.2130\end{array}$ \\
\hline Cao et al. & 2009 & RIW & China & $\begin{array}{c}\text { Agriculture, } \\
\text { Manufacturing and } \\
\text { service }\end{array}$ & SRM & $\begin{array}{l}\text { Time } \\
\text { series }\end{array}$ & More & $\begin{array}{c}\text { Constant } \\
\text { price }\end{array}$ & $\begin{array}{l}1982- \\
2000\end{array}$ & $\begin{array}{c}-0.0350 \\
0.0500\end{array}$ \\
\hline Cao G. & 2006 & Chinese & China & Service & DEA & $\begin{array}{c}\text { Panel } \\
\text { data }\end{array}$ & More & $\begin{array}{l}\text { Current } \\
\text { price }\end{array}$ & $\begin{array}{l}2000- \\
2003\end{array}$ & $\begin{array}{c}0.0152 \\
0.2848\end{array}$ \\
\hline Cao J. & 2007 & Chinese & China & Aggregate & SRM & $\begin{array}{l}\text { Time } \\
\text { series }\end{array}$ & $\begin{array}{c}\text { Labor and } \\
\text { capital }\end{array}$ & $\begin{array}{c}\text { Constant } \\
\text { price }\end{array}$ & $\begin{array}{l}1980- \\
2005\end{array}$ & $\begin{array}{c}-0.0401, \\
0.0884\end{array}$ \\
\hline Chen H. & 2009 & Thesis & $\begin{array}{l}\text { East, west } \\
\text { and central }\end{array}$ & Aggregate & DEA & $\begin{array}{c}\text { Panel } \\
\text { data }\end{array}$ & $\begin{array}{l}\text { Labor and } \\
\text { capital }\end{array}$ & $\begin{array}{c}\text { Unknow } \\
n\end{array}$ & $\begin{array}{l}1979- \\
2004\end{array}$ & $\begin{array}{c}-0.0703, \\
0.1461\end{array}$ \\
\hline $\begin{array}{c}\text { Chen and } \\
\text { Santos-Paulino }\end{array}$ & 2010 & WP & China & Manufacturing & SFA & $\begin{array}{c}\text { Panel } \\
\text { data }\end{array}$ & More & $\begin{array}{c}\text { Constant } \\
\text { price }\end{array}$ & $\begin{array}{l}1981- \\
2006\end{array}$ & $\begin{array}{l}0.0200 \\
0.0980\end{array}$ \\
\hline Chen et al. & 2009 & WP & China & Manufacturing & SFA & $\begin{array}{c}\text { Panel } \\
\text { data }\end{array}$ & $\begin{array}{c}\text { Labor and } \\
\text { capital }\end{array}$ & $\begin{array}{l}\text { Constant } \\
\text { price }\end{array}$ & $\begin{array}{l}1981- \\
2006\end{array}$ & $\begin{array}{l}0.0200 \\
0.1000\end{array}$ \\
\hline Chen et al. & 2009 & CER & China & Aggregate & DEA & $\begin{array}{c}\text { Panel } \\
\text { data }\end{array}$ & $\begin{array}{l}\text { Labor and } \\
\text { capital }\end{array}$ & $\begin{array}{c}\text { Unknow } \\
\mathrm{n}\end{array}$ & $\begin{array}{l}1997- \\
2004\end{array}$ & $\begin{array}{l}0.0369 \\
0.0578\end{array}$ \\
\hline Chen W. & 2006 & Chinese & $\begin{array}{l}\text { China, east, } \\
\text { central and } \\
\text { west }\end{array}$ & Agriculture & DEA & $\begin{array}{c}\text { Panel } \\
\text { data }\end{array}$ & More & $\begin{array}{c}\text { Constant } \\
\text { price }\end{array}$ & $\begin{array}{l}1991- \\
2003\end{array}$ & $\begin{array}{c}-0.3185 \\
0.3433\end{array}$ \\
\hline Chow and $\mathrm{Li}$ & 2002 & EDCC & China & Aggregate & SRM & $\begin{array}{l}\text { Time } \\
\text { series }\end{array}$ & $\begin{array}{c}\text { Labor and } \\
\text { capital }\end{array}$ & $\begin{array}{c}\text { Constant } \\
\text { price }\end{array}$ & $\begin{array}{c}1952- \\
1978\end{array}$ & $\begin{array}{l}0.0000 \\
0.0303\end{array}$ \\
\hline Chu et al. & 2009 & Chinese & China & Manufacturing & SRM & $\begin{array}{l}\text { Time } \\
\text { series }\end{array}$ & $\begin{array}{c}\text { Labor and } \\
\text { capital }\end{array}$ & $\begin{array}{c}\text { Constant } \\
\text { price }\end{array}$ & $\begin{array}{l}2002- \\
2007\end{array}$ & 0.0237 \\
\hline Coelli and Rao & 2005 & $\mathrm{AE}$ & China & Agriculture & DEA & $\begin{array}{c}\text { Panel } \\
\text { data }\end{array}$ & More & $\begin{array}{c}\text { Constant } \\
\text { price }\end{array}$ & $\begin{array}{l}1980- \\
2000\end{array}$ & 0.0600 \\
\hline Cui Z. & 2005 & Chinese & East & Aggregate & SRM & $\begin{array}{l}\text { Time } \\
\text { series }\end{array}$ & $\begin{array}{c}\text { Labor and } \\
\text { capital }\end{array}$ & $\begin{array}{l}\text { Constant } \\
\text { price }\end{array}$ & $\begin{array}{l}1979- \\
2002\end{array}$ & $\begin{array}{c}-0.0110 \\
0.2708\end{array}$ \\
\hline $\begin{array}{c}\text { Dekle and } \\
\text { Vandenbroucke }\end{array}$ & 2010 & $\mathrm{RDE}$ & China & Agriculture & SRM & $\begin{array}{l}\text { Time } \\
\text { series }\end{array}$ & More & $\begin{array}{c}\text { Constant } \\
\text { price }\end{array}$ & $\begin{array}{l}1978- \\
2003\end{array}$ & 0.0060 \\
\hline Deng and $\mathrm{Yu}$ & 2006 & Chinese & East & Aggregate & DEA & $\begin{array}{l}\text { Panel } \\
\text { data }\end{array}$ & $\begin{array}{c}\text { Labor and } \\
\text { capital }\end{array}$ & $\begin{array}{c}\text { Constant } \\
\text { price }\end{array}$ & $\begin{array}{l}1981- \\
2004\end{array}$ & $\begin{array}{c}0.0030 \\
0.0490\end{array}$ \\
\hline Diao and Tao & 2003 & Chinese & China & Agriculture & SRM & $\begin{array}{l}\text { Time } \\
\text { series }\end{array}$ & More & $\begin{array}{c}\text { Constant } \\
\text { price }\end{array}$ & $\begin{array}{l}1980- \\
2001\end{array}$ & $\begin{array}{c}-0.0791 \\
0.0806\end{array}$ \\
\hline Ezaki and Sun & 1999 & AEJ & $\begin{array}{l}\text { China, east, } \\
\text { central and } \\
\text { west }\end{array}$ & Aggregate & SRM & $\begin{array}{l}\text { Time } \\
\text { series }\end{array}$ & $\begin{array}{c}\text { Labor and } \\
\text { capital }\end{array}$ & $\begin{array}{c}\text { Constant } \\
\text { price }\end{array}$ & $\begin{array}{l}1981- \\
1995\end{array}$ & $\begin{array}{c}-0.1130 \\
0.1120\end{array}$ \\
\hline Fan and Zhang & 2002 & EDCC & $\begin{array}{c}\text { China, east, } \\
\text { central and } \\
\text { west }\end{array}$ & Agriculture & SRM & $\begin{array}{l}\text { Time } \\
\text { series }\end{array}$ & More & $\begin{array}{c}\text { Constant } \\
\text { price }\end{array}$ & $\begin{array}{c}1953- \\
1997\end{array}$ & $\begin{array}{c}-0.1923, \\
0.1553\end{array}$ \\
\hline Fan S. & 1991 & AJAE & China & Agriculture & SFA & $\begin{array}{c}\text { Panel } \\
\text { data }\end{array}$ & More & $\begin{array}{l}\text { Constant } \\
\text { price }\end{array}$ & $\begin{array}{l}1965- \\
1985\end{array}$ & $\begin{array}{l}0.0074 \\
0.0213\end{array}$ \\
\hline Fan S. & 1997 & $\begin{array}{l}\text { Food } \\
\text { Policy }\end{array}$ & China & Agriculture & SRM & $\begin{array}{l}\text { Time } \\
\text { series }\end{array}$ & More & $\begin{array}{c}\text { Constant } \\
\text { price }\end{array}$ & $\begin{array}{l}1953- \\
1995\end{array}$ & $\begin{array}{c}-0.2297 \\
0.1650\end{array}$ \\
\hline Fan S. & 1998 & Chinese & China & Agriculture & AINA & $\begin{array}{l}\text { Time } \\
\text { series }\end{array}$ & More & $\begin{array}{c}\text { Constant } \\
\text { price }\end{array}$ & $\begin{array}{l}1953- \\
1995\end{array}$ & $\begin{array}{c}-0.1705, \\
0.1650\end{array}$ \\
\hline Fang et al. & 2004 & Chinese & China & Aggregate & SRM & $\begin{array}{l}\text { Time } \\
\text { series }\end{array}$ & $\begin{array}{c}\text { Labor and } \\
\text { capital }\end{array}$ & $\begin{array}{c}\text { Constant } \\
\text { price }\end{array}$ & $\begin{array}{c}1979- \\
1999\end{array}$ & $\begin{array}{c}-0.0591 \\
0.1412\end{array}$ \\
\hline Feng $\mathrm{H}$. & 1993 & Chinese & China & Agriculture & AINA & $\begin{array}{l}\text { Time } \\
\text { series }\end{array}$ & More & $\begin{array}{c}\text { Constant } \\
\text { price }\end{array}$ & $\begin{array}{c}1950- \\
1990\end{array}$ & $\begin{array}{c}-0.1414, \\
0.1700\end{array}$ \\
\hline Fu and Floor & 2004 & WP & China & Manufacturing & DEA & $\begin{array}{c}\text { Panel } \\
\text { data }\end{array}$ & $\begin{array}{c}\text { Labor and } \\
\text { capital }\end{array}$ & $\begin{array}{c}\text { Constant } \\
\text { price }\end{array}$ & $\begin{array}{c}1991- \\
1997\end{array}$ & $\begin{array}{c}-0.2180 \\
0.2150\end{array}$ \\
\hline Fu and Gong & 2009 & AEP & China & Manufacturing & DEA & $\begin{array}{c}\text { Panel } \\
\text { data }\end{array}$ & More & $\begin{array}{c}\text { Constant } \\
\text { price }\end{array}$ & $\begin{array}{l}2001- \\
2005\end{array}$ & 0.0111 \\
\hline
\end{tabular}




\begin{tabular}{|c|c|c|c|c|c|c|c|c|c|c|}
\hline Gao and Wang & 2010 & Chinese & China & Manufacturing & DEA & $\begin{array}{c}\text { Panel } \\
\text { data }\end{array}$ & $\begin{array}{c}\text { Labor and } \\
\text { capital }\end{array}$ & $\begin{array}{l}\text { Constant } \\
\text { price }\end{array}$ & $\begin{array}{l}2003- \\
2007\end{array}$ & 0.0853 \\
\hline Gao J. & 2003 & Chinese & China & Manufacturing & AINA & $\begin{array}{l}\text { Time } \\
\text { series }\end{array}$ & More & $\begin{array}{l}\text { Current } \\
\text { price }\end{array}$ & $\begin{array}{l}1992- \\
2000\end{array}$ & $\begin{array}{c}-0.1437 \\
0.1320\end{array}$ \\
\hline $\begin{array}{c}\text { Graham and } \\
\text { Wada }\end{array}$ & 2001 & wp & $\begin{array}{c}\text { East, west } \\
\text { and central }\end{array}$ & Aggregate & SRM & $\begin{array}{l}\text { Panel } \\
\text { data }\end{array}$ & $\begin{array}{l}\text { Labor and } \\
\text { capital }\end{array}$ & $\begin{array}{c}\text { Constant } \\
\text { price }\end{array}$ & $\begin{array}{c}1978- \\
1997\end{array}$ & $\begin{array}{c}-0.0200 \\
0.2600\end{array}$ \\
\hline Gu and Meng & 2002 & Chinese & China & Agriculture & DEA & $\begin{array}{c}\text { Panel } \\
\text { data }\end{array}$ & More & Unknow & $\begin{array}{l}1981- \\
1995\end{array}$ & $\begin{array}{c}-0.0260 \\
0.1080\end{array}$ \\
\hline Guo and Jia & 2005 & Chinese & China & Aggregate & $\begin{array}{l}\text { SRM, } \\
\text { LVA, } \\
\text { POA }\end{array}$ & $\begin{array}{l}\text { Time } \\
\text { series }\end{array}$ & $\begin{array}{l}\text { Labor and } \\
\text { capital }\end{array}$ & $\begin{array}{c}\text { Constant } \\
\text { price }\end{array}$ & $\begin{array}{l}1979- \\
2004\end{array}$ & $\begin{array}{c}-0.0599 \\
0.0613\end{array}$ \\
\hline Guo and Jia & 2004 & Chinese & China & Aggregate & SRM & $\begin{array}{l}\text { Time } \\
\text { series }\end{array}$ & $\begin{array}{c}\text { Labor and } \\
\text { capital }\end{array}$ & $\begin{array}{c}\text { Constant } \\
\text { price }\end{array}$ & $\begin{array}{l}1978- \\
2002\end{array}$ & $\begin{array}{c}-0.0012 \\
0.0034\end{array}$ \\
\hline Guo et al. & 2005 & Chinese & $\begin{array}{c}\text { China, east, } \\
\text { central and } \\
\text { west }\end{array}$ & Aggregate & DEA & $\begin{array}{l}\text { Panel } \\
\text { data }\end{array}$ & $\begin{array}{l}\text { Labor and } \\
\text { capital }\end{array}$ & $\begin{array}{c}\text { Constant } \\
\text { price }\end{array}$ & $\begin{array}{l}1979- \\
2003\end{array}$ & $\begin{array}{c}-0.0161 \\
0.0378\end{array}$ \\
\hline Han and Zhai & 2005 & Chinese & $\begin{array}{l}\text { East, west } \\
\text { and central }\end{array}$ & Agriculture & DEA & $\begin{array}{c}\text { Panel } \\
\text { data }\end{array}$ & More & $\begin{array}{l}\text { Current } \\
\text { price }\end{array}$ & $\begin{array}{l}1982- \\
2002\end{array}$ & $\begin{array}{c}-0.0621, \\
0.9430\end{array}$ \\
\hline $\begin{array}{l}\text { Hayami and } \\
\text { Ruttan }\end{array}$ & 1985 & Book & China & Agriculture & AINA & $\begin{array}{l}\text { Time } \\
\text { series }\end{array}$ & More & $\begin{array}{c}\text { Constant } \\
\text { price }\end{array}$ & $\begin{array}{c}1953- \\
1989\end{array}$ & $\begin{array}{c}-0.1352, \\
0.1471\end{array}$ \\
\hline He et al. & 2009 & Chinese & East & Agriculture & DEA & $\begin{array}{c}\text { Panel } \\
\text { data }\end{array}$ & More & $\begin{array}{c}\text { Constant } \\
\text { price }\end{array}$ & $\begin{array}{l}1993- \\
2005\end{array}$ & $\begin{array}{c}-0.0410 \\
0.1520\end{array}$ \\
\hline He Y. & 2007 & Chinese & $\begin{array}{c}\text { China, east, } \\
\text { central and } \\
\text { west }\end{array}$ & Aggregate & DEA & $\begin{array}{l}\text { Panel } \\
\text { data }\end{array}$ & $\begin{array}{l}\text { Labor and } \\
\text { capital }\end{array}$ & $\begin{array}{c}\text { Constant } \\
\text { price }\end{array}$ & $\begin{array}{l}1986- \\
2003\end{array}$ & $\begin{array}{c}-0.0430 \\
0.0790\end{array}$ \\
\hline Hong et al. & 2005 & Chinese & East & Agriculture & SRM & $\begin{array}{l}\text { Time } \\
\text { series }\end{array}$ & More & $\begin{array}{c}\text { Constant } \\
\text { price }\end{array}$ & $\begin{array}{l}1999- \\
2003\end{array}$ & 0.0184 \\
\hline $\mathrm{Hu}$ and Liu & 2007 & Chinese & China & Aggregate & SRM & $\begin{array}{l}\text { Time } \\
\text { series }\end{array}$ & More & $\begin{array}{c}\text { Constant } \\
\text { price }\end{array}$ & $\begin{array}{l}1994- \\
2004\end{array}$ & $\begin{array}{c}-0.0103 \\
0.0039\end{array}$ \\
\hline Hu et al. & 2008 & Chinese & $\begin{array}{c}\text { China, east, } \\
\text { central and } \\
\text { west }\end{array}$ & Aggregate & SRM & $\begin{array}{l}\text { Time } \\
\text { series }\end{array}$ & $\begin{array}{l}\text { Labor and } \\
\text { capital }\end{array}$ & $\begin{array}{c}\text { Constant } \\
\text { price }\end{array}$ & $\begin{array}{l}1978- \\
2005\end{array}$ & $\begin{array}{c}-0.0055 \\
0.0812\end{array}$ \\
\hline $\begin{array}{c}\text { Huang and } \\
\text { Zhou }\end{array}$ & 2010 & Chinese & China & Agriculture & SFA & $\begin{array}{c}\text { Panel } \\
\text { data }\end{array}$ & More & Unknow & $\begin{array}{l}1979- \\
2008\end{array}$ & $\begin{array}{l}0.0075 \\
0.0212\end{array}$ \\
\hline Islam et al. & 2006 & AEJ & China & Aggregate & SRM & $\begin{array}{l}\text { Time } \\
\text { series }\end{array}$ & $\begin{array}{c}\text { Labor and } \\
\text { capital }\end{array}$ & $\begin{array}{c}\text { Constant } \\
\text { price }\end{array}$ & $\begin{array}{l}1979- \\
2002\end{array}$ & $\begin{array}{c}-0.0128 \\
0.1017\end{array}$ \\
\hline Jeanneney et al. & 2006 & WP & $\begin{array}{c}\text { China, east, } \\
\text { central and } \\
\text { west }\end{array}$ & Aggregate & DEA & $\begin{array}{l}\text { Panel } \\
\text { data }\end{array}$ & $\begin{array}{l}\text { Labor and } \\
\text { capital }\end{array}$ & $\begin{array}{c}\text { Constant } \\
\text { price }\end{array}$ & $\begin{array}{l}1993- \\
2001\end{array}$ & $\begin{array}{l}0.0126 \\
0.0660\end{array}$ \\
\hline Jiang et al. & 2005 & Chinese & $\begin{array}{c}\text { China, east, } \\
\text { central and } \\
\text { west }\end{array}$ & Agriculture & DEA & $\begin{array}{l}\text { Panel } \\
\text { data }\end{array}$ & More & $\begin{array}{c}\text { Constant } \\
\text { price }\end{array}$ & $\begin{array}{l}1978- \\
2002\end{array}$ & $\begin{array}{c}-0.0330 \\
0.0570\end{array}$ \\
\hline Jin et al. & 2006 & Chinese & China & Aggregate & SRM & $\begin{array}{l}\text { Time } \\
\text { series }\end{array}$ & $\begin{array}{c}\text { Labor and } \\
\text { capital }\end{array}$ & $\begin{array}{c}\text { Constant } \\
\text { price }\end{array}$ & $\begin{array}{l}1980- \\
2003\end{array}$ & $\begin{array}{c}-0.0946 \\
0.1139\end{array}$ \\
\hline Jin X. & 2006 & Chinese & China & Aggregate & DEA & $\begin{array}{c}\text { Panel } \\
\text { data }\end{array}$ & $\begin{array}{c}\text { Labor and } \\
\text { capital }\end{array}$ & $\begin{array}{l}\text { Current } \\
\text { price }\end{array}$ & $\begin{array}{l}1992- \\
2003\end{array}$ & $\begin{array}{c}-0.0950 \\
0.2380\end{array}$ \\
\hline Jin Z. & 2003 & Chinese & Central & Agriculture & LVA & $\begin{array}{l}\text { Time } \\
\text { series }\end{array}$ & $\begin{array}{c}\text { Labor and } \\
\text { capital }\end{array}$ & $\begin{array}{c}\text { Constant } \\
\text { price }\end{array}$ & $\begin{array}{l}1979- \\
2000\end{array}$ & 0.0189 \\
\hline Kalirajan et al. & 1996 & AJAE & $\begin{array}{c}\text { China, east, } \\
\text { central and } \\
\text { west }\end{array}$ & Agriculture & SFA & $\begin{array}{l}\text { Panel } \\
\text { data }\end{array}$ & More & $\begin{array}{c}\text { Constant } \\
\text { price }\end{array}$ & $\begin{array}{c}1970- \\
1987\end{array}$ & $\begin{array}{c}-0.5186 \\
0.4780\end{array}$ \\
\hline Kong et al. & 1999 & AEJ & China & Manufacturing & SFA & $\begin{array}{c}\text { Panel } \\
\text { data }\end{array}$ & $\begin{array}{c}\text { Labor and } \\
\text { capital }\end{array}$ & $\begin{array}{c}\text { Constant } \\
\text { price }\end{array}$ & $\begin{array}{c}1991- \\
1994\end{array}$ & $\begin{array}{c}-0.0730 \\
0.1240\end{array}$ \\
\hline $\begin{array}{c}\text { Lambert and } \\
\text { Parker }\end{array}$ & 1998 & JAE & $\begin{array}{c}\text { China, east, } \\
\text { central and } \\
\text { west }\end{array}$ & Agriculture & DEA & $\begin{array}{c}\text { Panel } \\
\text { data }\end{array}$ & More & $\begin{array}{l}\text { Current } \\
\text { price }\end{array}$ & $\begin{array}{c}1970- \\
1995\end{array}$ & $\begin{array}{c}-0.0910 \\
0.2770\end{array}$ \\
\hline $\mathrm{Li}$ and $\mathrm{Chen}$ & 2008 & Chinese & $\begin{array}{c}\text { China, east, } \\
\text { central and } \\
\text { west }\end{array}$ & Aggregate & DEA & $\begin{array}{c}\text { Panel } \\
\text { data }\end{array}$ & $\begin{array}{l}\text { Labor and } \\
\text { capital }\end{array}$ & $\begin{array}{c}\text { Constant } \\
\text { price }\end{array}$ & $\begin{array}{l}1978- \\
2005\end{array}$ & $\begin{array}{c}-0.0230 \\
0.0710\end{array}$ \\
\hline $\mathrm{Li}$ and $\mathrm{Li}$ & 2008 & Chinese & China & Manufacturing & SFA & $\begin{array}{c}\text { Panel } \\
\text { data }\end{array}$ & More & $\begin{array}{l}\text { Constant } \\
\text { price }\end{array}$ & $\begin{array}{l}1986- \\
2005\end{array}$ & $\begin{array}{l}0.0006 \\
0.0354\end{array}$ \\
\hline li and liu & 2011 & EM & China & Aggregate & SFA & $\begin{array}{c}\text { Panel } \\
\text { data }\end{array}$ & More & $\begin{array}{c}\text { Constant } \\
\text { price }\end{array}$ & $\begin{array}{l}1987- \\
2006\end{array}$ & $\begin{array}{l}-0.011 \\
0.0782\end{array}$ \\
\hline $\mathrm{Li}$ and Meng & 2006 & Chinese & $\begin{array}{c}\text { China, east, } \\
\text { central and } \\
\text { west }\end{array}$ & Agriculture & DEA & $\begin{array}{l}\text { Panel } \\
\text { data }\end{array}$ & More & $\begin{array}{c}\text { Constant } \\
\text { price }\end{array}$ & $\begin{array}{l}1978- \\
2004\end{array}$ & $\begin{array}{c}-0.0120 \\
0.0590\end{array}$ \\
\hline $\mathrm{Li}$ and Zeng & 2009 & Chinese & China & Aggregate & SRM & $\begin{array}{l}\text { Time } \\
\text { series }\end{array}$ & $\begin{array}{c}\text { Labor and } \\
\text { capital }\end{array}$ & $\begin{array}{c}\text { Constant } \\
\text { price }\end{array}$ & $\begin{array}{l}1980- \\
2007\end{array}$ & $\begin{array}{c}-0.0467 \\
0.0967\end{array}$ \\
\hline Li et al. & 1992 & Chinese & China & Aggregate & SRM & $\begin{array}{l}\text { Time } \\
\text { series }\end{array}$ & $\begin{array}{c}\text { Labor and } \\
\text { capital }\end{array}$ & $\begin{array}{c}\text { Constant } \\
\text { price }\end{array}$ & $\begin{array}{c}1953- \\
1990\end{array}$ & $\begin{array}{c}-0.3346 \\
0.2058\end{array}$ \\
\hline Li et al. & 2008 & Chinese & China & Manufacturing & DEA & $\begin{array}{c}\text { Panel } \\
\text { data }\end{array}$ & $\begin{array}{c}\text { Labor and } \\
\text { capital }\end{array}$ & $\begin{array}{c}\text { Constant } \\
\text { price }\end{array}$ & $\begin{array}{l}1999- \\
2003\end{array}$ & $\begin{array}{l}0.0200 \\
0.1500\end{array}$ \\
\hline Li J. & 1992 & ESQ & China & Aggregate & SRM & $\begin{array}{c}\text { Time } \\
\text { series }\end{array}$ & $\begin{array}{l}\text { Labor and } \\
\text { capital }\end{array}$ & $\begin{array}{c}\text { Constant } \\
\text { price }\end{array}$ & $\begin{array}{c}1953- \\
1990\end{array}$ & $\begin{array}{c}-0.3346 \\
0.2058\end{array}$ \\
\hline
\end{tabular}




\begin{tabular}{|c|c|c|c|c|c|c|c|c|c|c|}
\hline Li W. & 1997 & JPE & China & Manufacturing & SRM & $\begin{array}{c}\text { Panel } \\
\text { data }\end{array}$ & $\begin{array}{c}\text { Labor and } \\
\text { capital }\end{array}$ & $\begin{array}{l}\text { Constant } \\
\text { price }\end{array}$ & $\begin{array}{l}1981- \\
1989\end{array}$ & $\begin{array}{c}-0.0218, \\
0.1075\end{array}$ \\
\hline Liang Z. & 2000 & Chinese & China & Aggregate & LVA & $\begin{array}{l}\text { Time } \\
\text { series }\end{array}$ & More & $\begin{array}{l}\text { Constant } \\
\text { price }\end{array}$ & $\begin{array}{c}1978- \\
1997\end{array}$ & $\begin{array}{l}0.0127 \\
0.0196\end{array}$ \\
\hline Lin J. Y. & 1992 & AER & China & Agriculture & SRM & $\begin{array}{c}\text { Panel } \\
\text { data }\end{array}$ & More & $\begin{array}{l}\text { Constant } \\
\text { price }\end{array}$ & $\begin{array}{l}1978- \\
19874\end{array}$ & $\begin{array}{l}0.0003, \\
0.0029\end{array}$ \\
\hline Liu and $\mathrm{Hu}$ & 2008 & Chinese & $\begin{array}{c}\text { China, east, } \\
\text { central and } \\
\text { west }\end{array}$ & Aggregate & SRM & $\begin{array}{l}\text { Time } \\
\text { series }\end{array}$ & $\begin{array}{c}\text { Labor and } \\
\text { capital }\end{array}$ & $\begin{array}{l}\text { Constant } \\
\text { price }\end{array}$ & $\begin{array}{l}1987- \\
2005\end{array}$ & $\begin{array}{c}0.0020 \\
0.0793\end{array}$ \\
\hline Liu and Liu & 2000 & Chinese & China & Manufacturing & AINA & $\begin{array}{l}\text { Time } \\
\text { series }\end{array}$ & $\begin{array}{c}\text { Labor and } \\
\text { capital }\end{array}$ & $\begin{array}{l}\text { Current } \\
\text { price }\end{array}$ & $\begin{array}{l}1976- \\
1984\end{array}$ & $\begin{array}{c}-0.0920, \\
0.1111\end{array}$ \\
\hline Liu and Wang & 2003 & $\mathrm{RP}$ & China & Manufacturing & SRM & $\begin{array}{c}\text { Panel } \\
\text { data }\end{array}$ & $\begin{array}{c}\text { Labor and } \\
\text { capital }\end{array}$ & $\begin{array}{l}\text { Current } \\
\text { price }\end{array}$ & 1995 & $\begin{array}{l}0.0879 \\
0.1278\end{array}$ \\
\hline Liu and Zhou & 2008 & Chinese & East & Manufacturing & DEA & $\begin{array}{c}\text { Panel } \\
\text { data }\end{array}$ & $\begin{array}{c}\text { Labor and } \\
\text { capital }\end{array}$ & $\begin{array}{l}\text { Constant } \\
\text { price }\end{array}$ & $\begin{array}{l}1997- \\
2005\end{array}$ & $\begin{array}{c}-0.0430, \\
0.2060\end{array}$ \\
\hline Liu and Zhou & 2008 & Chinese & East & Manufacturing & DEA & $\begin{array}{c}\text { Panel } \\
\text { data }\end{array}$ & $\begin{array}{c}\text { Labor and } \\
\text { capital }\end{array}$ & $\begin{array}{l}\text { Constant } \\
\text { price }\end{array}$ & 2006 & 0.0620 \\
\hline Liu and Zhu & 2007 & Chinese & China & Aggregate & SRM & $\begin{array}{l}\text { Time } \\
\text { series }\end{array}$ & $\begin{array}{c}\text { Labor and } \\
\text { capital }\end{array}$ & $\begin{array}{l}\text { Current } \\
\text { price }\end{array}$ & $\begin{array}{l}1985- \\
2005\end{array}$ & $\begin{array}{c}-0.2254, \\
0.0838\end{array}$ \\
\hline Liu et al. & 2009 & Chinese & China & Aggregate & SRM & $\begin{array}{l}\text { Time } \\
\text { series }\end{array}$ & $\begin{array}{c}\text { Labor and } \\
\text { capital }\end{array}$ & $\begin{array}{l}\text { Constant } \\
\text { price }\end{array}$ & $\begin{array}{l}1979- \\
2007\end{array}$ & $\begin{array}{c}0.0181, \\
0.0359\end{array}$ \\
\hline Liu et al. & 2007 & Chinese & China & Manufacturing & SFA & $\begin{array}{c}\text { Panel } \\
\text { data }\end{array}$ & More & $\begin{array}{l}\text { Constant } \\
\text { price }\end{array}$ & $\begin{array}{l}1996- \\
2005\end{array}$ & $\begin{array}{c}0.0900 \\
0.5800\end{array}$ \\
\hline Lu and Jin & 2005 & Chinese & China & Manufacturing & SRM & $\begin{array}{c}\text { Panel } \\
\text { data }\end{array}$ & $\begin{array}{c}\text { Labor and } \\
\text { capital }\end{array}$ & $\begin{array}{c}\text { Current } \\
\text { price }\end{array}$ & $\begin{array}{l}1990- \\
2000\end{array}$ & $\begin{array}{c}-0.0333, \\
0.0109\end{array}$ \\
\hline Ma J. & 1989 & Chinese & $\begin{array}{c}\text { China, east, } \\
\text { central and } \\
\text { west }\end{array}$ & Manufacturing & SRM & $\begin{array}{l}\text { Time } \\
\text { series }\end{array}$ & $\begin{array}{c}\text { Labor and } \\
\text { capital }\end{array}$ & $\begin{array}{c}\text { Current } \\
\text { price }\end{array}$ & $\begin{array}{c}1984- \\
1993\end{array}$ & $\begin{array}{c}-0.0264, \\
0.0794\end{array}$ \\
\hline Mao and Koo & 1997 & CER & $\begin{array}{l}\text { East, west } \\
\text { and central }\end{array}$ & Agriculture & DEA & $\begin{array}{c}\text { Panel } \\
\text { data }\end{array}$ & More & $\begin{array}{c}\text { Unknow } \\
n\end{array}$ & $\begin{array}{l}1979- \\
1984\end{array}$ & $\begin{array}{l}0.0045, \\
0.1132\end{array}$ \\
\hline McMillan et al. & 1989 & JPE & China & Agriculture & SRM & $\begin{array}{l}\text { Time } \\
\text { series }\end{array}$ & More & $\begin{array}{l}\text { Constant } \\
\text { price }\end{array}$ & $\begin{array}{l}1979- \\
1984\end{array}$ & $\begin{array}{l}0.0045, \\
0.1132\end{array}$ \\
\hline Mead R. W. & 2003 & $\mathrm{ECP}$ & China, west & Aggregate & SRM & $\begin{array}{l}\text { Time } \\
\text { series }\end{array}$ & More & $\begin{array}{l}\text { Constant } \\
\text { price }\end{array}$ & $\begin{array}{l}1984- \\
1999\end{array}$ & $\begin{array}{c}-0.0750, \\
0.1559\end{array}$ \\
\hline Meng and $\mathrm{Gu}$ & 2001 & Chinese & $\begin{array}{c}\text { China, east, } \\
\text { central and } \\
\text { west }\end{array}$ & Agriculture & DEA & $\begin{array}{c}\text { Panel } \\
\text { data }\end{array}$ & More & $\begin{array}{c}\text { Current } \\
\text { price }\end{array}$ & 1998 & $\begin{array}{c}-0.0350, \\
0.1650\end{array}$ \\
\hline Meng and $\mathrm{Li}$ & 2004 & $\begin{array}{c}\text { Chinese } \\
\text { WP }\end{array}$ & $\begin{array}{c}\text { China, east, } \\
\text { central and } \\
\text { west }\end{array}$ & Aggregate & DEA & $\begin{array}{c}\text { Panel } \\
\text { data }\end{array}$ & $\begin{array}{l}\text { Labor and } \\
\text { capital }\end{array}$ & $\begin{array}{c}\text { Constant } \\
\text { price }\end{array}$ & $\begin{array}{c}1952- \\
1998\end{array}$ & $\begin{array}{c}-0.0310, \\
0.0451\end{array}$ \\
\hline Ni and Wang & 2005 & Chinese & China & Aggregate & SRM & $\begin{array}{l}\text { Time } \\
\text { series }\end{array}$ & $\begin{array}{c}\text { Labor and } \\
\text { capital }\end{array}$ & $\begin{array}{l}\text { Constant } \\
\text { price }\end{array}$ & $\begin{array}{l}1979- \\
2002\end{array}$ & $\begin{array}{c}-0.0267, \\
0.1644\end{array}$ \\
\hline $\mathrm{Ni} \mathrm{H}$. & 2008 & Chinese & China & Aggregate & SRM & $\begin{array}{l}\text { Time } \\
\text { series }\end{array}$ & $\begin{array}{c}\text { Labor and } \\
\text { capital }\end{array}$ & $\begin{array}{l}\text { Constant } \\
\text { price }\end{array}$ & $\begin{array}{l}1953- \\
2005\end{array}$ & $\begin{array}{c}-0.0105, \\
0.0165\end{array}$ \\
\hline Nin et al. & 2010 & JPA & China & Agriculture & DEA & $\begin{array}{c}\text { Panel } \\
\text { data }\end{array}$ & More & $\begin{array}{l}\text { Constant } \\
\text { price }\end{array}$ & $\begin{array}{l}1962- \\
2006\end{array}$ & $\begin{array}{c}-0.1050, \\
0.1400\end{array}$ \\
\hline Nin-Pratt et al. & 2010 & JPA & China & Agriculture & DEA & $\begin{array}{c}\text { Panel } \\
\text { data }\end{array}$ & More & $\begin{array}{c}\text { Unknow } \\
n\end{array}$ & $\begin{array}{l}1962- \\
2006\end{array}$ & $\begin{array}{c}-0.1050, \\
0.1400\end{array}$ \\
\hline Peng and Gou & 2007 & Chinese & China & Aggregate & SRM & $\begin{array}{l}\text { Time } \\
\text { series }\end{array}$ & $\begin{array}{c}\text { Labor and } \\
\text { capital }\end{array}$ & $\begin{array}{l}\text { Constant } \\
\text { price }\end{array}$ & $\begin{array}{l}1986- \\
2004\end{array}$ & $\begin{array}{c}-0.1504, \\
0.0921\end{array}$ \\
\hline Ren and Yuan & 2006 & Chinese & China & Manufacturing & DEA & $\begin{array}{c}\text { Panel } \\
\text { data }\end{array}$ & $\begin{array}{c}\text { Labor and } \\
\text { capital }\end{array}$ & $\begin{array}{l}\text { Constant } \\
\text { price }\end{array}$ & $\begin{array}{l}1997- \\
2003\end{array}$ & $\begin{array}{c}0.0280, \\
0.0860\end{array}$ \\
\hline $\begin{array}{l}\text { Rong and } \\
\text { Wang }\end{array}$ & 2004 & Chinese & China & Manufacturing & SRM & $\begin{array}{l}\text { Time } \\
\text { series }\end{array}$ & $\begin{array}{c}\text { Labor and } \\
\text { capital }\end{array}$ & $\begin{array}{l}\text { Constant } \\
\text { price }\end{array}$ & $\begin{array}{l}1986- \\
2002\end{array}$ & $\begin{array}{c}-0.2051, \\
0.1176\end{array}$ \\
\hline Shen and Zhao & 2006 & Chinese & East & Aggregate & SRM & $\begin{array}{l}\text { Time } \\
\text { series }\end{array}$ & $\begin{array}{c}\text { Labor and } \\
\text { capital }\end{array}$ & $\begin{array}{l}\text { Constant } \\
\text { price }\end{array}$ & $\begin{array}{l}1979- \\
2003\end{array}$ & $\begin{array}{c}-0.0630, \\
0.0972\end{array}$ \\
\hline Shen et al. & 2007 & Chinese & China & Manufacturing & DEA & $\begin{array}{c}\text { Panel } \\
\text { data }\end{array}$ & $\begin{array}{c}\text { Labor and } \\
\text { capital }\end{array}$ & $\begin{array}{l}\text { Current } \\
\text { price }\end{array}$ & $\begin{array}{l}1985- \\
2003\end{array}$ & $\begin{array}{c}-0.0150, \\
0.0550\end{array}$ \\
\hline Shen K. & 1999 & Chinese & China & Aggregate & SRM & $\begin{array}{l}\text { Time } \\
\text { series }\end{array}$ & $\begin{array}{c}\text { Labor and } \\
\text { capital }\end{array}$ & $\begin{array}{l}\text { Constant } \\
\text { price }\end{array}$ & $\begin{array}{c}1953- \\
1997\end{array}$ & $\begin{array}{c}-0.0003, \\
0.0585\end{array}$ \\
\hline Shen K. & 1997 & Chinese & China & Aggregate & SRM & $\begin{array}{l}\text { Time } \\
\text { series }\end{array}$ & $\begin{array}{c}\text { Labor and } \\
\text { capital }\end{array}$ & $\begin{array}{l}\text { Current } \\
\text { price }\end{array}$ & $\begin{array}{l}1953- \\
1994\end{array}$ & $\begin{array}{c}-0.0873, \\
0.1070\end{array}$ \\
\hline Shen N. & 2006 & Chinese & $\begin{array}{c}\text { China, east, } \\
\text { central and } \\
\text { west }\end{array}$ & Manufacturing & DEA & $\begin{array}{c}\text { Panel } \\
\text { data }\end{array}$ & $\begin{array}{c}\text { Labor and } \\
\text { capital }\end{array}$ & $\begin{array}{c}\text { Current } \\
\text { price }\end{array}$ & $\begin{array}{l}1985- \\
2003\end{array}$ & $\begin{array}{c}-0.0220, \\
0.0620\end{array}$ \\
\hline Shi and Liu & 2006 & Chinese & China & Aggregate & SRM & $\begin{array}{l}\text { Time } \\
\text { series }\end{array}$ & $\begin{array}{c}\text { Labor and } \\
\text { capital }\end{array}$ & $\begin{array}{l}\text { Constant } \\
\text { price }\end{array}$ & $\begin{array}{l}1979- \\
2003\end{array}$ & $\begin{array}{c}-0.0851, \\
0.0750\end{array}$ \\
\hline Sun and Ren & 2005 & Chinese & China & Aggregate & SRM & $\begin{array}{l}\text { Time } \\
\text { series }\end{array}$ & $\begin{array}{c}\text { Labor and } \\
\text { capital }\end{array}$ & $\begin{array}{l}\text { Constant } \\
\text { price }\end{array}$ & $\begin{array}{l}1981- \\
2002\end{array}$ & $\begin{array}{c}-0.0422, \\
0.0967\end{array}$ \\
\hline Sun and Nian & 2011 & Chinese & $\begin{array}{c}\text { China, east, } \\
\text { central and } \\
\text { west }\end{array}$ & Service & DEA & $\begin{array}{c}\text { Panel } \\
\text { data }\end{array}$ & $\begin{array}{l}\text { Labor and } \\
\text { capital }\end{array}$ & $\begin{array}{l}\text { Constant } \\
\text { price }\end{array}$ & $\begin{array}{c}2005- \\
2009\end{array}$ & $\begin{array}{c}-0.0220, \\
0.1070\end{array}$ \\
\hline Tang A. M. & 1986 & Book & China & Agriculture & AINA & $\begin{array}{l}\text { Time } \\
\text { series }\end{array}$ & More & $\begin{array}{l}\text { Constant } \\
\text { price }\end{array}$ & $\begin{array}{c}1953- \\
1989\end{array}$ & $\begin{array}{c}-0.1686, \\
0.1742\end{array}$ \\
\hline
\end{tabular}




\begin{tabular}{|c|c|c|c|c|c|c|c|c|c|c|}
\hline Tong et al. & 2009 & WP & $\begin{array}{c}\text { China, east, } \\
\text { central and } \\
\text { west }\end{array}$ & Agriculture & $\begin{array}{l}\text { DEA, } \\
\text { SFA }\end{array}$ & $\begin{array}{c}\text { Panel } \\
\text { data }\end{array}$ & More & $\begin{array}{c}\text { Constant } \\
\text { price }\end{array}$ & $\begin{array}{l}1994- \\
2005\end{array}$ & $\begin{array}{c}-0.2560 \\
0.5240\end{array}$ \\
\hline Tu Z. & 2007 & Chinese & China & Manufacturing & DEA & $\begin{array}{c}\text { Panel } \\
\text { data }\end{array}$ & $\begin{array}{c}\text { Labor and } \\
\text { capital }\end{array}$ & $\begin{array}{l}\text { Constant } \\
\text { price }\end{array}$ & $\begin{array}{l}1996- \\
2004\end{array}$ & $\begin{array}{c}-0.1170, \\
0.1760\end{array}$ \\
\hline $\begin{array}{l}\text { Wang and } \\
\text { Cheng }\end{array}$ & 2005 & Chinese & China & Aggregate & SRM & $\begin{array}{l}\text { Time } \\
\text { series }\end{array}$ & $\begin{array}{c}\text { Labor and } \\
\text { capital }\end{array}$ & $\begin{array}{l}\text { Constant } \\
\text { price }\end{array}$ & $\begin{array}{l}1979- \\
2002\end{array}$ & $\begin{array}{c}-0.0457, \\
0.0827\end{array}$ \\
\hline Wang and $\mathrm{Ge}$ & 2007 & Chinese & $\begin{array}{c}\text { China, east, } \\
\text { central and } \\
\text { west }\end{array}$ & Agriculture & DEA & $\begin{array}{c}\text { Panel } \\
\text { data }\end{array}$ & More & $\begin{array}{c}\text { Constant } \\
\text { price }\end{array}$ & $\begin{array}{l}1982- \\
2004\end{array}$ & $\begin{array}{c}-0.0010, \\
0.0880\end{array}$ \\
\hline Wang and $\mathrm{Gu}$ & 2005 & Chinese & Central & Manufacturing & DEA & $\begin{array}{c}\text { Panel } \\
\text { data }\end{array}$ & More & $\begin{array}{l}\text { Constant } \\
\text { price }\end{array}$ & $\begin{array}{l}1994- \\
2002\end{array}$ & $\begin{array}{c}-0.1400, \\
0.1200\end{array}$ \\
\hline Wang and Liu & 2006 & Chinese & China & Aggregate & SRM & $\begin{array}{l}\text { Time } \\
\text { series }\end{array}$ & $\begin{array}{c}\text { Labor and } \\
\text { capital }\end{array}$ & $\begin{array}{l}\text { Constant } \\
\text { price }\end{array}$ & $\begin{array}{l}1953- \\
2001\end{array}$ & $\begin{array}{c}-0.2901, \\
0.1511\end{array}$ \\
\hline Wang and Yan & 2004 & $\begin{array}{l}\text { Chinese } \\
\text { WP }\end{array}$ & $\begin{array}{c}\text { China, east, } \\
\text { central and } \\
\text { west }\end{array}$ & Aggregate & DEA & $\begin{array}{l}\text { Panel } \\
\text { data }\end{array}$ & $\begin{array}{c}\text { Labor and } \\
\text { capital }\end{array}$ & $\begin{array}{l}\text { Constant } \\
\text { price }\end{array}$ & $\begin{array}{l}1979- \\
2001\end{array}$ & $\begin{array}{c}-0.0503, \\
0.0720\end{array}$ \\
\hline Wang and Yao & 2003 & CER & China & Aggregate & SRM & $\begin{array}{l}\text { Time } \\
\text { series }\end{array}$ & More & $\begin{array}{l}\text { Constant } \\
\text { price }\end{array}$ & $\begin{array}{c}1953- \\
1999\end{array}$ & $\begin{array}{c}-0.0167, \\
0.0306\end{array}$ \\
\hline Wang and Zhou & 2008 & Chinese & China & Aggregate & DEA & $\begin{array}{c}\text { Panel } \\
\text { data }\end{array}$ & More & $\begin{array}{l}\text { Constant } \\
\text { price }\end{array}$ & $\begin{array}{l}1995- \\
2005\end{array}$ & $\begin{array}{c}-0.0170, \\
0.0480\end{array}$ \\
\hline Wang et al. & 2005 & Chinese & China & Aggregate & DEA & $\begin{array}{c}\text { Panel } \\
\text { data }\end{array}$ & $\begin{array}{c}\text { Labor and } \\
\text { capital }\end{array}$ & $\begin{array}{l}\text { Constant } \\
\text { price }\end{array}$ & $\begin{array}{l}1953- \\
2002\end{array}$ & $\begin{array}{c}-0.2670, \\
0.1980\end{array}$ \\
\hline Wang et al. & 2009 & Chinese & China & Aggregate & SRM & $\begin{array}{l}\text { Time } \\
\text { series }\end{array}$ & More & $\begin{array}{l}\text { Constant } \\
\text { price }\end{array}$ & $\begin{array}{l}1953- \\
2007\end{array}$ & $\begin{array}{l}0.0181, \\
0.0374\end{array}$ \\
\hline Wang et al. & 2008 & Chinese & China & Service & $\begin{array}{c}\text { SRM,D } \\
\text { EA }\end{array}$ & $\begin{array}{c}\text { Panel } \\
\text { data }\end{array}$ & $\begin{array}{c}\text { Labor and } \\
\text { capital }\end{array}$ & $\begin{array}{l}\text { Constant } \\
\text { price }\end{array}$ & $\begin{array}{l}1980- \\
2005\end{array}$ & $\begin{array}{c}-0.0278, \\
0.0720\end{array}$ \\
\hline Wang Q. & 2009 & Chinese & East & Aggregate & SRM & $\begin{array}{l}\text { Time } \\
\text { series }\end{array}$ & $\begin{array}{c}\text { Labor and } \\
\text { capital }\end{array}$ & $\begin{array}{l}\text { Constant } \\
\text { price }\end{array}$ & $\begin{array}{l}1980- \\
2006\end{array}$ & 0.0880 \\
\hline Wen G. J. & 1993 & EDCC & China & Agriculture & AINA & $\begin{array}{l}\text { Time } \\
\text { series }\end{array}$ & More & $\begin{array}{l}\text { Constant } \\
\text { price }\end{array}$ & $\begin{array}{l}1953- \\
1989\end{array}$ & $\begin{array}{c}-0.1762, \\
0.1889\end{array}$ \\
\hline Wen $\mathrm{H}$. & 2005 & Chinese & $\begin{array}{c}\text { China, east, } \\
\text { central and } \\
\text { west }\end{array}$ & Aggregate & SRM & $\begin{array}{l}\text { Time } \\
\text { series }\end{array}$ & $\begin{array}{c}\text { Labor and } \\
\text { capital }\end{array}$ & $\begin{array}{c}\text { Constant } \\
\text { price }\end{array}$ & $\begin{array}{l}1989- \\
2001\end{array}$ & $\begin{array}{c}-0.0131 \\
0.0905\end{array}$ \\
\hline Wong L. & 1986 & Book & China & Agriculture & AINA & $\begin{array}{l}\text { Time } \\
\text { series }\end{array}$ & More & $\begin{array}{c}\text { Constant } \\
\text { price }\end{array}$ & $\begin{array}{c}1953- \\
1989\end{array}$ & $\begin{array}{c}-0.1651, \\
0.1792\end{array}$ \\
\hline Woo W. T. & 1997 & $\mathrm{CE}$ & China & Aggregate & SRM & $\begin{array}{l}\text { Time } \\
\text { series }\end{array}$ & $\begin{array}{c}\text { Labor and } \\
\text { capital }\end{array}$ & $\begin{array}{l}\text { Constant } \\
\text { price }\end{array}$ & $\begin{array}{c}1979- \\
1993\end{array}$ & $\begin{array}{c}-0.0519, \\
0.0547\end{array}$ \\
\hline Wu and Wang & 2002 & Chinese & China & Aggregate & SRM & $\begin{array}{l}\text { Time } \\
\text { series }\end{array}$ & More & $\begin{array}{l}\text { Constant } \\
\text { price }\end{array}$ & $\begin{array}{c}1981- \\
1998\end{array}$ & $\begin{array}{l}0.0294, \\
0.0420\end{array}$ \\
\hline Wu et al. & 2001 & RDE & $\begin{array}{c}\text { China, east, } \\
\text { central and } \\
\text { west }\end{array}$ & Agriculture & DEA & $\begin{array}{c}\text { Panel } \\
\text { data }\end{array}$ & More & $\begin{array}{c}\text { Constant } \\
\text { price }\end{array}$ & $\begin{array}{c}1980- \\
1995\end{array}$ & $\begin{array}{c}-0.0395 \\
0.0853\end{array}$ \\
\hline Wu S. & 2007 & Chinese & China & Aggregate & SRM & $\begin{array}{l}\text { Time } \\
\text { series }\end{array}$ & $\begin{array}{c}\text { Labor and } \\
\text { capital }\end{array}$ & $\begin{array}{c}\text { Constant } \\
\text { price }\end{array}$ & $\begin{array}{l}1952- \\
2003\end{array}$ & $\begin{array}{c}-0.0050, \\
0.0228\end{array}$ \\
\hline Wu Y. & 2008 & Chinese & China & Aggregate & SFA & $\begin{array}{c}\text { Panel } \\
\text { data }\end{array}$ & More & $\begin{array}{l}\text { Constant } \\
\text { price }\end{array}$ & $\begin{array}{l}1993- \\
2004\end{array}$ & $\begin{array}{l}0.0164, \\
0.0430\end{array}$ \\
\hline Xiao and Lin & 2011 & Chinese & China & Aggregate & DEA & $\begin{array}{c}\text { Panel } \\
\text { data }\end{array}$ & $\begin{array}{c}\text { Labor and } \\
\text { capital }\end{array}$ & $\begin{array}{l}\text { Constant } \\
\text { price }\end{array}$ & $\begin{array}{l}2003- \\
2007\end{array}$ & $\begin{array}{l}0.0110, \\
0.1250\end{array}$ \\
\hline Xiao and Wang & 2006 & Chinese & Central & Manufacturing & DEA & $\begin{array}{c}\text { Panel } \\
\text { data }\end{array}$ & More & $\begin{array}{l}\text { Constant } \\
\text { price }\end{array}$ & $\begin{array}{l}1999- \\
2003\end{array}$ & $\begin{array}{c}-0.1010, \\
0.7670\end{array}$ \\
\hline Xie et al. & 2008 & Chinese & China & Manufacturing & SRM & $\begin{array}{c}\text { Panel } \\
\text { data }\end{array}$ & More & $\begin{array}{l}\text { Current } \\
\text { price }\end{array}$ & $\begin{array}{l}1998- \\
2005\end{array}$ & 0.1026 \\
\hline Xin and Qin & 2009 & WP & $\begin{array}{l}\text { East, west } \\
\text { and central }\end{array}$ & Agriculture & DEA & $\begin{array}{c}\text { Panel } \\
\text { data }\end{array}$ & More & $\begin{array}{l}\text { Constant } \\
\text { price }\end{array}$ & $\begin{array}{l}1988- \\
2005\end{array}$ & $\begin{array}{c}-0.0480, \\
0.0830\end{array}$ \\
\hline $\mathrm{Xu}$ and $\mathrm{Du}$ & 2005 & Chinese & China & Aggregate & SRM & $\begin{array}{l}\text { Time } \\
\text { series }\end{array}$ & $\begin{array}{c}\text { Labor and } \\
\text { capital }\end{array}$ & $\begin{array}{l}\text { Constant } \\
\text { price }\end{array}$ & $\begin{array}{l}1953- \\
2003\end{array}$ & $\begin{array}{l}0.0276 \\
0.0501\end{array}$ \\
\hline $\mathrm{Xu}$ and Wang & 2008 & Chinese & East & Aggregate & DEA & $\begin{array}{c}\text { Panel } \\
\text { data }\end{array}$ & $\begin{array}{c}\text { Labor and } \\
\text { capital }\end{array}$ & $\begin{array}{l}\text { Constant } \\
\text { price }\end{array}$ & $\begin{array}{l}1990- \\
2005\end{array}$ & $\begin{array}{c}0.0089 \\
0.0165\end{array}$ \\
\hline $\begin{array}{l}\text { Yang and } \\
\text { Wang }\end{array}$ & 2008 & Chinese & $\begin{array}{c}\text { China, east, } \\
\text { central and } \\
\text { west }\end{array}$ & Manufacturing & DEA & $\begin{array}{c}\text { Panel } \\
\text { data }\end{array}$ & $\begin{array}{l}\text { Labor and } \\
\text { capital }\end{array}$ & $\begin{array}{c}\text { Constant } \\
\text { price }\end{array}$ & $\begin{array}{l}2000- \\
2005\end{array}$ & $\begin{array}{c}-0.3990 \\
0.9760\end{array}$ \\
\hline Yang T. & 1994 & Chinese & China & Manufacturing & SRM & $\begin{array}{l}\text { Time } \\
\text { series }\end{array}$ & $\begin{array}{c}\text { Labor and } \\
\text { capital }\end{array}$ & $\begin{array}{l}\text { Current } \\
\text { price }\end{array}$ & $\begin{array}{c}1981- \\
1990\end{array}$ & $\begin{array}{c}-0.5229 \\
0.9603\end{array}$ \\
\hline Ye Y. & 2002 & Chinese & $\begin{array}{c}\text { China, east, } \\
\text { central and } \\
\text { west }\end{array}$ & Aggregate & SRM & $\begin{array}{l}\text { Time } \\
\text { series }\end{array}$ & $\begin{array}{l}\text { Labor and } \\
\text { capital }\end{array}$ & $\begin{array}{c}\text { Constant } \\
\text { price }\end{array}$ & $\begin{array}{c}1979- \\
1998\end{array}$ & $\begin{array}{c}0.0359 \\
0.0558\end{array}$ \\
\hline Young A. & 2003 & JPE & China & Non-agricultural sector & SRM & $\begin{array}{l}\text { Time } \\
\text { series }\end{array}$ & More & $\begin{array}{l}\text { Constant } \\
\text { price }\end{array}$ & $\begin{array}{c}1978- \\
1998\end{array}$ & 0.0140 \\
\hline Zeng and $\mathrm{Li}$ & 2008 & Chinese & $\begin{array}{c}\text { China, east, } \\
\text { central and } \\
\text { west }\end{array}$ & Agriculture & DEA & $\begin{array}{c}\text { Panel } \\
\text { data }\end{array}$ & More & $\begin{array}{c}\text { Constant } \\
\text { price }\end{array}$ & $\begin{array}{l}1981- \\
2005\end{array}$ & $\begin{array}{c}-0.0865 \\
0.1534\end{array}$ \\
\hline Zeng X. & 2008 & Chinese & China & Agriculture & DEA & $\begin{array}{c}\text { Panel } \\
\text { data }\end{array}$ & More & $\begin{array}{c}\text { Constant } \\
\text { price }\end{array}$ & $\begin{array}{l}1981- \\
2005\end{array}$ & $\begin{array}{c}-0.0380 \\
0.0830\end{array}$ \\
\hline
\end{tabular}




\begin{tabular}{|c|c|c|c|c|c|c|c|c|c|c|}
\hline Zhang and Gui & 2008 & Chinese & $\begin{array}{c}\text { China, east, } \\
\text { central and } \\
\text { west }\end{array}$ & Aggregate & DEA & $\begin{array}{c}\text { Panel } \\
\text { data }\end{array}$ & $\begin{array}{c}\text { Labor and } \\
\text { capital }\end{array}$ & $\begin{array}{c}\text { Constant } \\
\text { price }\end{array}$ & $\begin{array}{l}1979- \\
2005\end{array}$ & $\begin{array}{c}-0.0424, \\
0.0886\end{array}$ \\
\hline Zhang and Shi & 2003 & Chinese & China & Aggregate & SRM & $\begin{array}{l}\text { Time } \\
\text { series }\end{array}$ & $\begin{array}{c}\text { Labor and } \\
\text { capital }\end{array}$ & $\begin{array}{c}\text { Constant } \\
\text { price }\end{array}$ & $\begin{array}{c}1953- \\
1998\end{array}$ & $\begin{array}{c}-0.2909, \\
0.1260\end{array}$ \\
\hline Zhang and $\mathrm{Xu}$ & 2009 & Chinese & China & Aggregate & SRM & $\begin{array}{l}\text { Time } \\
\text { series }\end{array}$ & $\begin{array}{c}\text { Labor and } \\
\text { capital }\end{array}$ & $\begin{array}{c}\text { Constant } \\
\text { price }\end{array}$ & $\begin{array}{l}1980- \\
2005\end{array}$ & $\begin{array}{r}-0.0376, \\
0.0849\end{array}$ \\
\hline Zhang et al. & 2006 & Chinese & China & Manufacturing & DEA & $\begin{array}{c}\text { Panel } \\
\text { data }\end{array}$ & More & $\begin{array}{c}\text { Constant } \\
\text { price }\end{array}$ & $\begin{array}{l}1999- \\
2005\end{array}$ & $\begin{array}{r}-0.0030, \\
0.0130\end{array}$ \\
\hline Zhang et al. & 2009 & Chinese & China & Manufacturing & SFA & $\begin{array}{c}\text { Panel } \\
\text { data }\end{array}$ & $\begin{array}{c}\text { Labor and } \\
\text { capital }\end{array}$ & $\begin{array}{l}\text { Constant } \\
\text { price }\end{array}$ & $\begin{array}{l}1981- \\
2006\end{array}$ & $\begin{array}{c}0.0200, \\
0.1000\end{array}$ \\
\hline Zhang Y. & 2007 & Chinese & China & Aggregate & DEA & $\begin{array}{c}\text { Panel } \\
\text { data }\end{array}$ & $\begin{array}{c}\text { Labor and } \\
\text { capital }\end{array}$ & $\begin{array}{l}\text { Constant } \\
\text { price }\end{array}$ & $\begin{array}{l}1981- \\
2004\end{array}$ & $\begin{array}{r}-0.0900, \\
0.1700\end{array}$ \\
\hline Zhang Z. & 2008 & Chinese & $\begin{array}{c}\text { China, east, } \\
\text { central and } \\
\text { west }\end{array}$ & Service & DEA & $\begin{array}{c}\text { Panel } \\
\text { data }\end{array}$ & $\begin{array}{c}\text { Labor and } \\
\text { capital }\end{array}$ & $\begin{array}{c}\text { Constant } \\
\text { price }\end{array}$ & $\begin{array}{l}1994- \\
2004\end{array}$ & $\begin{array}{r}-0.0060, \\
0.2280\end{array}$ \\
\hline Zhao and $\mathrm{Hu}$ & 2005 & Chinese & China & Aggregate & SRM & $\begin{array}{l}\text { Time } \\
\text { series }\end{array}$ & $\begin{array}{c}\text { Labor and } \\
\text { capital }\end{array}$ & $\begin{array}{c}\text { Constant } \\
\text { price }\end{array}$ & $\begin{array}{l}1952- \\
2003\end{array}$ & $\begin{array}{c}-0.0028, \\
0.0256\end{array}$ \\
\hline $\begin{array}{c}\text { Zhao and } \\
\text { Zhang }\end{array}$ & 2006 & Chinese & China & Agriculture & SRM & $\begin{array}{c}\text { Panel } \\
\text { data }\end{array}$ & More & $\begin{array}{c}\text { Constant } \\
\text { price }\end{array}$ & $\begin{array}{l}1986- \\
2003\end{array}$ & $\begin{array}{l}0.0005, \\
0.0283\end{array}$ \\
\hline Zhao et al. & 2005 & Chinese & $\begin{array}{c}\text { China, east, } \\
\text { central and } \\
\text { west }\end{array}$ & Aggregate & DEA & $\begin{array}{c}\text { Panel } \\
\text { data }\end{array}$ & $\begin{array}{c}\text { Labor and } \\
\text { capital }\end{array}$ & $\begin{array}{c}\text { Constant } \\
\text { price }\end{array}$ & $\begin{array}{l}1980- \\
2003\end{array}$ & $\begin{array}{r}-0.1730, \\
0.1510\end{array}$ \\
\hline Zhao H. & 2004 & Chinese & China & Agriculture & SRM & $\begin{array}{l}\text { Time } \\
\text { series }\end{array}$ & $\begin{array}{c}\text { Labor and } \\
\text { capital }\end{array}$ & $\begin{array}{c}\text { Constant } \\
\text { price }\end{array}$ & $\begin{array}{l}1980- \\
2000\end{array}$ & $\begin{array}{c}-0.0732, \\
0.4366\end{array}$ \\
\hline Zhao X. & 2008 & Chinese & $\begin{array}{c}\text { China, east, } \\
\text { central and } \\
\text { west }\end{array}$ & Manufacturing & DEA & $\begin{array}{c}\text { Panel } \\
\text { data }\end{array}$ & More & $\begin{array}{c}\text { Constant } \\
\text { price }\end{array}$ & $\begin{array}{l}2002- \\
2005\end{array}$ & $\begin{array}{r}-0.0010, \\
0.0540\end{array}$ \\
\hline Zheng and $\mathrm{Hu}$ & 2005 & Chinese & $\begin{array}{c}\text { China, east, } \\
\text { central and } \\
\text { west }\end{array}$ & Aggregate & DEA & $\begin{array}{c}\text { Panel } \\
\text { data }\end{array}$ & More & $\begin{array}{c}\text { Constant } \\
\text { price }\end{array}$ & $\begin{array}{l}1980- \\
2000\end{array}$ & $\begin{array}{c}-0.0204, \\
0.1091\end{array}$ \\
\hline Zheng et al. & 1995 & Chinese & East & Manufacturing & SFA & $\begin{array}{c}\text { Panel } \\
\text { data }\end{array}$ & More & $\begin{array}{c}\text { Constant } \\
\text { price }\end{array}$ & $\begin{array}{c}1991- \\
1992\end{array}$ & $\begin{array}{c}-0.1389 \\
0.1785\end{array}$ \\
\hline Zheng et al. & 2008 & Chinese & China & Aggregate & SRM & $\begin{array}{l}\text { Time } \\
\text { series }\end{array}$ & More & $\begin{array}{c}\text { Constant } \\
\text { price }\end{array}$ & $\begin{array}{l}1978- \\
2005\end{array}$ & $\begin{array}{l}0.0079 \\
0.0427\end{array}$ \\
\hline zheng et al. & 2009 & WD & China & Aggregate & SRM & $\begin{array}{l}\text { Time } \\
\text { series }\end{array}$ & $\begin{array}{c}\text { Labor and } \\
\text { capital }\end{array}$ & $\begin{array}{c}\text { Unknow } \\
\mathrm{n}\end{array}$ & $\begin{array}{l}1978- \\
1995\end{array}$ & $\begin{array}{l}0.0079 \\
0.0427\end{array}$ \\
\hline Zhi D. & 1997 & Chinese & China & Aggregate & SRM & $\begin{array}{l}\text { Time } \\
\text { series }\end{array}$ & $\begin{array}{c}\text { Labor and } \\
\text { capital }\end{array}$ & $\begin{array}{l}\text { Current } \\
\text { price }\end{array}$ & $\begin{array}{c}1978- \\
1994\end{array}$ & $\begin{array}{c}-0.0280, \\
0.0957\end{array}$ \\
\hline Zhi D. & 1995 & Chinese & China & Aggregate & SRM & $\begin{array}{l}\text { Time } \\
\text { series }\end{array}$ & $\begin{array}{c}\text { Labor and } \\
\text { capital }\end{array}$ & $\begin{array}{c}\text { Constant } \\
\text { price }\end{array}$ & $\begin{array}{c}1978- \\
1993\end{array}$ & $\begin{array}{c}-0.0472, \\
0.0877\end{array}$ \\
\hline Zhu and $\mathrm{Li}$ & 2005 & Chinese & China & Manufacturing & SRM & $\begin{array}{c}\text { Panel } \\
\text { data }\end{array}$ & More & $\begin{array}{c}\text { Constant } \\
\text { price }\end{array}$ & $\begin{array}{l}1987- \\
2002\end{array}$ & $\begin{array}{c}-0.0566, \\
0.0317\end{array}$ \\
\hline Zhu W. & 2008 & Chinese & China & Aggregate & SRM & $\begin{array}{l}\text { Time } \\
\text { series }\end{array}$ & $\begin{array}{c}\text { Labor and } \\
\text { capital }\end{array}$ & $\begin{array}{c}\text { Constant } \\
\text { price }\end{array}$ & $\begin{array}{l}1984- \\
2004\end{array}$ & $\begin{array}{c}-0.1867, \\
0.1936\end{array}$ \\
\hline
\end{tabular}

Notes: 1. Time-paper in the second column denotes the date of publication for published work and the date of finishing the paper as a working paper respectively.

2. There are two values in the TFPG Range column. The former is the minimum TFPG in the respective primary study and the latter is the maximum TFPG. 


\section{1: Further Explanation of the CHNS Data}

1. Food consumption is calculated as follows: We use the household inventory change data and first calculate the changes in food inventory during the survey period. Then, as the number of meals eaten at home for the same three consecutive days is also collected for all family members, we can assign different weights to the three daily meals (breakfast, lunch and dinner) according to each person's dietary habit, and multiply these weights by the number of meals eaten at home during this period to calculate the total number of person-days, which is used to divide the inventory change during these days for each food group and generate the food consumption per person per day (Du et al., 2002; Du et al., 2004; Guo et al., 2000; Popkin et al., 2002; Wang et al., 2002).

2. To calculate the total calorie intake and share of calorie obtained from protein and fat, the China Food Composition Tables from 2002 and 2004 (CDC, 2002, 2004) are used to convert the detailed food consumption data to the intake of calorie, protein and fat as listed in the book. Moreover, the edible proportion of each food item is also used in the conversion to make sure that the nutrient intake is the actual level of nutrition consumed by people, not the nutrient availability. We further sum up the nutrient intake from all food products consumed in each household and capture the nutrient intake per capita per day.

3. We only use samples with full information and per capita calorie intake greater than 520 and less than 10000 kilocalories, and make sure that the calorie shares of 6 selected food groups are less than 0.9.

4. We use the generated per capita net income in the survey as income variables and deflate the data in 2004 and 2006 to 2009 value using the national CPI in the corresponding years, which are 113.873 in 2004 and 110.206 in 2006, respectively. 
5. In addition, prices are only collected for 45 specific food and beverage products both in supermarkets and in free shops in the surveyed communities, while more than 1000 different food products are reported in the household consumption, thus we follow McKelvey's (2011) method by using the price of one representative food to stand for the price level in the corresponding food group. Finally, the cleaned free shop prices are used as the representative price for that group. 


\section{2: Descriptive Statistic of Nutrition Improvement and}

\section{Dietary Changes Indices}

\begin{tabular}{llllllll}
\hline Variable & Obs. & Mean & Std. Dev. & Min & Max & Unit & Definition \\
\hline Pkcal & 12267 & 2223 & 840.6484 & 524.6844 & 9898.1530 & $\mathrm{kcal}$ & Per capita calorie intake \\
Protein & 12267 & $12.57 \%$ & 0.0336 & $2.22 \%$ & $48.28 \%$ & - & Share of calorie obtained from protein \\
Fat & 12267 & $31.16 \%$ & 0.1192 & $2.06 \%$ & $89.76 \%$ & - & Share of calorie obtained from fat \\
UnitV & 12267 & 9.37 & 4.4916 & 1.7225 & 117.9015 & Yuan $/ 500 \mathrm{~g}$ & Unit value of food \\
UnitVK & 12267 & 4.81 & 2.3926 & 1.1328 & 45.8746 & Yuan $/ 500 \mathrm{kcal}$ & Unit value of calorie \\
Diversity & 12267 & 16.48 & 5.4465 & 2.0000 & 44.0000 & Counts & Number of food categories consumed \\
UnitK & 12267 & 2.02 & 0.4669 & 0.4273 & 5.9929 & $\mathrm{kcal} / \mathrm{g}$ & Uning the survey time \\
BMI & 12267 & 23.17 & 3.3338 & 0.0000 & 42.7246 & $\mathrm{~kg} / \mathrm{m}{ }^{2}$ & Body mass index \\
CS-Staple & 12267 & $54.08 \%$ & 0.1628 & $0.00 \%$ & $89.99 \%$ & - & Calorie share of staple food \\
CS-Fruit & 12267 & $1.23 \%$ & 0.0299 & $0.00 \%$ & $54.58 \%$ & - & Calorie share of fruit \\
CS-Meat & 12267 & $10.85 \%$ & 0.1033 & $0.00 \%$ & $74.00 \%$ & - & Calorie share of meat \\
CS-Dairy & 12267 & $0.40 \%$ & 0.0178 & $0.00 \%$ & $58.55 \%$ & - & Calorie share of dairy \\
CS-Vegetable & 12267 & $3.98 \%$ & 0.0329 & $0.00 \%$ & $66.32 \%$ & - & Calorie share of vegetable \\
CS-Oil & 12267 & $17.04 \%$ & 0.1035 & $0.00 \%$ & $87.20 \%$ & - & Calorie share of oil \\
ES-Staple & 12267 & $25.86 \%$ & 0.1477 & $0.00 \%$ & $88.34 \%$ & - & Expenditure share of staple food \\
ES-Fruit & 12267 & $3.19 \%$ & 0.0753 & $0.00 \%$ & $90.18 \%$ & - & Expenditure share of fruit \\
ES-Meat & 12267 & $23.85 \%$ & 0.2019 & $0.00 \%$ & $90.83 \%$ & - & Expenditure share of meat \\
ES-Dairy & 12267 & $0.90 \%$ & 0.0490 & $0.00 \%$ & $77.38 \%$ & - & Expenditure share of dairy \\
ES-Vegetable & 12267 & $12.67 \%$ & 0.0872 & $0.00 \%$ & $68.83 \%$ & - & Expenditure share of vegetable \\
ES-Oil & 12267 & $9.81 \%$ & 0.0789 & $0.00 \%$ & $88.67 \%$ & - & Expenditure share of oil \\
\hline
\end{tabular}




\section{3: Definitions and Descriptive Analysis of Variables}

\begin{tabular}{lllllll}
\hline Variable & Obs. & Mean & Std. Dev. & Min & Max & Definition \\
\hline income & 12266 & 8434.3990 & 11012.91 & 0.8429 & 288000 & Per capita income in 2004 \\
lnincome & 12266 & 8.5131 & 1.1263 & -0.1710 & 12.5707 & Logarithm of per capita income in 2004 \\
hhsize & 12267 & 4.0730 & 1.7843 & 1.0000 & 15.0000 & Household size \\
hhmale & 12267 & 0.8347 & 0.3715 & 0.0000 & 1.0000 & Gender of household head \\
hhage & 12266 & 54.2008 & 13.0960 & 0.0000 & 99.0000 & Age of household head \\
hheduyear & 12267 & 7.5096 & 3.9872 & 0.0000 & 18.0000 & Education year of household head \\
hhactivity & 12267 & 2.0174 & 1.6481 & 0.0000 & 5.0000 & Activity level of household head \\
mcookedu & 12267 & 4.9703 & 3.7151 & 0.0000 & 18.0000 & $\begin{array}{l}\text { Mean education year of people who } \\
\text { cooked during the survey time }\end{array}$ \\
& & & & & & Mean activity level of people who \\
mcookact & 12267 & 1.5257 & 1.2970 & 0.0000 & 5.0000 & cooked during the survey time \\
schild & 12267 & 0.0279 & 0.0770 & 0.0000 & 0.6000 & Ratio of children aged 0 to 5 \\
sf610 & 12267 & 0.0149 & 0.0593 & 0.0000 & 0.5000 & Ratio of female aged 6 to 10 \\
sf1118 & 12267 & 0.0406 & 0.0976 & 0.0000 & 0.6000 & Ratio of female aged 11 to 18 \\
sfadult & 12267 & 0.3330 & 0.1891 & 0.0000 & 1.0000 & Ratio of female aged 19 to 60 \\
sfold & 12267 & 0.1056 & 0.1870 & 0.0000 & 1.0000 & Ratio of female older than 60 \\
sm610 & 12267 & 0.0176 & 0.0637 & 0.0000 & 0.6667 & Ratio of male aged 6 to 10 \\
sm1118 & 12267 & 0.0489 & 0.1084 & 0.0000 & 0.6667 & Ratio of male aged 11 to 18 \\
smadult & 12267 & 0.3111 & 0.1929 & 0.0000 & 1.0000 & Ratio of male aged 19 to 60 \\
smold & 12267 & 0.0937 & 0.1682 & 0.0000 & 1.0000 & Ratio of male older than 60 \\
y2006 & 12267 & 0.3345 & 0.4718 & 0.0000 & 1.0000 & Year dummy for 2006 \\
y2009 & 12267 & 0.3416 & 0.4743 & 0.0000 & 1.0000 & Year dummy for 2009 \\
\hline
\end{tabular}




\section{4: Non-income Effect of Nutrition Improvement}

\begin{tabular}{|c|c|c|c|c|c|c|c|c|}
\hline Variables & Pkcal & Protein & Fat & UnitV & UnitVK & Diversity & UnitK & BMI \\
\hline hhsize & $\begin{array}{l}25.2285 \\
(5.03)^{* * * *}\end{array}$ & $\begin{array}{l}0.0001 \\
(0.46)\end{array}$ & $\begin{array}{l}-0.0015 \\
(-2.08)^{* *}\end{array}$ & $\begin{array}{l}0.0281 \\
(1.16)\end{array}$ & $\begin{array}{l}-0.021 \\
(-1.62)\end{array}$ & $\begin{array}{l}0.3086 \\
(10.59)^{* * * *}\end{array}$ & $\begin{array}{l}0.0076 \\
(2.65)^{* * * *}\end{array}$ & $\begin{array}{l}0.058 \\
(2.80)^{* * * *}\end{array}$ \\
\hline hhmale & $\begin{array}{l}-41.719 \\
(-1.95)^{*}\end{array}$ & $\begin{array}{l}-0.001 \\
(-1.14)\end{array}$ & $\begin{array}{l}-0.0157 \\
(-5.18)^{* * *}\end{array}$ & $\begin{array}{l}-0.1044 \\
(-1.01)\end{array}$ & $\begin{array}{l}-0.0301 \\
(-0.55)\end{array}$ & $\begin{array}{l}-0.151 \\
(-1.22)\end{array}$ & $\begin{array}{l}-0.0125 \\
(-1.02)\end{array}$ & $\begin{array}{l}-0.5756 \\
(-6.52) * * *\end{array}$ \\
\hline hhage & $\begin{array}{l}-8.6709 \\
(-9.06)^{* * *}\end{array}$ & $\begin{array}{l}-0.0001 \\
(-1.78)^{*}\end{array}$ & $\begin{array}{l}0.0001 \\
(0.72)\end{array}$ & $\begin{array}{l}-0.0019 \\
(-0.42)\end{array}$ & $\begin{array}{l}0.0001 \\
(0.06)\end{array}$ & $\begin{array}{l}-0.0041 \\
(-0.74)\end{array}$ & $\begin{array}{l}-0.0007 \\
(-1.30)\end{array}$ & $\begin{array}{l}-0.0109 \\
(-2.75)^{* * *}\end{array}$ \\
\hline hheduyear & $\begin{array}{l}-4.5646 \\
(-1.85)^{*}\end{array}$ & $\begin{array}{l}0.0003 \\
(3.26)^{* * * *}\end{array}$ & $\begin{array}{l}0.0014 \\
(3.85)^{* * * *}\end{array}$ & $\begin{array}{l}0.0202 \\
(1.69)^{*}\end{array}$ & $\begin{array}{l}0.0296 \\
(4.66)^{* * * *}\end{array}$ & $\begin{array}{l}0.1375 \\
(9.59)^{* * *}\end{array}$ & $\begin{array}{l}-0.0059 \\
(-4.19) * * *\end{array}$ & $\begin{array}{l}0.0407 \\
(3.99)^{* * * *}\end{array}$ \\
\hline hhactivity & $\begin{array}{l}11.56 \\
(1.58)\end{array}$ & $\begin{array}{l}-0.0003 \\
(-1.04)\end{array}$ & $\begin{array}{l}-0.0032 \\
(-3.04)^{* * * *}\end{array}$ & $\begin{array}{l}-0.1231 \\
(-3.47)^{* * * *}\end{array}$ & $\begin{array}{l}-0.0697 \\
(-3.69) * * *\end{array}$ & $\begin{array}{l}-0.0847 \\
(-1.99)^{* *}\end{array}$ & $\begin{array}{l}0.0005 \\
(0.12)\end{array}$ & $\begin{array}{l}-0.004 \\
(-0.13)\end{array}$ \\
\hline mcookedu & $\begin{array}{l}-2.0191 \\
(-0.76)\end{array}$ & $\begin{array}{l}0.0007 \\
(6.28)^{* * * *}\end{array}$ & $\begin{array}{l}0.0017 \\
(4.46)^{* * *}\end{array}$ & $\begin{array}{l}0.0508 \\
(3.97)^{* * * *}\end{array}$ & $\begin{array}{l}0.0321 \\
(4.72)^{* * *}\end{array}$ & $\begin{array}{l}0.0258 \\
(1.68)^{*}\end{array}$ & $\begin{array}{l}-0.0012 \\
(-0.80)\end{array}$ & $\begin{array}{l}0.0054 \\
(0.50)\end{array}$ \\
\hline mcookact & $\begin{array}{l}46.7696 \\
(5.71)^{* * * *}\end{array}$ & $\begin{array}{l}-2.40 \mathrm{E}-03 \\
(-7.16)^{* * * *}\end{array}$ & $\begin{array}{l}-0.0049 \\
(-4.22)^{* * *}\end{array}$ & $\begin{array}{l}-0.1972 \\
(-4.97)^{* * *}\end{array}$ & $\begin{array}{l}-0.1198 \\
(-5.68)^{* * *}\end{array}$ & $\begin{array}{l}-0.48 \\
(-10.08)^{* * *}\end{array}$ & $\begin{array}{l}0.0111 \\
(2.37)^{* *}\end{array}$ & $\begin{array}{l}-0.1973 \\
(-5.83) * * *\end{array}$ \\
\hline schild & $\begin{array}{l}-1.72 \mathrm{E}+03 \\
(-15.41)^{* * *}\end{array}$ & $\begin{array}{l}1.60 \mathrm{E}-03 \\
(0.34)\end{array}$ & $\begin{array}{l}0.0109 \\
(0.69)\end{array}$ & $\begin{array}{l}-0.0597 \\
(-0.11)\end{array}$ & $\begin{array}{l}0.0517 \\
(0.18)\end{array}$ & $\begin{array}{l}3.2597 \\
(5.04)^{* * *}\end{array}$ & $\begin{array}{l}0.028 \\
(0.44)\end{array}$ & $\begin{array}{l}-2.837 \\
(-6.17)^{* * *}\end{array}$ \\
\hline sf610 & $\begin{array}{l}-1.82 \mathrm{E}+03 \\
(-13.79) * * *\end{array}$ & $\begin{array}{l}0.0058 \\
(1.07)\end{array}$ & $\begin{array}{l}0.0443 \\
(2.36)^{* * *}\end{array}$ & $\begin{array}{l}-0.3546 \\
(-0.55)\end{array}$ & $\begin{array}{l}0.2194 \\
(0.64)\end{array}$ & $\begin{array}{l}3.3495 \\
(4.36)^{* * *}\end{array}$ & $\begin{array}{l}-0.1192 \\
(-1.57)\end{array}$ & $\begin{array}{l}-2.7007 \\
(-4.95)^{* * *}\end{array}$ \\
\hline sf1118 & $\begin{array}{l}-950.105 \\
(-10.54)^{* * *}\end{array}$ & $\begin{array}{l}0.0017 \\
(0.47)\end{array}$ & $\begin{array}{l}0.0166 \\
(1.30)\end{array}$ & $\begin{array}{l}-0.5596 \\
(-1.28)\end{array}$ & $\begin{array}{l}-0.3188 \\
(-1.37)\end{array}$ & $\begin{array}{l}1.9051 \\
(3.64)^{* * * *}\end{array}$ & $\begin{array}{l}0.0313 \\
(0.61)\end{array}$ & $\begin{array}{l}-0.1539 \\
(-0.41)\end{array}$ \\
\hline sfadult & $\begin{array}{l}-624.0785 \\
(-9.71)^{* * *}\end{array}$ & $\begin{array}{l}0.003 \\
(1.12)\end{array}$ & $\begin{array}{l}0.0149 \\
(1.63)\end{array}$ & $\begin{array}{l}0.341 \\
(1.10)\end{array}$ & $\begin{array}{l}0.2279 \\
(1.38)\end{array}$ & $\begin{array}{l}1.099 \\
(2.94)^{* * * *}\end{array}$ & $\begin{array}{l}-0.0036 \\
(-0.10)\end{array}$ & $\begin{array}{l}0.8225 \\
(3.10)^{* * *}\end{array}$ \\
\hline sfold & $\begin{array}{l}-834.1868 \\
(-10.41)^{* * *}\end{array}$ & $\begin{array}{l}-3.20 \mathrm{E}-03 \\
(-0.97)\end{array}$ & $\begin{array}{l}0.0069 \\
(0.60)\end{array}$ & $\begin{array}{l}-1.1118 \\
(-2.87)^{* * *}\end{array}$ & $\begin{array}{l}-0.6273 \\
(-3.04)^{* * *}\end{array}$ & $\begin{array}{l}-0.5378 \\
(-1.16)\end{array}$ & $\begin{array}{l}0.0438 \\
(0.95)\end{array}$ & $\begin{array}{l}0.0816 \\
(0.25)\end{array}$ \\
\hline sm610 & $\begin{array}{l}-1.43 \mathrm{E}+03 \\
(-11.31)^{* * *}\end{array}$ & $\begin{array}{l}0.0026 \\
(0.51)\end{array}$ & $\begin{array}{l}0.0273 \\
(1.52)\end{array}$ & $\begin{array}{l}-0.351 \\
(-0.57)\end{array}$ & $\begin{array}{l}-0.2025 \\
(-0.62)\end{array}$ & $\begin{array}{l}2.5518 \\
(3.48)^{* * * *}\end{array}$ & $\begin{array}{l}0.0556 \\
(0.77)\end{array}$ & $\begin{array}{l}-2.5261 \\
(-4.85)^{* * *}\end{array}$ \\
\hline sm1118 & $\begin{array}{l}-678.1615 \\
(-7.87)^{* * *}\end{array}$ & $\begin{array}{l}0.0027 \\
(0.77)\end{array}$ & $\begin{array}{l}0.0194 \\
(1.59)\end{array}$ & $\begin{array}{l}-0.3357 \\
(-0.80)\end{array}$ & $\begin{array}{l}-0.1552 \\
(-0.70)\end{array}$ & $\begin{array}{l}1.6958 \\
(3.39)^{* * *}\end{array}$ & $\begin{array}{l}0.0286 \\
(0.58)\end{array}$ & $\begin{array}{l}-0.4779 \\
(-1.34)\end{array}$ \\
\hline smadult & $\begin{array}{l}-400.1285 \\
(-6.98)^{* * *}\end{array}$ & $\begin{array}{l}0.0026 \\
(1.10)\end{array}$ & $\begin{array}{l}0.0072 \\
(0.88)\end{array}$ & $\begin{array}{l}0.293 \\
(1.06)\end{array}$ & $\begin{array}{l}0.159 \\
(1.08)\end{array}$ & $\begin{array}{l}0.5572 \\
(1.67)^{*}\end{array}$ & $\begin{array}{l}-0.0122 \\
(-0.37)\end{array}$ & $\begin{array}{l}0.7692 \\
(3.25)^{* * * *}\end{array}$ \\
\hline y2006 & $\begin{array}{l}-130.1862 \\
(-7.02) * * *\end{array}$ & $\begin{array}{l}-0.0009 \\
(-1.15)\end{array}$ & $\begin{array}{l}0.0116 \\
(4.39)^{* * * *}\end{array}$ & $\begin{array}{l}-0.022 \\
(-0.24)\end{array}$ & $\begin{array}{l}0.0388 \\
(0.81)\end{array}$ & $\begin{array}{l}-0.1623 \\
(-1.51)\end{array}$ & $\begin{array}{l}-0.0087 \\
(-0.81)\end{array}$ & $\begin{array}{l}-0.0166 \\
(-0.22)\end{array}$ \\
\hline y2009 & $\begin{array}{l}-169.2608 \\
(-8.48) * * *\end{array}$ & $\begin{array}{l}0.0017 \\
(2.04)^{* *}\end{array}$ & $\begin{array}{l}0.0134 \\
(4.72)^{* * * *}\end{array}$ & $\begin{array}{l}1.8597 \\
(19.25)^{* * *}\end{array}$ & $\begin{array}{l}1.053 \\
(20.50) * * *\end{array}$ & $\begin{array}{l}0.4603 \\
(3.97)^{* * *}\end{array}$ & $\begin{array}{l}-0.0119 \\
(-1.04) \\
\end{array}$ & $\begin{array}{l}-0.0702 \\
(-0.85)\end{array}$ \\
\hline $\begin{array}{l}\text { Region } \\
\text { dummy }\end{array}$ & Yes & Yes & Yes & Yes & Yes & Yes & Yes & Yes \\
\hline Obs. & 12264 & 12264 & 12264 & 12264 & 12264 & 12264 & 12264 & 12264 \\
\hline $\mathrm{F}$ & $30.89 * * *$ & $26.18 * * *$ & $32.17 * * *$ & $77.69 * * *$ & $69.48 * * *$ & $65.01 * * *$ & $28.36 * * *$ & $19.09 * * *$ \\
\hline $\mathrm{R}^{2}$-adj. & 0.1457 & 0.1257 & 0.151 & 0.3045 & 0.281 & 0.2676 & 0.1351 & 0.0936 \\
\hline
\end{tabular}


3.5: Non-income Effect of Food Structural Change

\begin{tabular}{|c|c|c|c|c|c|c|c|c|c|c|c|c|}
\hline \multirow{2}{*}{ Variables } & \multicolumn{6}{|c|}{ Calorie share } & \multicolumn{6}{|c|}{ Expenditure share } \\
\hline & staple & fruit & meat & dairy & vegetable & oil & staple & fruit & meat & dairy & vegetable & oil \\
\hline \multirow[t]{2}{*}{ hhsize } & 0.0029 & -0.0007 & 0.0024 & -0.0003 & -0.0003 & -0.0026 & 0.0002 & -0.0018 & 0.0050 & $\begin{array}{l}-0.0009 \\
\end{array}$ & -0.0003 & -0.0011 \\
\hline & $(3.23)^{* * *}$ & $(-4.00)^{* * *}$ & $(4.04) * * *$ & $(-2.94) * * *$ & $(-1.44)$ & $(-3.94) * * *$ & $(0.22)$ & $(-3.91) * * *$ & $(4.51) * * *$ & $(-2.85) * * *$ & $(-0.52)$ & $(-2.22)^{* *}$ \\
\hline \multirow[t]{2}{*}{ hhmale } & 0.0183 & -0.0011 & -0.0097 & -0.0008 & -0.0004 & -0.0061 & 0.0105 & -0.0017 & -0.0114 & -0.0019 & -0.0034 & -0.0034 \\
\hline & $(4.73)^{* * *}$ & $(-1.43)$ & $(-3.90) * * *$ & $(-1.74)^{*}$ & $(-0.42)$ & $(-2.17) * *$ & $(3.20)^{* * *}$ & $(-0.88)$ & $(-2.39)^{* *}$ & $(-1.38)$ & $(-1.52)$ & $(-1.67)^{*}$ \\
\hline \multirow[t]{2}{*}{ hhage } & 0.0001 & 0.0000 & -0.0002 & 0.0000 & 0.0001 & 0.0002 & 0.0001 & 0.0001 & -0.0006 & 0.0000 & 0.0002 & 0.0001 \\
\hline & $(0.32)$ & $(0.73)$ & $(-1.65)^{*}$ & $(0.25)$ & $(1.61)$ & $(1.36)$ & $(0.39)$ & $(1.43)$ & $(-2.87)^{* * *}$ & $(0.15)$ & (1.64) & -0.99 \\
\hline \multirow[t]{2}{*}{ hheduyear } & -0.0021 & 0.0003 & 0.0017 & 0.0001 & 0.0001 & -0.0001 & -0.0023 & 0.0007 & 0.0029 & 0.0003 & 0.0000 & -0.0008 \\
\hline & $(-4.74) * * *$ & $(3.69) * * *$ & $(5.79)^{* * *}$ & $(2.41)^{* * *}$ & $(0.53)$ & $(-0.44)$ & $(-6.07)^{* * *}$ & $(3.11)^{* * *}$ & $(5.24)^{* * *}$ & $(1.82)^{*}$ & $(-0.15)$ & $(-3.33) * * *$ \\
\hline \multirow[t]{2}{*}{ hhactivity } & 0.0048 & 0.0000 & -0.0015 & -0.0001 & -0.0001 & -0.0015 & 0.0036 & 0.0003 & -0.0029 & 0.0002 & -0.0003 & -0.0002 \\
\hline & $(3.63)^{* * *}$ & $(0.15)$ & $(-1.71)^{*}$ & $(-0.90)$ & $(-0.34)$ & $(-1.56)$ & $(3.15)^{* * *}$ & $(0.48)$ & $(-1.77)^{*}$ & $(0.48)$ & $(-0.38)$ & $(-0.30)$ \\
\hline \multirow[t]{2}{*}{ mcookedu } & -0.0028 & 0.0005 & 0.0014 & 0.0003 & -0.0003 & -0.0003 & -0.0027 & 0.0009 & 0.0035 & 0.0008 & -0.0014 & -0.0009 \\
\hline & $(-5.92)^{* * *}$ & $(5.23)^{* * *}$ & $(4.42)^{* * *}$ & $(5.52)^{* * *}$ & $(-2.27)^{* *}$ & $(-0.93)$ & $(-6.73) * * *$ & $(3.84) * * *$ & $(5.91)^{* * *}$ & $(4.81)^{* * *}$ & $(-4.91)^{* * *}$ & $(-3.39)^{* * *}$ \\
\hline \multirow[t]{2}{*}{ mcookact } & 0.0079 & -0.0012 & -0.0079 & -0.0008 & 0.0011 & 0.0027 & 0.0103 & -0.0027 & -0.0161 & -0.0020 & 0.0048 & 0.0048 \\
\hline & $(5.30) * * *$ & $(-4.14)^{* * *}$ & $(-8.23) * * *$ & $(-4.47) * * *$ & $(3.11)^{* * *}$ & $(2.48) * *$ & $(8.11)^{* * *}$ & $(-3.65) * * *$ & $(-8.87)^{* * *}$ & $(-3.81) * * *$ & $(5.53) * * *$ & $(6.10) * * *$ \\
\hline \multirow[t]{2}{*}{ schild } & -0.0237 & 0.0176 & 0.0088 & 0.0088 & -0.0111 & -0.0058 & -0.0179 & 0.0471 & 0.0444 & 0.0270 & -0.0504 & -0.0118 \\
\hline & $(-1.18)$ & $(4.35)^{* * *}$ & $(0.68)$ & $(3.50) * * *$ & $(-2.36)^{* *}$ & $(-0.39)$ & $(-1.04)$ & $(4.68) * * *$ & $(1.80)^{*}$ & $(3.83) * * *$ & $(-4.31) * * *$ & $(-1.11)$ \\
\hline \multirow[t]{2}{*}{ sf610 } & -0.0686 & 0.0179 & 0.0222 & 0.0087 & -0.003 & 0.0222 & -0.0498 & 0.0372 & 0.0755 & 0.0307 & -0.027 & 0.0102 \\
\hline & $(-2.87) * * *$ & $(3.73)^{* * *}$ & $(1.44)$ & $(2.94) * * *$ & $(-0.54)$ & (1.28) & $(-2.44)^{* *}$ & $(3.12)^{* * *}$ & $(2.57)^{* *}$ & $(3.67)^{* * *}$ & $(-1.95)^{*}$ & -0.81 \\
\hline \multirow[t]{2}{*}{ sf1118 } & -0.0251 & 0.0071 & -0.0036 & -0.0008 & -0.0005 & 0.0173 & -0.0148 & 0.0194 & 0.0262 & 0.0004 & -0.0192 & 0.013 \\
\hline & $(-1.54)$ & $(2.19) * *$ & $(-0.34)$ & $(-0.39)$ & $(-0.12)$ & $(1.46)$ & $(-1.07)$ & $(2.38)^{* *}$ & (1.31) & $(0.06)$ & $(-2.03)^{* *}$ & -1.51 \\
\hline \multirow[t]{2}{*}{ sfadult } & -0.026 & 0.0061 & 0.0056 & 0.0004 & -0.0031 & 0.009 & -0.0287 & 0.0108 & 0.0362 & 0.0044 & -0.0136 & -0.0008 \\
\hline & $(-2.24) * *$ & $(2.62)^{* * *}$ & $(0.74)$ & $(0.30)$ & $(-1.12)$ & (1.07) & $(-2.89) * * *$ & $(1.86)^{*}$ & $(2.53)^{* *}$ & (1.08) & $(-2.01)^{* *}$ & $(-0.13)$ \\
\hline \multirow[t]{2}{*}{ sfold } & -0.0154 & 0.0009 & -0.0267 & 0.0025 & 0.0005 & 0.0249 & 0.0036 & -0.0004 & -0.0100 & 0.0092 & 0.0001 & 0.0235 \\
\hline & $(-1.06)$ & $(0.30)$ & $(-2.85)^{* * *}$ & (1.38) & $(0.15)$ & $(2.37)^{* *}$ & $(0.29)$ & $(-0.06)$ & $(-0.56)$ & $(1.81)^{*}$ & $(0.01)$ & $(3.06) * * *$ \\
\hline \multirow[t]{2}{*}{ sm610 } & -0.0226 & 0.0105 & 0.0272 & 0.0097 & -0.0155 & -0.0097 & -0.0154 & 0.0307 & 0.0838 & 0.0344 & -0.0457 & -0.0135 \\
\hline & $(-0.99)$ & $(2.30)^{* *}$ & $(1.84)^{*}$ & $(3.42) * * *$ & $(-2.89)^{* * *}$ & $(-0.59)$ & $(-0.79)$ & $(2.69) * * *$ & $(2.99) * * *$ & $(4.30)^{* * *}$ & $(-3.45)^{* * *}$ & $(-1.12)$ \\
\hline \multirow[t]{2}{*}{ sm1118 } & -0.0296 & 0.0042 & 0.0121 & 0.0021 & -0.0028 & 0.014 & -0.0194 & 0.0131 & 0.0564 & 0.0009 & -0.0158 & 0.0148 \\
\hline & $(-1.90)^{*}$ & (1.33) & $(1.21)$ & (1.11) & $(-0.77)$ & $(1.24)$ & $(-1.46)$ & $(1.68) *$ & $(2.95)^{* * *}$ & $(0.16)$ & $(-1.75)^{*}$ & $(1.79)^{*}$ \\
\hline \multirow[t]{2}{*}{ smadult } & -0.0125 & 0.0018 & 0.0031 & 0.0007 & 0.0003 & 0.0070 & -0.0176 & 0.0014 & 0.032 & 0.0015 & -0.0119 & -0.0011 \\
\hline & $(-1.21)$ & $(0.84)$ & $(0.46)$ & $(0.57)$ & $(0.11)$ & $(0.93)$ & $(-1.99)^{* *}$ & $(0.28)$ & $(2.51)^{* *}$ & $(0.41)$ & $(-1.98)^{* *}$ & $(-0.20)$ \\
\hline y2006 & -0.0048 & 0.0035 & 0.0096 & -0.0007 & -0.0021 & 0.0021 & -0.0121 & 0.0158 & -0.0175 & -0.0002 & 0.0243 & -0.0074 \\
\hline
\end{tabular}




\begin{tabular}{|c|c|c|c|c|c|c|c|c|c|c|c|c|}
\hline \multirow{3}{*}{ y2009 } & $(-1.42)$ & $(5.27) * * *$ & $(4.43) * * *$ & $(-1.70)^{*}$ & $(-2.68) * * *$ & $(0.84)$ & $(-4.21) * * *$ & $(9.41)^{* * *}$ & $(-4.25)^{* * *}$ & $(-0.15)$ & $(12.46)^{* * *}$ & $(-4.16) * * *$ \\
\hline & -0.0181 & 0.006 & 0.0108 & -0.0010 & -0.0008 & 0.0026 & -0.0362 & 0.0183 & -0.0031 & 0.0023 & 0.0354 & -0.0086 \\
\hline & $(-5.02) * * *$ & $(8.29) * * *$ & $(4.61)^{* * * *}$ & $(-2.17) * *$ & $(-0.96)$ & $(1.01)$ & $(-11.78)^{* * * *}$ & $(10.17)^{* * *}$ & $(-0.70)$ & $(1.78) *$ & $(16.91)^{* * *}$ & $(-4.49) * * *$ \\
\hline $\begin{array}{l}\text { Region } \\
\text { dummy }\end{array}$ & Yes & Yes & Yes & Yes & Yes & Yes & Yes & Yes & Yes & Yes & Yes & Yes \\
\hline Obs. & 12264 & 12264 & 12264 & 12264 & 12264 & 12264 & 12264 & 12264 & 12264 & 12264 & 12264 & 12264 \\
\hline $\mathrm{F}$ & $51.41 * * *$ & $26.63 * * *$ & $56.49 * * *$ & $15.07 * * *$ & $11.92 * * *$ & $18.06 * * *$ & $80.27 * * *$ & $34.92 * * *$ & $74.00 * * *$ & $9.39 * * *$ & $36.80 * * *$ & 32.46 \\
\hline $\mathrm{R}^{2}$-adj. & 0.2234 & 0.1276 & 0.2405 & 0.0743 & 0.0587 & 0.0887 & 0.3115 & 0.1622 & 0.2941 & 0.0457 & 0.1697 & 0.1522 \\
\hline
\end{tabular}

Note: $*, * *, * * *$ refer to significant levels at $10 \%, 5 \%$, and $1 \%$ respectively. 


\section{1: Descriptive Analysis of Variables}

\begin{tabular}{|c|c|c|c|c|c|c|}
\hline Variable & Obs. & Mean & Std. Dev. & Min & Max & Definition \\
\hline Engel & 8837 & $41.37 \%$ & 0.2205 & $0.08 \%$ & $89.99 \%$ & Engel index \\
\hline pce & 8837 & 12203.8700 & 15284.3800 & 706.0126 & 336000 & per capita gross income \\
\hline lnpce & 8837 & 9.0930 & 0.7455 & 6.5596 & 12.7249 & logarithm of per capita gross income \\
\hline g05 & 8837 & 0.0614 & 0.2494 & 0 & 2 & number of girls aged between 0 and 5 \\
\hline g610 & 8837 & 0.0648 & 0.2557 & 0 & 3 & number of girls aged between 6 and 10 \\
\hline g1118 & 8837 & 0.1639 & 0.4013 & 0 & 3 & number of girls aged between 11 and 18 \\
\hline ag05 & 8837 & 0.0565 & 0.2292 & 0.0000 & 1.8378 & adjusted number of girls aged between 0 and 5 \\
\hline ag610 & 8837 & 0.0596 & 0.2352 & 0.0000 & 2.7588 & adjusted number of girls aged between 6 and 10 \\
\hline ag1118 & 8837 & 0.1371 & 0.3357 & 0.0000 & 2.5101 & adjusted number of girls aged between 11 and 18 \\
\hline b05 & 8837 & 0.0731 & 0.2735 & 0 & 3 & number of boys aged between 0 and 5 \\
\hline b610 & 8837 & 0.0790 & 0.2804 & 0 & 3 & number of boys aged between 6 and 10 \\
\hline b1118 & 8837 & 0.1935 & 0.4307 & 0 & 3 & number of boys aged between 11 and 18 \\
\hline adult & 8837 & 3.2906 & 1.4534 & 1 & 13 & number of adults (older than 18) \\
\hline hheduyear & 8837 & 7.9751 & 4.0246 & 0 & 18 & education year of household head \\
\hline g05edu & 8837 & 0.4561 & 2.0605 & 0 & 24 & interaction term of g05 and hheduyear \\
\hline g610edu & 8837 & 0.4834 & 2.1229 & 0 & 24 & interaction term of g610 and hheduyear \\
\hline g1118edu & 8837 & 1.3007 & 3.5692 & 0 & 36 & interaction term of g1118 and hheduyear \\
\hline ag05edu & 8837 & 0.4191 & 1.8934 & 0.0000 & 22.0536 & interaction term of ag05 and hheduyear \\
\hline ag610edu & 8837 & 0.4445 & 1.9522 & 0.0000 & 22.0704 & interaction term of ag610 and hheduyear \\
\hline ag1118edu & 8837 & 1.0883 & 2.9863 & 0.0000 & 30.1212 & interaction term of ag1118 and hheduyear \\
\hline b05edu & 8837 & 0.5076 & 2.1443 & 0 & 24 & interaction term of b05 and hheduyear \\
\hline b610edu & 8837 & 0.5879 & 2.3383 & 0 & 26 & interaction term of b610 and hheduyear \\
\hline b1118edu & 8837 & 1.5471 & 3.7692 & 0 & 36 & interaction term of b1118 and hheduyear \\
\hline adultedu & 8837 & 25.1259 & 15.9240 & 0 & 132 & interaction term of adult and hheduyear \\
\hline y2006 & 8837 & 0.3307 & 0.4705 & 0 & 1 & dummy for 2006 \\
\hline y2009 & 8837 & 0.3592848 & 0.479818 & 0 & 1 & dummy for 2009 \\
\hline
\end{tabular}

Note: 12676 observations have full information, while we only use the one with Engel index greater than 0 and less than 0.9 in our regression to control the measurement error. In the end we get 8837 observations. 


\section{2: Results in Original Model}

\begin{tabular}{|c|c|c|c|c|c|c|c|c|}
\hline \multirow{3}{*}{ Variable } & \multicolumn{4}{|l|}{ Linear Model } & \multicolumn{4}{|c|}{ Partial Linear Model } \\
\hline & \multicolumn{2}{|c|}{ Before Adjustment } & \multicolumn{2}{|c|}{ After Adjustment } & \multicolumn{2}{|c|}{ Before Adjustment } & \multicolumn{2}{|c|}{ After Adjustment } \\
\hline & Urban & Rural & Urban & Rural & Urban & Rural & Urban & Rural \\
\hline lnpce & $\begin{array}{l}-0.2093 \\
(-31.33)^{* * *}\end{array}$ & $\begin{array}{l}-0.2050 \\
(-45.78)^{* * *}\end{array}$ & $\begin{array}{l}-0.2093 \\
(-31.33)^{* * *}\end{array}$ & $\begin{array}{l}-0.2050 \\
(-45.78)^{* * *}\end{array}$ & & & & \\
\hline girl05 & $\begin{array}{l}0.0145 \\
(1.12)\end{array}$ & $\begin{array}{l}-0.0168 \\
(-2.27)^{* * *}\end{array}$ & $\begin{array}{l}0.0157 \\
(1.12)\end{array}$ & $\begin{array}{l}-0.0183 \\
(-2.27)^{* *}\end{array}$ & $\begin{array}{l}0.0184 \\
(1.23)\end{array}$ & $\begin{array}{l}-0.0237 \\
(-2.76)^{* * * *}\end{array}$ & $\begin{array}{l}0.0200 \\
(1.23)\end{array}$ & $\begin{array}{l}-0.0258 \\
(-2.76)^{* * *}\end{array}$ \\
\hline girl610 & $\begin{array}{l}0.0030 \\
(0.25)\end{array}$ & $\begin{array}{l}-0.0036 \\
(-0.50)\end{array}$ & $\begin{array}{l}0.0033 \\
(0.25)\end{array}$ & $\begin{array}{l}-0.0040 \\
(-0.50)\end{array}$ & $\begin{array}{l}0.0096 \\
(0.68)\end{array}$ & $\begin{array}{l}-0.0137 \\
(-1.62)\end{array}$ & $\begin{array}{l}0.0104 \\
(0.68)\end{array}$ & $\begin{array}{l}-0.0149 \\
(-1.62)\end{array}$ \\
\hline $\operatorname{girl1118}$ & $\begin{array}{l}0.0000 \\
(-0.01)\end{array}$ & $\begin{array}{l}0.0026 \\
(0.58)\end{array}$ & $\begin{array}{l}-0.0001 \\
(-0.01)\end{array}$ & $\begin{array}{l}0.0032 \\
(0.58)\end{array}$ & $\begin{array}{l}-0.0003 \\
(-0.03)\end{array}$ & $\begin{array}{l}-0.0014 \\
(-0.27)\end{array}$ & $\begin{array}{l}-0.0004 \\
(-0.03)\end{array}$ & $\begin{array}{l}-0.0017 \\
(-0.27)\end{array}$ \\
\hline boy 05 & $\begin{array}{l}0.0175 \\
(1.31)\end{array}$ & $\begin{array}{l}-0.0027 \\
(-0.41)\end{array}$ & $\begin{array}{l}0.0175 \\
(1.31)\end{array}$ & $\begin{array}{l}-0.0027 \\
(-0.41)\end{array}$ & $\begin{array}{l}0.0211 \\
(1.37)\end{array}$ & $\begin{array}{l}-0.0018 \\
(-0.23)\end{array}$ & $\begin{array}{l}0.0211 \\
(1.37)\end{array}$ & $\begin{array}{l}-0.0018 \\
(-0.23)\end{array}$ \\
\hline boy610 & $\begin{array}{l}0.0192 \\
(1.63)\end{array}$ & $\begin{array}{l}-0.0017 \\
(-0.26)\end{array}$ & $\begin{array}{l}0.0192 \\
(1.63)\end{array}$ & $\begin{array}{l}-0.0017 \\
(-0.26)\end{array}$ & $\begin{array}{l}0.0174 \\
(1.28)\end{array}$ & $\begin{array}{l}-0.0070 \\
(-0.93)\end{array}$ & $\begin{array}{l}0.0174 \\
(1.28)\end{array}$ & $\begin{array}{l}-0.0070 \\
(-0.93)\end{array}$ \\
\hline boy1118 & $\begin{array}{l}0.0278 \\
(3.46)^{* * * *}\end{array}$ & $\begin{array}{l}0.0153 \\
(3.50)^{* * * *}\end{array}$ & $\begin{array}{l}0.0278 \\
(3.46)^{* * *}\end{array}$ & $\begin{array}{l}0.0153 \\
(3.50)^{* * * *}\end{array}$ & $\begin{array}{l}0.0286 \\
(3.12)^{* * * *}\end{array}$ & $\begin{array}{l}0.0120 \\
(2.37)^{* *}\end{array}$ & $\begin{array}{l}0.0286 \\
(3.12)^{* * *}\end{array}$ & $\begin{array}{l}0.0120 \\
(2.37)^{* *}\end{array}$ \\
\hline Adult & $\begin{array}{l}-0.0015 \\
(-0.60)\end{array}$ & $\begin{array}{l}0.0033 \\
(2.27)^{* *}\end{array}$ & $\begin{array}{l}-0.0015 \\
(-0.60)\end{array}$ & $\begin{array}{l}0.0033 \\
(2.27)^{* *}\end{array}$ & $\begin{array}{l}-0.0038 \\
(-1.31)\end{array}$ & $\begin{array}{l}0.0032 \\
(1.91)^{*}\end{array}$ & $\begin{array}{l}-0.0038 \\
(-1.31)\end{array}$ & $\begin{array}{l}0.0032 \\
(1.91)^{*}\end{array}$ \\
\hline y2006 & $\begin{array}{l}-0.2169 \\
(-2.24)^{* *}\end{array}$ & $\begin{array}{l}-0.2373 \\
(-1.39)\end{array}$ & $\begin{array}{l}-0.2169 \\
(-2.24)^{* *}\end{array}$ & $\begin{array}{l}-0.2373 \\
(-1.39)\end{array}$ & $\begin{array}{l}-0.0038 \\
(-0.04)\end{array}$ & $\begin{array}{l}-0.0974 \\
(-0.49)\end{array}$ & $\begin{array}{l}-0.4513 \\
(-4.29)^{* * *}\end{array}$ & $\begin{array}{l}-0.0974 \\
(-0.49)\end{array}$ \\
\hline y2009 & $\begin{array}{l}0.0463 \\
(0.53)\end{array}$ & $\begin{array}{l}-0.1239 \\
(-0.82)\end{array}$ & $\begin{array}{l}0.0463 \\
(0.53)\end{array}$ & $\begin{array}{l}-0.1239 \\
(-0.82)\end{array}$ & $\begin{array}{l}0.0264 \\
(0.26)\end{array}$ & $\begin{array}{l}0.0313 \\
(0.18)\end{array}$ & $\begin{array}{l}-0.1333 \\
(-1.42)\end{array}$ & $\begin{array}{l}0.0313 \\
(0.18)\end{array}$ \\
\hline $\begin{array}{l}\text { Community } \\
\text { dummy }\end{array}$ & Yes & Yes & Yes & Yes & Yes & Yes & Yes & Yes \\
\hline Observations & 3072 & 5761 & 3072 & 5761 & 3072 & 5761 & 3072 & 5761 \\
\hline F test & $19.06 * * *$ & $20.89 * * *$ & $19.06 * * *$ & $20.89 * * *$ & $5.60^{* * *}$ & $7.66^{* * *}$ & $5.60^{* * *}$ & $7.66^{* * * *}$ \\
\hline Adjusted $\mathrm{R}^{2}$ & 0.5685 & 0.6030 & 0.5685 & 0.6030 & 0.2504 & 0.3367 & 0.2504 & 0.3367 \\
\hline \multicolumn{9}{|c|}{ Sample Selection Test } \\
\hline & $6.12 * * *$ & $10.85 * * *$ & $6.12 * * *$ & $10.85 * * *$ & $6.12 * * *$ & $10.85 * * *$ & $6.12 * * *$ & $10.85 * * *$ \\
\hline
\end{tabular}

Notes: 1. Sample selection bias are detected in both samples, thus we add the inverse Mill's ratio as additional control variable in the OLS model.

2. We use the community dummy to control the heterogeneity across regions, which are not reported in this table.

3. *, **, *** denote significant level at $10 \%, 5 \%$ and $1 \%$ respectively.

4. Numbers in parenthesis are $t$ values. 


\section{3: Results in Extended Model}

\begin{tabular}{|c|c|c|c|c|c|c|c|c|}
\hline \multirow{3}{*}{ Variables } & \multicolumn{4}{|c|}{ Linear Model } & \multicolumn{4}{|c|}{ Partial Linear Model } \\
\hline & \multicolumn{2}{|c|}{ Before Adjustment } & \multicolumn{2}{|c|}{ After Adjustment } & \multicolumn{2}{|c|}{ Before Adjustment } & \multicolumn{2}{|c|}{ After Adjustment } \\
\hline & Urban & Rural & Urban & Rural & Urban & Rural & Urban & Rural \\
\hline lnpce & $\begin{array}{l}-0.2168 \\
(-31.38) * * *\end{array}$ & $\begin{array}{l}-0.2092 \\
(-45.90) * * *\end{array}$ & $\begin{array}{l}-0.2168 \\
(-31.38) * * *\end{array}$ & $\begin{array}{l}-0.2092 \\
(-45.90) * * *\end{array}$ & & & & \\
\hline girl05 & $\begin{array}{l}-0.0464 \\
(-1.37)\end{array}$ & $\begin{array}{l}-0.0272 \\
(-1.61)\end{array}$ & $\begin{array}{l}-0.0505 \\
(-1.37)\end{array}$ & $\begin{array}{l}-0.0296 \\
(-1.61)\end{array}$ & $\begin{array}{l}-0.0424 \\
(-1.06)\end{array}$ & $\begin{array}{l}-0.0349 \\
(-1.80)^{*}\end{array}$ & $\begin{array}{l}-0.0461 \\
(-1.06)\end{array}$ & $\begin{array}{l}-0.0380 \\
(-1.80)^{*}\end{array}$ \\
\hline girl610 & $\begin{array}{l}0.0002 \\
(0.01)\end{array}$ & $\begin{array}{l}0.0060 \\
-0.39\end{array}$ & $\begin{array}{l}0.0002 \\
-0.01\end{array}$ & $\begin{array}{l}0.0066 \\
-0.39\end{array}$ & $\begin{array}{l}0.0213 \\
-0.6200\end{array}$ & $\begin{array}{l}-0.0074 \\
(-0.40)\end{array}$ & $\begin{array}{l}0.0231 \\
-0.62\end{array}$ & $\begin{array}{l}-0.0080 \\
(-0.40)\end{array}$ \\
\hline girl1118 & $\begin{array}{l}0.0075 \\
-0.42\end{array}$ & $\begin{array}{l}0.0047 \\
-0.44\end{array}$ & $\begin{array}{l}0.0090 \\
-0.42\end{array}$ & $\begin{array}{l}0.0056 \\
-0.44\end{array}$ & $\begin{array}{l}0.0097 \\
-0.4600\end{array}$ & $\begin{array}{l}-0.0026 \\
(-0.22)\end{array}$ & $\begin{array}{l}0.0116 \\
-0.46\end{array}$ & $\begin{array}{l}-0.0031 \\
(-0.22)\end{array}$ \\
\hline boy05 & $\begin{array}{l}0.0002 \\
(0.01)\end{array}$ & $\begin{array}{l}-0.0024 \\
(-0.18)\end{array}$ & $\begin{array}{l}0.0002 \\
-0.01\end{array}$ & $\begin{array}{l}-0.0024 \\
(-0.18)\end{array}$ & $\begin{array}{l}0.0054 \\
-0.1600\end{array}$ & $\begin{array}{l}-0.0061 \\
(-0.40)\end{array}$ & $\begin{array}{l}0.0054 \\
-0.16\end{array}$ & $\begin{array}{l}-0.0061 \\
(-0.40)\end{array}$ \\
\hline boy610 & $\begin{array}{l}0.0151 \\
(0.56)\end{array}$ & $\begin{array}{l}-0.0096 \\
(-0.68)\end{array}$ & $\begin{array}{l}0.0151 \\
-0.56\end{array}$ & $\begin{array}{l}-0.0096 \\
(-0.68)\end{array}$ & $\begin{array}{l}0.0340 \\
-1.0800\end{array}$ & $\begin{array}{l}-0.0259 \\
(-1.60)\end{array}$ & $\begin{array}{l}0.0340 \\
-1.08\end{array}$ & $\begin{array}{l}-0.0259 \\
(-1.60)\end{array}$ \\
\hline boy1118 & $\begin{array}{l}0.0207 \\
(1.06)\end{array}$ & $\begin{array}{l}0.0094 \\
(0.96)\end{array}$ & $\begin{array}{l}0.0207 \\
(1.06)\end{array}$ & $\begin{array}{l}0.0094 \\
(0.96)\end{array}$ & $\begin{array}{l}0.0154 \\
(0.68)\end{array}$ & $\begin{array}{l}0.0103 \\
(0.91)\end{array}$ & $\begin{array}{l}0.0154 \\
(0.68)\end{array}$ & $\begin{array}{l}0.0103 \\
(0.91)\end{array}$ \\
\hline Adult & $\begin{array}{l}0.0006 \\
(0.11)\end{array}$ & $\begin{array}{l}0.0056 \\
(2.10)^{* *}\end{array}$ & $\begin{array}{l}0.0006 \\
(0.11)\end{array}$ & $\begin{array}{l}0.0056 \\
(2.10)^{* *}\end{array}$ & $\begin{array}{l}0.0007 \\
(0.12)\end{array}$ & $\begin{array}{l}0.0072 \\
(2.33)^{* *}\end{array}$ & $\begin{array}{l}0.0007 \\
(0.12)\end{array}$ & $\begin{array}{l}0.0072 \\
(2.33)^{* *}\end{array}$ \\
\hline hhedu & $\begin{array}{l}0.0034 \\
(2.01)^{* *}\end{array}$ & $\begin{array}{l}0.0040 \\
(2.84) * * *\end{array}$ & $\begin{array}{l}0.0034 \\
(2.01)^{* *}\end{array}$ & $\begin{array}{l}0.0040 \\
(2.84)^{* * *}\end{array}$ & $\begin{array}{l}0.0041 \\
(2.09)^{* *}\end{array}$ & $\begin{array}{l}0.0056 \\
(3.45)^{* * *}\end{array}$ & $\begin{array}{l}0.0041 \\
(2.09)^{* *}\end{array}$ & $\begin{array}{l}0.0056 \\
(3.45) * * *\end{array}$ \\
\hline girl05edu & $\begin{array}{l}0.0063 \\
(1.82)^{*}\end{array}$ & $\begin{array}{l}0.0012 \\
(0.54)\end{array}$ & $\begin{array}{l}0.0069 \\
(1.82)^{*}\end{array}$ & $\begin{array}{l}0.0013 \\
(0.54)\end{array}$ & $\begin{array}{l}0.0061 \\
(1.50)\end{array}$ & $\begin{array}{l}0.0010 \\
(0.41)\end{array}$ & $\begin{array}{l}0.0066 \\
(1.50)\end{array}$ & $\begin{array}{l}0.0011 \\
(0.41)\end{array}$ \\
\hline girl610edu & $\begin{array}{l}0.0000 \\
(0.00)\end{array}$ & $\begin{array}{l}-0.0016 \\
(-0.78)\end{array}$ & $\begin{array}{l}0.0000 \\
(0.00)\end{array}$ & $\begin{array}{l}-0.0017 \\
(-0.78)\end{array}$ & $\begin{array}{l}-0.0015 \\
(-0.42)\end{array}$ & $\begin{array}{l}-0.0012 \\
(-0.50)\end{array}$ & $\begin{array}{l}-0.0016 \\
(-0.42)\end{array}$ & $\begin{array}{l}-0.0013 \\
(-0.50)\end{array}$ \\
\hline girl1118edu & $\begin{array}{l}-0.0010 \\
(-0.54)\end{array}$ & $\begin{array}{l}-0.0005 \\
(-0.39)\end{array}$ & $\begin{array}{l}-0.0012 \\
(-0.54)\end{array}$ & $\begin{array}{l}-0.0006 \\
(-0.39)\end{array}$ & $\begin{array}{l}-0.0014 \\
(-0.63)\end{array}$ & $\begin{array}{l}-0.0002 \\
(-0.14)\end{array}$ & $\begin{array}{l}-0.0016 \\
(-0.63)\end{array}$ & $\begin{array}{l}-0.0002 \\
(-0.14)\end{array}$ \\
\hline boy05edu & $\begin{array}{l}0.0018 \\
(0.58)\end{array}$ & $\begin{array}{l}-0.0002 \\
(-0.09)\end{array}$ & $\begin{array}{l}0.0018 \\
(0.58)\end{array}$ & $\begin{array}{l}-0.0002 \\
(-0.09)\end{array}$ & $\begin{array}{l}0.0019 \\
(0.52)\end{array}$ & $\begin{array}{l}0.0003 \\
(0.15)\end{array}$ & $\begin{array}{l}0.0019 \\
(0.52)\end{array}$ & $\begin{array}{l}0.0003 \\
(0.15)\end{array}$ \\
\hline boy610edu & $\begin{array}{l}0.0002 \\
(0.07)\end{array}$ & $\begin{array}{l}0.0011 \\
(0.61)\end{array}$ & $\begin{array}{l}0.0002 \\
(0.07)\end{array}$ & $\begin{array}{l}0.0011 \\
(0.61)\end{array}$ & $\begin{array}{l}-0.0022 \\
(-0.67)\end{array}$ & $\begin{array}{l}0.0024 \\
(1.17)\end{array}$ & $\begin{array}{l}-0.0022 \\
(-0.67)\end{array}$ & $\begin{array}{l}0.0024 \\
(1.17)\end{array}$ \\
\hline boy1118edu & $\begin{array}{l}0.0003 \\
(0.17)\end{array}$ & $\begin{array}{l}0.0005 \\
(0.46)\end{array}$ & $\begin{array}{l}0.0003 \\
(0.17)\end{array}$ & $\begin{array}{l}0.0005 \\
(0.46)\end{array}$ & $\begin{array}{l}0.0011 \\
(0.48)\end{array}$ & $\begin{array}{l}-0.0001 \\
(-0.08)\end{array}$ & $\begin{array}{l}0.0011 \\
(0.48)\end{array}$ & $\begin{array}{l}-0.0001 \\
(-0.08)\end{array}$ \\
\hline Adultedu & $\begin{array}{l}-0.0001 \\
(-0.24)\end{array}$ & $\begin{array}{l}-0.0003 \\
(-0.81)\end{array}$ & $\begin{array}{l}-0.0001 \\
(-0.24)\end{array}$ & $\begin{array}{l}-0.0003 \\
(-0.81)\end{array}$ & $\begin{array}{l}-0.0004 \\
(-0.72)\end{array}$ & $\begin{array}{l}-0.0005 \\
(-1.36)\end{array}$ & $\begin{array}{l}-0.0004 \\
(-0.72)\end{array}$ & $\begin{array}{l}-0.0005 \\
(-1.36)\end{array}$ \\
\hline y2006 & $\begin{array}{l}-0.1817 \\
(-1.86)^{*}\end{array}$ & $\begin{array}{l}-0.2279 \\
(-1.33)\end{array}$ & $\begin{array}{l}-0.1817 \\
(-1.86)^{*}\end{array}$ & $\begin{array}{l}-0.2279 \\
(-1.33)\end{array}$ & $\begin{array}{l}-0.1717 \\
(-1.72)^{*}\end{array}$ & $\begin{array}{l}0.0135 \\
(0.08)\end{array}$ & $\begin{array}{l}-0.4352 \\
(-4.07)^{* * *}\end{array}$ & $\begin{array}{l}0.0135 \\
(0.08)\end{array}$ \\
\hline y2009 & $\begin{array}{l}0.0481 \\
(0.55)\end{array}$ & $\begin{array}{l}-0.1191 \\
(-0.79)\end{array}$ & $\begin{array}{l}0.0481 \\
(0.55)\end{array}$ & $\begin{array}{l}-0.1191 \\
(-0.79)\end{array}$ & $\begin{array}{l}-0.1376 \\
(-1.47)\end{array}$ & $\begin{array}{l}0.1092 \\
(0.81)\end{array}$ & $\begin{array}{l}-0.1376 \\
(-1.47)\end{array}$ & $\begin{array}{l}0.1670 \\
(1.27)\end{array}$ \\
\hline $\begin{array}{l}\text { Community } \\
\text { dummy }\end{array}$ & Yes & Yes & Yes & Yes & Yes & Yes & Yes & Yes \\
\hline Observations & 3072 & 5761 & 3072 & 5761 & 3071 & 5760 & 3071 & 5760 \\
\hline F test & $18.58 * * *$ & $20.66 * * *$ & $18.58 * * *$ & $20.66 * * *$ & $5.63 * * *$ & $7.74 * * *$ & $5.63 * * *$ & $7.74 * * *$ \\
\hline Adjusted $\mathrm{R}^{2}$ & 0.5705 & 0.6046 & 0.5705 & 0.6046 & 0.2584 & 0.3435 & 0.2584 & 0.3435 \\
\hline Sample Select & $\begin{array}{l}\mathrm{n} \text { Test } \\
5.33 * * *\end{array}$ & $10.49 * * *$ & $5.33 * * *$ & $10.49 * * *$ & $5.33 * * *$ & $10.49 * * *$ & $5.33 * * *$ & $10.49 * * *$ \\
\hline
\end{tabular}

Notes: 1. Sample selection bias are detected in both samples, thus we add the inverse Mill's ratio as additional control variable in the OLS model. 
2. We use the community dummy to control the heterogeneity across regions, which are not reported in this table.

3. *, **, *** denote significant level at $10 \%, 5 \%$ and $1 \%$ respectively.

4. Numbers in parenthesis are $\mathrm{t}$ values. 


\section{Curriculum Vitae}

\section{Personal information:}

Name $\quad \mathrm{Xu}$ Tian

Address $\quad$ Stumpfebiel 2, 007. 37073 Göttingen

Date of Birth $\quad$ 12.08.1984

Place of Birth Huanggang city, Hubei province, China

\section{Education:}

2002-2006 Bachelor in Economics, Beijing Normal University, China

2007-2009 Master in Applied Economics, Tsinghua University, China

2009-2013 PhD in Agricultural Economics

Supervisor: Prof. Xiaohua YU, Ph.D.

Courant Research Centre Poverty Equity and Growth \&

Department of Agricultural Economics and Rural Development

Georg-August University Göttingen, Germany

Göttingen, den 19.01.2014 